HNF-MR-0540

Revision 0

\title{
The U.S. Department of Energy Pollution Prevention Program: Applications for Small Business
}

M. D. Betsch

Rust Federal Services of Hanford Inc.

Date Published

May 1997

Prepared for the U.S. Department of Energy

Assistant Secretary for Environmental Management

Froject Hanford Management Contractor for the

U.S. Department of Energy under Contract DE-AC06-96RL13200

Approved for public release; distribution is unlimited 


\section{RELEASE AUTHORIZATION}

Document Number: HNF-MR-0540, Rev. 0

Poliution Prevention Program:

Applications for Smali Business

Release Date: May 14, 1997

\section{This document was reviewed following the clearance requirements of DOE Order 1430.1D and is}

\section{APPROVED FOR PUBLIC RELEASE}

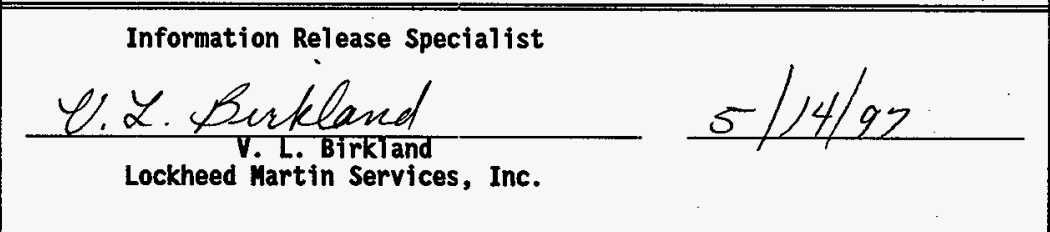

LEGAL DISCLAIMER. This report was prepared as en account of work sponsored by an agency of the United States Goverment. Heither the United States Government nor any agency thereof, not any of their employees, nor any of their contractors, subcontractors or their employees, makes any warranty, express or implied, or assumes any legal liability or responsibility for the accuracy, completeness, or any third party's use or the results of such use of any information, apparatus, product, or process disclosed, or represents that its use would not infringe privately owned rights. Reference herein to any specific connercial product, process, or service by trade name, tradenark, manufacturer, or otherwise, does not necessarily constitute or imply its endorsenent, recommendation, or favoring by the United states Government or any agency thereof or its contractors or subcontractors. The views and opinions of authors expressed herein do not necessarily state or reflect those of the United states Government or any agency thereof.

This report has been reproduced from the best ovajlable copy. Available in paper copy and microfiche. Available to the U.S. Department of Energy and its contractors from office of scientific and rechnical Inforwation

P.0. Box 62

Dak Ridge, TN 37831

Telephone: $423 / 576-8401$

Available to the public from

U.S. Department of Commerce

National Technical Infornation Service

5285 Port Royal Road

Springfield, va 22161

Telephone:

$703 / 487-4650$ 
THE U.S. DEPARTMENT OF ENERGY POLLUTION PREVENTION PROGRAM: APPLICATIONS FOR SMALL BUSINESS

By

MARY DIANE BETSCH

A project report submitted in partial fulfillment of the requirements for the degree of

MASTER OF SCIENCE IN ENVIRONMENTAL SCIENCE

WASHINGTON STATE UNIVERSITY

Program in Environmental Science and Regional Planning

May 1997 
THIS PAGE INTENTIONALIY

LEFT BIAANK 
To the Faculty of Washington State University:

The members of the Committee appointed to examine the project report of MARY DIANE BETSCH find it satisfactory and recommend that it be accepted.

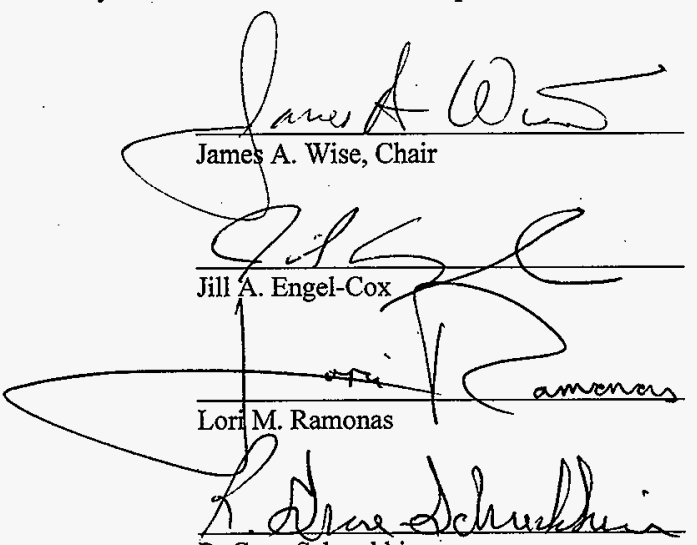

R. Gene Schreckhise 
THIS PAGE INTENTIONALLY LEET BLANK

\lrcorner




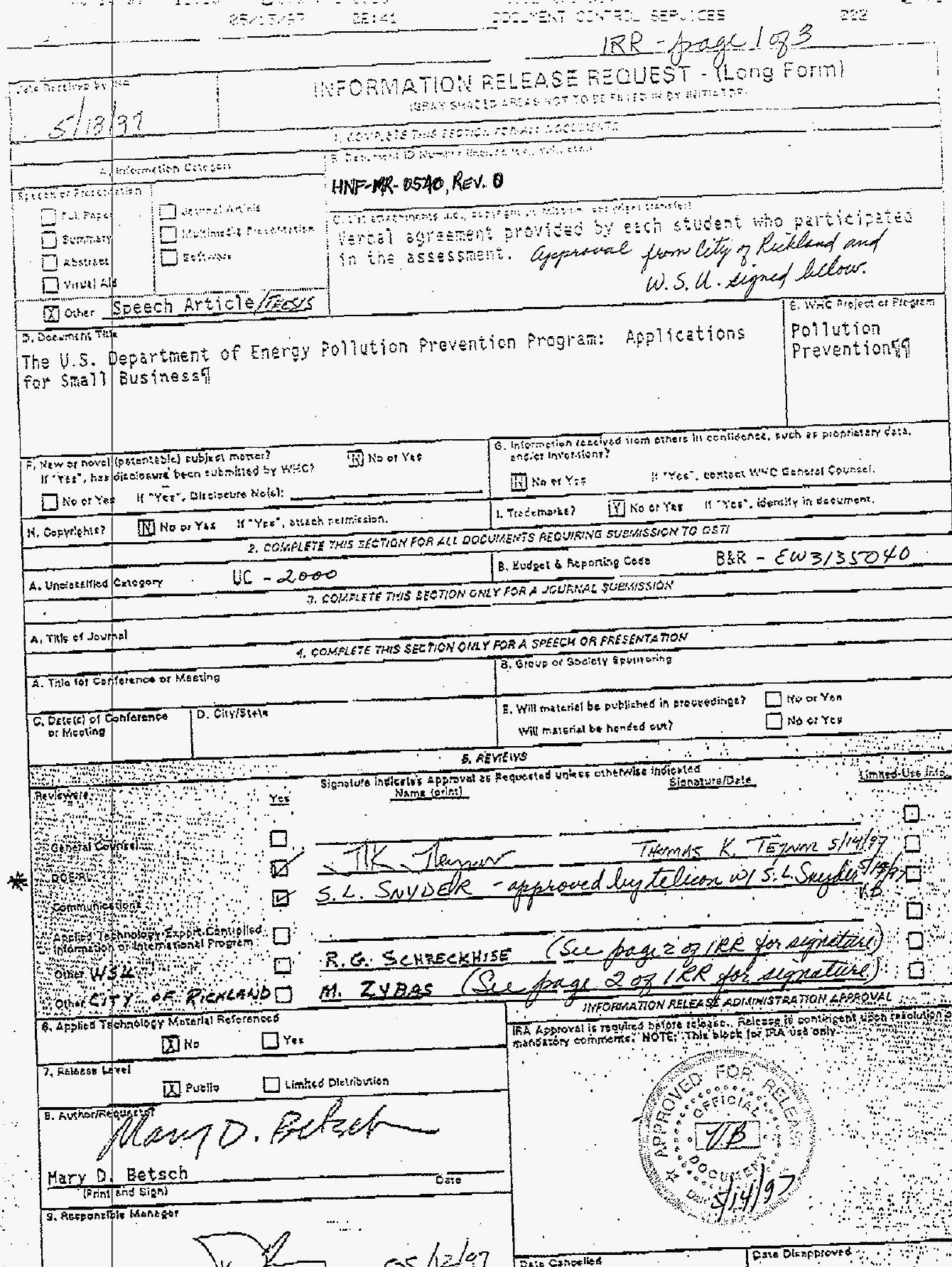





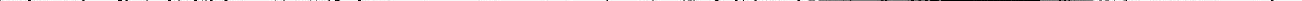


THIS PAGE TNTENTTONALIY LEFT BLANE 
HINF-HR-0540 Rev.0

Document iD Number

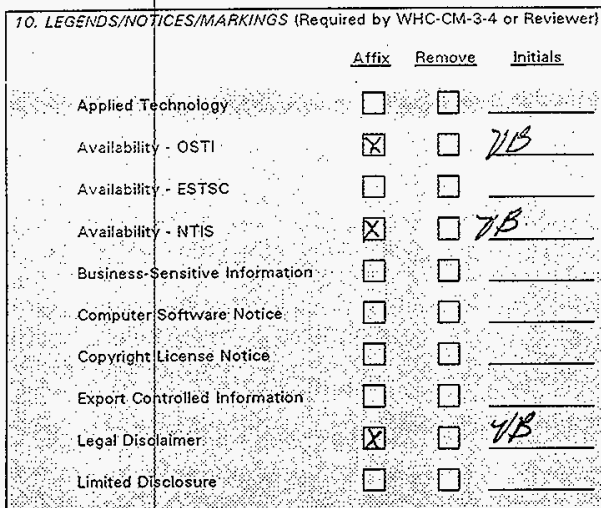

11 MANDATORY COMMENTS ILIST only maridatory comments here All other comments shall be made on the document and jeturiged

to the author

Official Use Only

Patent Status

Predecisional Infornation

Programinatic Notice

Proprietary Information

Purpose and Use

Thesis/Dissertation

Trademark Disclaime

other:

Atfix Remove hitiels

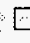

$\square$

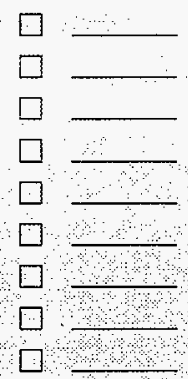

Reyiewer (Print \& Sign)

|

Resolved by Author/Requestor (Print \& Sign)
Date 
THIS PAGTI TNTENTIONATTY

$$
\text { Y F ? M.A.NK }
$$




\section{Acknowledgments}

I wish to express my appreciation to everyone who played a role in this project.

This research is about businesses, without whose participation this study could not have occurred. I am extremely grateful to the participating companies who made the pollution prevention assessments possible. I am indebted to the business owners and managers who made time for extensive interviews and follow-up inquiry and especially their willingness to let me and others examine their operations.

My deepest appreciation goes to Dr. James Wise, my master professor-a genius in my opinion. Countless discussions with him provided the focus for this project. He guided me through the process with insight, advise, counsel, encouragement, and expressions of confidence. Much of the wisdom and innovation in the report resulted from his contributions.

I sincerely appreciate the others on my graduate committee, Ms. Jill Engel-Cox, Dr. Lori Ramonas, and Dr. Gene Schreckhise for the extensive reviews they provided to enhance this report. I would like to further thank Jill who helped with the conceptual development of this project several years ago and "dreamed" this project into existence with me.

I am grateful to the students of the fall 1996 Introduction to Pollution Prevention class at Washington State University at Tri-Cities who conducted five of the assessments as their class project and whose data are included in this report. These students are: Laurie Hay, Bonnie Knight, Chuck Keeler, Chris Lathim, Clark McBride, Steve Mischke, Larry Olsen, Jim Perryman, Robert Smasne, Craig Stoker, and Laurie Vaillancourt.

I am also very grateful to the city of Richland and the U.S. Department of Energy for their financial sponsorship. It was through these agencies that the pollution prevention assessments were funded and were conducted under the direction of RUST Federal Services of Hanford, Inc.

Additional thanks must go to colleagues, friends, and family for providing moral support and inspiration, especially my father August Bodhaine who exemplifies my hero. My greatest appreciation is reserved for my husband Gary Betsch whose constant love, patience, and support empowered me to see this to completion by providing those "welcome diversions." This effort could only be endured through his constant renewal of my spirit.

Thank you all!

Mary D. Betsch 
TFTS PAGE INTENTIONATLS 7 STAANK 


\title{
Dedication
}

\author{
To my Dad
}

August Bodhaine 
THTS PAGE INTENTIONAII 


\section{Preface}

This report shows the benefits small businesses can realize by instituting cost-effective pollution prevention improvements. It is a series of pollution prevention assessments that were conducted at small businesses in Richland, Washington. It describes a technology transfer test of U.S. Department of Energy (USDOE) pollution prevention methods to small businesses through eleven pollution prevention assessments conducted at small businesses in the city of Richland. The assessment method tested was first developed at the USDOE Hanford Site, located in Richland, Washington.

Two pilot studies were initially conducted to determine the usefulness of the assessment method for small businesses. Then, four additional pollution prevention assessments were conducted using a refined process. In order to determine the assessment method's usefulness by different practitioners, a number of the assessments contained in this report were conducted by the undergraduate and graduate students at Washington State University at Tri-Cities as part of their class projects. These students were trained in the pollution prevention assessment process by the author of this report and conducted five small business assessments using the same methods and materials as in the remainder of the study. The author gratefully acknowledges the contributions from the ES/RP 428 Introduction to Pollution Prevention class, taught by Ms. Jill Engel-Cox and Dr. James Duncan, to the research conducted in this project. 
THIS PAGE INTENTIONATE LEFT BLANK 
THE U.S. DEPARTMENT OF ENERGY POLLUTION PREVENTION PROGRAM:

\title{
APPLICATIONS FOR SMALL BUSINESS
}

\author{
Abstract \\ by Mary Diane Betsch, M.S. \\ Washington State University \\ May 1997
}

Chair: James A. Wise

According to the U.S. Small Business Administration, small businesses represent

94-percent of all U.S. business, generating a significant portion of the waste entering the environment. These waste streams offer small businesses an opportunity to initiate pollution prevention practices through cost-effective changes in production, operation, and raw materials use. The U.S. Department of Energy (USDOE) developed a Pollution Prevention Opportunity Assessment approach to evaluate its own input materials and parameters of a process or activity, identify pollution and waste exiting the process or activity, and generate and evaluate options for pollution prevention. This assessment process was transferred from large government activities to small businesses in Richland, Washington through a program cosponsored by the USDOE, the city of Richland, Washington State University at Tri Cities, and RUST Federal Services of Hanford, Inc. This pollution prevention program study showed that the USDOE-developed Pollution 
THIS PAGE INTENTIONAI.WX LEET BLANK 
Prevention Opportunity Assessment process was an adaptable and effective tool for small businesses which resulted in their increased ability to move beyond environmental compliance and become environmentally competitive. Over 60-percent of the source-reduction activities required no capital investment and that for those opportunities requiring capital investments, the investment was recoverable within two years. The successful transfer of the pollution prevention assessment process from large organizations to small businesses shows that federal and local governments can help small businesses save money by reducing waste and energy consumption, significantly minimizing the impact on the local environment. 


\section{Table of Contents}

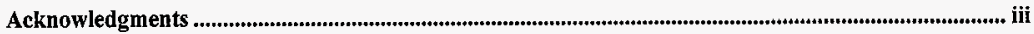

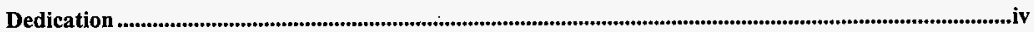

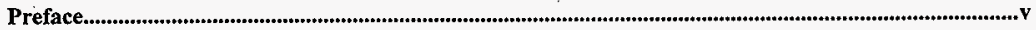

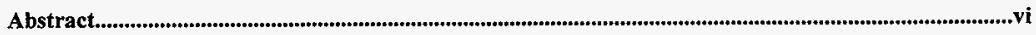

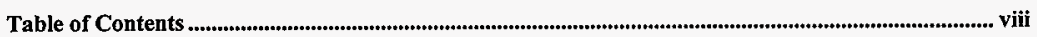

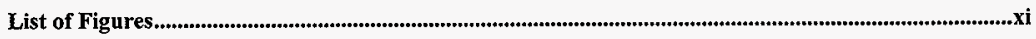

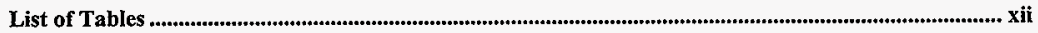

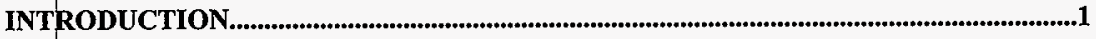

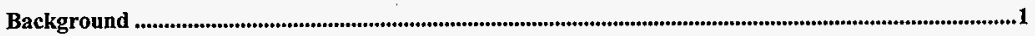

CHAPTER 1: LITERATURE REVIEW AND CASE STUDIES ..........................................12

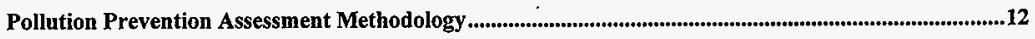

Pollution Prevention Assessment Methods: U. S. Envirommental Protection Agency ..........................13

Pollution Prevention Assessment Methods: U.S. Department of Energy Kansas City Plant ..................16

Pollution Prevention Assessment Methods: Industrial Assessment Centers.........................................19

Pollution Prevention Assessment Methods: U. S. Department of Energy's Hanford Site .......................21

Pollution Prevention Assessment Methods: Washington State Department of Ecology.........................25

Pollution Prevention Assessment Methods: Alaska Health Project........................................................28

Pollution Prevention Assessment Methods: Pollution Prevention Financial Analysis and Cost

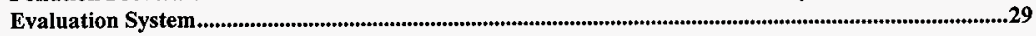

Pollution Prevention Assessment Methods: Waste Diversion Cost Analysis Model ................................30

Pollution Prevention Assessment Methods: Climate Wise Opportunities Assessment .............................32

Pollution Prevention Assessment Methods: Texas Natural Resource Conservation Commission Environmental Accounting Worksheet.............................................................................................33

Pollution Prevention Assessment Methods: Various Profit and Non-Profit Agencies .............................35 
THIS PAGE INTENTIONATIS I.EFT BLANK 
Total Quality Environmental Management......................................................................................................39

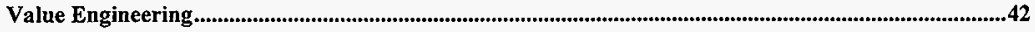

Analysis of Best Methods for Small Businesses ...........................................................................................44

CHAPTER 2: METHODS AND MATERIALS ...............................................................48

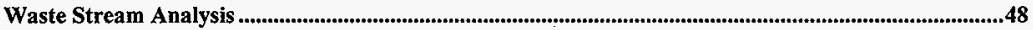

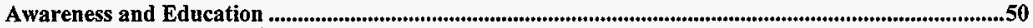

Pollution Prevention Opportunity Assessment Process ....................................................................................52

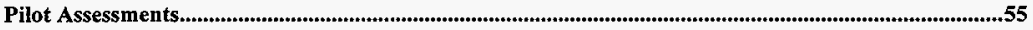

Industry Selection Criteria and Process.................................................................................................................59

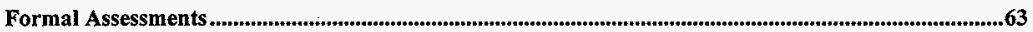

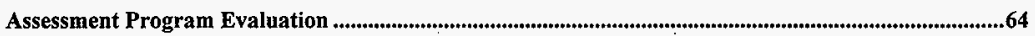

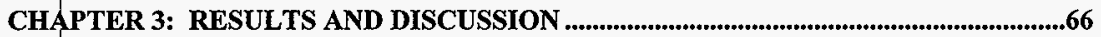

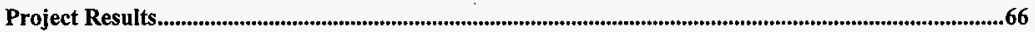

Case Study Results .................................................................................................................................69

Assessments Conducted by the Pollution Prevention Class.........................................................................83

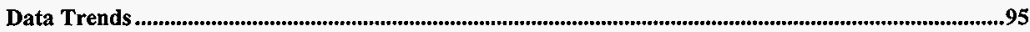

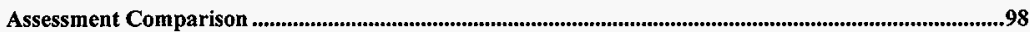

Comparison of Project Results to Other Pollution Prevention Programs ................................................101

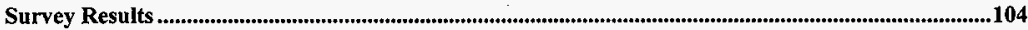

Barriers and Incentives to Pollution Prevention ............................................................................................107

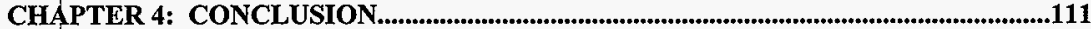

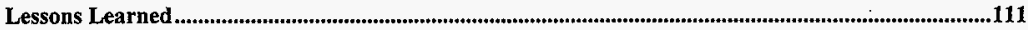

Recommended Program Adjustments....................................................................................................114

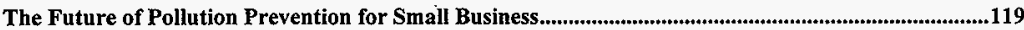

REFERENCES..............................................................................................................121 
THIS PAGE INTENTIONAILY LEIT BLANK 
Appendix A: Applicable Laws and Regulations ........................................................................................124

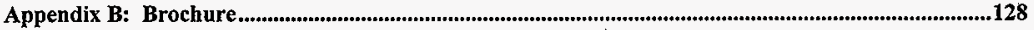

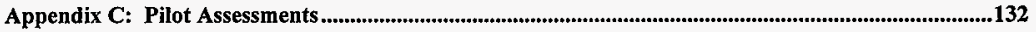

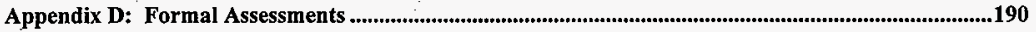

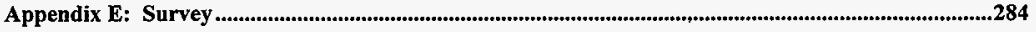

Appendix F: Public and Private Technical Assistance Programs................................................................287

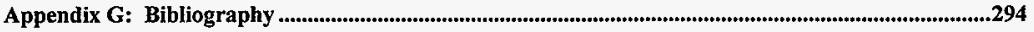


THIS PAGE INTTINTTONALESE

LEIT BIANK 


\section{List of Figures}

Figure 1 Material flows in a business without pollution prevention..............................................................................5

Figure 2 Material flows in a business with pollution prevention................................................................................6

Figure 3 Washington state hazardous waste reduction progress towards the 50 -percent policy goal. .........................8

Figure 4 Washington state progress towards the 50-percent recycling goal............................................................9

Figure 5 Washington State Toxic Release Inventory results. ...................................................................................10

Figure 6 The Pollution Prevention Opportunity Assessment process.....................................................................53

Figure 7 Pollution prevention opportunities identified by media type. ......................................................................66

Figure 8 Pollution prevention opportunities summarized according to the U.S. Environmental Protection Agency pollution prevention hierarchy

Figure 9 Pollution prevention techniques.

Figure 10 Distribution of opportunities by type and payback. ..................................................................................69

Figure 11 Commercial laundry implementation cost versus annual cost savings....................................................72

Figure 12 Automotive repair shop implementation cost versus annual cost savings................................................74

Figure 13 Winery implementation cost versus annual cost savings..........................................................................76

Figure 14 Medical clinic implementation cost versus annual cost savings..............................................................78

Figure 15 Hotel implementation cost versus annual cost savings...........................................................................80

Figure 16 Apartment complex implementation cost versus annual cost savings.......................................................82

Figure 17 Construction firm implementation cost versus annual cost savings..........................................................8

Figure 18 Supermarket implementation cost versus annual cost savings. ..................................................................86

Figure 19 Autobody shop implementation cost versus annual cost savings. .............................................................87

Figure 20 Printing and graphics firm implementation cost versus anmual cost savings............................................90

Figure 21 Landscaping firm implementation cost versus anmual cost savings. ......................................................92

Figure 22 Average payback period by pollution prevention method.........................................................................98

Figure 23 Eco-Efficiency as a holistic approach to business management practices. ...............................................115 
THIS PAGE INTENTIONALW LEIT BLANE 


\section{List of Tables}

Table 1 The U.S. Environmental Protection Agency assessment worksheets (USEPA 1992)................................14

Table 2 Matrix of pollution prevention methods. ......................................................................................................47

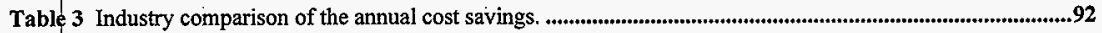

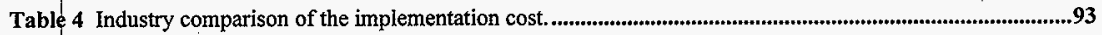

Table 5 Summary of pollution prevention opportunities by industry, .........................................................................94

Table 6 Source reduction related opportunities and their related cost savings and payback periods..........................95

Table 7 Recycling opportunities and their related cost savings and payback periods. ..............................................96

Table 8 Energy recovery opportunities and their related cost savings and payback periods......................................97

Table 9 Treatment opportunities and their related cost savings and payback periods.................................................97

Table 10 Factors for and against implementation of pollution prevention initiatives...............................................105

Table 11 Scale of response to satisfaction and usefulness. ............................................................................................105

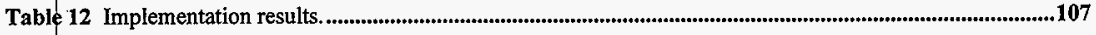




\section{Introduction}

The most pressing environmental challenges threatening the environment and prosperity

of Washington state can only be addressed by industry, government and community leaders working in a spirit of partnership. Through two grants funded at the federal and local level, this research project conducted Pollution Prevention Opportunity Assessments (P2OA's) for small businesses in the Tri-Cities region of south central Washington state. The U.S. Department of Energy (USDOE) developed the P2OA method to evaluate input materials and parameters of a process or activity, identify pollution and waste exiting the process or activity, and generate and evaluate options for pollution prevention.

This process was transferred to small businesses in the city of Richland and demonstrated that the identification of waste minimization opportunities in small businesses was economically advantageous to the firm through reduced expenditures for utilities, raw materials, and waste products. The assessments provided a means for small businesses to increase their ability to implement technologies and techniques which, in turn, allowed them to move beyond environmental compliance and become environmentally competitive.

This study showed that the USDOE-developed P2OA process was an effective tool on which to build an environmental foundation for small businesses to demonstrate cost effectiveness through implementation of pollution prevention and energy conservation initiatives.

\section{Background}

The U.S. Small Business Administration defines "small business" as one that is 
independently owned and operated and not dominant in its field of operation. ${ }^{(1)}$ The

Administration has developed size standards that define the maximum size of an eligible small business: 1) retail and service- $\$ 3.5$ to $\$ 13.5$ million; 2) construction $-\$ 7.0$ to $\$ 17.0$ million; 3 ) agriculture- $\$ 0.5$ to $\$ 3.5$ million; 4) wholesale-no more than 100 employees; and 5) manufacturing - 500 to 1,500 employees. For the purposes of this study "small business" is defined as less than 100 employees.

According to the U.S. Small Business Administration, small businesses represent 94-percent of all U.S. business (Slater 1991). Small businesses have remained beyond the range of the latest developments in environmental technology and regulations. Some of the common beliefs shared by small businesses include: 1) small businesses generally do not consider themselves a large part of the environmental problem; 2) they lack environmental information and their communications and assistance networks are often underdeveloped; 3) many small businesses are finding themselves subject to environmental regulations for the first time; and (4) small businesses share a common skepticism about government, especially at the federal level. Recognition of these concerns represents a growing area of opportunity for pollution prevention.

\section{United States Business}

If the United States is to have sustainable economic development, small businesses must be both environmentally sound and competitive. According to Wackernagel and Rees (1996), "a sustainable economy uses essential products and processes of nature no more quickly than nature can renew them. Furthermore, a sustainable economy discharges wastes no more quickly than

(1) Text report from the U.S. Small Business Administration Homepage, http://commerce.state.nc.us/commerce/sbtdc/capopps/sba.html. 
nature can absorb them." Achieving this will require a new mode of operation for industry that not only compels businesses to meet environmental standards, but also empowers them to meet and go beyond these standards.

The past 30-years of generally unsatisfactory waste management practices revealed the error of previous actions, largely by industry, and the overall ignorance of those actions on the environment. In the $1970^{\prime}$ 's, Congress enacted an array of legislation to addresses the pollution apparent in the environmental media of air, water, and land. The media-specific statutes were intended to influence environmental improvement by controlling pollution. Those regulated relied heavily on capture, treatment, and disposal to manage wastes, emissions, or effluents after they had been generated. In response to media-specific regulations, pollution control addressed air pollutants, water discharges, and management of solid and hazardous wastes separately, which inevitably resulted in cross-media (i.e., moving pollutants from one environmental media to another) transfers of pollutants.

Controlling pollution after it has been generated is a short-term solution to a long-term problem with resulting long-term costs of emission control, waste disposal, water effluent control, permits and fines, equipment maintenance, down time, and potential liabilities. None of the pollution control options address long-term environmental problems. This limits the capacity for solutions to be reached as emission and waste generation rates increase. End-of-pipe solutions to environmental problems may address many regulatory requirements, but in general they offer few benefits to the company that implements them. For these reasons, environmental agencies and others began promoting the use of pollution prevention through voluntary programs to enhance environmental protection. 
Pollution prevention can extend environmental protection beyond what is possible with end-of-the-pipe pollution control. Essentially, all nonproduct outputs including by-products, emissions, and wastes can be reduced by addressing wastes at their source. This approach offers greater, long-term protection of all environmental media. The simplest way to minimize pollution is not to produce it. This is the foundation of pollution prevention.

On October 27, 1990, the U.S. Congress passed the Pollution Prevention Act of 1990 (1990). Congress declared as a national policy of the United States that

"pollution should be prevented or reduced at the source whenever feasible; pollution that cannot be prevented should be recycled in an environmentally safe manner, whenever feasible; pollution that cannot be prevented or recycled should be treated in an environmentally safe manner whenever feasible; and disposal or other release into the environment should be employed only as a last resort and should be conducted in an environmentally safe manner" (Pollution Prevention Act of 1990 1990).

The Pollution Prevention Act of 1990 revolutionized the way many business operated (USEPA 1992). Figure 1 shows the typical flows of materials in a business where raw materials, energy, and water eventually end up as either product or waste. Pollution prevention is a hierarchy of activities with source reduction first, recycling and reuse next, then energy recovery, and finally treatment. 


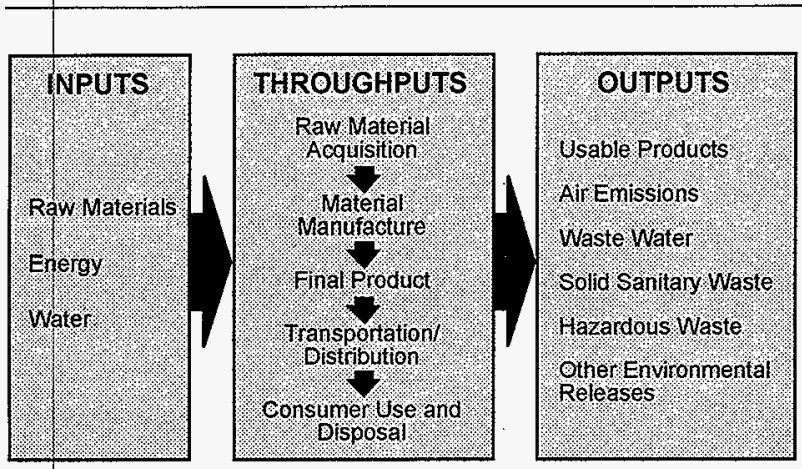

Figure 1 Material flows in a business without pollution prevention.

Figure 2 illustrates the benefits of pollution prevention at all stages in a business process or activity. The strategy of source reduction is elimination of waste before it is generated. The intent in applying this hierarchy is always to start at the top of the pollution prevention hierarchy, looking first for opportunities that eliminate the generation of pollutants. Recycling is a waste management option second only to source reduction. It is the reuse and reclamation of materials. Energy recovery can be incorporated at all stages of a product's life cycle. Once pollution prevention options are identified, then pollution control technologies become less preferable options. Instituting pollution prevention opportunities at any stage of a process minimizes the output to the environment and saves a company money. The philosophy and approach to solving problems that are raised by the increasing environmental awareness will make the difference in how business is conducted in the future. 


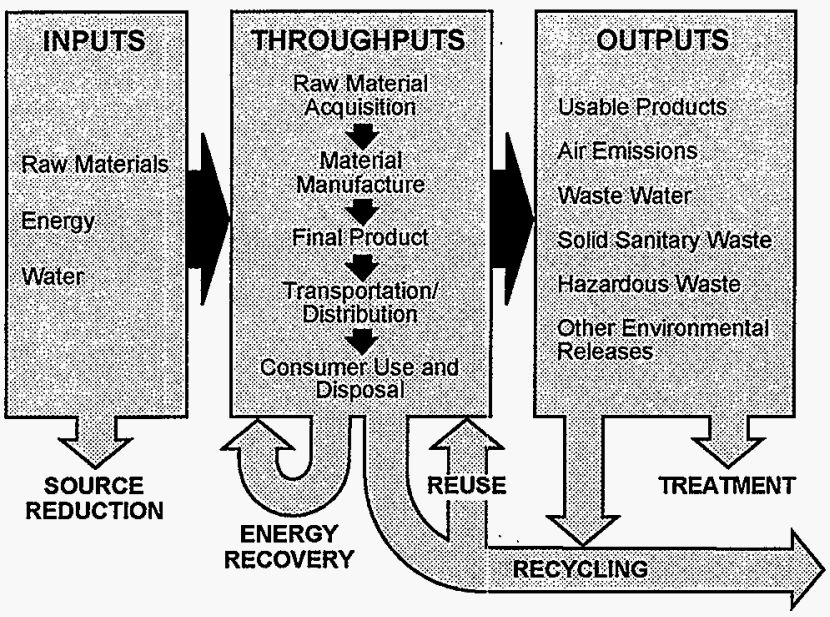

Figure 2 Material flows in a business with pollution prevention.

Industries have significant opportunities to reduce or prevent pollution at the source with cost-effective changes in production, operation, and raw materials use. According to Underwood

"businesses can eliminate one-third to one-half of their waste generation by implementing source reduction techniques according to some federal government agencies estimates. At the same time, certain private sector studies suggest some industry sectors can cut their waste by up to 80 -percent. Further, one recent study (Underwood 1993) showed that 25-percent of all source reduction activities require no capital investment for implementation, and of those that require capital, 50 -percent of the investments were recouped in savings, on average, in less than 18 months."

However, many in industry, particularly small businesses, are unaware of pollution prevention options and the improvement these technologies can make on the bottom-line.

Small businesses often lack the in-house expertise and up-front funding needed to initiate waste minimization programs. Some technical assistance is available to industry through federal and state programs and other sources, but these programs are limited. Today, U.S. businesses are 
facing an ever increasing set of environmental regulatory requirements and constraints that help to ensure a healthy environment for the public. These requirements are especially burdensome for smaller businesses who must contend with the myriad of local, state, and federal requirements and still maintain economic viability.

Washington State Business

As Washington state's population grew from nearly 2 million in 1940 to well over 5 million in 1996 (WDOE 1995a), more and more demands were being placed on the environment by the actions of Washington's citizens and businesses. As a result, the volume of waste was increasing and the sources of water and air pollution were becoming more widespread. In adopting the 1990 Hazardous Waste Reduction Act (RCW 1994), the Washington State Legislature set a statewide policy goal of reducing the amount of hazardous waste generated by 50 -percent by the year 1995 . The goal equaled 58 million $\mathrm{kg}$ (128 million pounds), which was 50-percent of the 116 million $\mathrm{kg}$ ( 255 million pounds) generated by all businesses in 1990 (WDOE 1995b). The primary method used to achieve this goal was to require hazardous waste generators and hazardous substance users to prepare pollution prevention plans. While preparing a plan is required, implementation of the plans is voluntary. Figure 3 illustrates that a reduction trend in hazardous waste generation has been evident since $1992 .{ }^{(2)}$ These data were adjusted for the changing economy. The adjustment factors were calculated from information provided by the Washington State Department of Revenue (WDOE 1995b). Gross business income from all Washington businesses was the normalization measure used. Comparing waste

(2) Personal communications, B. Lemcke, Washington State Department of Ecology, Olympia, WA, 29 January 1997. 
with the adjustment factors equates to a 37-percent reduction from 1990 to 1995 . The 1995 goal was not achieved due largely to the immense number of small businesses generating waste (96percent) with little or no means for implementing pollution prevention initiatives. ${ }^{(3)}$

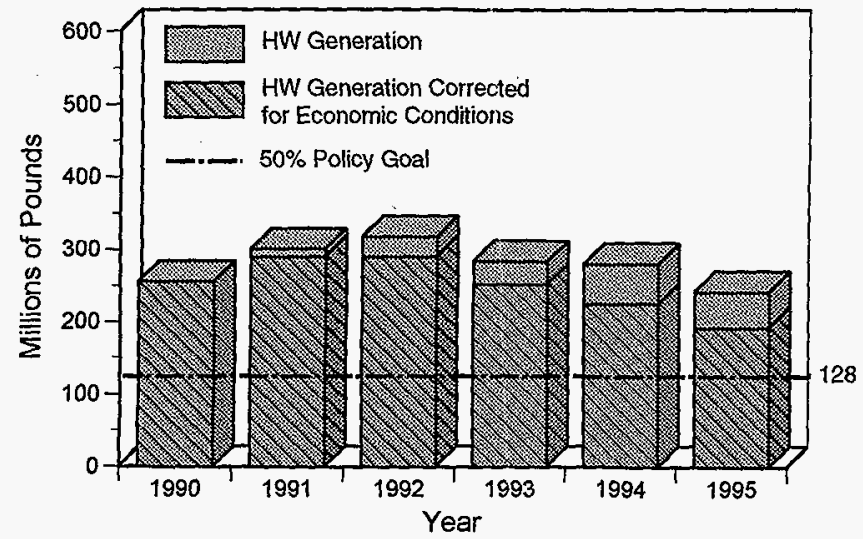

Figure 3 Washington state hazardous waste reduction progress towards the 50-percent policy goal. (Washington State Department of Ecology 1993 Annual Progress Report, 95-401, January 1995)

The Solid Waste Management Reduction and Recycling Act, (RCW 1969, as amended) set a state goal to achieve a 50-percent recycling rate by the year 1995 . The recycling rate was intended for residential and commercial concerns combined. The 1995 total commercial waste recycled was $904,245 \mathrm{~kg}(1,993,520$ pounds $)$ out of $1,238,871 \mathrm{~kg}(2,731,243$ pounds) recycled. The recycling rate in 1995 was 38-percent $t^{(4)}$ and can be seen in Figure 4.

(3) Personal communications, B. Lemcke, Washington State Department of Ecology, Olympia, WA, 29 January 1997.

(4) Personal communications, M. Benedict, Washington State Department of Ecology, Yakima, WA, 6 February 1997. 


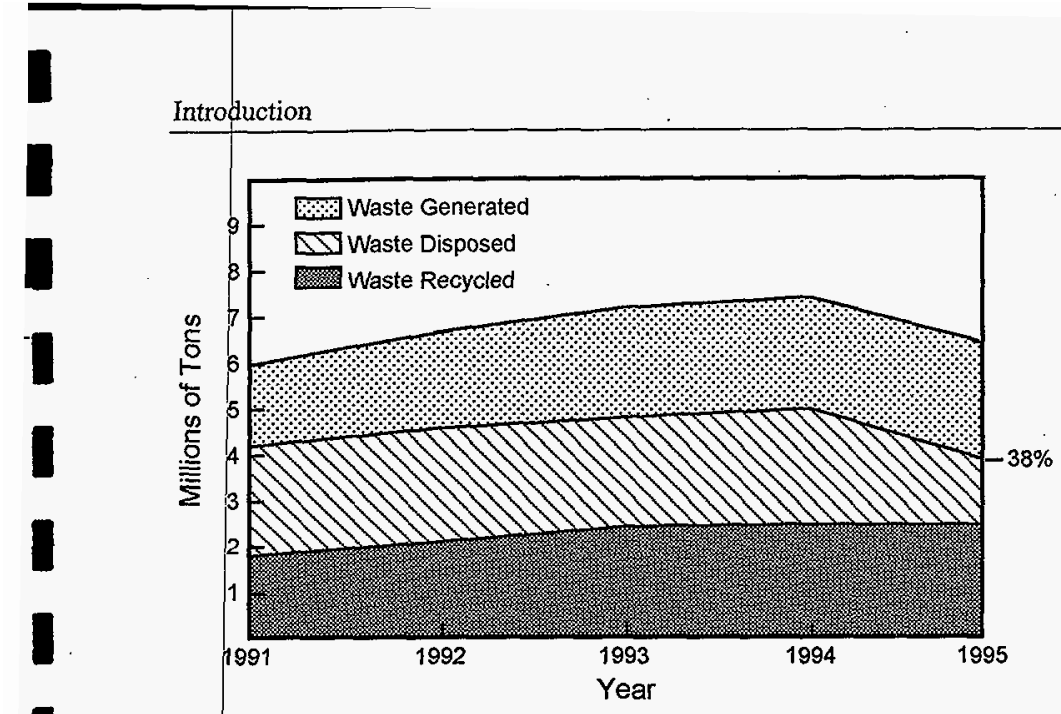

Figure 4 Washington state progress towards the 50-percent recycling goal.

(Washington State Department of Ecology Fourth Annual Status Report Including the 1994 Recycling Survey, 96-500, February 1996)

The Toxics Release Inventory, as required by the Emergency Planning and CommunityRight-To-Know Act of 1986 (1986), is another indicator of Washington's pollution prevention progress. According to WDOE (1995b), the number of businesses filing reports for Toxics Release Inventory declined between 1989 and 1994, indicating that fewer facilities were required to report because they no longer exceeded reporting thresholds. Total quantities of chemicals released have also decreased between 1989 and 1994. These results are identified on Figure 5. A description of the applicable laws and regulations for Washington state businesses is identified in Appendix A. 


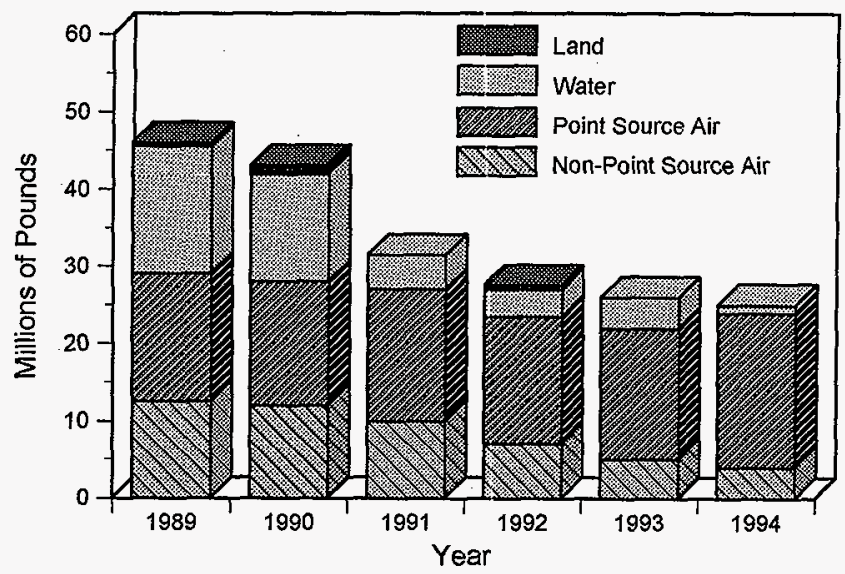

Figure 5 Washington State Toxic Release Inventory results.

(Washington State Department of Ecology 1993 Annual Progress Report, 95-401, January 1995)

\section{City of Richland}

The city of Richland has developed a vision for the year 2020 which states that "by the year 2020, Richland will be a vibrant community where 80-percent of the economy is based in private industry and commerce. ${ }^{n(5)}$ Richland has over 2,000 businesses, ${ }^{(6)}$ many of which consume energy and/or generate air pollutants, solid sanitary and hazardous waste, and waste water. Less than 10 industries in Richland are considered large (greater than 100 employees), with the remaining majority determined small business (less than 100 employees). The aggressive vision, combined with the large infrastructure of small business, provided the impetus for identifying pollution prevention initiatives for small businesses in the city of Richland.

(5) Personal communications, A. Carlson, Richland, WA, 18 February 1997.

(6) Personal communications, City of Richland Business License Department, 30 July 1996. 
Pollution prevention alternatives offered small businesses the opportunity to increase

productivity, improve customer satisfaction, reduce waste, conserve energy, and minimize costs.

By documenting these savings in the pollution prevention opportunity assesșment, small businesses were able to make sound judgments towards implementation. 


\section{Chapter 1: Literature Review and Case Studies}

\section{Pollution Prevention Assessment Methodology}

The literature review described below is a compilation of the pollution prevention assessment models that were used in developing the assessment tool for this study. In addition, a discussion of other assessment tools and related environmental improvement approaches, applicable to the small business community, are described. Following most of the assessment processes, there are a series of case studies that demonstrate the validity of the assessment methodology. This anecdotal information combines an industry process or activity with the assessment method to illustrate the tool's capabilities.

A pollution prevention assessment is considered the standard method used to identify pollution prevention opportunities and evaluate the costs and benefits for implementation. A pollution prevention assessment serves two basic purposes: 1) to establish a baseline of data by collecting background information on a business' current purchasing, waste generation, and management practices; and 2) to identify potential waste reduction options for evaluation. Although many pollution prevention measures can be adopted without the help of an assessment, the data generated in an assessment can provide a business with a better understanding of the types and amounts of waste generated as well as identify opportunities worth investigating.

Assessment approaches range from a simple payback method to a more complex total life cycle cost assessment. At the minimum, a pollution prevention assessment includes:

- Analysis of the waste stream, 
- Description of the process,

- Identification of pollution prevention opportunities, and

- Evaluation of the opportunities.

Additional elements are included for more complex assessment methods. Typically, an assessment team is developed which is comprised of a diverse group of individuals which can include operators and line personnel, engineers, scientists, environmental specialists, and managers or business owners.

The assessment tool used for this study was a combination of the models developed by the U.S. Environmental Protection Agency (USEPA), the U.S. Department of Energy's (USDOE) Kansas City Plant, the Industrial Assessment Center, and the USDOE's Hanford Site. Each of these assessment approaches are described in the literature search in the order in which they were used in building the assessment tool for small businesses. The USEPA assessment process was the initial starting point for most agencies and businesses in the United States. From there, the various assessment approaches were developed due in a large part to the flexibility of the USEPA model.

\section{Pollution Prevention Assessment Methods: U. S. Environmental Protection Agency}

The USEPA developed a guide for industry on pollution prevention assessments (USEPA 1992). It summarizes the benefits of a businesses' pollution prevention program and suggests ways to incorporate pollution prevention in every day business practices. It outlines procedures for conducting a preliminary assessment to identify opportunities for waste reduction or elimination. It then describes how to use the results of the preliminary assessment to prioritize areas for a detailed assessment, how to use the detailed assessment to identify pollution 
prevention options, and how to implement those options that withstand feasibility analysis.

Methods of evaluating, adjusting, and maintaining the program are also described, as is cost analysis for pollution prevention projects. The USEPA assessment worksheets are depicted in Table 1.

Table 1 The U.S. Environmental Protection Agency assessment worksheets (USEPA 1992).

\begin{tabular}{ll}
\hline \multicolumn{1}{c}{ Worksheet Title } & Summarizes the overall program \\
\hline Assessment Overview & $\begin{array}{l}\text { Lists background information about the facility, including location, } \\
\text { products, and operations. }\end{array}$ \\
Process Information & $\begin{array}{l}\text { A checklist of process information that can be collected before the } \\
\text { assessment effort begins. }\end{array}$ \\
Input Materials Summary & $\begin{array}{l}\text { Records input materials information for a specific production or } \\
\text { process area. This includes name, supplier, hazardous component or } \\
\text { properties, cost, delivery and shelf-life information, and possible } \\
\text { substitutes. }\end{array}$ \\
Products Summary & $\begin{array}{l}\text { Identifies hazardous components, production rate, revenues, and } \\
\text { other information about products. }\end{array}$ \\
Waste Stream Summary & $\begin{array}{l}\text { Summarizes the information collected for several waste streams. This } \\
\text { sheet can be used to prioritize waste streams to assess. }\end{array}$ \\
Option Generation & $\begin{array}{l}\text { Records options proposed during brainstorming or nominal group } \\
\text { technique sessions. Includes the rationale for proposing each option. }\end{array}$ \\
Option Description & Describes and summarizes information about proposed options. \\
Profitability & Identifies capital and operating costs and the payback period.
\end{tabular}

The USEPA recommends an all-media assessment approach that deals with air, water, and solid waste emissions and releases. After the site is visited, and during the preliminary assessment phase the processes, operations, and wastes are prioritized and the most important waste problems are identified. Areas of opportunity are identified and then a detailed assessment is conducted where each operational area of the facility is evaluated. Data are collected and once 
the sources and nature of wastes generated have been described, the assessment team enters the creative phase and pollution prevention options are proposed and screened. The final step is a technical evaluation to determine whether or not the proposed pollution prevention options are likely to work in a specific application. The USEPA encourages people using the guide to modify the procedures and forms to fit their own circumstances.

\section{Case Study: Dairy}

The USEPA assessment methodology was implemented at a plant that annually produced 89 million L (23.4 million gallons) of milk and milk products, fruit juice drinks, and jugs from high density polyethylene pellets (Springer 1992). The plant was organized so that product and byproducts from the primary operation are transferred to another area in the plant for processing into a variety of products. For example, the cream pumped through the clarifier is transferred to the ice cream mix process or is packaged for sale as cream. Additionally, a portion of the skim milk is transferred to the buttermilk process and a portion to the pasteurization and homogenization for packaging and sale. Each of the products produced at the plant generates waste including milk solids ( $\$ 8,800$ annual cost to the dairy), spills and leaks ( $\$ 790$ annual cost to the dairy), and cleaning of the physical containers and machinery $(\$ 194,190$ annual cost to the dairy). Producing the plastic jugs creates an additional 4,920 L (1,300 gallons) of dust annually. Several waste minimization opportunities were recommended at the dairy that centered on instituting a wastewater minimization plan. The plan included ongoing employee awareness, minimizing cleanup water use by using high-pressure and automatic shut-off hose nozzles, and installing an activated sludge treatment system to treat the pit-collected wastewater before being sent to the sewer because the waste did not meet disposal standards. 
Employing these recommendations reduced the uncontained milk waste 38-percent and the wastewater 90 -percent, for an annual savings of $\$ 320,810$. The payback period for the $\$ 661,200$ implementation cost was 2.1 years. The simple assessment method showed a costeffective payback using 9 . worksheets and an industry-specific checklist to help identify opportunities.

\section{Pollution Prevention Assessment Methods: U.S. Department of Energy Kansas City Plant}

The USDOE used the USEPA assessment method to benchmark development of a similar assessment approach. The USDOE's Kansas City Plant was given a directive by the USDOE Headquarters to develop an assessment process as a model for all USDOE facilities (USDOE 1996a). These facilities are comprised of numerous sites located in many different parts of the country that range from single to multi-disciplinary facilities and vary in size. There is also a tremendous diversity of technologies, processes, and activities. The Pollution Prevention Opportunity Assessment ( $\mathrm{P} 2 \mathrm{OA})$ addresses these complexities and recognizes that processes vary in the quantity of energy used and pollution and/or waste generated. It also addressed the perceived risk and hazards associated with an operation.

Since the USDOE's P2OA process was based on USEPA's format, it relies on worksheets to guide the assessment process. The Kansas City Plant's assessment included an evaluation of energy conservation as well as pollution prevention opportunities. The Kansas City Plant's process differed from most programs in the concept of the graded approach. This approach introduced three levels of detail for assessments based on the prioritization of the activity. The graded approach allowed flexibility for the individual sites evaluated, yet provided 
a consistent structure. If used properly, the graded approach allows a site to concentrate its resources on the most critical areas and most important waste problems first.

\section{Level 1 Activity Characterization}

Level I (Activity Characterization) of the graded approach provides a systematic approach using a "weighted sums evaluation" to determine if a more detailed analysis is necessary. This approach starts with the prioritization of the site's waste streams followed by the development of a list of processes, projects, and/or activities that contribute to waste streams on that priority list. Next, the activity or project is defined and past and present pollution prevention opportunities identified. A minimal amount of descriptive, quantitative, and qualitative information is necessary.

After collecting the activity information, it is necessary to determine whether or not the assessment should continue to a Level II or III analysis. If the activity does not contain any of the materials or waste streams on the priority list and there is no potential for further pollution prevention, then the Level I documentation is satisfactory and the analysis is complete.

However, those activities on the priority list, or those activities that have potential for pollution preyention are then included and evaluated further to determine the next level of effort to be performed.

Level II Informal Assessment

The principle objectives of the Level II (Informal Assessment) graded approach are to: 1) develop and screen pollution prevention opportunities; and 2) recommend viable options for implementation. This level does not require the collection of new data as much of the 
information is available in the Level I assessment. However, a more detailed analysis of each opportunity is performed in this process.

\section{Level III Formal Assessment}

The primary objectives of the Level III (Formal Assessment) graded approach are to: 1) conduct a detailed analysis of opportunities for the activity; 2) provide justification for the implementation of those opportunities; and 3) document the results in a written report. The Level III assessment requires considerably more documentation to complete the assessment. It requires collection of quantitative data for a material balance and a thorough cost-benefit analysis.

\section{Case Study: Foam Molding}

The USDOE at the Kansas City Plant pollution prevention process was applied to a foam molding process (USDOE 1996a). The processing and flow of the polyurethane products generated approximately $108 \mathrm{~kg}$ ( 238 pounds) of product, $18 \mathrm{~kg}$ ( 39 pounds) of hazardous liquid waste, $151 \mathrm{~kg}$ (332 pounds) of hazardous solid waste, less than $1 \mathrm{~kg}$ ( 2 pounds) of volatile emissions, and $29 \mathrm{~kg}$ ( 65 pounds) of solid waste per complete process. The foam molding process began with foam machine calibration, then foam mixing and pouring, and finally foam product curing. At each stage, wastes were generated for treatment and eventual disposal.

Over ten pollution prevention opportunities were identified including installing in-line calibration, reducing solvent purge, developing polymeric substitutes, and training the operators. Two of the options were implemented. A polymeric substitute was developed and utilized, reducing over $9,000 \mathrm{~kg}(19,000$ pounds $)$ of hazardous waste annually. Additionally, the volume of solvent purge used was reduced by 35 -percent. Conducting the foam molding assessment 
took a total of 310 hours to complete including planning and organization, assessment

worksheets, option generation, final report, and regulatory requirements.

Comparison of Assessment Methods for Large and Small Businesses

When comparing assessments conducted at large federal facilities to small businesses, the biggest difference observed is the magnitude at which the assessment is conducted. In the dairy case study example, the entire facility including all processes (i.e., milk and milk products, fruit juice drinks, and jugs from high density polyethylene pellets) were evaluated. In the foam molding case study example, the assessment was targeted specifically to a particular process within the facility. Large governmental facility assessments are limited to the number of opportunities identified for a particular process or activity and, consequently, additional pollution preyention assessments are required for all the individual processes or activities within the larger framework of the facility. Furthermore, USDOE facilities are generally too large for one assessment and therefore are broken down into "small businesses" within the single "large business."

\section{Pollution Prevention Assessment Methods: Industrial Assessment Centers}

The Industrial Assessment Center program, targeted toward small-and medium-sized manufacturing firms, was developed and funded by the USDOE and implemented by various college and universities in the United States. ${ }^{(7)}$ The program's headquarters was at Rutgers University. The Center's services were offered at no direct cost to manufacturers and served almost 3,200 manufacturing plants since 1976. Teams of engineering students and faculty

(7) Text report from Rutgers, The State University of New Jersey Homepage, http://oipea-www.rutgers.edu. 
located at 30 college and universities conducted energy audits or industrial assessments and provided recommendations to manufacturers to help them identify opportunities to improve productivity, reduce waste, and save energy. The recommendations from industrial assessments averaged about $\$ 55,000$ in potential annual savings for each manufacturer.

In order for a manufacturing firm to qualify for a no-cost assessment, a manufacturing plant must be within certain Standard Industrial Codes and must be located within $252 \mathrm{~km}$ (150 miles) of a center. In addition, the plant must meet any one of the following criteria: gross sales below $\$ 75$ million, a maximum of 500 employees, and annual energy bills below $\$ 1.75$ million.

The assessment process used by each of the individual Industrial Assessment Centers is unique. However, since it was previously funded in part by the USEPA, the processes developed by the USEPA were utilized in total or in part. For one Center, the assessment team performs a one-day site visit at an industrial plant which follows an extensive preaudit data-gathering function. Following the site visit, the audit team prepares a report for the manufacturer that includes information about the plant's energy use, processes, and other operations. In addition, each report has several assessment recommendations that provide anticipated savings, implementation costs, and simple payback for each assessment recommendation presented.

Another approach to performing a waste assessment begins with a general-questions list that is comprised of energy consumption and waste generation related questions. The questions list is completed by the business owner prior to the site visit. From the completed questions list, the assessment team selects the most costly waste streams and begins to identify alternatives. Once the waste streams have been selected after the site visit, one of four methods is employed. The first method is elimination or reduction at the source of the waste generation stream. The 
second method is on-site recovery or recycling. Thirdly, waste exchanges are investigated to find perspective buyers or recyclers of waste materials. Finally, alternatives are evaluated for using the waste material to manufacture an additional product. For this particular assessment program, no specific worksheets were utilized for the analysis except for the questions list.

Case Study: Painting Operations

In 1993, the Industrial Assessment Centers located at Colorado State University, the University of Louisville, and the University of Tennessee, under the direction of the University City Science Center, performed waste assessments at 70 small and medium-sized painting firms (Kirsch, Looby, and Kirk'1993). One plant in particular produced 2.5 million car and truck mirrors annually generating $79,490 \mathrm{~L}$ ( 21,000 gallons) of paint sludge at a disposal cost of almost $\$ 1.2$ million.

An estimated annual savings of $\$ 179,900$ was achieved from installing hydroclones to remove paint solids from the paint booth water-curtain drainage. Other pollution prevention opportunities included sending the paint sludge to a drying service for dry powder disposal at a cost savings of $\$ 24,300$. One final opportunity achieved an annual savings of $\$ 7,200$ for recycling steel paint cans. The methodology employed achieved a exemplary assessment including a simple payback for the firm to evaluate its implementation.

\section{Pollution Prevention Assessment Methods: U. S. Department of Energy's Hanford Site}

Although other assessment methods were evaluated prior to the development of the Hanford model, its approach is based primarily on the model the Kansas City Plant developed. 
Although it is similar in scope to the Kansas City Plant's approach, the process was streamlined significantly. The Hanford process was condensed into five worksheets and two worksheets for waste stream prioritization (USDOE 1996b). The Hanford process includes the following steps:

- Identify priority waste streams,

- Select activities for further study,

- Organize assessment teams,

- Conduct facility walk through,

- Describe activity and conduct material-balance,

- Brainstorm pollution prevention opportunities,

- Conduct a cost benefit analysis, and

- Implement the recommended opportunities.

Before conducting the actual $\mathrm{P} 2 \mathrm{OA}$, the waste streams are evaluated according to cost of disposal and quantity of waste generated over a given period of time. Those streams with the highest cost and quantity are considered for P2OA's. After a waste stream has been selected, it is necessary to determine the activity(ies) generating that waste. For example, spray painting is an activity that contributes to the generation of solvent in a waste stream.

The assessment team, comprised of individuals familiar with the waste generating activity, begins the information gathering process by conducting a walk through of the waste generating activity. Data are collected on the raw material and energy inputs as well as the waste and product outputs. A material balance evaluation is conducted to ensure all of the inputs and outputs are captured. The walk through also begins the brainstorming process. The formal brainstorming process is conducted after the initial data-gathering stage and the first two 
worksheets are complete. The purpose of the brainstorming session is to generate pollution

prevention opportunities. Those opportunities with potential for waste reduction and cost

savings are considered for a complete cost benefit analysis. Each opportunity is evaluated

independently on the third worksheet for the annual waste reduction and energy savings, the

annual cost savings, the implementation cost, and payback period. Those opportunities with a

payback period less than three years are considered candidates for implementation. The final two

worksheets are summaries that include the assessment team's recommendations for

implementation.

The Hanford model differs from the Kansas City approach in the assessment levels and the graded approach evaluation. Up to three levels (i.e., I, II, and III) of documentation are required for the Kansas City model depending on the expected outcome of the assessment. This is a more thorough method to investigate all waste streams and determine if pollution prevention opportunities are viable. The Hanford model simplified this level of detail by including a waste stream prioritization step. This step includes listing all waste streams and then identifying the related activities that are prioritized according to cost and quantity of waste generated annually. The formal evaluation process was deleted from the Hanford model and all feasible options with a potential cost savings and waste reduction were evaluated.

\section{Case Study: Decontamination Activities}

The Hanford Site pollution prevention assessment ${ }^{(8)}$ was conducted on decontamination activities on radioactive equipment and facilities. This assessment was unique in that although it

${ }^{(8)}$ Letter report from M.D. Betsch, Westinghouse Hanford Company, Richland, WA, to Westinghouse, ERC Team, and ICF Kaiser Hanford Company, Richland, WA, 10 January 1996. 
identified a particular activity (decontamination), many different facilities and companies were involved in the assessment. Several operations were evaluated including decontaminating floors, walls, vehicles, cranes, and augers. The decontamination process used a variety of approaches. For example, grit/sand blasting, high-pressure water blasting, and oxidation/reduction were all used. These methods generated caustic solutions, sludge, sand/grit, and contaminated water. Four opportunities were evaluated for potential implementation. They are as follows:

- Using a non-separable organic product in the high pressure water blast system,

- Installing an ion exchange closed loop recycling system,

- Eliminating a secondary waste stream by purchasing a $\mathrm{CO}_{2}$ blast system, and

- Flushing a transfer line with make-up water.

All four options had a payback of less than one year and an average annual cost savings of $\$ 713,400$ based on 1996 dollars.

Although the implementation costs were high (approximately $\$ 335,000$ per opportunity), the payback period was reasonable because of the following rationale:

- The disposal cost was calculated using the life-cycle costs,

- More than one company was evaluated,

- The largest waste streams were evaluated, and

- Costly waste types (i.e., low-level mixed waste) were reduced.

Other assessment methods, including the USEPA model (USEPA 1992) do not use life-cycle disposal costs and, therefore, the annual cost savings and payback is not as great considering the same activity or process evaluation. 


\section{Pollution Prevention Assessment Methods: Washington State Department of Ecology}

Businesses in Washington state were also given guidance on conducting periodic waste assessments by the Washington State Department of Ecology (WDOE). In response to

Washington Administrative Code Chapter 173-307 (WAC 1991), WDOE issued a guidance manual for completing mandatory pollution prevention plans (WDOE 1993a). Washington state businesses generating more than $1,197 \mathrm{~kg}$ (2,640 pounds) of hazardous waste annually and/or report under the Superfund Amendments and Reauthorization Act, Title III, Section 313 are required to prepare a pollution prevention plan. The guidance contains a lengthy assessment approach that is comprised of 17 worksheets in all. The following is a list of the WDOE process:

- Policy, scope and objectives,

- Employee involvement in planning,

- Facility description,

- Processes, wastes and toxic releases,

- Current and past practices,

- Identification of hazardous products,

- Identification of hazardous wastes,

- Processes to cover in planning,

- Process description,

- Opportunities by priority category,

- Opportunity evaluation,

- Selected opportunities and performance goals,

- Five-year implementation plan, 
- Cost accounting procedures,

- Financial description,

- Personnel training program, and

- Documentation of research.

The worksheets were developed with a pollution prevention plan in mind that was identified in Appendix $\mathrm{H}$ of the Washington Administrative Code, Chapter 173-303 (WAC 1991). Each worksheet responds to a particular requirement in the regulation and, therefore, a detailed process was developed and the assessment was imbedded in the planning process. The assessment approach looks at all processes in the business, as opposed to focusing up front on one waste stream and one activity.

The WDOE assessment process is more than a simple assessment of evaluating pollution prevention opportunities. It is a pollution prevention program including such broad items as:

- Obtaining management commitment,

- Developing a management policy,

- Employee involvement,

- Performance goals, and

- Training programs.

Worksheet number fifteen includes a financial description but does not include a cost evaluation. If an economic analysis of a pollution prevention opportunity is useful to the business for making decisions, WDOE notes that any method of economic analysis is acceptable as long as it seeks to capture total costs. Descriptions of several economic-analysis processes such as total cost, payback, and break-even, and cash flow analyses are included in the guidance. 
However, formulas for completing an economic analysis are not described. A risk analysis template is available to determine risks or potential liabilities when evaluating opportunities.

Case Study: Medical Electronics

A medical electronics company in Washington state practiced the assessment approach developed by the WDOE in an effort to help meet its own goals of cutting waste and increasing competitiveness (WDOE 1993b). The company, which manufactures medical diagnostic ultrasound systems, already employed a variety of pollution prevention measures through a Total Quality Management system for manufacturing. Some of these initiatives included recirculating cooling-wäter equipment, and a streamlined, centralized-chemical "just-in-time" inventory system.

A walk-through of the manufacturing process identified several ways to reduce hazardous substance use by over $38,500 \mathrm{~kg}(85,000$ pounds) and the generation of hazardous waste by $26,700 \mathrm{~kg}(59,000$ pounds) over a five-year period. The pollution prevention activities implemented included:

- Using less hazardous solvents,

- Increased worker training,

- Revised manufacturing standards,

- Using carbon dioxide for cleaning instead of freon,

- Changing to "no-clean" and "water-clean" soldering fluxes, and

- Upgrading existing equipment.

Since Washington state businesses generating hazardous waste are subject to pollution prevention planning requirements, the assessment is one method for meeting the requirements. 


\section{Pollution Prevention Assessment Methods: Alaska Health Project}

The Alaska Health Project manual (Wigglesworth 1988) was designed to help small businesses take the first step toward evaluating waste reduction opportunities and to build awareness of the benefits of waste reduction. The project primarily addressed a holistic pollution prevention program including writing a pollution prevention plan, organizing an audit team, developing a marketing plan, and reviewing business practices. A portion of the project information included a waste reduction audit comprised of four tasks.

Task I: Performing a preliminary investigation to identify the types and quantities of waste generated and waste generating processes.

Task II: Conducting a facility walkthrough to verify the information collected previously, to collect additional information, and to actually observe the processes and associated waste streams.

Task III: Reviewing the information collected in Tasks I and II to identify waste reduction options and priorities.

Task IV: Documenting the findings.

Four forms help guide the waste reduction audit: 1) process identification; 2) material identification; 3) waste identification; and 4) cost identification. A separate chapter is dedicated to evaluating waste reduction options from a technical and economic view to help choose which options to implement. This form, called the "Economic Evaluation Form," is for evaluating waste reduction options. Nine questions requiring a yes or no response such as, "is this option within your price range" and "does this option have an acceptable payback period?" are included 
to help guide the effort. The form and instructions, however, do not include information on how to calculate the results.

This approach is an attempt to identify potential pollution prevention opportunities.

However, it does not go any further into the economic analysis. Should a company choose to implement a pollution prevention initiative using this approach, the basis is strictly on estimated or potential savings, not on a detailed cost analysis.

Pollution Prevention Assessment Methods: Pollution Prevention Financial Analysis and Cost Evaluation System

The Tellus Institute developed a total cost accounting worksheet called P2/Finance (Tellus Institute 1993) for the USEPA for facilitating the financial analysis of pollution prevention projects. It was designed to simplify the task or organizing and analyzing cost data, calculating annual cash flows, and generating financial indicators for pollution prevention investments. The P2/Finance program is an elaborate program which calculates and reports simple payback, net present value, and internal rate of return. The user must be familiar with financial concepts and the use of spreadsheets to utilize this assessment tool as P2/Finance performs many functions and calculations automatically. A detailed guidance is provided with the software which operates under the Microsoft ${ }^{\oplus}$ Excel for Windows, Version 4.0 program.

Although the $\mathrm{P} 2 /$ Finance total cost assessment is a more comprehensive financial analysis, it only calculates the simple payback, net present value, and internal rate of return of a pollution prevention project. This assessment process assumes the identification of waste streams and pollution prevention opportunities has already occurred. In comparing this model to 
the U.S. Department of Energy Hanford model, P2/Finance could be utilized for one of the eight components-the cost benefit analysis.

\section{Case Study: Paper Coating Mill}

A case study was conducted to illustrate the difference between a company's financial analysis of a pollution prevention project and a total cost assessment (Tellus Institute 1993). The total cost assessment is expected to show a greater payback and return on investment. The process was tried at a paper coating mill that produced approximately $173,000 \mathrm{~kg}$ (190 tons) of paper annually. In this mill, two paper machines share a common waste water system. In some cases waste water is passed through a screening device to separate fiber and filler from water.

The pollution prevention recommendation for this study was the installation of a second screening device to handle the wastewater from the second machine and the splitting of the wastewater systems so that each machine would have a dedicated system. This would permit fiber, filler, and water reuse on both machines at all times. The estimated capital cost for the project was $\$ 1,469,400$. First, the company conducted a more traditional simple payback analysis revealing a payback of 4.2 years. Secondly, a total cost assessment was conducted that revealed additional savings and a payback of 1.6 years, illustrating the differences in profitability when a more comprehensive approach is used.

\section{Pollution Prevention Assessment Methods: Waste Diversion Cost Analysis Model}

The Clean Washington Center developed the "Waste Diversion Cost Analysis Model" (Clean Washington Center 1997) for comparing current and projected future costs, savings, and diversion rates of disposable waste streams that would be realized upon implementation of new 
or expanded recycling and/or reuse of recoverable materials. The Clean Washington Center, under the responsibility of Washington state's Department of Community, Trade, and Economic Development, is responsible for improving the markets for recyclable materials. Consequently, the focus of the cost analysis tool was on recycling and reuse of recoverable materials.

The software model runs under the Microsoft ${ }^{\oplus}$ Excel 5.0 spreadsheet program and allows varying levels of actual facility data depending on the desired specificity and accuracy of the results. Furthermore, the model permits cost comparisons of different recycling and waste reduction scenarios to determine the optimum design and cost-effectiveness for businesses' recycling and/or waste reduction programs. The program is limited to addressing pollution prevention opportunities related to 1) new or expanded recycling; 2) utilization of post-industrial or post-consumer material; and 3) acquisition of waste handling or storage equipment. Although the model is specific to reuse and recycling, it is a thorough analysis of all costs and rebates associated with the reuse or recycling initiatives.

Case Study: Expanded Recycling Program for a Boat Manufacturer

A custom boat manufacturer and repair shop used the Waste Diversion Cost Analysis Model (Clean Washington Center 1997). The manufacturer was interested in reducing solid and liquid wastes by implementing two recycling programs: 1) recycling fiberglass composite waste which accounted for one third of the total waste stream; and 2) recycling spent acetone solvent. The boat manufacturer identified firms for accepting the waste by-products. The potential recycler of the fiberglass composite would collect the material twice a month for a load charge of $\$ 30$ and a rebate of 1 cent per pound. The vendor that was identified for distilling the spent acetone would accept it in reusable containers purchased by the boat manufacturer. 
The assessment concluded that, for an investment of $\$ 1,000$ to set-up the program, the boat manufacturer could save $\$ 1,587$ annually by recycling fiberglass composite and acetone. The payback period was estimated to be 1.7 years. Further, the company would reduce their solid waste generation by almost 30-percent and increase their recycling rate to 45.5 -percent.

\section{Pollution Prevention Assessment Methods: Climate Wise Opportunities Assessment}

Climate Wise is a partnership between USEPA, USDOE, and U.S. industries (BSREF and Climate Wise 1996). The purpose of the program is to encourage and assist industries in using methods and technologies that are energy-efficient and environmentally sound. Climate Wise developed a guide for waste assessments that includes specific pollution prevention options a company can implement to save money (BSREF and Climate Wise 1996). The guide includes a "Quick Scan" assessment that is intended to help identify energy-efficiency and pollution prevention priority areas. This is a self assessment process that is conducted by the company's staff. The first step is to evaluate the importance of better performance in a particular efficiency area such as productivity. The second step is to evaluate the company's performance in a particular efficiency area relative to others in the same industry. The third and final step is to determine a score based upon the first two steps. The score will determine the priority areas for further evaluation.

Following the "Quick Scan" assessment is the "Option Screening Matrix" that provides a rough estimate as to whether or not the option should be investigated further. It is a spreadsheet that requests information on annual cost savings, implementation cost, and other economic analysis items. However, it does not include space for documentation of the resulting numbers that could be necessary for implementation. One item included in the "Option Screening Matrix" 
is another benefits column that no other assessment process specifically includes. Here, a

business can identify other external benefits, such as the environment, when implementing a particular activity.

The Climate Wise approach is similar in nature to the Alaska Health Project in that it is an initial screening of wastes generated at a firm and identification of pollution prevention opportunities. Although a cost benefit analysis is encouraged to document true cost savings and payback, the worksheets are not tailored for this activity.

Pollution Prevention Assessment Methods: Texas Natural Resource Conservation Commission Environmental Accounting Worksheet

The Texas Natural Resource Conservation Commission developed an "Environmental Accounting Worksheet"(9) for small businesses employing less than 10 people. The approach is a simplified assessment process that small businesses owners can complete themselves and the instructions are simple to follow and easy to understand. The 2-page form is comprised of five steps:

Step 1 Drawing a Map of the Process,

Step 2 Total Costs per Process per Year,

Step 3 Hidden Costs per Year,

Step $4 \quad$ Paying for the Inputs and Outputs per Year, and

Step 5 The Cost of Lost Materials.

Step number 1 involves preparing a flow chart of the raw materials used and wastes

generated. This step does not include the final product that most of the other assessment

(9) Personal communications from S. Allen, Austin, TX, 16 January 1997. 
approaches include. The second step identifies the costs associated with each of the raw materials used and wastes generated in step number 1 . The hidden costs, including regulatory and compliance requirements, are calculated in step number 3 . Step number 4 is a simple addition of the costs of materials and disposal. Step number 5 is a comparison of the current practice and alternatives. This step has three different versions, one for each of the three industry sectors that the Commission is targeting (e.g., printing, auto body, and manufacturing). The cost savings and a simple payback period are calculated in step number 5 . However, the waste quantity saved is not included in the evaluation. The steps rely heavily on waste disposal as the only cost calculation. Although this is usually the largest cost to any small business, other factors, including labor, are not included in the calculation.

The Commission recommends starting with the resources of largest quantity, the materials generating hazardous or non-hazardous waste, or the most expensive commodities. Furthermore, materials in two or more of the above mentioned categories are likely candidates for cost savings. A business is limited by the worksheet format to evaluating three pollution prevention opportunities.

\section{Case Study: Auto Body}

An auto body shop's processes were evaluated using the assessment approach developed by the Texas Natural Resource Conservation Commission. ${ }^{(10)}$ The first alternative evaluated was an on-site solvent recycling operation. This practice saved an estimated $\$ 4,320$ annually with a payback of less than 5 months. Recycling packaging materials was the second item evaluated. An annual cost savings of $\$ 800$ and an immediate payback concluded. The one-page form

\footnotetext{
(10) Personal communications from S. Allen, Austin, TX, 16 January 1997.
} 
worked well for very small businesses for which it was intended. For more complex processes, however, there are limitations such as identifying indirect costs. Since most small businesses do not have the time or resources for a complex waste assessment, the process developed by the Commission is ideal for the small business owner as it walks the preparer step-by-step through a simple economic analysis.

\section{Pollution Prevention Assessment Methods: Various Profit and Non-Profit Agencies}

Numerous approaches to quantifying cost savings for pollution prevention practices have been developed based upon many of the approaches discussed previously. A number of governmental agencies, institutions, and individuals have published documents on recommended approaches. The steps include (at a minimum) data collection, identification and ranking of pollution prevention alternatives, and a feasibility analysis. The pollution prevention alternatives range from obvious and easily implemented measures to longer-range and more sophisticated alternatives. Similarly, the methods range from simple payback to more detailed life cycle cost analysis. Example case studies are presented below.

Case Study: Wood Furniture

Two case studies targeting the wood furniture finishing industry were performed by the Northeast Waste Management Officials' Association in $1996 .^{(11)}$ In an effort to improve their image within Vermont and to comply with air emission standards, one firm, known as one of the state's "worst polluters," decided to take the steps necessary to change the way they did business. The production of the furniture involved the application of 70 different finishing materials and 9

(11) Letter from J.L. Griffith, Northeast Waste Management Officials' Association, Boston, MA, 22 November 1996. 
separate applications. This process generated $233,140 \mathrm{~kg}$ (257 tons) of volatile organic compound (VOC) emissions and 45,800 kg (50.5 tons) of hazardous air pollutant (HAP) emissions annually. Two pollution prevention initiatives were implemented to achieve reductions in emissions; switching to high volume, low pressure (HVLP) spray guns and using a high solids sealer and lacquer.

The traditional coating involved one sealer and two lacquer applications to meet the quality standards. A 35-percent solids lacquer was implemented that eliminated the need for a second lacquer application, saving materials and labor while reducing air emissions. Reportable emissions from the lacquer application step reduced VOCs and HAPs by more than 46-percent. Eliminating the second lacquer application eliminated the use of a second lacquer spray booth which, in turn, allowed for changes in the layout of the finishing department to make it more efficient. Other benefits included health and safety issues, reduced number of touch-ups required before lacquer application, and decreased repairs because the new lacquer covered defects better. The lacquer modification saved the firm $\$ 462,176$ annually with a payback period of 4 months.

The conversion to HVLP spray guns was immediately approved and implemented as the estimated annual cost savings of $\$ 145,000$. The initial capital cost was $\$ 8,125$ with a payback period of less than three weeks. Further, the HVLP improved the average transfer efficiency from 30-percent with conventional guns to 60-percent with HVLP guns. This resulted in a 39-percent reduction in the amount of finishing material used to coat the same item. The company implemented several other pollution prevention measures including switching to aqueous-based color primer and spray booth coating, and reclaiming lacquer dust for reuse.

The second firm, a manufacture of bleacher, stadium, and theater seating, implemented pollution prevention initiatives to prepare for the impending Clean Air Act standards for the 
wood furniture industry. Air emissions from this firm are mainly from the wood and metal

finishing processes. However, the case study focused primarily on the wood finishing operations. The firm implemented two pollution prevention initiatives: 1) switching to an automated UV cured coating system for the bleacher seating; and 2) switching to aqueous-based coatings for finishing the wood components of the stadium and theater seating.

Previously, the bleacher seating was finished by hand with two coats of polyurethane varnish on each side. With the new automated system, the boards are placed on a conveyor and rollers apply one coat of sealer to each side that is immediately cured by exposure to UV light. This is followed by the application of one topcoat to each side using a vacuum coater. This coat is also immediately cured by exposure to UV light. The primary benefit is increased productivity and improved on-time delivery to customers. However, the major environmental benefit is that VOC and HAP emissions were reduced from nearly $45,300 \mathrm{~kg}$ (50 tons) per year to $99 \mathrm{~kg}$ (219 pounds) per year. This reduction occurred as production increased by over 55-percent, from 9,000 units per week to over 14,000 . Additionally, the new system represents a 67 -percent reduction in labor requirements. Other benefits included reduced clean-up time and increased durability.

The second pollution prevention option was the replacement of the nitrocellulose solventbased coatings used on wood chair arms and backs with aqueous-based polyester coatings. The VOC emissions were reduced from $2.7 \mathrm{~kg}$ ( 6 pounds) per $3.8 \mathrm{~L}$ (1 gallon) to $0.9 \mathrm{~kg}$ (2 pounds) per $3.8 \mathrm{~L}$ (1 gallon). Additionally, the aqueous-based coatings do not require solvents for cleanup saving $625 \mathrm{~L}$ (165 gallons) annually.

This assessment was considered a thorough examination of all environmental and health and safety aspects as it addressed potential challenges of the implemented recommended 
opportunities. Although the UV process reduced VOC and HAP emissions and improved production, there were potential adverse human health effects associated with the use of UVcured coatings such as skin darkening, dryness and/or burning, and severe eye damage.

However, workers can be properly protected from these effects with proper training and close adherence to the procedures. The annual cost savings for implementing UV coatings for bleacher seating was $\$ 1,186,774$ with a payback period of 4.5 months.

The two case studies were rigorous evaluations of specific processes in the wood furniture finishing industry. All direct costs (i.e., capital expenditures, operation and maintenance, expenses or revenues), indirect costs (i.e., administrative costs, and regulatory compliance costs), and liability costs (i.e., penalties, fines, personal injury, natural resource damage) were among the elements evaluated. Some of the indirect and liability costs accounted for greater cost savings overall. The studies evaluated and tracked several years' worth of data and, therefore, concluded actual annual cost savings rather than the estimated savings usually performed in most waste assessments.

\section{Case Study: Printed Circuit Board Manufacturing}

Two specific processes, dry-film stripping and silk-screen cleaning, were evaluated at a printed circuit board manufacturing firm (Cantwell 1995). The waste streams resulting from both processes were composed of organics with heavy metal contact. The annual generation of hazardous waste was approximately $4,500 \mathrm{~kg}$ ( 5 tons) and the daily waste water discharge was about $34,000 \mathrm{~L}$ (9,000 gallons). Neither of the waste streams could be processed for metal recovery through the existing waste processing system because of the organic content. 
Although the printed circuit board manufacturing industry, as a whole, had not identified solutions to minimizing the waste streams, three options were identified in this assessment. The first option was to locate waste processing technologies for removal of heavy metals. This option would allow the regeneration of stripper and cleaning solvent for reuse while generating a significantly lower volume of sludge. The second option was to locate stripper additives that would precipitate out dry film solids, leaving a regenerated solution for reuse. The third option was to locate or develop dry stripping and/or cleaning techniques that would eliminate the generation of aqueous waste streams.

The analysis process used did not provide an economic evaluation of the options generated. The assessment involved contacting several vendors that could provide the services identified and a cursory evaluation was conducted as to whether or not the assessment team felt the technology offered immediate chances for implementation. However, further research and a detailed feasibility and cost analysis was recommended before implementation of the various opportunities. This process only identified several good ideas which was similar to the Alaska Health Project (Wigglesworth 1988) and Climate Wise (BSREF and Climate Wise 1996) models.

\section{Total Quality Environmental Management}

In addition to the specific assessment methods previously described, pollution prevention can support a number of business improvement processes which are described below. A broadbased movement called total quality management (TQM) is both a way of thinking and a set of management techniques (Shrivastava 1996). The primary objective of TQM is quality through continuous improvement. It assesses the quality of products and production processes and seeks continuous improvements while promoting the values and attitudes of quality enhancement. The 
values underlying quality and environmental management are mutually reinforcing, so they can be combined to support each other (Shrivastava 1996). Companies are combining the two to create total quality environmental management (TQEM) which requires periodic audits of environmental practices to assess and improve the quality of the environment with a strong emphasis on pollution prevention techniques.

According to Paul Shrivastava (1996) TQEM emphasizes three basic ideas. First, "the customer is always right." However, the most important customer is the environment and TQEM places a high priority on preserving and enhancing the environment. Second, continuous improvement means that no matter how good it is, it can always be improved. Plans and charts are used for improving performance and understanding that there is no end point, only continual change. Each project undertaken is carefully analyzed to make sure it is done right the first time which reduces waste. The third element is interaction and teamwork. Teams of individuals track, analyze, and solve waste-related problems by conducting a benchmarking exercise of other industries to find alternatives to waste problems.

Numerous large firms have adopted the TQEM approach for improving environmental and quality performance (Shrivastava 1996). One chemical manufacturing firm added waste reduction to its TEQM approach which led to a reduction of 6.8 million $\mathrm{kg}$ (15 million pounds) of waste annually (Shrivastava 1996). Another firm used the TQEM approach in dealing with its wastewater problem (Shrivastava 1996). The company recovered clean water and reusable heat by using heat absorption, filtration, and sedimentation.

The approach is more far-reaching than a simple pollution prevention assessment in that TQEM encompasses customer satisfaction and continuous improvement. In the assessment approaches described above, customer satisfaction can be calculated in as a benefit of 
implementing pollution prevention. However, it is not the single driving force for recommending opportunities in most cases. Continuous improvement is only implemented for pollution prevention if the company determines that it is necessary to go back and re-evaluate the assessment conducted previously. For example, if a firm implemented a waste water treatment system as a result of an assessment and was satisfied with the outcome, implementing a closed-loop recycling system would never take place unless a second assessment was conducted on the waste water system. However, the original assessment could be utilized as a first step in re-analyzing the process.

\section{Case Study: Pen Manufacturer}

A large manufacturer that makes pens succeeded in reducing trichloroethylene (TCE) use by applying total quality management problem-solving techniques (Houseman 1993). Since the firm's emissions to the atmosphere were high, identifying opportunities to reduce solvent emissions was undertaken by a team of individuals. The team established a goal of 50 -percent reduction in TCE emissions. A cause-and-effect diagram was used to evaluate the uses of TCE which led to a benchmarking effort. A representative from a chemical manufacturing firm was brought in to provide training for all operators and maintenance personnel, along with a detailed review of the mechanical operations and procedures of the firm's degreaser/still units.

The representative recommended between 6 and 12 pollution prevention opportunities for each of the 7 degreaser/still units. The firm's team also identified additional improvements. Such recommendations and improvements included: 1) clean the condensing coils; 2) check the water flow and temperature; 3 ) recalibrate the boiling sump thermometer; 4) repair the nonfunctional water separator; 5) run the still when operating the degreaser; 6) reduce excessive 
boiling action by removing electric heating elements; and 7) periodically transfer all the solvent to the still and boil the solvent off, returning it to the degreaser so that the contaminant remains in the still.

After several pollution prevention opportunities were implemented, the firm achieved a $\$ 30,000$ savings in the first year and hazardous waste reduction decreased by $16,330 \mathrm{~kg}(36,000$ pounds) annually. The TQEM approach played a significant role in accomplishing these results. The process facilitated the transfer of information between working groups. The firm's commitment to customer satisfaction also helped bring about the necessary changes in the purchase, use, and waste disposal of solvenis. The TQEM approach is a useful way of extending quality-management programs to environmental problems. It strives to achieve zero pollution through continuous improvement and periodic measurements of environmental performance.

\section{Value Engineering}

Prioritization of pollution prevention opportunities can also be guided by the value engineering (VE) approach which has been used as an analytical medium used.in industry since World War II. ${ }^{(12)}$ The VE approach is a method used to improve projects and processes through an analysis of functional requirements and the alternatives available to satisfy them. It is a search for opportunities to improve value by suggesting improvements in performance as well as cost effectiveness. The VE method can be incorporated into traditional pollution prevention assessment models to generate options and evaluate consequences.

The major components and methodology of the VE study include the following:(13)

${ }^{(12)}$ Text report from the Design for Competitive Advantage Homepage, http://mijuno.larc.nasa.gov.

${ }^{(13)}$ Text report from the U.S. Department of Energy Pollution Prevention Information Clearinghouse Homepage, http://146.138.5.107/EPIC.htm. 
1. Information Gathering: Data are collected and organized on the subject under study. A functional analysis is conducted to establish the required functional relationships.

2. Option Generation:

A range of alternative means of meeting required functions are generated.

3. Evaluation:

All ideas generated during the option-generation stage are evaluated in a screening process. The most promising alternatives are selected for further development.

4. Development:

The ideas selected are developed in detail sufficient to demonstrate their technical feasibility and significant costbenefit improvements.

5. Presentation:

The recommended alternatives are documented and presented to decision-making authorities.

The VE approach can be applied to the pollution prevention assessment models as demonstrated by USDOE's report entitled "Prioritization of Pollution Prevention Options Using a Value Engineering Approach."(14) Additional aspects the VE study adds to the pollution preyention assessment process are a functional analysis and evaluation criteria. The VE team performs a functional analysis to discover basic purposes of a process in contrast to its secondary

${ }^{(14)}$ Text report from the U.S. Department of Energy Pollution Prevention Information Clearinghouse Homepage, http://146.138.5.107/EPIC.htm. 
uses. This aids in determining the process' primary functions and in minimizing or eliminating secondary functions which, in turn, may produce unnecessary wastes. Criteria are selected to screen the options. This step is similar to the weighted-sums approach used at USDOE's Kansas City Plant (USDOE 1996a). Economic feasibility, magnitude of application, effects on health and safety, effect on the environment, effects on operations, time required for implementation, impacts on management effectiveness, technical risk, regulatory compliance, public image, and long term liability are some of the common VE criterion utilized for evaluation and ranking of alternatives.

The VE method can easily be incorporated into an assessment process to generate options and evaluate the consequences more thoroughly. Furthermore, the VE methodology would be utilized for complex waste streams only. The smaller the firm, the simpler the approach as the small firms do not usually have the resources necessary to conduct lengthy assessments including various aspects of the VE method. However, the greater detail in most cases documents a greater cost savings and identification of all potential environmental benefits.

\section{Analysis of Best Methods for Small Businesses}

A simple and understandable method for small business owners to evaluate a process or activity is the preferred assessment approach. The assessment tool developed at the USDOE Hanford Site was the chosen method for this study because of its simplicity. Small business owners typically do not have the resources or time available to conduct a detailed analysis and, therefore, a simple payback method is adequate. Furthermore, the simple payback identified in many of the assessment schemes is the longest payback period. The more complex models drive the payback periods lower by documenting intangibles and soft-dollar savings such as the 
consumer's willingness to pay. The simple payback method, therefore, offers the small business

owner a margin of error since its estimate is relatively high and conservative as compared to other methods.

The assessment method chosen for the small business community should embrace the entire process or activity. Several models specify a cost analysis for pollution prevention opportunities exclusively without a method for identifying the waste streams, describing the process or activity, and recognizing and evaluating potential pollution prevention opportunities. Assessing the complete process or activity will ensure that all waste streams are evaluated for potential pollution prevention measures.

Incorporating a pollution prevention assessment scheme as part of TQEM principles or VE methods is a reasonable approach for those businesses that have already established these philosophies as part of their business practice. However, most small businesses do not have these elaborate measures and instituting TQEM and VE as part of the pollution prevention assessment process would not be value-added. Furthermore, a pollution prevention assessment is in and of itself a process improvement tool.

Critical to any pollution prevention assessment is an all-media approach so that all impacts to the environment are accounted for and potential pollution prevention opportunities are identified for air, land, and water. Energy conservation is sometimes ignored, yet an analysis of a businesses' energy consumption can offer numerous opportunities. Opportunities for energy reduction initiatives should be included in a small business assessment tool.

A few of the assessment approaches identified a planning process as part of a business' pollution prevention program. For example, a pollution prevention program might include: 1) management commitment, 2) an environmental policy, 3) employee awareness, and 4) waste 
reduction goals. These elements, while certainly valuable to a business' infrastructure and environmental performance, are not required prior to or for a pollution prevention assessment and should be considered as supplementary to a pollution prevention assessment. All in all, a simple and understandable assessment method was identified as the best approach for the small business community. Table 2 is a matrix of the assessment approaches described in the literature review and it identifies the elements recommended for a pollution prevention assessment for small businesses. 
Literature Review and Case Studies

Table 2 Matrix of pollution prevention methods.

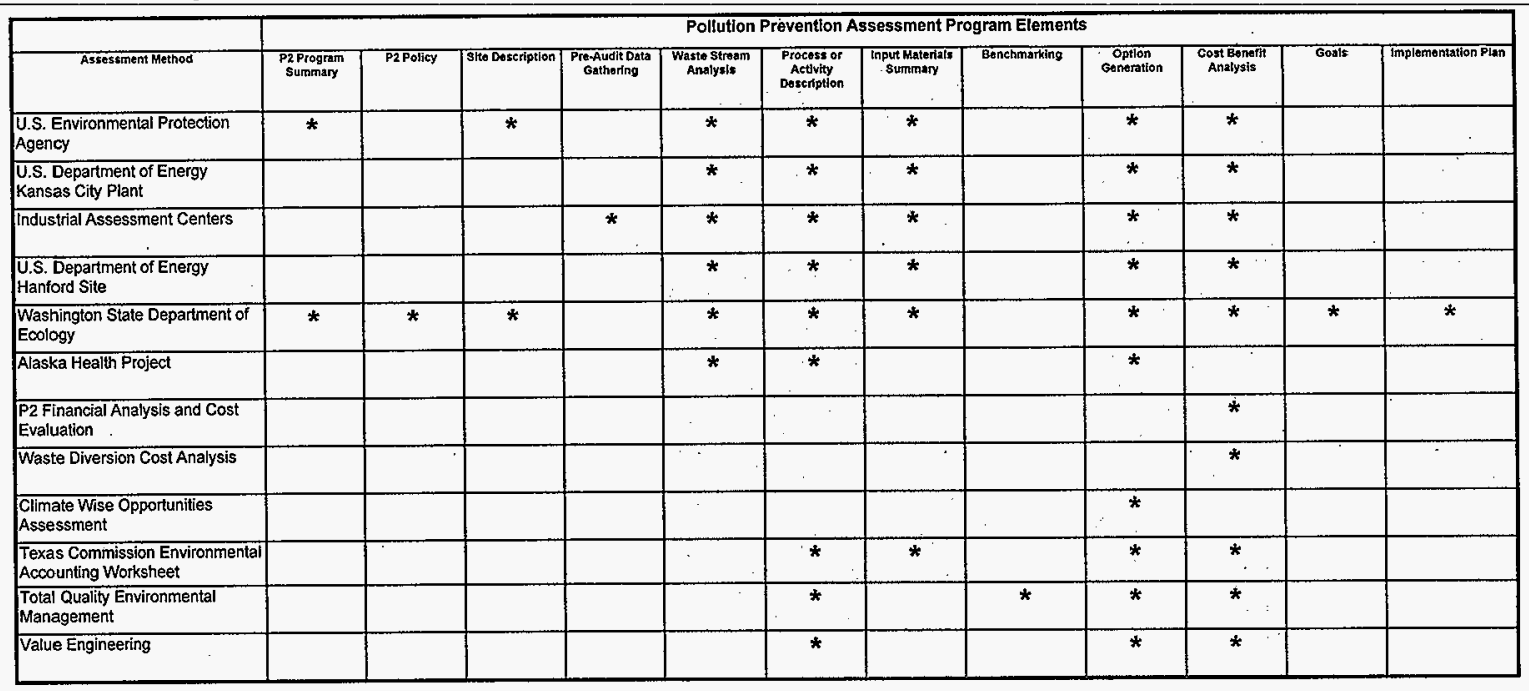

Shading denotes elements for best small business method 


\section{Chapter 2: Methods and Materials}

The methods and materials depict the various steps prior to the industry assessments, including a waste stream analysis of the city of Richland businesses and the industry selection process. Additionally, described in the methods and materials is the chosen assessment technique and an illustration of the individual pilot and formal assessments.

\section{Waste Stream Analysis}

This study was conducted to understand the magnitude of wastes generated from industry within the city of Richland, WA. A waste stream analysis was conducted on air emissions, hazardous waste generated, sanitary waste generated, and waste water discharges within the city. This analysis of Richland's commercial waste streams was conducted to identify the sources and quantities of waste generated. The Washington Department of Ecology (WDOE) provided a listing of all business names and addresses within Richland that have a valid U.S. Environmental Protection Agency (USEPA) hazardous waste identification number. This number identifies a business as a hazardous waste generator and waste shipped from each business is tracked with the identification number. Due to confidentiality, the exact quantities and types of waste were not released. However, it was a starting point in identifying those known businesses generating hazardous waste.

In addition to the list of businesses generating hazardous waste, more specific information on waste streams generated in the automotive industry was obtained from the WDOE. In 1992 and 1993, WDOE conducted non-voluntary audits of all businesses in the 
automotive industry. ${ }^{(15)}$ This process was termed the "shop sweep" campaign and was an effort to provide an element of technical assistance while noting areas of non-compliance. The audits were conducted by WDOE along with a representative from Benton County's Regional Solid Waste Office.

Seven businesses were evaluated in Richland under the "shop sweep" program; (i.e., six automotive shops and one machine shop). The evaluation identified the hazardous waste streams and revealed whether or not the stream was managed as hazardous waste. Other wastes such as shop towels were also assessed. The audit provided suggestions in the form of a "to do" list for improvement which mostly took the form of compliance directives and housekeeping rather than pollution prevention recommendations. Such directives included labeling, closing off floor drains, maintaining material safety data sheets, and covering waste containers.

Air emissions data were provided by the Benton County Clean Air Authority. The data listed small and large businesses and showed that the majority of the businesses subject to air permitting were large businesses. Six businesses were listed as small businesses and all were located in Richland. The data revealed specific emission problems, non-compliance fees paid, type of air emission, and the source of the emission.

A complete listing of all Richland businesses including the address and owner name was collected. The businesses included all with a current business license. The following types of businesses were selected as part of the analysis: Photography studios, mortuaries, grocery stores, lumber mills, restaurants, food vendors, caterers, manufacturing plants, production warehouses, construction contractors, research laboratories, automotive dealers, auto repair shops, barber and

(15) Personal communications from R. Parsloe, Yakima, WA, 12 September 1996. 
beauty shops, gas stations, hotels and motels, pool care companies, cleaners and laundry firms, landscaping and lawn care companies, janitorial service firms, car wash operations, and printing and graphics firms. Finally, informal conversations with Richland's Wastewater Treatment Plant personnel revealed that several businesses disposing of large quantities of waste water were exceeding their permit limits.

The waste stream analysis provided limited yet adequate information on the business' waste streams. The best information on a Richland's waste streams was found during the assessment process at the businesses themselves. However, assessing Richland's industries through the waste streams analysis revealed that the vast majority of opportunities for small businesses could be found in the solid sanitary waste and hazardous waste categories. The larger businesses were the primary generators with hazardous air emissions and waste water discharge permits.

\section{Awareness and Education}

Five 20-minute presentations were delivered to Rotary and Kiwanis groups to foster interest in the program and educate small business owners on the potential cost savings from implementing opportunities derived from a pollution prevention assessment. The presentation was directed at explaining pollution prevention and its effects, defining the approach of the pollution prevention assessment, showing the benefits of a businesses' participation in a pollution prevention assessment, and outlining the eligibility requirements of the program. At least one business responded to the program through the presentation.

As follow-up to the presentation, a tri-fold brochure was developed and distributed to small business owners (see Appendix B). The brochure described the pollution prevention 
assistance available to small businesses in the city of Richland. The focus of the brochure was to encourage small businesses owners who want more profit and less waste, to consider a "No-Cost Pollution Prevention Assessment." Several eastern Washington businesses were cited as having successfully achieved pollution prevention, which supported the premise that implementation of pollution prevention can improve a business' bottom-line. A short application form was included in the brochure. The preliminary information requested in the application included the firm's name, type of business, contact person, address, and phone number. Inquiry of the firm's environmental practices was necessary to properly evaluate the business-waste streams and emissions. Questions relating to the quantities of hazardous waste, solid waste, air emissions, and wastewater were asked as well as the types of environmental permits presently belonging to the businesses.

A letter from Richland's Engineering and Utilities Director was sent to over 100 small business owners. The letter emphasized the free service as a benefit to the small businesses and the environment. At least two businesses responded through the mailer. The local newspaper, the Tri-City Herald, published an article on the program to further solicit participation in the program. ${ }^{(16)}$ The article was printed alongside a story on pollution prevention at a local school district. The number of responses prompted from the newspaper article is unknown.

The program was personally explained to some of the businesses in the city of Richland generating hazardous waste, wastewater, air emissions, and solid sanitary waste. The businesses contacted were identified through the waste stream analysis, and, for breadth, an attempt was made to contact a variety of industries including construction companies, auto body shops,

(16) Newspaper article from the Tri-City Herald, 22 August 1996. 
barber/beauty shops, manufacturing plants, hotels, dry cleaners, landscaping and lawn care firms, printing and graphics firms, photography studios, restaurants, and grocery stores. This was accomplished through one-on-one conversations with the owner and/or manager of the small business. The dialogue usually consisted of a brief introduction, description of the program, and a request to participate. The majority of the businesses responded to the program through this means.

\section{Pollution Prevention Opportunity Assessment Process}

The U.S. Department of Energy's (USDOE) Hanford Site Pollution Prevention Opportunity Assessment (P2OA) process (USDOE 1996b) was selected as the method for describing the process or activities, collecting data on the quantity of waste generated and energy consumed, brainstorming sessions on pollution prevention opportunities, and quantifying the cost savings and the waste and/or energy savings (see Figure 6). This tool proved to be useful and provided effective data when it was used for activities at the USDOE Hanford Site which is located near Richland. Therefore, it was anticipated that it would provide favorable results when transferred to the small business arena. In addition, it was the challenge of this study to test USDOE's P2OA process for its application to small businesses in Richland. 


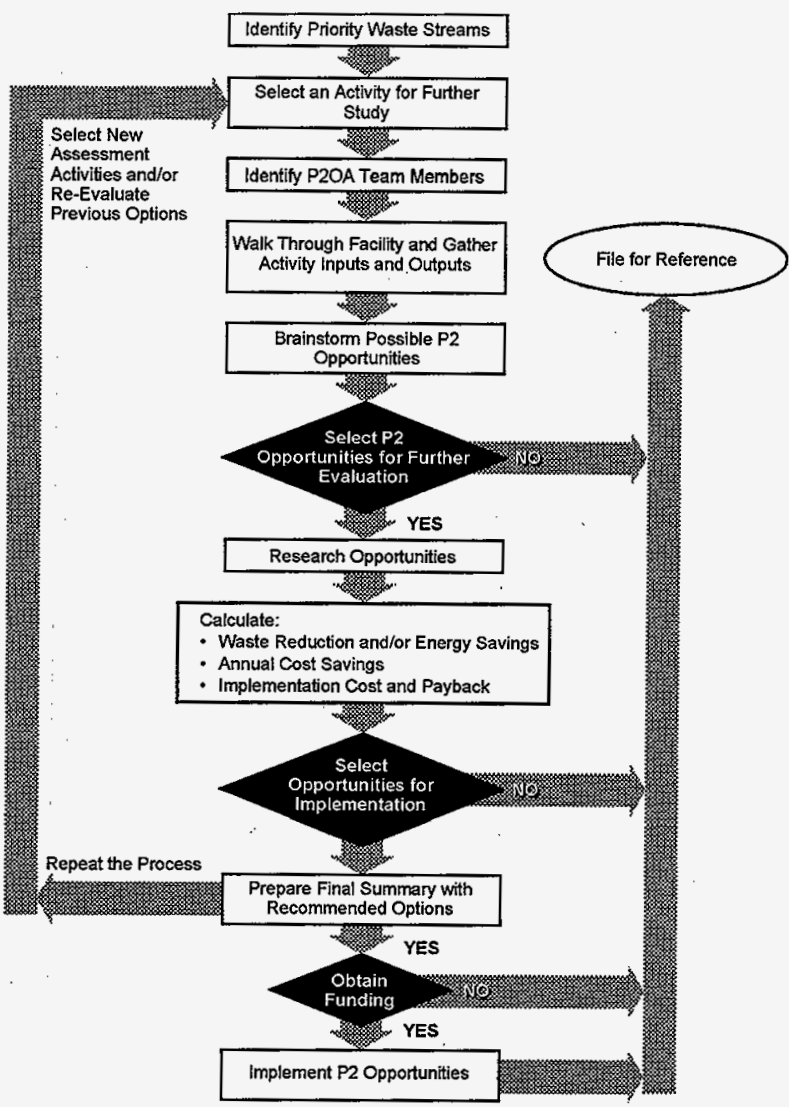

Figure 6 The Pollution Prevention Opportunity Assessment process.

Prior to beginning the $\mathrm{P} 2 \mathrm{OA}$ process, a thorough literature search is conducted on each industry to identify the potential areas of high waste generation and energy consumption as well as to begin to identify potential waste minimization opportunities. The information is compiled from a variety of sources, the best of which are usually university programs, state solid waste 
offices, large business owners, and trade publications. In general, pollution prevention opportunities had been implemented in all the industries selected for this study to some degree.

The $\mathrm{P} 2 \mathrm{OA}$ is comprised of five worksheets, each with a specific step in the assessment process. The first worksheet describes the overall description of the activity under analysis which includes a detailed written description of each step of the process including pollution prevention practices already implemented. It also lists the title of the assessment, date, facility, activity title, and names and phone numbers of the assessment team. A walk-through of the business is conducted to learn about the activity or process and assist in the compilation of data required in the first worksheet. During the walk-through, potential waste reduction opportunities are identified, inefficiencies are noted, material and waste containers are examined, and the sources of waste are captured. The walk-through began at the beginning of the process and it ended at the product stage. Occasionally, photos are taken at the business to better understand the layout configuration and to identify potential problem areas.

The second worksheet goes one step further in the process description by quantifying the materials used and energy consumed and the product and waste output. A material balance is conducted to guarantee all the inputs and outputs are included as well as to provide an overall quantity of waste generated. A one-hour brainstorming session conducted with the business employees follows the completion of the first two worksheets. During the brainstorming meeting, pollution prevention opportunities are identified for improved practices and procedures, material substitution, equipment modification, recycling and reuse, and waste segregation.

Development of a list of potential opportunities identified in the literature search initiates the brainstorming process. After exhausting all potential ideas, the customer, usually the small 
business owner or manager, selects three to four opportunities for further evaluation. Allowing the customer to choose was expected to improve the implementation potential.

The third worksheet is a cost-benefit analysis where the estimated cost savings, waste or energy savings, and simple payback are calculated. Each opportunity is evaluated independent of the others and is recorded on worksheet three. The current practice and recommended action are described in detail and, if equipment or materials are required, vendors are recommended. The expertise of Richland's Energy Resource Management and Water and Waste Utilities personnel was tapped for energy and water-related opportunities.

The fourth worksheet is a one-page summary of the information compiled in the third worksheet. It includes a table of the opportunities researched, the waste class reduced, the annual waste quantity reduction, the annual cost savings, the implementation cost, and the payback in years. The fifth and final worksheet is a discussion of the opportunities investigated and a recommended schedule for implementation. The recommendations are primarily based upon the payback period. The final report includes all five worksheets and a cover page. The report was presented to the customer in person and explained in detail.

\section{Pilot Assessments}

A commercial laundry and an automotive repair shop were chosen first as pilot assessments to determine the suitability of application of Hanford's P2OA process (USDOE 1996b) to the small business sector (see Appendix C). The two industries were chosen for their potential to provide a good benchmark to develop a small business assessment process. The commercial laundry was recommended by Richland's personnel as a firm who might benefit from technical assistance and recommendations in treatment technologies. 
The automotive repair shop identified had a good grasp of business management and was able to easily provide the required data. Furthermore, the owner had been in the automotive repair business in Richland for many years and was knowledgeable about the economy as well as the operations of the business.

The contacts at the commercial laundry and the automotive repair shop were the production manager and owner, respectively.

Summary descriptions of the firms evaluated are provided below.

\section{Summary: Commercial Laundry}

The commercial laundry serviced industries as far away from Richland as Hermiston, OR and Yakima, WA. The majority of their business came from hospitals, restaurants, grocery stores, automotive shops, and print shops. Other materials laundered included mop heads and mats. The firm washed and dried $3,600 \mathrm{~kg}$ ( 8,000 pounds) of laundry a day. Most laundry, including coveralls, uniforms, linens, and shop towels were rented to the customer. The firms' waste water stream contained a high content of fats, oils, and grease. The waste water discharge was $113,500 \mathrm{~L}$ ( 30,000 gallons) daily to Richland's sewer system. A shaker screen was the only treatment device in place.

\section{Summary: Automotive Repair Shop}

The shop was comprised of five bays, for conducting brake repair; front end alignment; exhaust; inspection; and diagnostics and air conditioning. The shop serviced approximately 3,000 vishicles a year. Prior to the assessment, the 
shop had implemented numerous initiatives to manage waste properly. However, all were waste management practices rather than pollution prevention practices. A large waste management company maintained the firm's parts washers, and disposed of its greases, antifreeze, oil, and other fluids. Many of the recycling practices that the automotive repair shop implemented were random in nature and no formal recycling program was in place. The shop had recently purchased a second automotive repair shop nearby.

The Hanford-specific P2OA worksheets were utilized in conducting the pilot assessments. An introductory meeting initiated each assessment. The meeting consisted of gathering pre-assessment information such as permits, waste manifests, and material inventory data. During the formal walk-through, a sketch of the facility was drawn to assist in identifying the waste sources. Once the first two worksheets were completed, the contact was given the worksheets to review for completeness and accuracy. The brainstorm session followed.

At the brainstorming meeting for the commercial laundry, the production manager and two production workers were present. The production manager identified several opportunities the laundry could research themselves and, therefore, chose more technical opportunities to evaluate through the assessment process. At the automotive repair shop brainstorming session, the owner was the only individual involved in the brainstorming session even though two other employees were invited. The pollution prevention opportunities chosen for further evaluation were limited to the list of opportunities the author presented at the brainstorming session as no additional opportunities were identified by the owner. 
Once a draft copy of the entire assessment process was complete, a copy was delivered to each of the contacts for review. The contact at the commercial laundry spent considerable time evaluating the draft whereas the contact for the automotive repair shop apparently did not. The lack of involvement was primarily due to the recent acquisition of an additional automotive repair shop and gas station with the subsequent additional demands on the owner's time. The final version of the assessment was hand-delivered to each of the contacts and each section was reviewed and the recommendations were outlined.

Following the two pilot assessments, a list of lessons learned was developed that included methods that also worked well. The lessons learned described below were used for enhancing the formal assessments which followed:

- Get the customer involved and informed of the progress throughout the process,

- Do a detailed literature search first,

- Emphasize employee involvement during the brainstorming session,

- Allow the customer to determine the opportunities for investigation,

- Draw a diagram of the production/floor area,

- Talk to employees while on the walk-through to gather added information,

- Look for all waste and emission sources and types,

- Consider timing of the assessment for optimum customer involvement,

- Batch questions for the vendors, the customer, and regulators,

- Continue using the same general assessment approach for the formal assessments, and

- Emphasize source reduction opportunities over recycling or treatment. 


\section{Industry Selection Criteria and Process}

A total of 13 businesses completed the application process and offered plenty of variety for selecting four more businesses in applying the P2OA tool. Among the businesses were a winery, restaurant, two medical clinics, hotel, construction company, grocery store, printing and graphics firm, autobody shop, Laundromat, beauty shop, landscaping firm, apartment complex, and manufacturing plant. Of those, four were chosen for the assessment process: the winery, medical clinic, hotel, and apartment complex. The businesses were selected based on their potential for pollution prevention and need for assistance. Additionally, a complete study required applying the pollution prevention principles to all media - air, land, and water. Therefore, it was necessary to select businesses providing the ability to study solid and hazardous waste, waste water, and air emissions.

As part of the process for developing a formal assessment process specific to small business, the Hanford P2OA model (USDOE 1996b) was modified slightly by removing all references to radioactive waste and other federal facility-specific information. The business name replaced the facility name and the business contact was added to the first worksheet. For the most part, the main components of the assessment process remained unchanged. However, the title was changed from "Pollution Prevention Opportunity Assessment" to "Pollution Prevention Assessment" for differentiation. A complete guidance was provided on the reverse side of the worksheets as well. Summaries of the four businesses conducted by the author are provided below. 
Summary: Winery

The winery bottled approximately 10,000 cases of wine a year. The winery had implemented a number of solid waste minimization measures prior to the assessment. Virtually all solid waste was either consumed in the process or recycled and reused. The primary areas identified for opportunity were chemical usage, energy consumption, and waste water.

\section{Summary: Medical Clinic}

The medical clinic treated approximately 105 patients daily. The clinic was privately owned, with the owner working on the premises. The largest waste stream identified was hazardous infectious waste which was managed extremely conservatively. The medical clinic's consumption of electricity offered opportunity for energy efficiency improvements due, in a large part, to the lighting.

Summary: Hotel

The hotel was comprised of 105 guest rooms, several banquet rooms, a restaurant, kitchen, pool and spa, and laundry facilities. A recent lighting retrofit was completed throughout the hotel except for the guest rooms due to a problem with television interference from the electronic ballasts. The hotel had limited recycling practices due to the improper mixing of recyclables and non-recyclables and the small quantity of recyclables generated. The hotel was part of a larger 
franchise where decisions were made at the corporate level. The hotel recently was bought out by another firm and was in the process of changing management.

\section{Summary: Apartment Complex}

The 1-year old apartment complex was comprised of 228 apartments with a pool, spa, sports court, common entertainment area, and several garages. The apartment had recently instituted a goal for pollution prevention and specifically requested recycling opportunities for the residents.

In addition to the four assessments conducted by the author, the Fall semester 1996 "Introduction to Pollution Prevention (ES/RP 428)" class at Washington State University at TriCities conducted five additional assessments as their class project. The assessments completed by the class consisted of a construction firm, supermarket, autobody shop, printing and graphics firm, and landscaping firm. Summary descriptions of the five firms are provided below.

\section{Summary: Construction Company}

The construction firm principally did foundation work and, therefore, generated mostly wood and concrete wastes. The assessment focused on the maintenance shop which serviced all the heavy equipment. Wastes generated in this area included motor oil, antifreeze, grease, and oily rags. Housekeeping was a primary concern to the customer. 
Summary: Supermarket

The store included several areas including a bakery, produce, deli, meat, and seasonal plants and flowers sections. The supermarket provided opportunities for waste water and solid waste reductions as well as energy saving ideas. All operations were performed by employees or contracted to other firms. The grocery store was part of a larger franchise where decisions were made at the corporate level.

Summary: Autobody Shop

The autobody shop was a collision repair facility for approximately 45 cars a month. Hazardous wastes generated included paint, solvent, and thimner from preparation, painting and equipment cleaning. Solvent was the largest waste management concern identified for the shop. A recent acquisition of

high-volume, low-pressure paint guns had already cut their paint waste generation in half.

Summary: Printing and Graphics Firm

The shop, in business since 1978, was divided into three production areas including graphic design, offset printing, and cutting and binding. Hazardous wastes were generated in the graphic design and offset printing areas and managed by a large commercial waste management firm. Solid wastes were primarily generated in the curting and binding areas. Although a small firm, several pollution prevention initiatives were already in place. 
Summary: Landscaping and Nursery Firm

The landscaping and nursery firm was a 30-year old family owned business. It was located on a 2.8 ha ( 7 acre) lot and divided into three primary areas: 1) retail store; 2) nursery; and 3) landscaping construction and maintenance yard. Pesticides and fertilizers dominated the hazardous waste components whereas bender board, plastics, and cardboard comprised a large portion of the solid waste generation. A drip irrigation system was in place for watering the plants and operated during the growing season.

\section{Formal Assessments}

The formal assessments were conducted essentially the same as the pilot assessments including the literature search, facility walk through, brainstorming, cost benefit analysis, and summary (see Appendix D for the four formal assessments conducted by the author). Each of the four assessments were unique in waste and energy consumption opportunities. City of Richland personnel were intimately involved in the process for sustainability of the program at the culmination of this project. These individuals attended facility walk-throughs, brainstorming sessions, and the final presentations to the business owners. In addition, they provided detailed reviews of all the assessments and a monthly meeting was conducted to further exchange information and results of the program.

In addition to the four assessments conducted by the author, five extra assessments were conducted by the pollution prevention class as their class project. These assessments were conducted to test the assessment approach and see if others could 
utilize the method with similar results. The pollution prevention class was trained in the assessment process and the pilot assessments were available as guides to help facilitate the process. The lessons learned from the pilot studies were shared with the students to minimize problems in their assessments. Short fact sheets were prepared for each of the businesses the class visited which included the business name, the business address and phone number, the type of business, the contact, and the activities and typical wastes generated at the business. The class' professors identified the teams of students for each business based upon a questionnaire that the students completed regarding their interests. The P2OA teams were made up of two or tlree people.

The teams followed the same method used for completing the four formal assessments conducted by the author. The business owners were invited to the "Introduction to Pollution Prevention" class for a formal 30-minute presentation of the project results. The presentation was typically divided up among the team members and each step of the $\mathrm{P} 2 \mathrm{OA}$ process was explained in detail. Photos of the businesses and diagrams assisted in understanding the businesses' practices. The final report was delivered to the business owners by mail or in person depending on the choice of the P2OA team.

\section{Assessment Program Evaluation}

A one page survey was developed to measure the progress of implementation and gauge the appropriateness of the assessment process for small businesses (see Appendix E). The survey was comprised of ten questions which could be answered with a short answer, a yes/no response, a satisfaction rating, or a ranking criteria. The surveys were hand-delivered to the assessment 
point of contact to assist in a greater return rate. The surveys were returned via facsimile or U.S. mail. 


\section{Chapter 3: Results and Discussion}

The results and discussion is an analysis of the assessment results and a comparison to similar assessment programs found in the literature. A discussion of each of the business' pollution prevention opportunities is described in detail showing the cost savings associated with each initiative.

\section{Project Results}

Of the 40 opportunities investigated, across the 11 businesses assessed in both the pilot and formal assessments, over half the opportunities related to reduced impacts to the land while energy and water conservation measures comprised the majority of the other half of the opportunities. Just one opportunity was identified for improving air quality. These opportunities identified by media type are shown in Figure 7 .

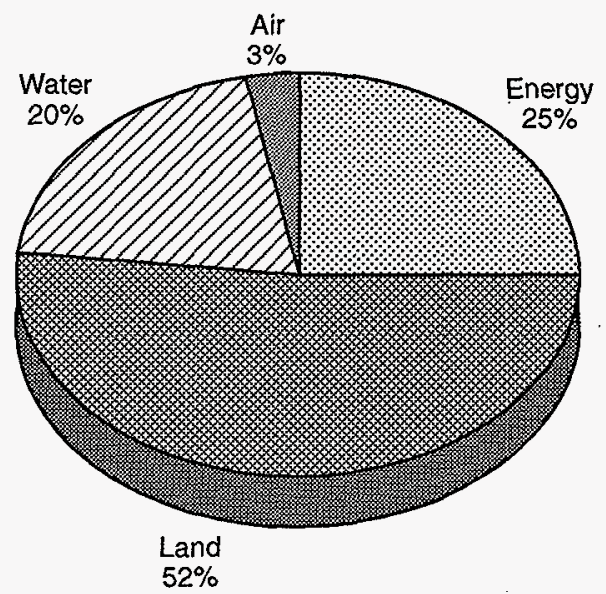

Figure 7 Pollution prevention opportunities identified by media type. 
Figure 8 identifies the percentage of source reduction, recycling, energy recovery, and treatment opportunities evaluated in this study. The U.S. Environmental Protection Agency (USEPA) pollution prevention hierarchy was used to summarize these results where source reduction is at the top of the hierarchy, recycling and reuse are next, then energy recovery, and finally treatment. These results are subdivided by 10 common pollution prevention techniques as illustrated in Figure 9.

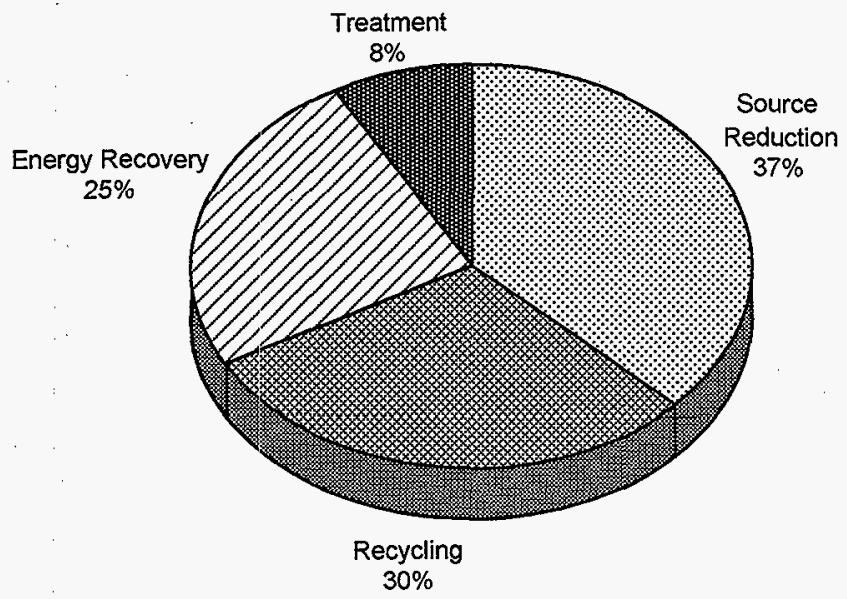

Figure 8 Pollution prevenkion opportunities summarized according to the U.S. Environmental Protection Agency pollution prevention hierarchy. 


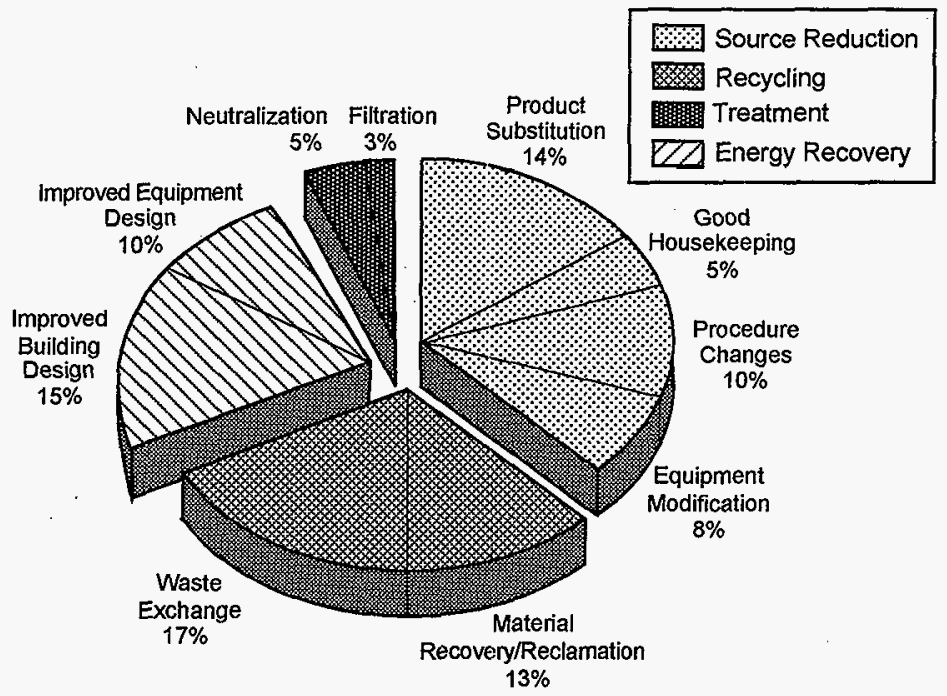

Figure 9 Pollution prevention techniques.

A graphical representation of the distribution of pollution prevention opportunities by type and payback is given in Figure 10. Source reduction opportunities which are at the top of USEPA's pollution prevention hierarchy, showed primarily an immediate payback with 2 opportunities showing less than a 1 year payback period and 3 opportunities indicating less than a 2 year payback period. Recycling opportunities were identified in all payback period categories in a fairly even distribution. Energy recovery opportunities showed less than a 2 year payback period and greater than a 3 year payback period. Finally, treatment opportunities, which are at the bottom of USEPA's pollution prevention hierarchy, comprised long payback periods in the "less than 3 years" category and "greater than 3 years" category.

Eight of the opportunities did not provide a cost savings and/or a payback period and the result was termed "not available." The data not available was due to the annual cost savings, 
and/or implementation cost not calculated, primarily due to future liabilities which were unknown. In two cases there was no annual cost savings realized from implementation of the opportunity and therefore the payback was not calculated. This data was defined as "not available."

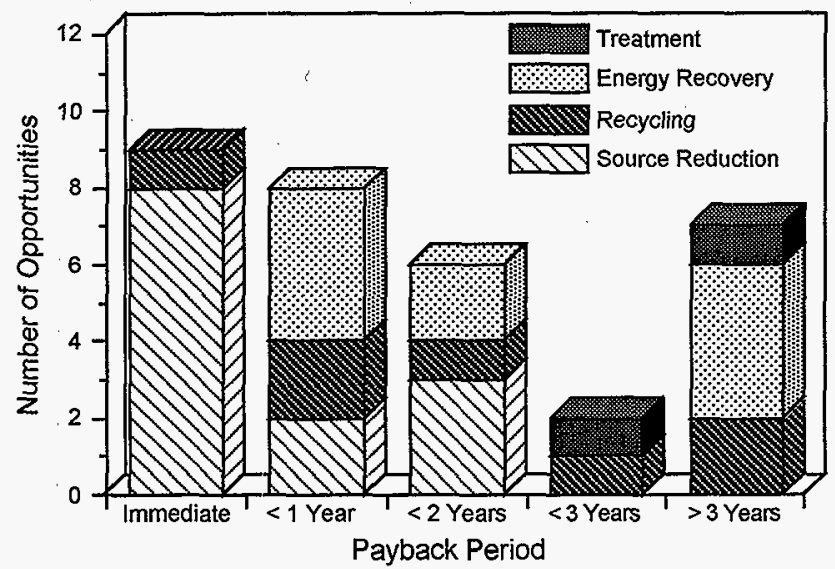

Figure 10 Distribution of opportunities by type and payback.

\section{Case Study Results}

\section{Commercial Laundry}

Three opportunities were evaluated for the commercial laundry, two treatment techniques and one recycling option. Because the laundry had difficulty maintaining a neutral $\mathrm{pH}$, and because no pre-treatment methods were currently in place, the owner decided to investigate primarily treatment methods in an effort to neutralize the waste water discharge to the Publicly Owned Treatment Works and meet compliance standards. The $\mathrm{pH}$ ranged between 8 and 11.5 with 10 as the permit limit. 
The first opportunity investigated was installation of an equalization tank with an acid drip system for $\mathrm{pH}$ adjustment. The type and size of the tank was limited by the small space available at the laundry. A vertical cone-bottom equalization tank and mixer with a 22,700 L (6,000 gallon) capacity and three hour retention time was recommended. A finishing tank placed next to the equalization tank provided the acid-drip system which used sulfuric acid as the neutralizing agent. This opportunity provided no waste reduction or energy savings due to the waste management practice. However, an annual cost savings of $\$ 6,930$ would be realized from the elimination of potential fines, reduced annual reporting requirements, and need of an engineering review as required by the laundry's compliance schedule. The implementation cost of the system was estimated at $\$ 19,500$ for a payback period of 2.8 years.

Implementation of a dissolved air flotation system was the second opportunity evaluated that would provide liquid and solid separation. Dissolved air flotation is a process in which microscopic air bubbles attach to solid waste particles suspended in a liquid causing the solid particles to float. ${ }^{(17)}$ The float blanket is removed and pressed into a dry cake disposable in the local landfill. As with the $\mathrm{pH}$ adjustment system, this option did not allow any waste reduction or energy savings. The annual cost savings however, was $\$ 17,000$. The implementation cost was $\$ 164,740$ for a payback of 9.7 years.

The third and final opportunity was designing and installing a wastewater recycling system. Approximately 40-percent of the wastewater would be rerouted for reuse. The remaining wastewater with total dissolved solids exceeding the limits would be sent to the process tank for further treatment. Over 1 million L (275,200 gallons) of wastewater would be

${ }^{(17)}$ Letter from J. Averill, Hydro Modular Systems, Oklahoma City, OK, 25 July 1996. 
reused with an annual cost savings of $\$ 5,340$. The implementation of a wastewater recycling system is approximately $\$ 71,300$ providing a payback period of 13.3 years.

Each of the three opportunities was contingent on the previous opportunity having already been implemented and, therefore, it was recommended to implement each of the opportunities in sequence. It was further recommended, however, that due to the high cost of implementation, the laundry may desire to wait to implement the dissolved air flotation and the recycling systems until after the U.S. Environmental Protection Agency (USEPA) has published the guideline for industrial laundries (estimated implementation in $1998^{(18)}$ ) to ensure the system is adequate to meet the new limits. The opportunities investigated at the commercial laundry were averaged and are shown in Figure 11.

A bench scale test was performed at the commercial laundry which illustrated the principle of industrial ecology where one businesses waste can be another businesses resource. A sample of waste sludge from a nearby potato plant was identified as a potential ingredient to the commercial laundry's waste water discharge to assist in breaking the fats, oils, and grease bond. The test, which involved pouring the potato sludge into the settling tank, did not provide positive results in breaking the bond and was not investigated further.

(18) Personal communications from M. Jordan, Washington DC, 5 June 1996. 


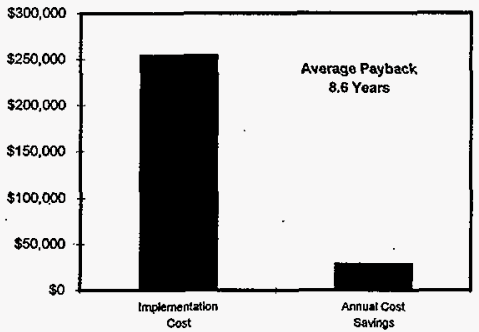

Figure 11 Commercial laundry implementation cost versus annual cost savings.

\section{Automotive Repair Shop}

The automotive repair shop already had implemented several waste management practices and were controlling their waste properly. A waste management firm was involved in the management and/or recycling of the shop's antifreeze, oil, brake fluid, freon, and solvent. The opportunities chosen for evaluation included using a post-consumer absorbent, improved solvent operating practices, and crushing oil filters for recycling.

A post-consumer absorbent, ${ }^{(19)}$ made from reclaimed cellulose wood fibers from the pulp and paper industry was recommended to replace the diatomaceous earth that was used for spill and floor cleanup. The annual waste reduction was estimated at $748 \mathrm{~kg}$ (1,648 pounds) for a cost savings of $\$ 290$. The payback for this option was immediate as there was no implementation cost associated with switching products and practices.

The second opportunity evaluated was improving the solvent operating practices which included several steps to ensure the most efficient use of solvent. The steps included: 1) replacing one solvent washer with a cyclonic washer that used a less hazardous solvent; 2)

(19) Personal communications from S. Valentine, Bellingham, WA, 14 August 1996. 
relocating both solvent washers so that they were side by side for two-stage cleaning; 3 ) turning the solvent stream off when not in use; 4) allowing car parts to drain completely; and 5) replacing solvent only when it is dirty. The total waste reduction, through implementation of all the ideas, was $1,779 \mathrm{~L}$ ( 468 gallons) per year for a cost savings of $\$ 772$. The implementation cost was $\$ 34$ for a payback of less than 1 month.

Crushing oil filters for recycling was the final opportunity evaluated for the automotive repair shop. The oil filter crusher exerts $18,100 \mathrm{~kg}(40,000$ pounds) of force on the filter which provides over 98-percent recovery of waste oil for recycling. The crushed filter can also be recycled as scrap metal. Although the state regulations indicate that a firm may puncture the filter and allow it to drain for 24-hours before disposing of the filter in the solid waste sanitary landfill, this opportunity allows for recycling both the oil and filter media. The filters and waste oil provided a reduction of 680 and $231 \mathrm{~kg}$ (1,500 and 510 pounds), respectively, for a total waste reduction of $912 \mathrm{~kg}(2,010$ pounds) and a cost savings of $\$ 670$. The cost of the crusher was $\$ 1,290$ for a payback period of 1.9 years.

All three opportunities were recommended for implementation as all had a payback period of less than three years. The opportunities investigated were averaged and are shown in Figure 12. Furthermore, each of the opportunities could be implemented at the second automotive repair shop recently purchased by the owner and he would realize similar savings. 


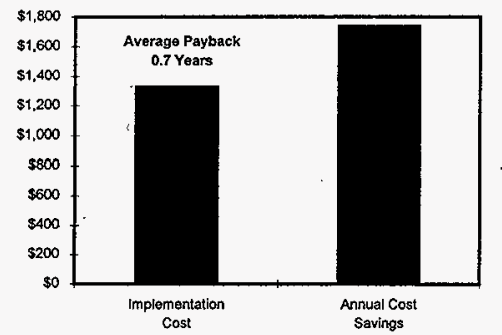

Figure 12 Automotive repair shop implementation cost versus annual cost savings.

Winery

Two energy-related and one hazardous waste opportunities were investigated for their applicability and potential waste reduction and cost savings at the winery. Aesthetics was of primary importance to the business owners as visitors frequent the facilities for formal and informal events. Two of the opportunities investigated were evaluated in light of that concern.

The $200 \mathrm{~m}^{2}\left(2,000 \mathrm{ft}^{2}\right)$ cellar is maintained at $16^{\circ} \mathrm{C}\left(60^{\circ} \mathrm{F}\right)$, and dropped to $-4^{\circ} \mathrm{C}\left(25^{\circ} \mathrm{F}\right)$ during cold stabilization, a wine making process which lasts for several days. It was recommended to paint the cellar composition roof with a reflective roof coating to minimize energy loss. It was demonstrated that a reflective coating could cut the winery's summertime air conditioning by 22-percent. Pure white is the ideal color for maximizing energy efficiency although pastel colors are available from most manufacturers. The estimated energy savings was $7,210 \mathrm{kWh}$ per year for an annual cost savings of $\$ 415$. The implementation cost was $\$ 4,000$ with a payback period of 9.6 years. The payback could be lowered if the owners paint the roof themselves and save the labor cost of $\$ 1,000$.

The second opportunity evaluated was insulating the fermentation tanks, chillers, and the associated piping. Four fermentation tanks were located inside the cellar and 8 outside with 
various sizes ranging from $1.5 \mathrm{~m}$ diameter by $2.4 \mathrm{~m}$ high ( $5^{\prime}$ diameter by $8^{\prime}$ high) to $3 \mathrm{~m}$ diameter by $3.4 \mathrm{~m}$ high $\left(10^{\prime}\right.$ diameter by $11^{\prime}$ high). The two $22,680 \mathrm{~kg}$ (25-ton) chillers cool the tanks. The recommended action was to install bubble foil-insulated jacketing fabricated to the exact shape of the tanks and chillers. This would save an estimated $23,110 \mathrm{kWh} /$ year for a cost savings of $\$ 1,150$. The implementation cost was estimated at $\$ 26,440$ for design and fabrication of the 12 fermentation tanks, the two chillers, and the associated piping. The payback was 23 years which could be reduced with a $\$ 3,600$ reduction in the implementation cost by installing the insulation in-house.

The third and final opportunity considered for this assessment was using an alternative filtration product in place of diatomaceous earth. The product identified was an igneous mineral. The product has a low settling rate which enables it to more easily remain in suspension as it enters the pressure filtration system. The waste reduction was estimated to be $272 \mathrm{~kg}$ ( 600 pounds) for an annual cost savings of $\$ 68$. There were no costs for switching products and, therefore, implementation was recommended since the payback was immediate.

Replacing filtration products was recommended for instant implementation as it was an immediate cost savings. It was further recommended to insulate the fermentation tanks, chillers and associated piping in three stages by insulating three tanks per year due to the high implementation cost. It has been noted in this industry that wrapping the tanks improves the tank. appearance ${ }^{(20)}$ and, therefore, was an added benefit to implementation. Since the aesthetics of the winery was imperative, it was recommended to implement the reflective roof coating if a pastel color was chosen to complement the painted exterior of the building. All the opportunities

\footnotetext{
(20) Personal communications from R. Landby, Kennewick, WA, 16 December 1996.
} 
evaluated for the winery were averaged and are illustrated in Figure 13.

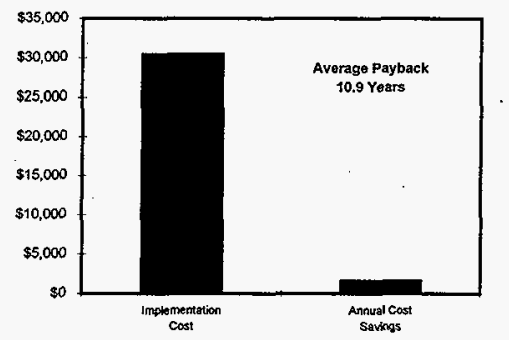

Figure 13 Winery implementation cost versus annual cost savings.

\section{Medical Clinic}

The largest waste stream at the medical clinic was infectious waste and was, therefore, considered for one of the opportunities. Additionally, paper and energy consumption were investigated in this assessment.

Infectious wastes are generated from syringes and other sharp instruments, tissue culture bottles, membrane filters, specimen collection bottles, slides and plates, rubber gloves, and swabs. A waste management firm collected the infectious waste from the clinic. The sanitary and infectious waste were combined when collected by the waste management firm. Only 7.5-percent of the combined waste was actually infectious waste. Since the costs associated with the disposal of infectious waste was high, it was recommended to segregate the waste streams properly. This would be accomplished by establishing a written plan to ensure effective waste minimization practices prior to disposal. This opportunity provided the greatest annual waste reduction and cost savings of the three opportunities investigated. Approximately $14,310 \mathrm{~L}$ $(3,780$ gallons) of waste would be reduced with an annual savings of $\$ 27,750$. The 
implementation cost which was writing the plan and purchasing signs and posters for awareness was $\$ 1,500$ for a payback of less than one month.

The second option, duplexing copies and recycling paper, was chosen because of the large quantity of paper generation per patient and copying of large medical documents.

Additionally, the small copy machines were cumbersome, time consuming, and in constant need of repair. The recommendation included copying paperwork for patients on both sides of paper and recycling paper. The implementation included purchasing a refurbished copy machine capable of copying 60 copies per minute and containing a duplexing feature. The calculation of waste reduction revealed that the medical clinic could save $1,590 \mathrm{~kg}(3,510$ pounds) of paper per year by duplexing and recycling for a cost savings of $\$ 5,095$. The implementation cost of the copier was estimated at $\$ 5,500$ for a payback of 1.1 years.

A lighting retrofit was the third opportunity evaluated and, since one side of the facility was new and contained relatively energy-efficient lighting, the investigation was focused on the old side. New electronic ballasts could be easily retrofitted into the existing fluorescent lighting systems. The opportunity also included replacing all the incandescent lighting with highefficient fluorescent lighting. The annual energy savings from this opportunity was estimated to be $16,130 \mathrm{kWh}$ for a cost savings of $\$ 612$. The implementation cost, including materials and labor, was $\$ 4,023$ which concluded a payback period of 6.6 years. The opportunities described above were averaged and are represented in Figure 14. 


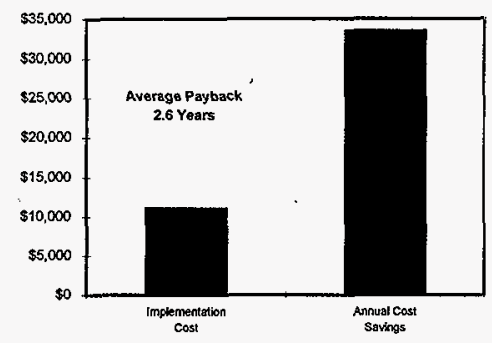

Figure 14 Medical clinic implementation cost versus annual cost savings.

It was recommended to the medical clinic to implement the waste segregation practices immediately due to the high cost of infectious waste disposal. Furthermore, the practice of duplexing copies and recycling was recommended for implementation since reconditioned copiers were available at the time the assessment was completed. Although the payback for the lighting retrofit was over 6 years, it was recommended for implementation because the city of Richland would provide a 3 to 5 -year term loan at 3 to 3.5 -percent interest. Therefore, the medical clinic could realize a cost savings upon implementation of this opportunity.

\section{Hotel}

Because the hotel was recently purchased by a new management firm, the opportunities selected for evaluation were primarily opportunities that could be performed in-house by the engineering and housekeeping departments at little or no cost. Those opportunities selected were: Use environmentally safe ice melt, install toilet adaptations to reduce water use, and install energy efficient electronic ballasts in the bathrooms.

A non-hazardous, environmentally safe ice melt was recommended to replace the miscellaneous blends of rock salt-based and calcium chloride brands the hotel was currently 
purchasing. The recommended ice melt was safer for grass and vegetation than the other brands and did not require the protection of special gloves or goggles for application. The total annual waste reduction was $113 \mathrm{~kg}$ (250 pounds) as the recommended brand lasts twice as long as other brands, for a cost savings of $\$ 83$ per year. This initiative did not require any implementation costs and therefore the payback was immediate.

The second opportunity evaluated was installing toilet adaptations to the existing toilets for water conservation. The recommended adaptation was an adjustable flush flapper expected to reduce the gallons per flush from 19 to $27 \mathrm{~L}$ to 11 to $17 \mathrm{~L}$ ( 5 to 7 gallons to 3 to 4.5 gallons). The water savings resulting from implementation of this initiative could be as high as 1,231,072 L (325,215 gallons) per year resulting in a cost savings of $\$ 513$. The implementation cost was $\$ 583$ for a payback of 1.1 years.

The past several years, the hotel had undergone a lighting retrofit for the majority of the lighting systems. However, the ballasts and lamps in the guest bathrooms were not replaced with an energy efficient system because of radio and television interference. An energy efficient hybrid ballast was identified for the ballast that was manufactured specifically for low frequency operation and was not expected to interfere with high frequency electronic equipment. This initiative provided an annual energy savings of $5,010 \mathrm{kWh}$ and a cost savings of $\$ 194$ per year. The resulting long payback period of 16 years was due to a high implementation cost of $\$ 3,045$.

The results of the study showed a recommendation for implementation of the environmentally safe ice melt and the toilet adaptations. Due to the long payback period for the retrofit of energy efficient lighting in the bathrooms, this opportunity was not recommended. However, it was recommended to replace the ballasts with the hybrid ballasts when the existing 
ballasts need replacement. Each of the opportunities evaluated are shown in Figure 15 as an average implementation cost and average cost savings.

Several additional opportunities were given a cursory review including recycling guest soaps, recycling batteries; using rechargeable batteries, recycling glass, and recycling fluorescent tubes. A detailed cost analysis was not performed on the above opportunities. However, feasibility of the opportunities were addressed and where appropriate, a vendor was identified.

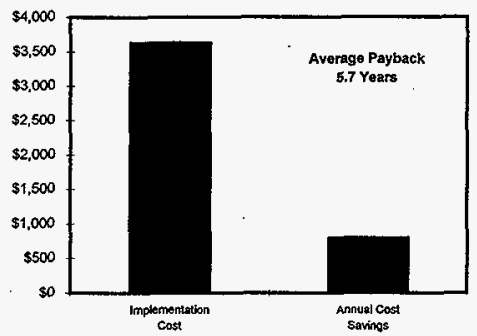

Figure 15 Hotel implementation cost versus annual cost savings.

\section{Apartment Complex}

The apartment complex selected opportunities for evaluation based upon the apartment manager's goals which were to save money and implement recycling. Five opportunities selected including the following: 1) lighting retrofit for apartment controlled lighting; 2) lighting retrofit for apartment renters; 3) wrap hot water heaters with insulated blankets; 4) heat pool and spa with solar; and 5) implement a recycling program.

The apartment complex controlled lighting included the cabana (entertainment and office area) and the outdoor lighting. The recommendation included retrofitting the incandescents with compact fluorescents and retrofitting the magnetic ballasts and lamps with electronic ballasts and 
energy efficient lamps. The overall energy șavings for this opportunity was $61,650 \mathrm{kWh}$ per year for a cost savings of $\$ 2,676$. The implementation cost including labor was $\$ 4,530$ which provided a payback period of 1.7 years.

The apartment complex was also interested in retrofitting the interior apartment lighting as low utility cost is seen by many apartment complexes as a selling feature. The recommended action included retrofitting the incandescents with compact fluorescents and retrofitting the magnetic ballasts and lamps in the kitchen with electronic ballasts and energy efficient lamps. The energy savings related to this opportunity was $1,087,614 \mathrm{kWh} /$ year for a cost savings to the renters of $\$ 47,203$. The implementation cost assumed by the apartment complex was $\$ 1,524$ for a payback period of less than one month.

The next opportunity evaluated involved wrapping the apartment water heaters with insulation to reduce energy consumption. The savings for this option would be reaped by the apartment owners themselves at an annual cost savings of $\$ 2,246$ associated with a $52,241 \mathrm{kWh}$ energy savings. The implementation cost assumed by the apartment complex was $\$ 3,531$ for a payback of 1.6 years.

Solar heating for the pool and spa was also evaluated for potential savings in propane. The savings associated with this opportunity related to the seasonal swimming months of May through September. It was further recommended to keep the propane tank in place for heating the spa in the off season. The cost savings associated with this opportunity were $\$ 5,139$ per year which related to an average reduction in propane of $13,056 \mathrm{~L}(3,449$ gallons). The implementation cost was expected to be less than $\$ 4,500$ for an estimated payback of 0.8 years.

The final oppoitunity analyzed was implementation of a recycling program. The program recommended would function like a curbside program where residents would collect recyclables 
in a recycling container and on a specified day of the week set the container near the dumpsters for pickup by the maintenance crew. The maintenance crew would then transport the individual recycling containers via an existing system to a larger recycling container where the city of Richland would pick up and transport to the recycling center. The total waste reduction for implementation of this initiative could be as high as $15,422 \mathrm{~kg}$ (17 tons) per year assuming an 80 -percent participation rate. The associated cost savings would be $\$ 826$. The implementation cost was $\$ 7,168$ for a payback of 8.7 years.

The results of the study conducted at the apartment complex are represented graphically by the average annual cost savings and average implementation cost in Figure 16. It was recommended to implement the lighting retrofit for the complex and the solar heating initiatives immediately due to the relatively short payback period. Considering the apartment renters will receive the benefit of reduced utilities through implementation of the apartment lighting retrofit and the water heater insulation, it was reconmmended for the apartment complex management to determine if the improvements add significant value as a selling feature for potential apartment renters before implementing. The recycling program was recommended despite the long payback period because this was one of the goals identified at the onset of the assessment.

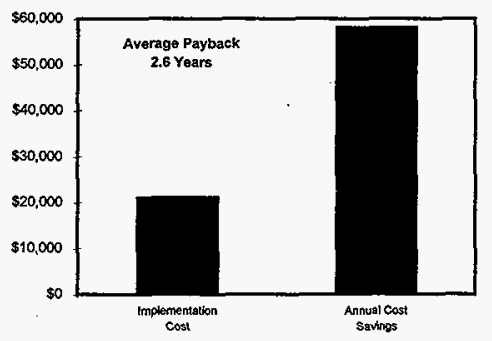

Figure 16 Apartment complex implementation cost versus annual cost savings. 


\section{Assessments Conducted by the Pollution Prevention Class}

\section{Construction Firm(2l)}

The focus of this assessment was on the construction firm's maintenance shop which services and repairs motor vehicles, small engines, and heavy equipment. Four opportunities were evaluated for minimizing waste.

The first option investigated was a modification to purchasing practices. Motor oil, transmission fluids, and hydraulic fluids were purchased in 4 and 19 L (1 and 5 gallon) containers with approximately 5-percent of the product remaining in the container prior to disposal. It was recommended to purchase bulk engine oil, hydraulic fluid, and transmission fluid to reduce inventory tracking and eliminate disposal costs. A bulk contract reduced the cost per liter of product with an overall annual cost savings of $\$ 7,600$. The waste reduction associated with the cost savings was 5,489 L (1,450 gallons). The implementation cost was zero and, therefore, the payback was immediate.

Installing a parts washer was the second opportunity evaluated. The existing parts washer was broken and the mechanics were using a naphtha solvent to clean parts in a tub. Two alternatives were reconmended: 1) purchasing a new parts washer with a filtration mechanism; or 2) establishing a contract with a commercial recycling service to manage a parts washer and the solvent. It was estimated that the construction firm would save $303 \mathrm{~L}$ ( 80 gallons) of solvent annually through filtration. Future liabilities were identified as a benefit in the cost analysis, but was not calculated and, therefore, the payback was not quantified.

(21) Pollution prevention class assessment conducted by Larry Olsen, Clark McBride, and Craig Stoker. 
The third opportunity involved removing the above-ground fuel tanks used to fuel company equipment. In the winter months, the pad below the tank collected water from snow melt causing any spilled fuel to percolate to the ground. Removing the fuel tank and purchasing fuel from a commercial vendor was recommended to reduce future liabilities and spills. No cost or waste calculations were performed.

A tiered cleaning system was recommended in the final opportunity. The first tier involved cleaning the machinery with water to remove dirt and the second tier required the use of a steam cleaning system with an oil water separator for recycling the water for reuse. The implementation cost was estimated at $\$ 11,300$; however, no annual waste reduction or cost savings was calculated due to unknown future liabilities.

This firm understood the consequences of non-compliance as the firm previously spent over $\$ 15,000$ cleaning up soil that had been contaminated from a leaking underground fuel tank. Since the firm has been involved first-hand with the regulators, all four opportunities were recommended for immediate implementation to reduce waste and potential liability. A comparison of the average implementation cost versus the annual cost savings of all the opportunities identified at the construction firm is depicted in Figure 17.

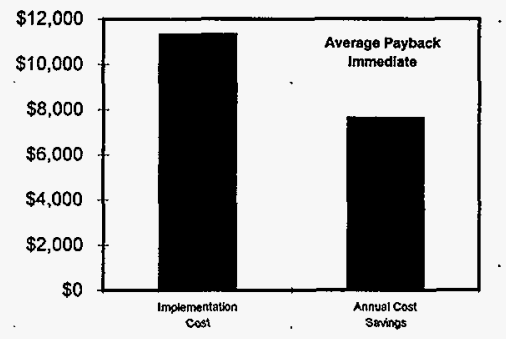

Figure 17 Construction firm implementation cost versus annual cost savings. 
Supermarket(22)

The supermarket was committed to pollution prevention and implementing environmentally sound practices. Because the management and employees have embraced pollution prevention, many of the opportunities for this firm were already implemented and much of the focus of the assessment was on energy efficiencies.

Replacing high-energy consumption light bulbs with energy-efficient lighting was the first opportunity evaluated. It was recommended that at the next relamping, the supermarket install a more energy-efficient lighting system to save approximately $36,700 \mathrm{kWh}$ per year for a cost savings of $\$ 1,460$. The implementation cost for materials was estimated to be $\$ 524$ for a payback of 4 months.

The second opportunity involved compacting the plastic materials used in the store for recycling. A local plastic recycler was identified who would provide storage bins, an electric compaction baler, training on the equipment, and weekly pick up service at no cost to the supermarket. The waste reduction was $21 \mathrm{~m}^{3}$ ( 730 cubic feet) per year and a cost savings of $\$ 105$ annually. The implementation cost involved 4 hours of training which provided a payback of 8 months.

Hanging plastic strips on the refrigerated sections was also evaluated for potential cost and energy savings. The plastic strips trap some of the cool air inside the refrigerated display cases and still allow the items to be visible with easy access. This opportunity identified a waste reduction of $74,000 \mathrm{kWh}$ per year for a cost savings of $\$ 2,960$. The implementation cost, including labor and materials, was $\$ 1,160$ providing a payback of 4 months.

${ }^{(22)}$ Pollution prevention class assessment conducted by Chuck Keeler and Chris Lathim. 
All three opportunities were recommended for implementation as all had less than a year payback periods. These opportunities are represented in Figure 18.

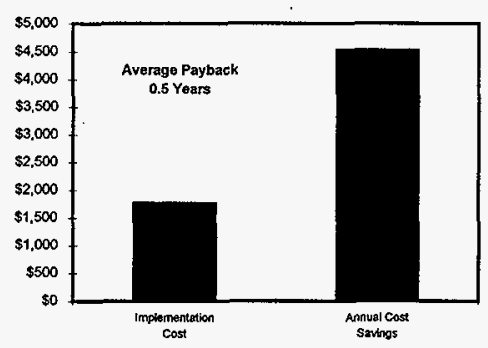

Figure 18 Supermarket implementation cost versus annual cost savings.

Autobody Shop(23)

The autobody shop generated wastes such as paint, cleaning solvent, and paint thinners.

This company understood the benefits of pollution prevention as they had recently purchased high volume low pressure paint guns, cutting their waste generation in half. Three other opportunities were identified for consideration.

The first option was installing a solvent distillation unit which would provide a 50-percent reduction in air emissions, an 80-percent reduction in disposal costs, and a 90-percent reduction in the amount of solvent purchased. The calculated waste reduction was $284 \mathrm{~L}$ (75 gallons) for a cost savings of $\$ 1,750$. The cost for a distillation apparatus was $\$ 5,300$ which provided a payback of 3 years.

A post-consumer absorbent, made from reclaimed cellulose wood fibers from the pulp and paper industry was recommended to replace diatomaceous earth used for spill and floor

${ }^{(23)}$ Pollution prevention class assessment conducted by Laurie Hay and Jim Perryman. 
cleanup. This is the same product recommended for the automotive repair firm. The annual waste reduction was estimated at $23 \mathrm{~kg}$ ( 50 pounds) for a cost savings of $\$ 20$. The payback for this option was immediate as there was no implementation cost associated with switching products and practices.

Although the autobody shop was in the habit of flattening cardboard boxes, the cardboard was placed in the dumpster for disposal in the landfill. It was recommended, in the third and final opportunity, to recycle cardboard through a local recycling firm. It was identified that if the shop recycled $3 \mathrm{~m}^{3}$ ( 4 cubic yards) per week, the recycling service was free. However, if the shop collected less than $3 \mathrm{~m}^{3}$ ( 4 cubic yards) weekly, the cost for the service would be $\$ 20$ per month. The estimated waste reduction for this recycling activity was $3 \mathrm{~m}^{3}$ (2.7 cubic yards) per year for an annual cost savings of $\$ 519$ without the service cost and $\$ 279$ with the service cost. The implementation cost was zero and therefore the payback period was immediate.

Each of the three opportunities evaluated had less than a 3-year payback period and were all recommended for implementation. Added benefits, including safety concerns, were also identified as reasons for implementation. A comparison of the implementation costs versus the annual cost savings is depicted in Figure 19.

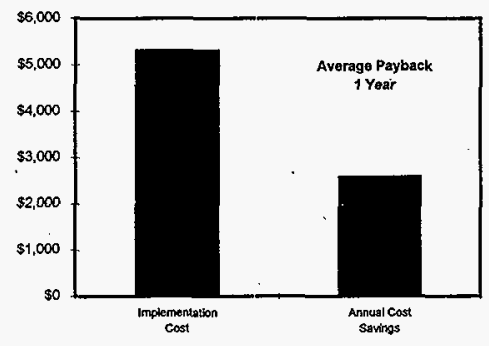

Figure 19 Autobody shop implementation cost versus annual cost savings. 
Printing and Graphics Firm(24)

Typical wastes generated at the printing and graphics firm included paper, cardboard, ink, film, chemicals, rags, solvent, and toner cartridges. Seven opportunities targeted at each of the three production areas (i.e., graphic design, offset printing, and cutting and binding) were evaluated.

First, it was recommended to reuse cardboard boxes for packaging the printed product for delivery to the customer. It was further suggested to print the company name and logo on a sheet of paper and affix it to the top of the box for advertisement. This option would realize a waste reduction of $340 \mathrm{~kg}$ annually for a cost savings of $\$ 340$. The implementation cost was $\$ 25$ for printing the top sheet for a payback of less than a month.

A second option was to replace the existing printer with a printer which would accept refurbished cartridges. Implementation of this opportunity would save 8 cartridges annually for a cost savings of $\$ 344$. The cost of a new printer is between $\$ 550$ and $\$ 1,020$, depending on the type, revealing a payback between 1.6 years and 3.0 years. The third opportunity, recycling laser toner cartridges, is a direct result from the previous opportunity identified. Three printers use approximately 15 toner cartridges annually which could be recycled, saving 15 cartridges from landfill disposal. The cost savings was not identified as it would not result in a reduction in dumpster size or pick up service. There was no implementation cost for this opportunity.

An alternative was identified related to the naphtha-based cleaner used for offset printing. The alternative, less hazardous product was a general-purpose cleaner formulated to remove ink and grease. The printing and graphics firm could realize a waste reduction of $140 \mathrm{~kg}$ (309 pounds) per year resulting in an annual savings of $\$ 570$ if this opportunity was implemented.

${ }^{(24)}$ Pollution prevention class assessment conducted by Steve Mischke and Laurie Vaillancourt. 
There was no implementation cost associated with changing products and, therefore, the payback period was immediate.

Although 25-percent of the firm's waste paper was reused by local schools, recycling the paper was evaluated for its benefit to the company and the environment. It was recommended to recycle excess paper by allowing a volunteer to take it to a nearby recycling station as no recycling pick up service was available to commercial businesses. Approximately $910 \mathrm{~kg}(2,000$ pounds) of waste paper would be reduced, however, no tangible cost savings would be realized. The implementation cost was zero.

An opportunity that would improve the air quality of the work environment was also evaluated. The fixer and developer used by the firm emitted an acetic acid-type odor and, if the developer overflowed into the fixer bath, an ammonia odor was produced. The recommended opportunity was to install a chemical filter on the film processor to reduce or eliminate the odor. No measurable waste reduction or cost savings would be realized from its implementation. The filters cost $\$ 524$ apiece, including installation. The payback period was not calculated as there were no cost savings.

The final opportunity evaluated was an alternative product for replacing the naphthabased cleaner used for offset printing. The alternative recommended had similar features for removing ink and grease. The waste reduction of $150 \mathrm{~kg}$ (331 pounds) annually would have a cost savings of $\$ 560$. There were no implementation costs for implementation of this initiative which resulted in an imumediate payback period.

It was recommended to begin using one of the alternative products to minimize the use of hazardous products. All the other initiatives were recommended based upon the short payback 
periods. The average implementation cost compared to the average annual cost savings for the printing and graphics firm is shown in Figure 20.

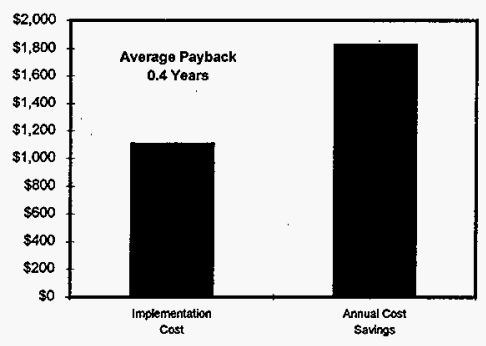

Figure 20 Printing and graphics firm implementation cost versus annual cost savings.

\section{Landscaping Firm(25)}

The landscaping firm had few waste management practices implemented at the beginning of the assessment. The firm had been in business for over 30 years and many of the old practices for managing waste, such a burning trash, were still practiced. The opportunities evaluated focused on waste management, compliance, and clean up opportunities.

The first opportunity was improved housekeeping practices. The recommendation included cleaning up a $1.6 \mathrm{ha}$ (4-acre) lot that was cluttered with bender board, garbage, pipe, grass, branches, metal, tires, cars, and refrigerators. The clean up would be comprised of proper disposal, composting, and recycling. It was further recommended to train all the firm's employees of the new housekeeping practices. The waste reduction was not estimated due to the large area involved and unknown quantities of materials present. Because of the large potential

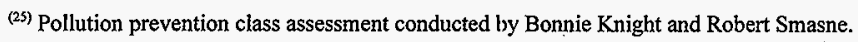


liability involved, the calculated annual cost savings was $\$ 500,000$. The implementation cost was estimated at $\$ 50,000$ and the payback would be achieved when the business was sold.

Because pesticides, fertilizers, and oils are discarded near the water supply, modifying the existing drip irrigation system to an evapotranspiration system would reduce the possibility of contaminated ground water. The waste reduction was not quantified, however, the liability was estimated at $\$ 25,000$ per day. The implementation cost for cleanup was $\$ 4,820$.

The third and final opportunity evaluated was implementing a recycling program for the landscaping materials such as pipe, bender board, cardboard, and grass and pruning waste. This recommendation would assist in controlling the problems associated with the 1.6 ha (4-acres) that need to be cleaned up. The annual waste reduction was estimated to save over $515 \mathrm{~kg}(1,135$ pounds), however, the cost savings was not calculated. The implementation cost was estimated at $\$ 790$.

The business owner was interested in planting the back lot with grass and Christmas trees. Implementation of all three opportunities would aid in this endeavor and were all recommended for implementation within one year of the assessment. The comparison of implementation cost and annual cost savings is illustrated in Figure 21. 


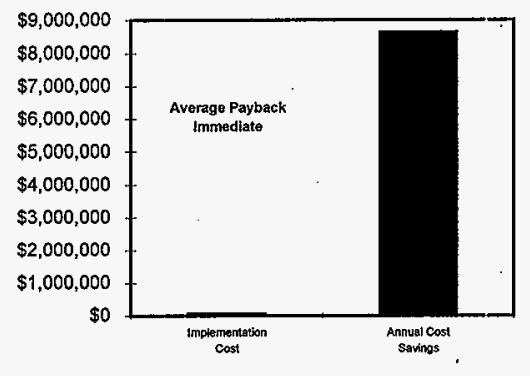

Figure 21 Landscaping firm implementation cost versus annual cost savings.

\section{Industry Comparisons}

The comparisons by industry of the annual average cost savings and average implementation cost are shown in Table 3 and Table 4.

Table 3 Industry comparison of the annual cost savings.

\begin{tabular}{lr}
\hline \multicolumn{1}{c}{ Industry } & $\begin{array}{c}\text { Annual Cost } \\
\text { Savings }\end{array}$ \\
\hline Landscaping Firm & $\$ 8,625,000$ \\
Apartment Complex & $\$ 58,090$ \\
Medical Clinic & $\$ 33,457$ \\
Commercial Laundry & $\$ 29,240$ \\
Construction Firm & $\$ 7,600$ \\
Supermarket & $\$ 4,525$ \\
Autobody Shop & $\$ 2,568$ \\
Printing and Graphics & $\$ 1,825$ \\
Automotive Repair & $\$ 1,732$ \\
Winery & $\$ 1,633$ \\
Hotel & $\$ 790$ \\
\hline
\end{tabular}


Table 4 Industry comparison of the implementation cost.

\begin{tabular}{lr}
\hline \multicolumn{1}{c}{ Industry } & $\begin{array}{c}\text { Implementation } \\
\text { Cost }\end{array}$ \\
\hline Commercial Laundry & $\$ 255,500$ \\
Landscaping Firm & $\$ 55,610$ \\
Winery & $\$ 30,400$ \\
Apartment Complex & $\$ 21,073$ \\
Construction Firm & $\$ 11,300$ \\
Medical Clinic & $\$ 11,026$ \\
Autobody Shop & $\$ 5,300$ \\
Hotel & $\$ 3,628$ \\
Supermarket & $\$ 1,764$ \\
Automotive Repair & $\$ 1,324$ \\
Printing and Graphics & $\$ 1,103$ \\
\hline
\end{tabular}

Table 5 summarizes the results of each opportunity associated with the annual waste reduction, the annual cost savings, the implementation cost, and payback in years. 
Table 5 Summary of pollution prevention opportunities by industry.

\begin{tabular}{|c|c|c|c|c|c|}
\hline Industry & $\begin{array}{c}\text { Pollution Prevention } \\
\text { Opportunity }\end{array}$ & $\begin{array}{c}\text { Annual Waste } \\
\text { Reduction }\end{array}$ & $\begin{array}{c}\text { Annual Cost } \\
\text { Savings }\end{array}$ & $\begin{array}{c}\text { Implementation } \\
\text { Cost }\end{array}$ & $\begin{array}{c}\text { Payback } \\
\text { (Years) }\end{array}$ \\
\hline Commercial Laundry & $\begin{array}{l}\text { Install equalization tank } \\
\text { Implement dissolved air flotation } \\
\text { Recycle wastewater }\end{array}$ & $\begin{array}{r}\text { None } \\
\text { None } \\
1,042 \mathrm{~kL}\end{array}$ & $\begin{array}{r}\$ 6,900 \\
\$ 17,000 \\
\$ 5,340\end{array}$ & $\begin{array}{r}\$ 19,500 \\
\$ 164,700 \\
\$ 71,300\end{array}$ & $\begin{array}{r}2.8 \\
9.7 \\
13.3\end{array}$ \\
\hline Automotive Repair Shop & $\begin{array}{l}\text { Use post-consumer absorbent } \\
\text { Improve solvent use practices } \\
\text { Crush oil filters }\end{array}$ & $\begin{array}{r}748 \mathrm{~kg} \\
1,779 \mathrm{~L} \\
907 \mathrm{~kg} \\
\end{array}$ & $\begin{array}{l}\$ 290 \\
\$ 772 \\
\$ 670 \\
\end{array}$ & $\begin{array}{r}\$ 0 \\
\$ 34 \\
\$ 1,290 \\
\end{array}$ & $\begin{array}{r}\text { Immediate } \\
<1 \text { month } \\
1.9 \\
\end{array}$ \\
\hline Winery & $\begin{array}{l}\text { Paint roof with reflective coating } \\
\text { Insulate tanks, chillers and piping } \\
\text { Filter with alternative product }\end{array}$ & $\begin{array}{r}7,212 \mathrm{kWh} \\
23,116 \mathrm{kWh} \\
272 \mathrm{~kg} \\
\end{array}$ & $\begin{array}{r}\$ 415 \\
\$ 1,150 \\
\$ 68 \\
\end{array}$ & $\begin{array}{r}\$ 4,000 \\
\$ 26,400 \\
\$ 0\end{array}$ & $\begin{array}{r}9.6 \\
23.0 \\
\text { Immediate } \\
\end{array}$ \\
\hline Medical Clinic & $\begin{array}{l}\text { Segregate infectious waste } \\
\text { Duplex copies and recycle } \\
\text { install energy efficient lighting }\end{array}$ & $\begin{array}{r}14,309 \mathrm{~L} \\
1,593 \mathrm{~kg} \\
16,131 \mathrm{kWh}\end{array}$ & $\begin{array}{r}\$ 27,750 \\
\$ 5,095 \\
\$ 612\end{array}$ & $\begin{array}{l}\$ 1,503 \\
\$ 5,500 \\
\$ 4,023\end{array}$ & $\begin{array}{l}0.1 \\
1.1 \\
6.6 \\
\end{array}$ \\
\hline Hotel & $\begin{array}{l}\text { Use environmentally safe ic: melt } \\
\text { Install toilet adaptations } \\
\text { Install energy efficient lighting }\end{array}$ & $\begin{array}{r}113 \mathrm{~kg} \\
1,231 \mathrm{~kL} \\
5,010 \mathrm{kWh} \\
\end{array}$ & $\begin{array}{r}\$ 83 \\
\$ 513 \\
\$ 194 \\
\end{array}$ & $\begin{array}{r}\$ 0 \\
\$ 583 \\
\$ 3,045 \\
\end{array}$ & $\begin{array}{r}\text { Immediate } \\
1.1 \\
16.0 \\
\end{array}$ \\
\hline Apartment Complex & $\begin{array}{l}\text { Retrofit complex lighting } \\
\text { Retrofit renters' lighting } \\
\text { Wrap hot water heaters } \\
\text { Heaf pool and spa with solar } \\
\text { Implement a recycling program }\end{array}$ & $\begin{array}{r}61,650 \mathrm{kWh} \\
1,087,614 \mathrm{kWh} \\
52,241 \mathrm{kWh} \\
13,056 \mathrm{~L} \\
15,422 \mathrm{~kg} \\
\end{array}$ & $\begin{array}{r}\$ 2,676 \\
\$ 47,203 \\
\$ 2,246 \\
\$ 5,139 \\
\$ 826 \\
\end{array}$ & $\begin{array}{l}\$ 4,530 \\
\$ 1,524 \\
\$ 3,531 \\
\$ 4,320 \\
\$ 7,168 \\
\end{array}$ & $\begin{array}{r}1.7 \\
<1 \text { month } \\
1.6 \\
0.8 \\
8.7 \\
\end{array}$ \\
\hline Construction Firm & $\begin{array}{l}\text { Purchase bulk oils and fluids } \\
\text { Install a parts washer } \\
\text { Remove fuel tank } \\
\text { Install an oil water separator }\end{array}$ & $\begin{array}{r}5,489 \mathrm{~L} \\
303 \mathrm{~L} \\
\text { Reduced spills } \\
\text { Not available } \\
\end{array}$ & $\begin{array}{r}\$ 7,600 \\
\text { Not available } \\
\text { Not available } \\
\text { Not available } \\
\end{array}$ & $\begin{array}{r}\$ 0 \\
\text { Not available } \\
\text { Not available } \\
\$ 11,300\end{array}$ & $\begin{array}{r}\text { Immediate } \\
\text { Not available } \\
\text { Not available } \\
\text { Not available } \\
\end{array}$ \\
\hline Supermarket & $\begin{array}{l}\text { Install energy efficient lighting } \\
\text { Recycle plasticwrap } \\
\text { Insulate refrigerators }\end{array}$ & $\begin{array}{r}36,700 \mathrm{kWh} \\
21 \mathrm{~m}^{3} \\
74,000 \mathrm{kWh}\end{array}$ & $\begin{array}{r}\$ 1,460 \\
\$ 105 \\
\$ 2,960 \\
\end{array}$ & $\begin{array}{r}\$ 524 \\
\$ 80 \\
\$ 1,160 \\
\end{array}$ & $\begin{array}{l}0.4 \\
0.8 \\
0.4\end{array}$ \\
\hline Autobody Shop & $\begin{array}{l}\text { Distill solvent } \\
\text { Use environmental absorbent } \\
\text { Recycle cardboard }\end{array}$ & $\begin{array}{r}284 \mathrm{~L} \\
23 \mathrm{~kg} \\
3 \mathrm{~m}^{3} \\
\end{array}$ & $\begin{array}{r}\$ 1,750 \\
\$ 20 \\
\$ 798 \\
\end{array}$ & $\begin{array}{r}\$ 5,300 \\
\$ 0 \\
\$ 0 \\
\end{array}$ & $\begin{array}{r}3.0 \\
\text { Immediate } \\
\text { Immediate } \\
\end{array}$ \\
\hline Printing and Graphics Firm & $\begin{array}{l}\text { Reuse paper cartons } \\
\text { Replace computer } \\
\text { Recycle toner cartridges } \\
\text { Use alternative 3-D Butyl Cleaner } \\
\text { Use alternative Formula } 707 \\
\text { Recycle paper and cardboard } \\
\text { Install a chemical odor filter }\end{array}$ & $\begin{array}{r}340 \mathrm{~kg} \\
7 \mathrm{~kg} \\
14 \mathrm{~kg} \\
140 \mathrm{~kg} \\
151 \mathrm{~kg} \\
910 \mathrm{~kg} \\
\text { Not applicable }\end{array}$ & $\begin{array}{r}\$ 340 \\
\$ 344 \\
\$ 0 \\
\$ 576 \\
\$ 565 \\
\$ 0 \\
\text { Not applicable } \\
\end{array}$ & $\begin{array}{r}\$ 25 \\
\$ 554 \\
\$ 0 \\
\$ 0 \\
\$ 0 \\
\$ 0 \\
\$ 524 \\
\end{array}$ & $\begin{array}{r}0.1 \\
1.6 \\
\text { Not applicable } \\
\text { Immediate } \\
\text { Immediate } \\
\text { Not applicable } \\
\text { Not applicable } \\
\end{array}$ \\
\hline Landscaping Firm & $\begin{array}{l}\text { Improve housekeeping practices } \\
\text { Install evapotranspiration system } \\
\text { Recycle paper and plastic }\end{array}$ & $\begin{array}{r}\text { Not available } \\
\text { Not available } \\
515 \mathrm{~kg}\end{array}$ & $\begin{array}{r}\$ 500,000 \\
\$ 8,125,000 \\
\text { Not available }\end{array}$ & $\begin{array}{r}\$ 50,000 \\
\$ 4,820 \\
\$ 790\end{array}$ & $\begin{array}{l}\text { When Sold } \\
\text { Immediate } \\
\text { Not available }\end{array}$ \\
\hline
\end{tabular}




\section{Data Trends}

Through the assessment process, four general types of source reduction practices were identified including procedure changes, equipment modification, product substitution, and good housekeeping practices. These all were exceptional initiatives compared to traditional end-of-the-pipe controls. They accomplished waste stream reductions, worker protection, and preservation of the environment. They also produced impressive savings by cutting raw materials usage and reducing future potential liabilities. Eight of the 15 source reduction initiatives were simple to implement with no capital investment and therefore an immediate payback (see Table 6). The average payback period was 3 months. Source reduction was clearly the first choice for implementation as businesses move from the traditional command and control to voluntary action linking the environment and the economy.

Table 6 Source reduction related opportunities and their related cost savings and payback periods.

\begin{tabular}{lrr}
\hline Source Reduction Opportunities & Cost Savings & Payback (yrs) \\
\hline Install an evapotranspiration system & $\$ 8,125,000$ & Immediate \\
Purchase bulk oils and fluids & $\$ 7,600$ & Immediate \\
Use alternative 3-D Butyl Cleaner & $\$ 576$ & Immediate \\
Use alternative Formula 707 & $\$ 565$ & Immediate \\
Use post-consumer absorbent & $\$ 290$ & Immediate \\
Use environmentally safe ice melt & $\$ 83$ & Immediate \\
Filter with alternative product & $\$ 68$ & Immediate \\
Use environmental absorbent & $\$ 20$ & Immediate \\
Improve solvent use practices & $\$ 772$ & $<1$ month \\
Segregate infectious waste & $\$ 27,750$ & 0.1 \\
Duplex copies and recycle & $\$ 5,095$ & 1.1 \\
Install toilet adaptations & $\$ 513$ & 1.1 \\
Replace computer & $\$ 344$ & 1.6 \\
Improve housekeeping practices & $\$ 500,000$ & When sold \\
Remove fuel tank & Not available & Not available \\
\hline
\end{tabular}

Recycling initiatives comprised two categories: 1) material recovery/reclamation, and 2) waste exchanges. All but two opportunities demonstrated a payback period of 3 years or less. 
The long payback period associated with implementation of a recycling program and installation of a wastewater recycling system was due primarily to high capital equipment costs. Although in most cases recycling requires energy for developing a new product, it is a viable solution for waste materials. A comparison of the recycling opportunities is listed in Table 7 showing an average payback period of 4 years.

Table 7 Recycling opportunities and their related cost savings and payback periods.

\begin{tabular}{lrr}
\hline \multicolumn{1}{c}{ Recycling Opportunities } & Cost Savings & Payback (yrs) \\
\hline Recycle cardboard & $\$ 798$ & Immediate \\
Reuse paper cartons & $\$ 340$ & 0.1 \\
Recycle plasticwrap & $\$ 105$ & 0.8 \\
Crush oil filters & $\$ 670$ & 1.9 \\
Distill solvent & $\$ 1,750$ & 3.0 \\
Implement a recycling program & $\$ 826$ & 8.7 \\
Recycle wastewater & $\$ 5,340$ & 13.3 \\
Recycle toner cartridges & $\$ 0$ & Not applicable \\
Recycle paper and cardboard & $\$ 0$ & Not applicable \\
Install a parts washer & Not available & Not available \\
Install an oil water separator & Not available & Not available \\
Recycle paper and plastic & Not available & Not available \\
\hline
\end{tabular}

Energy reduction and conservation measures ranged from a short payback period of less than one month to exceptionally long payback periods of 16 and 23 years (see Table 8). The average payback period was 6 years. The cost of electricity in the city of Richland is relatively inexpensive compared to the rest of the United States. Because of the low rates, it was difficult to provide a short payback for many of the initiatives. Those instances where the payback periods were less than 2 years were due primarily to the source of energy consumed and the length of time the source was operational. The longer the source consumed energy, the shorter the payback period. For example, in the case of the lighting retrofit for bathroom ballasts and lamps, the length of time the lights were on was 25 -percent of a 15 hour time period. 
Table 8 Energy recovery opportunities and their related cost savings and payback periods.

\begin{tabular}{lrr}
\hline \multicolumn{1}{c}{ Energy Recovery Opportunities } & Cost Savings & Payback (yrs) \\
\hline Retrofit renters' lighting & $\$ 47,203$ & $<1$ month \\
Insulate refrigerators & $\$ 2,960$ & 0.4 \\
Install energy efficient lighting & $\$ 1,460$ & 0.4 \\
Heat pool and spa with solar & $\$ 5,139$ & 0.8 \\
Wrap hot water heaters & $\$ 2,246$ & 1.6 \\
Retrofit complex lighting & $\$ 2,676$ & 1.7 \\
Install energy efficient lighting & $\$ 612$ & 6.6 \\
Paint roof with reftective coating & $\$ 415$ & 9.6 \\
Install energy efficient lighting & $\$ 194$ & 16.0 \\
Insulate tanks, chillers and piping & $\$ 1,150$ & 23.0 \\
\hline
\end{tabular}

Treatment techniques were among the least attractive options evaluated as the payback period for these opportunities ranged from 2.8 to 9.7 years due largely to waste management practices as opposed to waste minimization initiatives. The average payback period related to treatment techniques was 6.3 years. The treatment opportunities are summarized in Table 9 .

Table 9 Treatment opportunities and their related cost savings and payback periods.

\begin{tabular}{lrr}
\hline \multicolumn{1}{c}{ Treatment Opportunities } & Cost Savings & Payback (yrs) \\
\hline Install equalization tank & $\$ 6,900$ & 2.8 \\
Implement dissolved air flotation & $\$ 17,000$ & 9.7 \\
Install a chemical odor filter & Not applicable & Not applicable \\
\hline
\end{tabular}

Overall, the results of this study confirm the priorities that the U.S. Environmental Protection Agency (USEPA) established in the Pollution Prevention Act of 1990 (1990). At the top of the hierarchy is source reduction, followed by recycling, energy recovery, treatment, and environmentally sound disposal. Figure 22 depicts the average payback period by each of the methods in the hierarchy. Source reduction opportunities that eliminated waste achieved payback between one and two years, with most seeing immediate results. As the opportunities move down the hierarchy, the payback periods are generally longer. Source reduction opportunities identified the largest annual cost savings as well. 


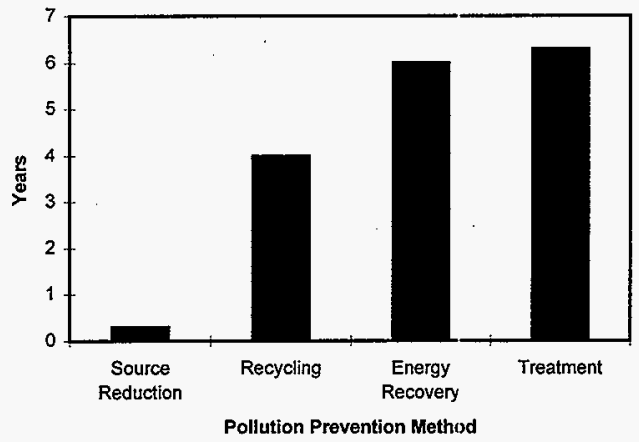

Figure 22 Average payback period by pollution prevention method.

\section{Assessment Comparison}

Two of the firms, the supermarket and the hotel, were part of a large corporate organization. Although implementation funds may be more easily identified for these firms, actual implementation required corporate agreement which may be time consuming. On the other hand, once corporate agreement is achieved, more operations within the corporation will achieve the waste reduction and, therefore, the pollution prevention opportunities will have more global and greater impact. Some easily implemented opportunities such as recycling batteries and guest soaps could be initiated as soon as they were identified as no start-up costs were associated with these initiatives.

The commercial laundry evaluated in this study accepted dirty laundry such as rags and uniforms from four other businesses that were studied. The discharge problems the commercial laundry was experiencing was from the inputs (i.e., dirty rags and uniforms) to their process, particularly rags. To assist in minimizing problems at the commercial laundry informal 
recommendations were addressed. For example, at the automotive repair shop, one verbal suggestion was to limit the saturation of grease and oil on the shop rags. The hotel on the other hand, operated its own laundry for the hotel laundry only and it was comparable in efficiencies and outcomes with the commercial laundry except in the oil and grease content. The commercial laundry generated wastewater with oil and grease whereas the hotel did not. Equipment in both firms was approximately 20 to 25 years old.

Several of the companies, such as the medical clinic, the automotive repair shop, the construction firm, the autobody shop, and the printing and graphics firm, relied on waste management firms for hazardous waste disposal and they all used the same service. This dependence was for compliance only and the businesses did not particularly concern themselves with any further pollution prevention action for these waste streams. Furthermore, many of these firms did not know any other techniques available other than waste management. Before the assessment was conducted, these businesses were, for the most part, content having someone else manage and dispose of their waste whether it was recycled offsite or disposed of prior to treatment. However, during and after the study, some of the businesses were surprised to realize the high cost for waste management. This was especially true in the case of the medical clinic where the managers did not realize their segregation practices had a high impact on their budget.

Most of the companies assumed their processes and activities were effective, however, they were unaware of the smaller inefficiencies such as leaving copy machines on when the business was closed, using improper segregation techniques, permitting solvent evaporation, making single-sided copies, installing inefficient lighting, allowing unauthorized use of thermostats, and conducting poor housekeeping practices. Inefficiencies identified at the apartment complex included inefficiencies due to poor equipment selection during construction. 
These inefficiencies included purchasing magnetic ballasts and lamps and water heaters over 17 years old with little insulation. The medical clinic was recognized as having the most inefficiencies, although other firms had sinilar problems. The winery was considered the most efficient. The study revealed plainly that the more costly the product or service, the more efficient the process. Furthermore, where raw materials and disposal costs are inexpensive, the greater the allowance for inefficiencies. This is no exception for the winery studied in this report. The cost to the winery for raw materials was high as a large variety of chemicals and other additives were used. The winery's use of raw materials was exceptional as very little solid waste was generated, and for the waste that was generated, the majority was reused as compost on the vineyard.

Eight of the businesses identified common problems associated with recycling commodities such as cardboard, white ledger paper, newspaper, glass, scrap metal, and pallets. Each business agreed that they would recycle these items if a pickup service were provided at no charge. The winery was already delivering their recyclables to the local recycler. The city of Richland has drop boxes available in several areas, but they are not for commercial use. The only method available for commercial businesses is to take cardboard, glass, white ledger paper, and newspaper, to a local recycling processor themselves. Pallets and scrap metal must be picked up by a scrap metal dealer or taken to a salvage yard.

The environmental regulations governing industry have traditionally prescribed technical solutions which inhibit innovation. ${ }^{(26)}$ The commercial laundry was subject to this command-and-control philosophy and, because treatment technologies were industry-standard,

(26) Personal communications from P. Irving, Richland, WA, 30 January 1997. 
two of the opportunities evaluated were of a treatment nature. This philosophy limited flexibility and, consequently, the payback periods were exceedingly high.

Conversely, the author believes that regulators fail to regulate where there is a viable and technological solution available to minimize waste. For example, the automotive repair shop was interested in crushing oil filters for recycling both the oil and the filter. Oil filter crushers cost between $\$ 1,500$ and $\$ 3,000$ and eliminated an estimated disposal fee of $\$ 545$ per 1,000 oil filters. The USEPA has ruled that oil filters can be placed in a sanitary landfill after draining for 24-hours; however the filter still retains approximately 44-percent of the oil in the filter originally. ${ }^{(27)}$ This has effectively limited the incentive for the automotive repair shops to implement this initiative as the annual cost savings was less than $\$ 700$.

\section{Comparison of Project Results to Other Pollution Prevention Programs}

Studies show that industries have significant opportunities to reduce or prevent pollution at the source with cost-effective changes in production, operation, and raw materials use. Leuteritz and Gold (1995) showed that 25-percent of all source reduction activities require no capital investment for implementation, and of those that require capital, 50-percent of the investments were recouped in savings on average, in less than 18 months.

The pollution prevention assessments conducted for this study exceeded that standard, identifying that 62-percent of the source-reduction activities required no capital investment. This study showed that the investments would be recovered within two years for those opportunities requiring capital investments. This indicates that small businesses may have more opportunity than larger firms for immediate payback, as the impact of their costs are more readily felt. This

${ }^{(27)}$ Brochure distributed by Safety-Kleen, Form number 91786, 1996. 
is especially true for those initiatives related to improved business practices such as good housekeeping.

Another such study was conducted at Colorado State University. ${ }^{(28)}$ This study evaluated energy conservation and pollution prevention opportunities at four manufacturing plants in Colorado. The average payback period for 33 opportunities was 1.3 years. The overall payback period for the 40 opportunities in this study was 3 years. The difference in payback periods could be caused by several factors including: 1) difference in natural resource costs, 2) type of opportunity identified, and 3) type and size of business evaluated.

The USEPA developed industry-specific checklists that provided ideas for achieving pollution prevention through good operating practices (USEPA 1992). These initiatives include: waste segregation, preventive maintenance programs, training and awareness programs, effective supervision, employee participation, production scheduling and planning, and cost accounting and allocation. The opportunities investigated in this study recognized several of the good operating recommendations that were developed by the USEPA.

The checklist recommendations for the medical clinic assessment included segregating infectious waste from solid sanitary waste. Also included was awareness training for the medical staff. The preventative maintenance program recommended for the automotive repair shop required relocating two solvent tanks side by side to minimize the solvent cleaning frequency. The medical clinic was recommended to install locking covers on the thermostats to discourage changing the thermostat setting which would increase energy consumption.

Another checklist for all industries developed by the USEPA details approaches to

${ }^{(28)}$ Letter from H.W. Edwards, Colorado State University, Fort Collins, CO, 12 January 1994. 
pollution prevention in areas related to material receiving, raw material and product storage, and operation and process changes (USEPA 1992). The checklist was compared against each of the opportunities identified in this study. The comparison revealed that, under the "material receiving" category, replacing diatomaceous earth with a post-consumer absorbent for the automotive repair and autobody shops provided an opportunity to switch to a less hazardous raw material. Additionally, a recommendation to the winery was to use an alternative product to filter the wine. Two opportunities for the printing and graphics firm recommended using alternative non-hazardous products instead to the existing washing process. Within the same category, another material receiving opportunity included purchasing bulk oils and fluids for the construction firm.

Numerous opportinities were identified in this study under the category of "raw material and product storage." These opportunities included: 1) recycling wastewater at the commercial laundry; 2) crushing oil filters at the automotive repair shop; 3) implementing a recycling program at the apartment complex; 4) installing a parts washer to recycle solvent and installing an oil water separator for recycling water at the construction firm; 5) recycling plasticwrap at the supermarket; 6) distilling solvent and recycling cardboard at the autobody shop; 7) reusing paper cartons, recycling toner cartridges, and recycling paper and cardboard at the printing and graphics firm; and 8) recycling paper and plastic at the landscaping firm.

Operation and process changes included: 1) improving solvent use practices at the automotive repair shop, 2) duplexing copies at the medical clinic, 3) replacing a computer at the printing and graphics firm, and 4) improving housekeeping practices and installation of a drip irrigation system at the landscaping firm. 
Energy-conservation practices were also addressed. Among those initiatives were: 1) improved housekeeping practices; 2) using more efficient motors; 3) using energy efficient heating and refrigeration; 4) improving or increasing insulation; and 5) using lower wattage lamps and/or ballasts. Five of the opportunities investigated in this study related to using lower wattage lamps and/or ballasts. Those opportunities were typically a complete lighting retrofit. The remaining energy-conservation initiatives related to improving or increasing insulation by wrapping tanks and painting a roof with reflective roof coating.

No treatment opportunities were compared to the checklist since the USEPA does not consider treatment technologies to be a pollution prevention activity and, instead, considers treatment a waste management activity.

\section{Survey Results}

An evaluation of the pollution prevention program was hand-delivered to each of the 11 businesses that participated in the study. Six of the 11 businesses responded to the survey, a 55-percent response rate. Table 10 describes the various reasons the businesses chose for and against implementation. The businesses were asked to rank the top 5 reasons for and against implementation. The results were added together for each of the reasons and summarized. It was not surprising that for most of the businesses, low up-front cost was a reason for implementing while high cost was a reason for not implementing. A business' desire to reduce costs was the main factor as the number of businesses selecting cost factors for and against implementing was half in both cases. On the other hand, many businesses selected other reasons for and against implementation. Other than the desire to reduce costs, the most important factor appeared to be time to implement which can indeed have an impact on the bottom-line. 
Table 10 Factors for and against implementation of pollution prevention initiatives.

\begin{tabular}{lcc}
\hline \multicolumn{1}{c}{ Reason } & $\begin{array}{c}\text { Selected For } \\
\text { Implementing }\end{array}$ & $\begin{array}{c}\text { Selected For Not } \\
\text { Implementing }\end{array}$ \\
\hline Initial Investment Cost* & 5 & 6 \\
Payback Period* $^{*}$ & 5 & 4 \\
Annual Cost Savings* & 5 & 3 \\
Time to. Implement & 3 & 5 \\
Reduce Regulatory Burden & 2 & 3 \\
Improve Worker Health and Safety & 3 & 1 \\
Reduce Impacts to Environment & 3 & 3 \\
Improve Public Image & 2 & 1 \\
Other & 0 & $1^{* *}$
\end{tabular}

* Denotes cost factors.

** Explanation provided: Payback period exceeds projected life of fixtures.

Table 11 identifies the overall satisfaction of the program with 1 indicating "very dissatisfied," 3 indicating. "neutral" and 5 indicating "very satisfied." It appears from the data collected that the pollution prevention program is above average and the businesses felt the results of the report were satisfactory and useful. In addition, all respondents said that they would recommend this assistance program to other small business owners and recommend that the city of Richland continue this service in the future. The type of firm the businesses recommended were businesses like their own.

Table 11 Scale of response to satisfaction and usefulness.

\begin{tabular}{lccccc}
\hline & \multicolumn{6}{c}{ Satisfaction with the Solutions } & Identified \\
\hline Scale: & 1 & 2 & 3 & 4 & 5 \\
Number of Businesses: & 0 & 0 & 0 & 4 & 2 \\
& & & & & \\
\hline
\end{tabular}

\begin{tabular}{lccccc}
\hline & \multicolumn{6}{c}{ Usefulness of the Information Provided } \\
\hline Scale: & 1 & 2 & 3 & 4 & 5 \\
Number of Businesses: & 0 & 0 & 0.5 & 3.5 & 2 \\
& & & & & \\
\hline
\end{tabular}


The number of pollution prevention. initiatives implemented at the close of this study was remarkable as many of the opportunities were implemented without a detailed analysis. For example, the commercial laundry implemented several ideas from the brainstorming session that were not selected for a detailed analysis because the firm felt they could consider those opportunities in-house. The majority of the opportunities implemented had little or no up-front cost associated with the improvement. The same reason is true for those ideas that the businesses plan to implement. On the other hand, those ideas that the firms do not plan to implement involve a high initial investment. Table 12 describes the implementation results. 
Table 12 Implementation results.

\begin{tabular}{l}
\hline \multicolumn{1}{c}{ Pollution Prevention Opportunities Implemented } \\
\hline Set thermostat controls and install locking covers \\
Purchase copier \\
Reduce temperature on hot water heaters \\
Install energy-efficient lighting \\
Recycle batteries \\
Reuse guest soaps \\
Reduce quantity of detergents used \\
Train customers on acceptable waste \\
Use lower pH products \\
Wash mats in cold water \\
$\quad$ Plan to Implement \\
\hline \\
Distill solvent \\
Recycle cardboard \\
Purchase bulk oils and fluids \\
Install a parts washer \\
Remove fuel tank \\
Install an oil water separator \\
Install toilet adaptations \\
Purchase environmentally safe ice melt \\
Recycle toner cartridges \\
Stop oiling dust mops
\end{tabular}

\begin{tabular}{l}
\hline \multicolumn{1}{c}{ Do not Plan to Implement } \\
\hline Install energy-efficient ballasts and lamps \\
Reuse paper cartons \\
Ozone technology \\
Acid-cracking \\
Chemical precipitation
\end{tabular}

\section{Barriers and Incentives to Pollution Prevention}

Numerous barriers as well as incentives for pollution prevention were identified during this study. The advantages to businesses who practice pollution prevention included: improved worker safety, reduced liabilities from improper disposal practices, reduced materials costs, reduced waste management and disposal costs, improved company image, and reduced environmental compliance. However, pollution prevention problems such as high capital 
implementation costs and cultural barriers were also noticed. The greatest incentive and barrier identified were economics.

Economic barriers occurred when a company could not make the capital investments essential to implementing pollution prevention practices. The landscaping firm and the commercial laundry did not have the initial investment necessary to implement environmentally sound waste management practices for compliance. Therefore, the waste generation practices continued. Conversely, the relatively short payback periods spurred some to plan to implement sometime in the future. Economics is what normally drives small businesses. Therefore, a pollution prevention initiative must show its economic validity for implementation to occur. Small business owners require an awareness of the true costs and benefits before implementing pollution prevention initiatives.

Makower (1993), states that "in 1992, U.S. companies spent $\$ 115$ billion complying with environmental regulations, according to the U.S. Environmental Protection Agency, about 2.1 percent of the gross national product." The cost of compliance is increasing for companies. Without sufficient analysis of costs and benefits, companies could be spending more than necessary on environmental improvements that bring little benefit, and not enough on others that could produce substantial improvements. The pollution prevention assessment method (USDOE 1996b) allows business owners to see, first-hand, the true costs of the business operations, including environmental costs.

Initiating environmentally sound practices can improve a company's image as was seen in the cases of the commercial laundry and the landscaping firm. The benefit of improved public relations was identified as one of the benefits in the cost benefit analysis for the commercial laundry. As the public becomes more aware of the environmental problems and solutions, a 
companies' environmental image will become more important. Furthermore, although not included in the assessment, all the opportunities identified, once implemented, will improve the small businesses' environmental image. According to the "1996 Green Gauge Report" (Roper Starch Worldwide 1996), 1 in 8 Americans assigns top concern status to the environment. Another survey conducted by Environmental Research Associates noted that consumers consider environmental attributes more important than brand names and look for environmental information on labels at least 50-percent of the time. ${ }^{(29)}$ Therefore, promoting the initiatives to their customers should add to their bottom line through increased sales.

Although the assessments revealed reductions in disposal and utility costs, reduced liabilities, and improved worker safety and health, implementation will require a paradigm shift. A pollution prevention initiative's economic viability and potential payback, while certainly compelling, do not guarantee that the initiative will be implemented (Marchetti et al. 1996). Ultimately, successful implementation depends on overcoming cultural barriers. The primary cultural barrier identified reflected a mind-set deeply rooted in the generation, treatment, and management of waste. Many of the small businesses were conducting business in much the same manner as when they were established 25-30 years ago. Then, business owners did not normally look at waste as a resource or a source of potential cost. Rather, it was part of the process and was managed accordingly, usually with little regard for the environment.

Overcoming these barriers requires fundamental changes in thinking and decision making as well as communicating pollution prevention to everyone in the business. The small businesses relying on waste management firms to handle their waste must see this not as an end to their

(29) Text report from Environmental Packaging Homepage, http://www.thompson.com/tpg/enviro/pack/packjan.html. 
waste, as it is removed from the site, but rather as an opportunity for eliminating up-stream pollution.

Businesses must anticipate, recognize, and meet the inevitable challenges to pollution prevention that are keys to successful implementation. Pollution prevention initiatives that cannot overcome economic and cultural barriers will not normally be implemented. 


\section{Chapter 4: Conclusion}

\section{Lessons Learned}

This study effectively demonstrated that the U.S. Department of Energy

(USDOE)-developed Pollution Prevention Opportunity Assessment (P2OA) process provides an effective base on which to build a tool for small business to demonstrate cost effectiveness through reduced expenditures for utilities, raw materials usage, and waste management costs. The tool employed was changed only slightly to provide a more amiable presentation for small business owners. The revised process was not only effective in substantiating savings in waste reduction and costs, but the product was a succinct method that was easily understood by the business community.

The average payback period for the 40 opportunities evaluated in this study was 3 years. Over 60-percent of the source reduction initiatives required no capital investment and that for those opportunities requiring capital investments, the investment was recoverable within 2 years. Since cost was identified as a driving force for implementation, showing the business owner the payback period through the pollution prevention assessment was justification for or against implementation.

The combined assessments demonstrate that small businesses can benefit by conserving energy and reducing waste. Furthermore, the USDOE P2OA method was useful in calculating the annual waste volume reduction, annual cost savings, and payback period. Benefits include reduced expenditures for utilities, raw materials, and waste management. Implementation of the 
pollution prevention opportunities recommended can generate annual cost savings that are sufficient for a timely recovery of the initial investments.

Conducting pollution prevention assessments for small business provided several lessons learned that are summarized below.

Effective communication with the owner is essential. The leader of the assessment team must gain the trust and respect of shop personnel at the introductory meeting. Understanding the owner's or manager's environmental priorities and pollution prevention goals is helpful in guiding the assessment towards achieving actual implementation upon conclusion of the report.

Permitting the owner or manager the opportunity to select the pollution prevention options for further evaluation is pivotal for implementation and resulting waste reduction savings.

\section{A thorough understanding of the business activities provides the best} pollution prevention opportunities. Proper preparation ensures that the site visit proceeds efficiently. Preparation includes understanding the business operations before the walk through. Understanding the raw materials and the wastestreams associated with each step in the process is helpful in identifying potential areas for improvement. Federal, state, and local programs, as well as universities and trade associations have an assortment of industry-specific information that can provide a basis of understanding and identifying potential pollution prevention opportunities. 
Evaluate the owner's willingness to change. Implementation of the pollution prevention opportunities is the ultimate goal in the assessment process.

Understanding the owner's personal interest in the assessment is critical to the actual waste minimization and/or energy conservation. A disinterested owner will rarely be excited about purchasing capital equipment while a supportive owner will recognize the cost savings and implement the desired change immediately.

Expect the worst. Unforeseen circumstances such as the identification of a regulatory violation, must be handled with caution. Since the assessment is an opportunity to showcase the reduction of waste and energy conservation through a cost benefit analysis, it can be seen as a mechanism for managing the problem area.

Engage shop personnel in the process. The shop personnel are typically the individuals with the best ideas for waste minimization as these people see the waste generated on a day-to-day basis and recognize inefficiencies. The shop personnel should be included in the brainstorming session and tapped as a resource for identifying potential pollution prevention opportunities.

Identify all media pollution prevention opportunities. The cross-functional assessment team should have experts representing all media including air, land, and water for the most effective assessment. This holistic approach minimizes the 
chance of cross-media transfer and provides the business with a more thorough investigation of pollution prevention and energy conservation opportunities.

Emphasize source reduction. As has been identified in this research report, source reduction has a much greater payback than any of the other pollution prevention methods including recycling, energy recovery, and treatment. Source reduction opportunities should be considered the highest priority for investigation and should be communicated to the business owner for his/her consideration in selecting the opportunities for furthor investigation.

\section{Recommended Program Adjustments}

Several adjustments to the pollution prevention program were identified that were recommended for implementation in the years following this study. First, it is recommended that the program continue under the responsibility of the city of Richland's individual technical assistance programs that were developed for businesses to achieve energy and pollution prevention savings in the years to come.

A multimedia assessment scheme for identifying reduction initiatives related to air, land, and water, is recommended for future implementation. City of Richland and Benton County staff in the resource management, solid waste, hazardous waste, waste water treatment, and the air authority all conduct individual audits, assessments, surveys, and compliance inspections of local businesses. These teams have specialized skills that could be used cooperatively to reveal additional pollution prevention opportunities when looking at a businesses' operations and practices holistically. The Tellus Institute (1996) has termed this approach "Eco-Efficiency" as 
the next step for companies committed to becoming more competitive, more innovative, and more environmentally responsible. Figure 23 is a visual representation of holistic thinking to advance sustainable business practices. Identification of extra opportunities will provide additional potential cost savings to the businesses.

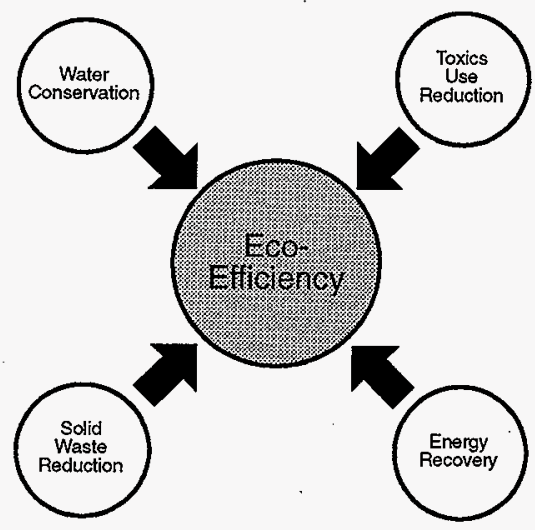

Figure 23 Eco-Efficiency as a holistic approach to business management practices.

The combination and integration of existing programs would provide two advantages. The first is that some information is common to both types of assessments. Examples of common information include description of the business and processes, characterization of the equipment, utility usage, and cost data. The second advantage is reduced cost for transportation to the business and reduced staff time for conducting the assessment, maximizing the city of Richland's technical assistance budget. The combination of cross-functional teams broadens the scope of the assessment by avoiding a single focus and potentially moving waste from one media to another. This integrated approach is a win-win situation for both the small business and 
Richland as less time will be spent in the business thereby reducing interruptions and preserving technical assistance time demands.

The USDOE's Industrial Assessment Centers, operated by local universities nationwide ${ }^{(30)}$ have demonstrated that it is feasible to include both pollution prevention and energy conservation in a single industrial assessment. These centers initially operated independently. Initially, the USDOE developed the centers called the "Energy Analysis and Diagnostic Centers" which conducted energy assessments only, while the USEPA-funded "Waste Minimization Assessment Centers" performed waste assessments. ${ }^{(31)}$ The two groups were merged into the Industrial Assessment Centers for conducting both energy conservation and waste reduction analyses.

Expanding the small business assessment program to include all businesses in Richland, Pasco, and Kennewick (Tri Cities), Washington would provide the infrastructure for industrial ecology and facilitate the interactions between businesses. Inclusion of the businesses in all three cities will allow for more diverse waste streams including agriculture and manufacturing. With these added types and quantities of businesses, which typically generate ongoing routine waste streams, industrial ecology principles can be practiced more readily.

Industrial ecology is essential to the Tri Cities development as new growth is desired due to the recent downsizing of the large government contract with the USDOE. As each city looks at attracting industry to their city, identification of industrial ecology will help position businesses to share waste and resources. This approach will provide growth while maintaining resources in an environmentally sustainable manner.

(30) Text report from Rutgers, The State University of New Jersey Homepage, http://oipea-www.rutgers.edu. (31) Text report from Rutgers, The State University of New Jersey Homepage, http://oipea-www.rutgers.edu. 
The assessments were well received, however, implementation will take time. Providing the assessment report is only the first step to saving the customer money and reducing waste and energy consumption. The customer must implement the recommendations in order to achieve the savings. While an assessment can take place any time during the year, many companies do not schedule money for such improvements until the beginning of their next fiscal year.

Moving from the assessment phase to implementation will require an established and easy program for requesting funding for capital expenditures through grants and loans. Numerous grant opportunities are available through federal and state programs and the city of Richland has 3 to 3:5 percent term loans available for energy-related improvements. Many of the grant applications require a detailed cost analysis that demonstrate energy efficient and pollution prevention techniques. The pollution prevention assessment provides a cost benefit analysis for use on the applications. The grant/loan requesting program should: 1) identify all applicable grants and loans applicable to Richland's small businesses; 2) provide a short description of each grant or loan; 3) list application deadlines as applicable; 4) describe the process for completing the application; and 5) follow-up by providing assistance in completing the application.

Numerous opportunities are available to small businesses for achieving pollution prevention and energy conservation measures. For example, the Associated Industries of the Inland Northwest have established a "Green Star" program for businesses implementing certain environmental practices and standards. ${ }^{(32)} \mathrm{A}$ business can be recognized as a "Green Star" company that can be used for promotional purposes and other public relations endeavors. Other

(32) Personal communications from K. Miktuk, Spokane, WA, 10 July 1998. 
partnership opportunities are available with the USEPA and the USDOE. Such programs require businesses to complete an environmental action plan and the federal agency provides free technical assistance.

Specific industries also have promotional programs such as the "Green Hotels Association" where hotels can receive recognition as an environmentally sound hotel by implementing certain practices. ${ }^{(33)}$ Many of the industry-specific programs require a small fee for participation.

A list of public and private partnership programs including short descriptions should be prepared for voluntary participation by small businesses in Richland. See Appendix F for a description for several of these related programs. This will be a valuable resource for small business owners as they may not have the time necessary to investigate these programs themselves. The program descriptions can be made available to anyone participating in a small business pollution prevention assessment.

A standard list of pollution prevention opportunities should be developed that can be easily implemented and do not require a cost benefit analysis. Examples include: purchasing recycled paper, using a "just-in-time" ordering system, transmitting information electronically, installing weather-stripping, turning off water and energy-consuming appliances when not in use, changing to reusable shipping containers, training staff in effective pollution prevention practices, and recycling paper, plastic, cardboard, glass, pallets, and scrap metal. An estimated cost for implementation should also be associated with each opportunity. This list of simple ideas can be supplementary to the pollution prevention assessment.

${ }^{(33)}$ Personal communications from P. Griffin, Houston, TX, 24 January 1997. 
It is not recommended to alter the pollution prevention assessment method as it was a simple method for calculating the annual cost savings, the annual waste reduction, and a payback period. Moreover, it was understandable by the business owners. The assessment process is not a "cookie-cutter" approach and each business has different needs and requirements from the assessment. The methods provided flexibility for the variety of business needs.

There are countless pollution prevention opportunities for small businesses in the city of Richland to help build environmentally responsible business practices into their production processes and activities. As demonstrated in this study, most companies can become far more profitable and productive by embracing pollution prevention. These opportunities offer an improved and new kind of bottom line-appropriate for $21^{\text {st }}$ century businesses!

\section{The Future of Pollution Prevention for Small Business}

The movement towards industrial ecology (Graedel and Allenby 1995) can help illuminate useful directions in which the business community as a whole could be changed. In an industrial ecology, industries are interacting systems rather than isolated components. This view provides the basis for thinking about ways to connect different waste-producing processes and activities. For example, using the waste from one business as a feedstock for another business demonstrates greater use of natural resources. The focus changes from merely minimizing waste from a single business process or activity to minimizing waste produced by a larger system - a business community.

The development of the pollution prevention framework for city of Richland's small business owners can easily be expanded to include the surrounding business community of Pasco and Kennewick that are located in eastern Washington. A program of this sort would be best 
suited for the systems approach associated with industrial ecology with a continued emphasis on collaboration with government, industry, academia, and other private and public institutions. Academia can play a central role in developing the concept of industrial ecology and institutionalizing its practice. Allenby and Richards (1994) notes that "only the university offers the possibility of a competent institution that has not become blinded or coopted by the current policy and management decision-making system." Developing industrial ecology systems is one step towards effecting change in the direction of sustainability.

The World Commission on Environment and Development labeled sustainable development in its 1987 report Our Common Future as "development that meets the needs of the present without compromising the ability of future generations to meet their own needs." If the United States is to succeed in sustainable management of natural resources, then industry, including small business, must play a key role by implementing poliution prevention and industrial ecology principles in their operations. 


\section{References}

Allenby, B.R. and Richards, D.J. 1994. The Greening of Industrial Ecosystems. National Academy Press, Washington, DC.

Business for Social Responsibility Education Fund (BSREF) and Climate Wise. 1996. Climate Wise Opportunities Assessment Guide. Business for Social Responsibility, Washington DC.

Cantwell, E. 1995. Pollution Prevention Opportunity Assessment Printed Circuit Board Manufacturing. UCRL-CR-122271, Lawrence Livermore National Laboratory, Livermore, CA.

Clean Washington Center. 1997. ReTAP Tool Kit Waste Diversion Cost Analysis Model. Clean Washington Center, Seattle, WA.

Emergency Planning and Community Right to Know Act of 1986. 1986. Public Law 99-499, 17 October 1986.

Graedel, T.E. and Allenby B.R. 1995. Industrial Ecology. Prentice Hall, Englewood Cliffs, NJ.

Houseman, J.C. 1993. "Case Study: Parker Pen's Total Quality Management Strategy to Prevent Pollution from Solvents." Pollution Prevention Review., 3(2) 187-195.

Kirsch, W.F., Looby, G.P., and Kirk, M.C. 1993. "Case Studies: How Four Manufacturers Improved Painting Operations to Reduce Waste." Pollution Prevention Review., 3(4) 429-436.

Leuteritz, K.J. and Gold, D. 1995. The NIST Manufacturing Extension Partnership Environmental Strategy. Air and Waste Management Association, 95-RA115.03, San Antonio, Texas.

Makower, J. 1993. The E-Factor. The Penguin Group, New York.

Marchetti, J.A., Poston, B., McPherson, E., and Webb, J.R. Winter 1996. "Overcoming the Barriers to Pollution Prevention." Pollution Prevention Review., 6(1) 41-50.

Pollution Prevention Act of 1990. 1990. Public Law 101-508 as amended by Public Law 102389, 6 October 1992.

Revised Code of Washington (RCW) Chapter 70.95. 1969, as amended. "Solid Waste Management Reduction and Recycling Act."

Revised Code of Washington (RCW) Chapter 70.95C. 1994. "Waste Reduction." 
Roper Starch Worldwide. 1996. 1996 Green Gauge. S.C. Johnson \& Son, Inc., Racine, Wisconsin.

Shrivastava, P. 1996. Greening Business: I'rofiting the Corporation and the Environment. Thomson Executive Press, Cincinnati, $\mathrm{OH}$.

Slater, W. 1991. "Big Opportunities in Small Business." Best's Review., 92 82-83.

Springer, J.S. Jr. 1992. Pollution Prevention Case Studies Compendium. EPA/600/R-92/046, U.S. Environmental Protection Agency, Cincinnati, $\mathrm{OH}$.

Tellus Institute. 1993. Pollution Prevention Financial Analysis and Cost Evaluation System for Microsoft Excel for Windows, Version 4.0. EPA/742-B-64-002, Tellus Institute, Boston, MA.

Tellus Institute. 1996. Environmental Perspectives. Tellus Institute, Boston, MA.

U.S. Department of Energy (USDOE) 1996a. Model Pollution Prevention Opportunity Assessment Guidance. DOE/DP/0136, USDOE, Kansas City, KS.

U.S. Department of Energy (USDOE) 1996b. Pollution Prevention Opportunity Assessments: A Training and Resource Guide. Publication \#DOE/RL-96-80 Richland, WA.

Underwood, J.D. 1993. "Going Green for Profit." Environmental Protection Agency Journal, EPA 175-N-93-021, 19(3) 9-13.

U.S. Environmental Protection Agency (USEPA). 1992. Facility Pollution Prevention Guide. EPA/600/R-92/088. Office of Research and Development, Washington, DC.

Wackernagel, M. and Rees, W. 1996. Our Ecological Footprint: Reducing Human Impact on the Earth. New Society Publishers, Gabriola Island, B.C.

Washington Administrative Code (WAC) 173-307. 1991. "Plans" Washington State Department of Ecology, Olympia, WA.

Washington State Department of Ecology (WDOE). 1993a. Pollution Prevention Planning in Washington State Businesses. Publication \$93-14, Washington State Department of Ecology, Olympia, WA.

Washington State Department of Ecology (WDOE). 1993b. Pollution Prevention Planning Guidance Manual. Publication \#91-2, Washington State Department of Ecology, Olympia, WA.

Washington State Department of Ecology (WDOE). 1995a. Washington's Environmental Health 1995. Publication \#95-700, Washington State Department of Ecology, Olympia, WA. 
Washington State Department of Ecology (WDOE). 1995b. Reducing Hazardous Wastes and Hazardous Substances in Washington: 1994 Annual Progress Report. Publication \#95-428, Washington State Department of Ecology, Olympia, WA.

Wigglesworth, D. A. 1988. Profiting from Waste Reduction in Your Small Business. Alaska Health Project, Anchorage, AK.

World Commission on Environment and Development. 1987. Our Common Future. Oxford University Press, New York. 


\section{Appendices}

Appendix A: Applicable Laws and Regulations 


\section{Applicable Federal and State Laws and Regulations for Washington State Small Businesses}

\section{Pollution Prevention Act of 1990}

On October 27, 1990, Congress passes the Pollution Prevention Act of 1990. The Congress declared as a national policy of the United States that "Pollution should be prevented or reduced at the source whenever feasible; pollution that cannot be prevented should be recycled in an environmentally safe manner, whenever feasible; pollution that cannot be prevented or recycled should be treated in an environmentally safe manner whenever feasible; and disposal or other release into the environment should be employed only as a last resort and should be conducted in an environmentally safe manner."

As one of the Environmental Protection Agency activities under the Pollution Prevention Act of 1990, the EPA administrator will assist in facilitating the adoption of source reduction principles by businesses. The strategy includes a clearinghouse, state matching grants, dissemination of information, an awards program, and technical assistance.

\section{Resource Conservation and Recovery Act}

In 1976, Congress passed the Resource Conservation and Recovery Act which directed the U.S. Environmental Protection Agency to develop and implement a program to protect human health and the environment from improper hazardous waste management practices. The program is designed to control the management of hazardous waste from its generation to its ultimate disposal-from "cradle-to-grave."

The Environmental Protection Agency first focused on large companies which generate the greatest portion of hazardous waste. Business establishments producing less than 1000 kilograms (2,200 pounds) of hazardous waste in a calendar month were exempted from most of the hazardous waste management regulations published by the Environmental Protection Agency in May 1980. In recent years, however, public attention has been focused on the potential for environmental and health problems that may result from mismanaging even small quantities of hazardous waste. For example, small amounts of hazardous waste dumped on the land may seep into the groundwater and contaminate the drinking water supply.

In November 1984, the Hazardous and Solid Waste Amendments to the Resource Conservation and Recovery Act were signed into law. With these amendments, Congress directed the Environmental Protection Agency to establish new requirements that would bring small quantity generators who generate between 100 and 1,000 kilograms of hazardous waste in a calendar month into the hazardous waste regulatory system. The Environmental Protection Agency issued final regulations for these 100 to 1,000 kilograms/month generators on March 24, 1986. 


\section{Title III of the Superfund Amendments and Reauthorization Act}

In 1986, the Superfund Amendments and Reauthorization Act was signed into law. Title III of the Superfund Amendments and Reauthorization Act is the Emergency Planning and Community Right-to-Know Act. Congress enacted this law in response to public concern about chemical accidents such as Bhopal, India where people lost their lives or suffered serious injury. Title III establishes requirements for federal, state, and local governments as well as for industry (both large and small businesses) regarding emergency response planning and everyone's rightto-know about hazardous chemicals in their community.

The requirements include preparation of a detailed chemical inventory, reporting hazardous substance spills, and providing information to local emergency planners. The State of Washington has adopted the federal Title I]I law and regulations (Washington Administrative Code Chapter 118-40). A generator must report if it exceeds the identified thresholds in any of the following sections: (1) Section 302-Emergency Response Planning; (2) Section 304 Emergency Release Reporting; (3) Sections 311 and 312-Hazardous Chemical Inventory Reporting; and (4) Section 313 Toxic Chemical Release Reporting

\section{The Hazardous Waste Management Act Revised Code of Washington Chapter 70.105 and 70.105A}

The purpose of this law was to establish a comprehensive state-wide framework for the planning, regulation, control and management of hazardous waste in order to prevent pollution to all media and conserve the natural resources of Washington state. This law was implemented with the Washington Administrative Code 173-303 Dangerous Waste Regulation. Revised Code of Washington Chapter $70.105 \mathrm{~A}$ was passed to revise hazardous waste fees by providing a waste reduction and recycling incentive.

\section{Washington's Hazardous Waste Reduction Act of 1990, Revised Code of Washington Title 70, Chapter 70-95C}

In the interest of protecting the public health, safety, and the environment, the legislature declared that "It is the policy of the state of Washington to encourage reduction in the use of hazardous substances and reduction in the generation of hazardous waste whenever economically and technically practicable." Furthermore, the Office of Waste Reduction encourages the voluntary reduction of hazardous substance usage and waste by providing technical workshops, a hotline, research and development programs, education, technical assistance, and an awards program.

The Pacific Northwest Hazardous Waste Advisory Council endorsed a goal of reducing the generation of hazardous waste by 50 -percent by 1995 . The legislature adopted this as a policy goal for the state of Washington but not a regulatory requirement in recognizing that many small businesses have already reduced the generation through appropriate hazardous waste reduction techniques and that many businesses have limited potential for significantly reducing the use and subsequent generation of hazardous wastes. 
Washington Administrative Code 173-303

This regulation implements the Revised Code of Washington Chapter 70.105, the Hazardous Waste Management Act of 1976 as amended in 1980 and 1983, and implements, in part, the Revised Code of Washington Chapter 70.105A, and Subtitle C of Public Law 94-580, the Resource Conservation and Recovery Act. The WAC 173-303 is called the Dangerous Waste Regulations" and provides the rules for designation and disposal of dangerous and extremely hazardous waste.

\section{Washington Administrative Code 173-307}

The 1990 legislature, through their passage of Washington's Hazardous Waste Reduction Act, established a policy to encourage reduction in the use of hazardous substances and hazardous waste generation whenever economically and technically practicable. A statewide goal of reducing the generation of hazardous waste by 50 percent by 1995 was set. The primary method the law uses to achieve this goal is requiring certain hazardous waste generators and hazardous substance users to prepare plans for voluntarily reducing hazardous substance use and hazardous waste generation. As mandated by law, the Washington State Department of Ecology developed a regulation to implement the requirements in the form of a plan and was adopted in the Washington Administrative Code, Chapter 173-307, Appendix H.

Under the Revised Code of Washington 70.95C.200, each generator generating more than 2,640 pounds of hazardous waste per year and each hazardous substance user must prepare a plan, including an executive summary for the voluntary reduction of the use of hazardous substances and the generation of hazardous wastes. Treatment storage and disposal facilities and recycling facilities are exempt. Additionally, generators are required to complete an annual progress report including a description of the progress made toward achieving the specific performance goal established in their plan. 
Appendix B: Brochure 


\section{TESTMONIALs...}

"Some of the products took off like wildfire the first month they were offered. Frankly, even we were surprised by the demand for low. toxicity products."

Joe Lucas, Inland Technology

"Our first concern is to reduce the amount of waste we generate from our own operations. Then, if industrial materials can be wisely reused instead of being disposed, everybody wins."

Mike Depow. Holnam, Lnc.

"We're so busy day to day, we didn't realize how these costs were adding up. Pollution Prevention analysis helps you step back and take a look at what's really going on."

Judy Setina-ware

Selfna Manufacturing Co;-Inc

\section{WGREASE PROTFIS}

\section{REDUCE POLIUTON}

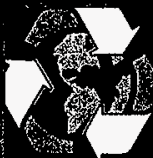

If you have a sinall business ant $\mathrm{watit}$. nonetofit

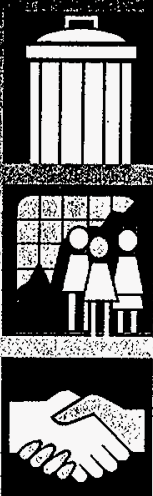

Program sponsored by:
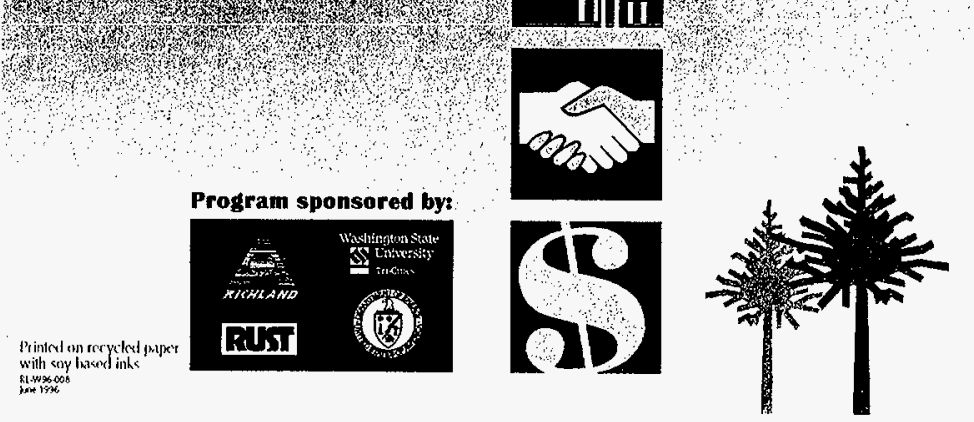

i
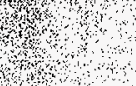

is 
somou गुmbso so spos playfip.ds

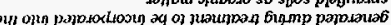

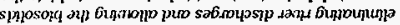
afluset fo wom

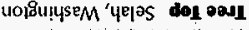

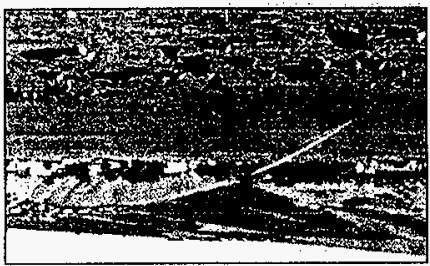

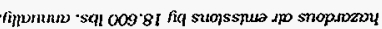

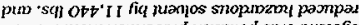

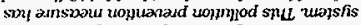

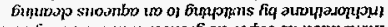

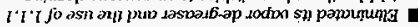

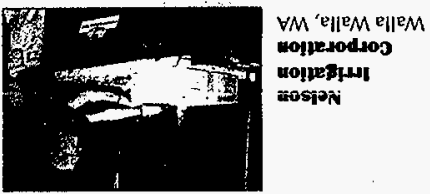

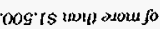
stinans pomuse zo ili painsat spuL pasmat pus pasum

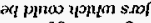

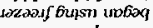
PuD jumbed xqu of subou buiss pexldois spuajos

Rods unpjoat of $\mathrm{mIS}$ manos 12 pastopur

$\forall M^{\prime} d r n g e$ nd

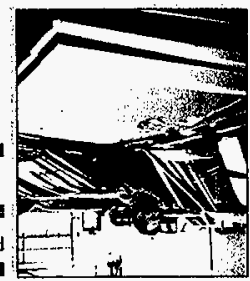

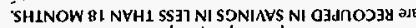

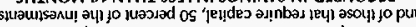

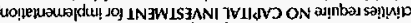

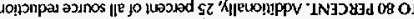
d? 18 3IS

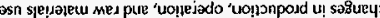
aм|

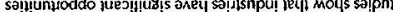

squamadinbor pefol paompan A ogeuy anqud panoudur $\mathrm{A}$ spsoo jesodspp paonpay $\mathrm{A}$ Apuponpoud panosdin Spsos peuonesado poonpay $/ \alpha$

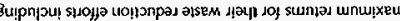

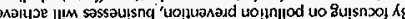

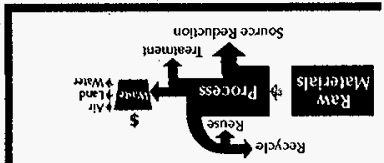

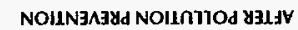

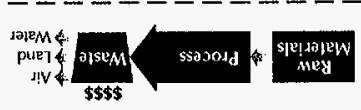

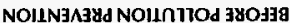

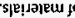

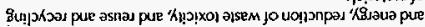

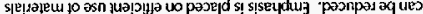

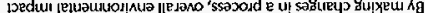

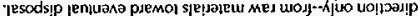
250 un s5วuls

SITnSJy SHבNITA

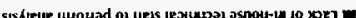
sookiopduo 001 uet) damad

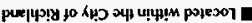

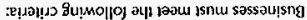

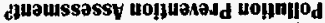
1500-0u $e$ do] orqf

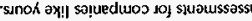

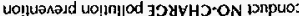

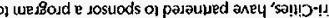
ze Rissan!un azels uolsu! 4 sem pue \%urduios

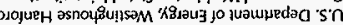

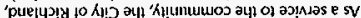

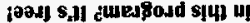
ojediplnded sossoujsnq feus ueo MoH

'au! uronog ay!

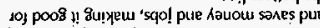

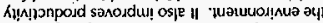

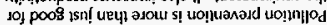

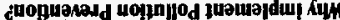

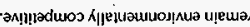

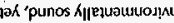

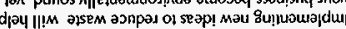
Hodoy juoussassy peut! ushy $M$ C 복 da-m에여 s!s גmol pue

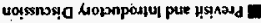
isapnjul ssajoJd juatussassy aul

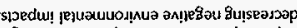

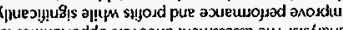

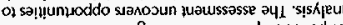

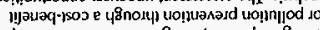

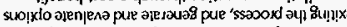

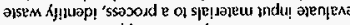

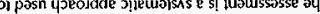

c]uวussass Holyuanodd uopn||Od e s! ley

JNT WOLOg 3hO4dWI

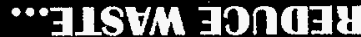




\section{APPLICATION...}

\section{POLLUTION PREVENTION}

\section{NO-COST ASSESSMENT}

\section{Application for Participation in} the No-Charde Assessment Prodram

The information will be reviewed to determine businesses for participation in the program.

Brsiness Name

Type of Business

Phone Number

Address

Contact Person

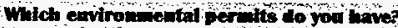

$\square$ Air $\square$ EPA Hazardous $\square$ Water Quality $\square$ Waste

Wich hamindons wastes do yo tenerato?

$\square$ Characteristic $\square$ comosive

Ignitable $\square$ Reactive

Please estinate how much waste you dispose of in the specified period by placind an " $\mathrm{X}^{\mathrm{m}}$ on the lines below.

ANNUAL

Hazardous

Waste

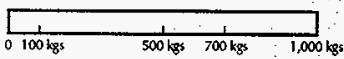

ANNUAL

Solid Waste

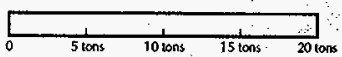

ANNUAL

Air Emission

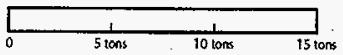

DAILY

Waste Water

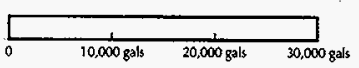


Pollution Prevention Opportunity Assessment

\author{
Pilot Study \\ Commercial Laundry
}




\section{Pollution Prevention Opportunity Assessment Worksheet 1 \\ Team and Activity Description}

\section{Date 06/10/96 \\ P2OA ID Code Laundry-1 \\ Facility Commercial Laundry}

Activity Washing Industrial Laundry

\begin{tabular}{|c|c|}
\hline Team Members (*Leader) & Telephone \\
\hline Mary Ann St. Martin & $943-7485$ \\
\hline Jill Engel-Cox & $372-0307$ \\
\hline Mary Betsch* & $372-1627$ \\
\hline
\end{tabular}

\section{Description of Activity to be Examined in this P2OA}

The Commercial laundry services industries such as hospitals, restaurants, grocery stores, bakeries, auto shops, and print shops in the Eastern Washington region. The majority of the laundry is rented to the customer. However, there is a small amount of drop off laundry. Dirty laundry is picked up from the various businesses and is dropped off at the back door where it is counted and sorted into two groups: industrial laundry which includes most of the colored laundry such as uniforms and shop towels, and linen laundry which includes the whites such as table cloths, aprons, bar towels, and sheets. The laundry is further sorted according to soil type from light soils to heavy soils. The linen laundry is usually light to heavy soils (polar grease) and the industrial laundry is medium to heavy soils (non-polar grease). The industrial laundry and the linen laundry each account for approximately $1 / 3$ of the laundry. The other $1 / 3$ is from dust control which includes mats and mops.

Once the laundry has been separated, it is ready to be washed. The laundry is loaded into washing machines and washed at a temperature between 150 and 170 degrees Fahrenheit. A wash cycle (formula) is picked according to the type of laundry. Powdered detergents are used in all operations. Liquid inject is used to measure and introduce ancillary products into wash wheels, such as Bleach, Tru Sour, Antichlor, and Fluf-It.

Powdered detergents used are as follows: (1) Prolong--it has a low $\mathrm{pH}$ and works well on nonpolar grease such as uniforms and mats; (2) Super Brite--this product has a high $\mathrm{pH}$ and works well on polar grease such as uniforms, linens, and towels; (3) Orthotex--this is a high $\mathrm{pH}$ product and is used in conjunction with SuperBrite to convert some of the polar grease from heavily soiled bar mops to a soap product. This is also used on burlap grill wipes for the same reason; and (4) Exact--it has a high pH and removes grease well on heavy non-polar grease such as shop towels. 
The liquid products are as follows: (1) Bleach--it is made up as needed and diluted to a $2 \%$ solution of available chlorine; (2) Antichlor--this product is used for neutralizing residual chlorine; (3) Tru Sour--a product for lowering the pH; and (4) Fluff-it--a fabric softener.

To keep effluent problems to a minimum, the non-polar loads are done individually while the other loads are being done in other washers.

The solids separator extracts the solids from the liquid that is generated during the washing process. The solids are captured in a shaker and disposed of as municipal solid waste.

Approximately two 5-gallon buckets of screened solid waste is collected daily. The liquid goes to a sump and then is discharged to the City of Richland Waste Water Treatment Plant. The heat from the hot water is recovered through a heat exchanger and is used to heat the inlet water. A flow meter determines the quantity of water discharged daily which is between 20,000 gallons and 30,000 gallons. Approximately two times a month new items are dyed in the washing machines. The dye is a non-hazardous product. There is no re-dying after the initial dye. After washing, the textiles go through an extractor process to remove as much water as possible to lower the drying time and BTU consumption.

Natural gas is used to operate a direct contact hot water heater (flame runs through the water) to heat the water to the required temperature. Natural gas is also used to operate a $100 \mathrm{hp}$ steam boiler which is used for heating water, finishing garments and linens, and for some plant heating in the winter.

From the extractor, the laundry is moved to the dryers which are powered with natural gas and electricity. There is one $200 \mathrm{lb}$. dryer and two $400 \mathrm{lb}$. dryers. The loads dry in 30 minutes to one hour.

Sometimes the laundry must be rewashed and it is sent back through the process. The clean laundry is sent to the finishing department where it is mended, ironed, or folded for disbursement out to the businesses again. If a piece of laundry is unusable, it is either thrown away or sold as rags. The flatwork ironer is steam heated and electrically powered. It is used for finishing linens, aprons, and sheets. The steam tunnel is used to finish garments. Each garment is placed on a hanger then sent through the steam tunnel for final pressing. In addition, a shirt press is used to finish uniform shirts.

At the dust control area, the mats are rolled and stored and the mops are oiled so that the dirt will adhere to the mop. The oil used is Diala ${ }^{\top \mathrm{M}}$ which is a non hazardous product. However, it increases the fats, oils, and grease content of the waste stream. The mops are wrapped in plastic bags before disbursement to the business. 
The Commercial Laundry Daily Discharge Quantities are as Follows:

Flow Rate

Biochemical Oxygen Demand (BOD)

Total Suspended Solids (TSS)

Oil and Grease

$\mathrm{pH}$
$73 \mathrm{gpm}$

$(60 \mathrm{~min} \times 8 \mathrm{hrs}=480.35,000$ gallons/day diviced by $480=73 \mathrm{gpm})$ 195 - $290 \mathrm{mg} / \mathrm{liter}$

$580 \mathrm{mg} /$ liter

$290 \mathrm{mg} / \mathrm{liter}$

Between 8 and 11.5 


\section{Commercial Laundry}

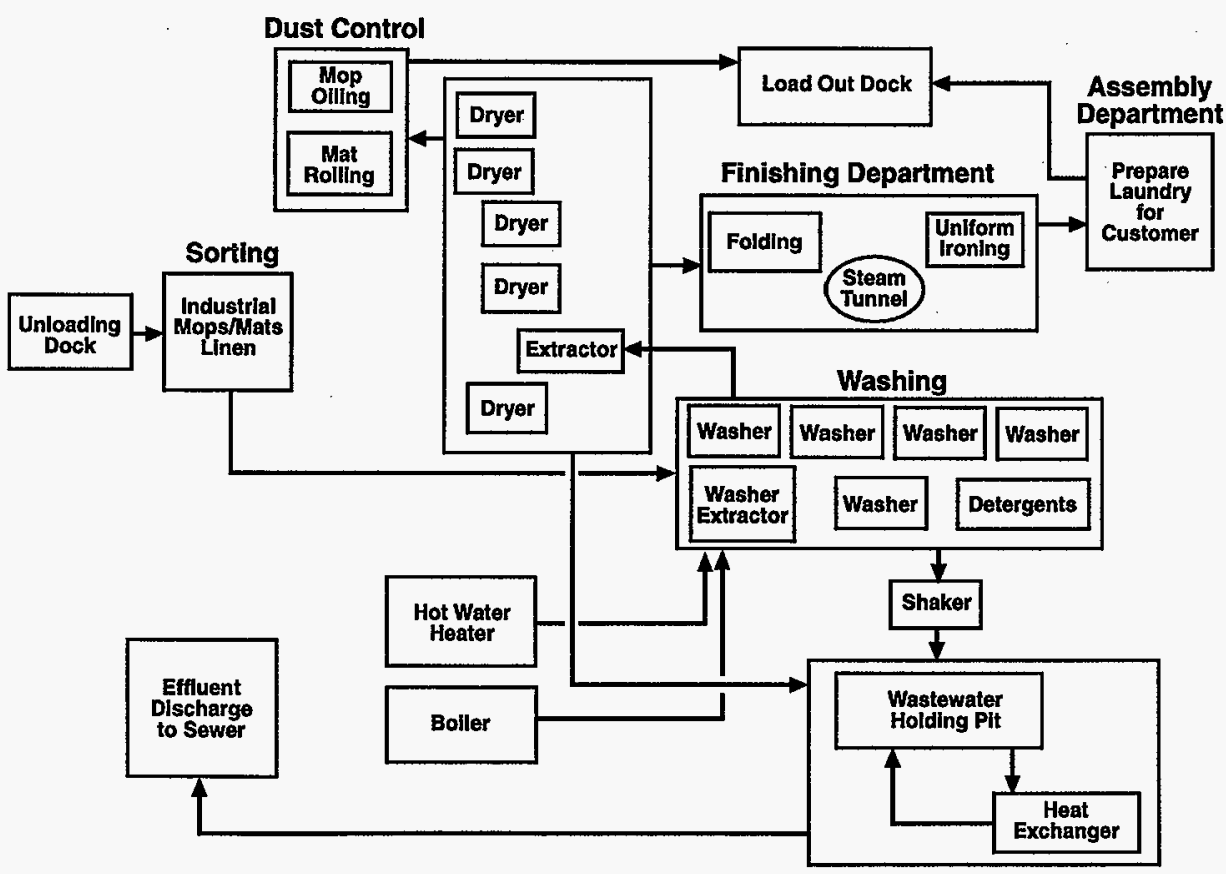




\section{Pollution Prevention Opportunity Assessment \\ Worksheet 2 \\ Activity Flow Diagram}

Date 06/10/96 P20A ID Code Laundry-1 Facility Commercial Laundry

Activity Washing Industrial Laundry

\begin{tabular}{|c|c|}
\hline \multicolumn{2}{|c|}{$\begin{array}{c}\text { Chemical and Radioactive } \\
\text { Inputs }\end{array}$} \\
\hline Name & Qty. \\
\hline Diala $^{\text {TM }}$ & 3.5 gals. \\
\hline Prolong & $50 \mathrm{lbs}$. \\
\hline Orthotex & $20 \mathrm{lbs}$. \\
\hline Super Brite & $60 \mathrm{lbs}$. \\
\hline Exact & $50 \mathrm{lbs}$. \\
\hline Fluf-It & $20 \mathrm{lbs}$. \\
\hline Tru-Sour & $60 \mathrm{lbs}$. \\
\hline Dye & 4 bags \\
\hline Antichlor & $20 \mathrm{oz}$. \\
\hline
\end{tabular}

\begin{tabular}{|lr|}
\hline \multicolumn{2}{|c|}{ Material Inputs } \\
\hline \multicolumn{1}{|c|}{ Name } & \multicolumn{1}{c|}{ Qty. } \\
\hline $\begin{array}{l}\text { Dirty Laundry } \\
\text { Hot Water }\end{array}$ & 35,000 lbs. \\
Hangers & 1,350 ea. \\
Plastic Wrap & $200 \mathrm{ft}$. \\
& \\
\hline
\end{tabular}

\begin{tabular}{|lr|}
\hline \multicolumn{2}{|c|}{ Energy Inputs } \\
\hline \multicolumn{1}{|c|}{ Name } & Qty. \\
\hline Natural Gas & 393 Therms \\
Electricity & $2,150 \mathrm{kWh}$ \\
& \\
& \\
& \\
& \\
\hline
\end{tabular}

\begin{tabular}{|c|}
\hline Activity \\
Washing Industrial Laundry \\
Activity Time Period \\
Daily (8 hours)
\end{tabular}

\begin{tabular}{|cc|}
\hline \multicolumn{2}{|c|}{ Product or Result Output } \\
\hline & \\
\hline Name & Qty. \\
\hline Clean Linens & $4,000 \mathrm{lbs}$. \\
Clean Mops/Mats & $4,000 \mathrm{lbs}$. \\
\hline
\end{tabular}

\begin{tabular}{|c|}
\hline Hazardous Waste Output \\
\hline Name \\
\hline \\
\\
\hline
\end{tabular}

\begin{tabular}{|lr|}
\hline \multicolumn{2}{|c|}{ Non-Hazardous Waste Output } \\
\hline \multicolumn{1}{|c|}{ Name } & Qty. \\
\hline Solids & $1.34 \mathrm{ft}^{3}$ \\
Waste Water & 35,000 gals. \\
\hline
\end{tabular}

\begin{tabular}{|c|}
\hline Radioactive Waste Output \\
\hline Name \\
\hline
\end{tabular}

\begin{tabular}{|c|}
\hline Mixed Waste Output \\
\hline Name \\
\hline
\end{tabular}

\begin{tabular}{|c|}
\hline \multicolumn{2}{|c|}{ Other } \\
\hline Name \\
\hline
\end{tabular}




\section{Pollution Prevention Opportunity Assessment \\ Worksheet 3 \\ Pollution Prevention Opportunity Description}

Date 07/22/96 P2OA ID Code Laundry-1 Facility Commercial Laundry

Activity Washing Industrial Laundry

P20 No. $1 \quad$ P2O Title Equalization Tank/pH Adjustment

\section{Current Practice}

No pre-treatment methods are currently employed at the Commercial laundry. Waste water is sent through a shaker screen and then to a sump which goes directly to the City of Richland Publicly Owned Treatment Works (POTW).

\section{Recommended Action}

Install a vertical, cone-bottom equalization tank and mixer with a 6,000 gallon capacity before neutralization. Flow equalization will balance out the highs and lows of the flow being discharged and the contaminant loadings as well. It is recommended to install an equalization tank that has at least three hours retention time. Install a finishing tank next for $\mathrm{pH}$ adjustment with an acid drip system. Sulfuric Acid is recommended as it is less expensive than other acids, does not contribute heavily to BOD, and will not corrode metal surfaces. However, sulfuric acid is an extremely hazardous substance. The Emergency Planning and Community Right to Know Act (40 CFR Part 355) specifies that no more than 1,000 lbs. of sulfuric acid can be on hand (the threshold planning quantity) at any one time. Assuming the Commercial laundry uses $98 \%$ sulfuric acid, with a density of 1.84 , this is approximately 65 gallons. Based upon information at other industrial laundries around the United States, Hydron Cetco estimates that the Commercial laundry will use approximately one 55-gallon drum of acid per month.

The sludge which accumulates on the bottom of the tank is acceptable for disposal in the municipal solid waste landfill upon approval from the Health Department and City of Richland.

The door to the wastewater room is 9'2" wide $x$ 7' 8 " high and the ceiling height in the room is 9'. However, there are two overhead beams that are open and the dimension between the two beams is 9'. The tank will fit between the two beams and will have a covered top.

The estimated quote provided by Hydron Cetco includes the following: 
- One 4,000 gallon carbon steel cone bottom equalization tank (7'-6" wide $\times 15^{\prime}$ high) with a two hp gear reduced mixer, stainless steel shaft and impeller. The equalization tank will be covered.

- One acid chemical feed pump will be provided along with $\mathrm{pH}$ controller and probe. The probe will be mounted in the equalization tank and the controller will be mounted on a control panel that will also control the chemical feed pump and equalization mixer. The chemical feed pump will be mounted on a shelf located on the side of the equalization tank.

\section{Calculation of Waste Reduction and/or Energy Savings}

This is a treatment technology and no in-plant waste reduction savings will be realized through this opportunity.

\section{Calculation of Annual Cost Savings \\ $\underline{\text { Costs }}$}

Chemicals: $\$ 3,675$

Hydron Cetco estimates that chemicals will cost no more than $\$ .50$ per 1,000 gallons processed. The Commercial laundry operates on the average 210 days/year with a flow of 35,000 gals/day.

35,000 gallons/day $\times \$ .50 / 1,000$ gallons $\times 210$ days/year $=\$ 3,675 /$ year

\section{Electricity: $\$ 258$}

The electricity rates in the City of Richland are as follows:

Summer Months: $\quad<20,000 \mathrm{kWh}=.0280$

$$
>20,000 \mathrm{kWh}=.0179
$$

Winter Months: $\quad<20,000 \mathrm{kWh}=.0320$

$$
>20,000 \mathrm{kWh}=.0240
$$

Service Charge: $\$ 12.50 /$ month

Demand Charge: $\$ 4.50 / \mathrm{kw}$ after the first $50 \mathrm{~kW}$

City Tax: $\$ 7.52 \%$

pH Control System/Mixer Electrical Requirements: 
Hydron Cetco estimates that the average draw is $1.8 \mathrm{~kW}$.

8 hours/day $\times 210$ days/year $\times 1.8 \mathrm{~kW}=3,024 \mathrm{kWh} /$ year

Summer Rate: $1,512 \mathrm{kWh} \times \mathbf{~} \$ 0.028 / \mathrm{kwh}=\$ 42 /$ year

Winter Rate: $1,512 \mathrm{kWh} \times \$ 0.032 / \mathrm{kwh}=\$ 48 /$ year

Service Charge: $\$ 12.50 /$ month $\times 12$ months/year $=\$ 150$

Tax: $(\$ 42+\$ 48+\$ 150) \times 0.0752 \operatorname{tax}=\$ 18 \operatorname{tax} /$ year

$\$ 240 /$ year $+\$ 18$ tax $/$ year $=\$ 258$

\section{Maintenance and Operations: $\$ 4,200$}

Hydron Cetco estimates that the average time involved in maintenance and operations is 1 hour per day. Production Engineers at the commercial laundry cost approximately $\$ 20 / \mathrm{hr}$. The commercial laundry operates on the average 210 days/year.

1 hour/day $\times \$ 20 / \mathrm{hr} \times 210$ days $/$ year $=\$ 4,200$

\section{Benefits}

\section{Elimination of Potential Fines: $\$ 750$}

The City of Richland Administrative Fine Policy which is currently in draft form, states that the maximum amount that can be imposed is $\$ 10,000$ per day for each violation. However, pretreatment violations are not created equally and requires a review of all surrounding facts in order to determine the appropriate enforcement response. Civil and criminal penalties can be sought for a single pretreatment violation. The focus of the calculation of the fine is focused on the seriousness, frequency, and persistence of the problem. Based upon The commercial laundry's demonstrated intent, the City of Richland Wastewater Treatment Plant personnel estimate that the initial fine imposed would be $\$ 250$ per violation. In 1995 , The commercial laundry's pH levels were beyond the limits 3 times out of 16 samples and can be assumed an average per year.

$\$ 250 /$ violation $\times 3$ times/year $=\$ 750$

\section{Reduced Annual Reporting Requírements: $\$ 4,320$}

Monthly, The commercial laundry completes an Industrial Wastewater Discharge Monitoring Report for the City of Richland. The report indicates the flow, $\mathrm{pH}$, temperature, and oil and grease content. A memorandum from the U.S. Environmental Protection Agency (EPA) 
(October 1992, The Use of Grab Samples to Detect Violations of Pretreatment Standards) states that "The EPA is aware that a number of Control Authorities currently rely on a single grab sample to determine compliance, particularly at small industrial users, as a way of holding down monitoring costs." The memo goes on to state that "a single grab sample may be properly substituted for a single composite sample where the industrial user, in its self-monitoring report, certifies that the individual grab sample is representative of its daily operation." Reporting requirements for sampling may be reduced to 1 sample due to compliance and discharge quantities within the limits.

The commercial laundry's new discharge permit, effective 09/01/96, states that "pH sampling will consist of 4 individual daily grab samples to conform with representative EPA sampling requirements during business hours." In addition, "individual $\mathrm{pH}$ samples need to be analyzed individually, they can not be composited." This cost will occur until May 1997 at which time a continuous $\mathrm{pH} /$ temperature monitor will be installed (per the compliance schedule outlined in the new permit) and the need for manually collecting samples will be eliminated.

4 grab samples $\times \$ 5 /$ sample $\times 1$ frequency/wk $\times 4$ wks $/$ month $\times 8$ months $=\$ 640$

4 grab samples $\times 2$ hrs/day $\times \$ 20 / \mathrm{hr} \times 1$ frequency/wk $\times 4$ wks/month $\times 8$ months $=\$ 5,120$

$\$ 640+\$ 5,120=\$ 5,760$

However, when the equalization tank and acid drip system is installed, the $\mathrm{pH}$ will be within limits. Once that has been documented, the Commercial laundry has the potential of eliminating three of the four samples taken daily based upon the EPA memo. This savings will occur until May 1997 at which time a continuous $\mathrm{pH} /$ temperature monitor will be installed (per the compliance schedule outlined in the new permit) and the need for manually collecting samples will be eliminated.

1 grab sample $\times \$ 5 /$ sample $\times 1$ frequency $/$ wk $\times 4$ wks/month $\times 8$ months $=\$ 160$

1 grab sample $\times 2$ hrs/day x $\$ 20 /$ hr $\times 1$ frequency/wk $\times 4$ wks/month $\times 8$ months $=\$ 1,280$

$\$ 160+\$ 1,280=\$ 1,440$

$\$ 5,760-\$ 1,440=\$ 4,320$

\section{Engineering Review per Compliance Schedule: $\$ 10,000$}

The compliance schedule outlined in the new Commercial laundry permit effective 09/01/96 states that the laundry must "submit an engineering evaluation of alternatives for achieving compliance with the final pH limits." This Pollution Prevention Assessment outlining pollution prevention opportunities for adjusting the $\mathrm{pH}$ will serve to meet this schedule per City of Richland personnel. 
The Westinghouse Pollution Prevention group estimates that the cost of a study of this sort is $\$ 10,000$.

Total Annual Costs: $\$ 8,133$

Total Annual Benefits: $\$ 15,070$

Total Annual Cost Savings: $\$ 6,937$

Benefits - Costs $=$ Total Annual Cost Savings

$\$ 15,070-\$ 8,133=\$ 6,937$

\section{Calculation of Implementation Cost and Payback}

Equalization Tank with Mixer: $\$ 19,500$

The cost to purchase one 4,000 gallon carbon steel cone bottom equalization tank ( 7 ' -6 " wide $\mathrm{x}$ 15 ' high) with a two hp gear reduced mixer, stainless steel shaft and impeller and acid chemical feed pump is $\$ 18,500$ with an additional $\$ 1,000$ for shipping.

Payback $=$ Implementation cost divided by annual cost savings

$\$ 19,500$ divided by $\$ 6,937=2.8$ years

\section{Vendor/Contact Information}

\section{Hydron Cetco}

Katy Huff

3539 South Main Street, Suite 220

Salt Lake City, UT 84115-4455

Phone: (801) 268-9988

Fax: (801) 268-9991

\section{Pasco Poly Tank}

Route 9

616 S. Road 40 E

Pasco, WA 99301

Phone: (509) 545-9959 


\section{Poly Cal Plastics $^{\text {TM }}$}

P.O. Box 80

French Camp, CA 95231

Phone: (209) 982-4904

Fax: (209) $982-0455$

Baker Tank Company

P.O. Box 40

Arp, TX 75750

Phone: (903) 859-2111

Fax: (903) 859-4191

Tenco-Hydro, Inc.

Alan Meyer

4620 Forest Avenue

Brookfield, Il 60513

Phone: (708) 387-0700

Fax: (708) 387-0732

Chem-Tainer ${ }^{\mathrm{TM}}$ Industries, Inc.

361 Neptune Ave.

W. Babylon, NY 11704

Phone: (516) 661-8300

Fax: (516) 661-8209

Tarus Equipment Co. Inc.

P.O. Box 14709

Columbus, $\mathrm{OH} 43214$

Phone: (614) 431-1241

Fax: (614) 431-5775 


\title{
Pollution Prevention Opportunity Assessment Worksheet 3 \\ Pollution Prevention Opportunity Description
}

\author{
Date 07/22/96 \\ P2OA ID Code Laundry-1 \\ Facility Commercial Laundry
}

Activity Washing Industrial Laundry

P2O No. 2

P2O Title Dissolved Air Flotation

\section{Current Practice}

No pre-treatment methods are currently employed at the Commercial laundry. Wastewater is sent through a shaker screen and then to a sump which goes directly to the City of Richland Publicly Owned Treatment Works (POTW). This opportunity, Dissolved Air Flotation (DAF) assumes however that an equalization tank with a mixer and an acid injection system for $\mathrm{pH}$ adjustment (P2O No. 1) are already in place.

The commercial laundry's new wastewater discharge permit (Permit No. CR-IU003), effective 09/01/96 does not have a limit on the Oil and Grease discharged to the POTW (previous permit limit was $<100 \mathrm{mg} / \mathrm{l}$ at any one time). However, the Environmental Protection Agency is developing guidance specific to Industrial Laundries which target Oil and Grease. Once this is effective (estimated 1998), Industrial Laundries will have three years to come into compliance. An estimated Oil and Grease limit is less than $100 \mathrm{mg} / \mathrm{l}$ per day.

\section{Recommended Action}

Install a Dissolved Air Flotation (DAF) unit for liquid/solid separation. DAF is a process in which microscopic air bubbles become attached to solids particles suspended in a liquid causing the solids particles to float. Air is dissolved into a liquid under pressure and then that air is converted into microscopic air bubbles and mixed with the stream to be treated. The air bubbles are mixed with the waste and become attached to the solids in the waste stream causing the air/solids agglomerate to float to the liquid surface where a solids (float) blanket is formed. The float blanket is removed by surface skimmers.

Discharged float is collected in a holding tank and then pressed into a dry cake which can be disposed of in the municipal solid waste landfill upon characterization and Department of Health and City of Richland approval.

Exiting the equalization tank, the wastewater is mixed with an organic cationic coagulant and an iron-salt coagulant aid before reaching the switchback mixing manifold. In the manifold, which 
has ports for monitoring probes and sample extraction, an organic anionic flocculent is added to the wastewater. The coagulant chemicals provide a positive charge to neutralize the negative charge in the dissolved and emulsified soils of the wastewater. Once the negative charge is neutralized, the flocculent joins floating particles, forming agglomerates of air bubbles attached to suspended and dissolved soils, which cling to floc particles and oil droplets.

From the switchback mixing manifold, wastewater flows to the mixing tank on the treatment unit. Here, the treated water encounters two more manifolds. One manifold introduces flocculent chemicals and air; the other introduces air only. The introduction of air and chemicals in the mixing tank is a patented process that the manufacturer claims is unique and uses treatment chemicals more efficiently than other DAF units.

From the mixing tank, wastewater flows to the separation tank and over and under a series of vertical baffles. The flow through the baffles is slow enough to allow the air bubbles to float contaminants to the surface, forming a sludge blanket. Heavier particles, which have a propensity to sink, fall from the water column and accumulate on the bottom of the separation tank. A chain-driven, paddle-type skimmer moves across the surface of the tank, removing the floating contaminants that comprise the sludge blanket. The skimmed contaminants fall into a V-bottomed trough that drains into the top of the sludge tank.

Sludge and sinkable solids collect on the bottom of the separation tank, which is shaped into three funnel-like structures with four sides. The funnel shape allows gravity to assist in the removal of tank bottom sediment, eliminating the need for an operator to perform this function.

An air diaphragm sludge pump, which is controlled either by a timer or manually, moves the contaminants from the separation tank bottom into the sludge receiving tank. The sludge tank is equipped with a mixer that agitates the wastewater to keep the sludge from settling. The mixer also blends diatomaceous earth with the sludge to facilitate dewatering.

From the sludge tank, another air diaphragm pump moves the sludge to the filter press for dewatering. Water and oils discharged from the press flow to a separation tank, where the water is pulled off the bottom after the mixture settles and separates naturally with the oil floating on the water. Water from the press is not recirculated through the system because once the polymers and flocculents have done their work, they tend not to "break" again. The remainder of the wastewater from the separation tank, exits over a weir and is discharged to the sewer. The filter cakes are non-hazardous and can be disposed of in the municipal solid waste landfill.

The modular pretreatment system has been designed for minimum maintenance. It is constructed of nonferrous materials, stainless steel, and aluminum to resist corrosion. Repair components typically are available off the shelf from a local industrial supply company.

A small business, Action Garment Rental, which has a flow approximately the size of $\mathrm{He}$ commercial laundry installed a DAF unit in 1992. Action Garment Rental uses approximately $35,000-40,000$ gallons of water per day with a flow rate of 50 gallons per minute (gpm). They 
noted significant pollutant reductions. Biochemical oxygen demand (BOD) was 300 to 350 $\mathrm{mg} / \mathrm{l}$; with the DAF enhancement it is down to 88 . Total suspended solids was 200 to 500; today it is 20 . Oil and grease was 1,300 to 1,400 ; it is now around 25 . These numbers are the numbers from the POTW tests, not Action Garment Rental numbers.

The Hydro Modular Systems' (HMS) estimate for a dissolved air flotation wastewater system to process $100-135 \mathrm{gpm}$ includes the following:

\section{Wastewater System:}

1. One Modular Treatment, Aeration and Mixing Cell

' 5' x 14' x 9' Stainless steel construction with conical bottoms

- Stainless steel piping (sludge) - Stainless manifold (mixing tubes)

- Pre-piped, pre-wired and skid mounted

- Patented aeration, mixing and settling system

- Automatic sludge removal system from top and semi-automatic sludge removal from bottom

-Independent sludge control panel

-Variable speed gear motor and rake

-Electric/pneumatic dump valves

-Pneumatic weir (to raise top sludge mat)

- Independent wastewater control panel

-Air control system

-Automatic start-up and shutdown

-Six inch gravity feed discharge line or optional three inch pump discharge

- Walkway (wrap around) and stairs with non-skid surface

- 6' W x 6' $\mathrm{L} \times 5^{\prime} \mathrm{H}$ Stainless steel sludge storage and mixing cone bottom tank (approx. 1,000 gallons) with level warning indicator

\section{One Automatic Flocculant Chemical Mixer with Metering Pump}

3. One Automatic Coagulant Chemical Mixer with Metering Pump or Chemical Feed Pump (depending on chemical program).

4. One Air Diaphragm Sludge Pump

5. One Feed Pump (Gorman-Rupp ${ }^{\text {TM }}$ ) and One Discharge Pump (Dunham-Bush) (Unless Gravity Feed)

\section{Service:}

HMS will provide a turn-key installation up to five days, test and provide all start-up support until compliance objectives are met and provide a limited one year replacement warranty on all components. 


\section{Filter Press and Components:}

1. JWJ Expandable filter press (Model $800 \mathrm{MM}$ )

10 Cubic feet expandable to 20 cubic feet

Recess, gasketed filter plates with center feed and four corner discharge

Air blow down manifold

Air/hydraulic system

Automatic pump control

Control box

Expansion piece

Shifter, semi-automatic

Back-up plate (for small batches)

One forkliftable dumpster

2. One air diaphragm sludge pump sized for press

3. One sludge tank mixer (heavy duty, sized for tank)

\section{Service:}

HMS will install and provide start-up and on-site training.

\section{Warranty:}

Original manufacturer's warranty.

The above systems and services are contingent on The commercial laundry providing the following:

Proper pre-screening

Piping to and from wastewater room

Suitable room for equipment

One overhead door $12^{\prime} \mathrm{W} \times 12$ ' $\mathrm{H}$ (if available)

240 Volt 3 phase (60) amp electrical service to wastewater room

Uninterrupted compressed air (1: - 20 CFM) to wastewater room

Uninterrupted fresh water supply $(1 ")$ to wastewater room

Pit pump to equalization

Proper equalization tank (approximately 6,000 gallons)

Equalization tank mixer

Any required permits

Laboratory tests

Treatment chemicals and specified by HMS

Clean/pump equalization tanks or pits completely before installation begins

Any additional electrical service

Equipment necessary to offload and locate system 


\section{Calculation of Waste Reduction and/or Energy Savings}

This is a treatment technology and no in-plant waste reduction savings will be realized through this opportunity.

\section{Calculation of Annual Cost Savings}

Costs

\section{Chemical Coagulant/Flocculant: $\$ 14,700$}

HMS estimates that wastewater treatment chemicals will cost approximately $\$ 2.00$ per 1,000 gallons processed. The commercial laundry operates on the average 210 days/year with a flow of 35,000 gals/day.

35,000 gallons/day $\times \$ 2.00 / 1,000$ gallons $\times 210$ days $/$ year $=\$ 14,700 /$ year

\section{Diatomaceous Earth: $\$ 3,150$}

Diatomaceous earth is packaged in 50 pound bags at a cost of $\$ 30$ each. HMS estimates that approximately $1 / 2$ bag will be used daily. The commercial laundry operates on the average 210 days/year.

$\$ 30 /$ bag divided by $2 \times 210$ days $/$ year $=\$ 3,150$

\section{Maintenance and Operation: $\mathbf{\$ 8 , 4 0 0}$}

HMS estimates that the average time involved in maintenance and operations is 2 hours per day. Production Engineers at The commercial laundry cost approximately $\$ 20 / \mathrm{hr}$. The commercial laundry operates on the average 210 days/year.

2 hours/day $\times \$ 20 / h r \times 210$ days $/$ year $=\$ 8,400 /$ year

\section{Electrical: $\$ 2,986$}

Electrical service includes a 240 Volt 3 Phase (60) Amp and Uninterrupted compressed air (1" line $-20 \mathrm{cfm}$ ).

The electricity rates in the City of Richland are as follows:

Summer Months: $\quad<20,000 \mathrm{kWh}=.0280$

$>20,000 \mathrm{kWh}=.0179$

Winter Months: $\quad<20,000 \mathrm{kWh}=.0320$

$$
>20,000 \mathrm{kWh}=.0240
$$

Service Charge: $\$ 12.50 /$ month

City Tax: $\$ 7.52 \%$ 


\section{Volt 3 Phase (60) Amp:}

Based upon a power factor of 0.8 the draw is $19.95 \mathrm{~kW}$

8 hours/day x 210 days/year $\times 19.95 \mathrm{~kW}=33,516 \mathrm{~kW} /$ year

Summer Rate: $16,758 \mathrm{kWh} \times \$ 0.028 / \mathrm{kWh}=\$ 469 /$ year

Winter Rate: $16,758 \mathrm{kWh} \times \$ 0.032 / \mathrm{kWh}=\$ 536 /$ year

Service Charge: $\$ 12.50 /$ month $\times 12$ months/year $=\$ 150$

Tax: $(\$ 469+\$ 536+\$ 150) \times 0.0752 \operatorname{tax}=\$ 87$ tax $/$ year

$\$ 1,155 /$ year $+\$ 87$ tax/year $=\$ 1,242$

Un-Interrupted Compressed Air (I" line - $20 \mathrm{cfm})$ :

HMS estimates that the unit will operate at 90 psi. Operating at $90 \mathrm{psi}$ at $20 \mathrm{cfm}$ correlates to approximately $7.5 \mathrm{hp}$.

$7.5 \mathrm{hp} \times 0.745 \mathrm{hp} / \mathrm{kW}=5.6 \mathrm{~kW}$.

Uninterrupted service includes 24 hours/day x 365 days/year $=8,760$ hours/year.

$5.6 \mathrm{~kW} \mathrm{x} 8,760$ hours/year $=49,056 \mathrm{kWh} /$ year.

Summer: $24,528 \mathrm{kWh} \times 0.0280=\$ 687$

Winter: $24,528 \mathrm{kWh} \times 0.0320=\$ 785$

Service Charge: $\$ 12.50 /$ month $\times 12$ months/year $=\$ 150$

Tax: $\$ 687+\$ 785+\$ 150 \times 0.0752 \operatorname{tax}=\$ 122$ tax $/$ year

$\$ 1,622 /$ year $+\$ 122$ tax $/$ year $=\$ 1,744$

Total Electrical Requirements: $\$ 1,242+\$ 1,744=\$ 2,986$

\section{Benefits}

\section{Reduced Annual Reporting Requirements: $\$ \mathbf{2 8 , 8 0 0}$}

The commercial laundry prepares monthly an Industrial Wastewater Discharge Monitoring Report for the City of Richland. The report indicates the flow, $\mathrm{pH}$, temperature, and oil and grease content. A memorandum from the U.S. Environmental Protection Agency (EPA) (October 1992, The Use of Grab Samples to Detect Violations of Pretreatment Standards) states 
that "The EPA is aware that a number of Control Authorities currently rely on a single grab sample to determine compliance, particularly at small industrial users, as a way of holding down monitoring costs." The memo goes on to state that "a single grab sample may be properly substituted for a single composite sample where the industrial user, in its self-monitoring report, certifies that the individual grab sample is representative of its daily operation." Reporting requirements, including sampling will be reduced to 1 sample due to compliance and discharge quantities within the limits.

The commercial laundry's new discharge permit, effective 09/01/96, states that "oil and grease sampling will consist of 4 individual daily grab samples to conform with representative EPA sampling requirements during business hours." In addition, "individual oil and grease samples need to be analyzed individually, they can not be composited."

4 grab samples $\times \$ 40 /$ sample $\times 1$ frequency/month $\times 12$ months/year $=\$ 1,920 /$ year

4 grab samples $\times 2$ hrs $/$ day $\times \$ 20 / \mathrm{hr} \times 1$ frequency/month $\times 12$ months/year $=\$ 1,920 /$ year

$\$ 1,920+\$ 1,920=\$ 3,840$

However, if the DAF wastewater treatment system is installed, and the oil and grease are reduced, the commercial laundry has the potential of eliminating three of the four samples taken daily based upon the EPA memo.

1 grab sample $\times \$ 40 /$ sample $\times 1$ frequency/month $\times 12$ months/year $=\$ 480 /$ year

1 grab sample $\times 2 \mathrm{hrs} /$ day $\times \$ 20 / \mathrm{hr} \times 1$ frequency/month $\times 12$ months $/$ year $=\$ 480 /$ year

$\$ 480+\$ 480=\$ 960$

$\$ 3,840-\$ 960=\$ 2,880$

In addition, it is estimated that the Commercial laundry spends 6 hours per month on environmental issues at a cost of $\$ 20$ per hour.

6 hours/month $\times \$ 20 /$ hour $\times 12$ months/year $=\$ 1,440 /$ year

The Commercial laundry estimates that reducing environmental liabilities will reduce reporting requirements by an estimated $50 \%$.

$\$ 1,440 /$ year $\times .50=\$ 720 /$ year

$\$ 25,200+\$ 720=\$ 25,920 /$ year

$\$ 25,920 /$ year $+2,880 /$ year $=\$ 28,800 /$ year 


\section{Elimination of Potential Fines: $\mathbf{2 , 0 0 0}$}

The City of Richland Administrative Fine Folicy which is currently in draft form, states that the maximum amount that can be imposed is $\$ 10,000$ per day for each violation. However, pretreatment violations are not created equally and requires a review of all surrounding facts in order to determine the appropriate enforcenent response. Civil and criminal penalties can be sought for a single pretreatment violation. The focus of the calculation of the fine is focused on the seriousness, frequency, and persistence of the problem. Based upon The commercial laundry's demonstrated intent, the City of Richland Wastewater Treatment Plant personnel estimate that the initial fine imposed would be $\$ 250$ per violation. It is estimated that the oil and grease limit will be $<100 \mathrm{mg} / 1$ with the new EPA Guidelines for Industrial Laundries. In 1995, The commercial laundry's oil and grease content was out of compliance 8 times out of 14 and can be assumed an average per year.

$\$ 250 /$ violation $\times 8$ times/year $=\$ 2,000$

\section{Improved Public Relations: $\$ \mathbf{1 5 , 4 3 8}$}

All effluent discharge information is available for public review which includes analytical data on actual discharge quantities, are public domain. If discharge limits are achieved through implementation of DAF, this will improve image of the Commercial laundry as a "green business" with their customers and Richland residents. The Commercial laundry currently spends $\$ 36,000$ per year on advertising in the yellow pages, television, radio, and sponsorship. If release limits are reduced through the implementation of DAF technology, then it is worth advertising to their clients as a "green practice." It is estimated by The commercial laundry that $50 \%$ of their customer base comes through advertising and of that, $10 \%$ of their customer base would choose The commercial laundry because it is a "green business." The commercial laundry currently has 1,150 customers at an average cost per customer of $\$ 3 /$ week profit.

$\$ 36,000 /$ year $\times .50=\$ 18,000 /$ year

$\$ 18,000 /$ year $\times .10=\$ 1,800 /$ year

1,150 total customers $\times .50=575$

$575 \times .10 \times \$ 3 /$ week $\times 52$ weeks $/$ year $=\$ 8,970$

$\$ 8,970-\$ 1,800=\$ 7,170$

In addition, new customers are an average profit of $\$ 6 /$ week profit and 1 new customer is gained weekly.

$1+2+3+4+5 \ldots+52$ weeks $=1,378$

$1,378 \times \$ 6 /$ week $=\$ 8,268 /$ year 
$\$ 7,170+\$ 8,268=\$ 15,438$

Total Annual Costs: $\$ 29,236$

Total Annual Benefits: $\$ 46,238$

Total Annual Cost Savings: $\$ 17,002$

Benefits - Costs $=$ Total Annual Cost Savings

$\$ 46,238-\$ 29,236=\$ 17,002$

\title{
Calculation of Implementation Cost and Payback
}

Dissolved Air Flotation Wastewater System: $\mathbf{\$ 1 0 6 , 6 5 0}$

DAF System: $\$ 96,000$

Installation: $\$ 7,250$

Freight: $\$ 3,400$

Filter Press: \$52,595

Press: $\$ 43,285$

Aro Air Diaphragm Pump Sized for Press: $\$ 960$

Heavy Duty Mixer Sized for Sludge Tank: $\$ 3,950$

Installation: $\$ 1,500$

Freight: $\$ 2,900$

Miscellaneous Piping, Valves, Switches, etc.: $\mathbf{\$ 5 , 5 0 0}$

The existing door frame in the wastewater room is $7^{\prime} 8^{\prime \prime}$ high $\times 9^{\prime} 2^{\prime \prime}$ wide and HMS requires a $12^{\prime}$ high $\times 12$ ' wide entrance for bringing in the equipment. The commercial laundry expects to spend approximately $\$ 3,000$ on enlarging the doorway and an additional $\$ 2,500$ in preparation of electrical and compressed air to the wastewater room.

Total Implementation Cost: $\$ 106,650+52,595+\$ 5,500=\$ 164,745$

$\$ 164,745$ divided by $\$ 17,002=9.7$ years

\author{
Vendor/Contact Information \\ Hydro Modular Systems (HMS) \\ Jim Averill \\ 320 West Hefner Road \\ Oklahoma City, OK 73114 \\ Phone: 1-800-366-5751
}


Phone: (405) 755-9728

Fax: (405) 755-6960

Process Engineers and Equipment Corporation

Richard Howie

7716 W. Rutter Parkway

Spokane, WA 99208

Phone: (509) 468-8201

Fax: (509) 468-8970

\section{Hydron Cetco}

Katy Huff

3539 South Main Street, Suite 220

Salt Lake City, UT $84115-4455$

Phone: (801) 268-9988

Fax: (801) 268-9991

Krofta $^{T M}$ Engineering Corporation

Kurt Kuehnel

101 Yokun Avenue

P.O. Box 972

Lenox, MS 01240

Phone: (413) 637-0740

Fax: (413) 637-0768

\section{HydroCal $^{\mathrm{TM}}$}

22732 Granite Way, Suite A

Laguna Hills, CA 92853

Phone: (714) 455-0765

Fax: (714) 455-0764

FRC Environmental Inc.

Chris Windsor

P.O. Box 2455

Gainesville, GA 30503

Phone: (770) 534-3681

Fax: (770) 535-1887 


\section{Ellis Corporation}

Jeff Davis

1146 Glenway Dr.

St. Louis, MO 63122-3141

Phone: (314) 965-3598

Fax: (314) 965-6253

Guaranteed Water Reclamation, Inc.

Ron Reich

56 Woolsey St.

Irvington, NJ 07111

Phone: (201) 374-5800

Fax: (201) 374-9610

WesTech

Jeff Belnap

3605 South West Temple

Salt Lake City, UT 84115

Phone: (801) 265-1000

Fax: (801) 265-1080 


\title{
Pollution Prevention Opportunity Assessment Worksheet 3 \\ Pollution Prevention Opportunity Description
}

\author{
Date 07/22/96 \\ P2OA ID Code Laundry-1 \\ Facility Commercial Laundry
}

Activity Washing Industrial Laundry

P2O No. 3

P2O Title Wastewater Recycling System

\section{Current Practice}

No pre-treatment methods are currently employed at the Commercial laundry. Waste water is sent through a shaker screen and then to a sump which goes directly to the City of Richland Publicly Owned Treatment Works (POTW). This opportunity, Closed-Loop Recycling System assumes however that an equalization tank and acid drip system for $\mathrm{pH}$ adjustment (P2O No. 1) as well as a Dissolved Air Flotation (P2O No. 2) are already in place.

The commercial laundry's new wastewater discharge permit (Permit No. CR-1U003), effective 09/01/96 does not have a limit on the Oil and Grease discharged to the POTW. However, the Environmental Protection Agency is developing guidance specific to Industrial Laundries which target Oil and Grease. Once this is effective (estimated 1998), Industrial Laundries will have three years to come into compliance. An estimated Oil and Grease limit is less than $100 \mathrm{mg} / \mathrm{l}$ per day.

\section{Recommended Action}

Install a wastewater filtration/recycling system design by Hydro Modular Systems (HMS). The wastewater will enter the equalization tank via the wash alley and will be pumped through the $\mathrm{DAF}$ system described in $\mathrm{P} 2 \mathrm{O}$ \#2. The discharge from the pre-treatment system will be monitored by a Total Dissolved Solids (TDS) meter and pumped to a process tank for further filtration. Only the pre-treated wastewater with acceptable levels of TDS will be sent to the process tank. The remaining wastewater will be sent to the City of Richland Publicly Owned Treatment Works (POTW).

The filtered wastewater will be delivered at one micron or less particle size which is more than adequate for reuse in first or second breaks. The average quantities of water available for reuse have been conservatively estimated at $40 \%$. The TDS value will be pre-determined as to which waters go for filtration and which go directly to the City. Only the waters with a TDS value considered to be useable in the process will be filtered avoiding TDS buildup. 
HMS estimated the "Advantage" Filter as the system best suited for the Commercial laundry. It has the following components:

\section{Filter:}

1. Cell $30 " \mathrm{~W} \times 100 " \mathrm{~L} \times 72 " \mathrm{H}$ stainless steel construction

- (16) Stainless steel filter screens (24" W x 36" H)

- Screens constructed of $24 \times 110$ mesh dutch weave with $4 X 4$ mesh backing

- (3) 3" Pumps and stainless steel piping sized for system

- (3) Additional level controls

- (5) Pneumatic valves (control direction of flow)

- (1) Air diaphragm sludge pump

- (1) Bag filter

- (1) 1,000 Gallon feed tank

- (1) 2,000 Gallon process tank

- PLC Touch screen controls

- (1) Semi-automatic backwash system with spray nozzles

\section{Installation:}

Equipment to install

All electrical

All labor and expense

Freight included

\section{Service:}

HMS will custom fabricate and install up to 3 days, test and provide all start-up support until objectives are met and provide a limited one year replacement warranty on all components.

\section{Calculation of Waste Reduction and/or Energy Savings}

\section{Water: 275,264 gallons}

Based upon information provided by HMS, the average quantities of water available for reuse conservatively is $40 \%$. The commercial laundry consumes an average of 920 units per month with one unit equal to $100 \mathrm{ft}^{3}$. The service size is 3 inch.

920 units $\times 100 \mathrm{ft}^{3} \times 7.48$ gals/ft3 $\times .40=275,264$ gallons

\section{Calculation of Annual Cost Savings}

Costs

Electricity: $\$ 973$ 
Electrical service includes a 240 Volt 3 Phase (30) Amp.

The electricity rates in the City of Richland are as follows:

Summer Months: $\quad<20,000 \mathrm{kWh}=.0280$

$>20,000 \mathrm{kWh}=.0179$

Winter Months: $\quad<20,000 \mathrm{kWh}=.032 .0$

$>20,000 \mathrm{kWh}=.0240$

Service Charge: $\$ 12.50 /$ month

Demand Charge: $\$ 4.50 / \mathrm{kW}$ after the first $50 \mathrm{~kW}$

City Tax: $\$ 7.52 \%$

240 Volt 3 Phase (30) Amp:

HMS estimates that the average draw is $15 \mathrm{~kW}$ draw.

8 hours/day $\times 210$ days/year $\times 15 \mathrm{~kW}=25,200 \mathrm{~kW} /$ year

Summer Rate: $12,600 \mathrm{kWh} \times \$ 0.028 / \mathrm{kWh}:=\$ 352 /$ year

Winter Rate: $12,600 \mathrm{kWh} \times \$ 0.032 / \mathrm{kWh}=\$ 403 /$ year

Service Charge: $\$ 12.50 /$ month $\times 12$ months $/$ year $=\$ 150$

Tax: $(\$ 352+\$ 403+\$ 150) \times 0.0752 \operatorname{tax}=\$ 68$ tax $/$ year

$\$ 905 /$ year $+\$ 68$ tax $/$ year $=\$ 973$

Maintenance and Operations: $\$ 4,200$

HMS estimates that the average time involved in maintenance and operations is 1 hour per day. Production Engineers at The commercial laundry cost approximately $\$ 20 / \mathrm{hr}$. The commercial laundry operates on the average 210 days/year.

1 hour $/$ day $\times \$ 20 / \mathrm{hr} \times 210$ days $/$ year $=\$ 4,200$

Benefits

Reduced Raw Water Consumption: $\$ \mathbf{3 , 2 1 3}$ 
HMS estimates a reduction of $40 \%$ water consumption. The commercial laundry currently uses an average of 920 units with one unit equal to $100 \mathrm{ft}^{3}$ of water annually and their service size is 3 inch. The City of Richland water rates are as follows:

Unit cost: $\$ 0.57 /$ unit

Monthly fee: $\$ 87(\$ 1,044$ annually)

Tax: $9.52 \%$

920 units/month $\times 12$ months/year $\times \$ 0.57 /$ unit $+\$ 1,044=\$ 7,336 /$ year

$\$ 7,336 \times \$ 0.0952=\$ 698 \operatorname{tax}$

$\$ 7,336+\$ 698=\$ 8,034$

$\$ 8,034 \times .40=\$ 3,213$

\section{Reduced Operating Costs: $\$ \mathbf{7 , 3 0 9}$}

Based upon information provided by HMS, the operational cost of the DAF system will be lower by $25 \%$. The operating costs provided in $\mathrm{P} 2 \mathrm{O} \# 2$ total $\$ 29,236$.

Maintenance: $\$ 8,400 /$ year

Chemical Coagulant/Flocculant: $\$ 14,700 /$ year

Diatomaceous Earth: $\$ 3,150$ year

Electrical: $\$ 2,986 /$ year

$\$ 29,236 \times .25=\$ 7,309$

Total Annual Costs: $\$ 5,173$

Total Annual Benefits: $\$ 10,522$

Total Annual Cost Savings: \$5,349

\section{Calculation of Implementation Cost and Payback}

\section{Wastewater Filtration System: $\$ \mathbf{7 1 , 3 1 4}$}

The cost to purchase an HMS wastewater filtration system is $\$ 68,914$ and $\$ 2,400$ for installation.

$\$ 68,914+\$ 2,400=\$ 71,314$

Payback $=$ Implementation cost divided by annual cost savings 
$\$ 71,314$ divided by $\$ 5,349=13.33$ years

\section{Vendor/Contact Information}

Hydro Modular Systems (HMS)

Jim Averill

320 West Hefner Road

Oklahoma City, OK 73114

Phone: 1-800-366-5751

Phone: (405) 755-9728

Fax: (405) 755-6960 


\section{Pollution Prevention Opportunity Assessment Worksheet 4 \\ Pollution Prevention Opportunities Summary}

Date $08 / 10 / 96$ P2OA ID Code Laundry-1 Facility Commercial Laundry

Activity Washing Industrial Laundry

\begin{tabular}{|c|c|c|c|c|c|c|}
\hline P2O No. & P20 Title & $\begin{array}{c}\text { Waste } \\
\text { Class } \\
\text { Reduced }\end{array}$ & $\begin{array}{c}\text { Annual Waste } \\
\text { Reduction or } \\
\text { Energy Savings }\end{array}$ & $\begin{array}{c}\text { Estimated } \\
\text { Annual } \\
\text { Savings }\end{array}$ & $\begin{array}{c}\text { Estimated } \\
\text { Implementation } \\
\text { Cost }\end{array}$ & Payback \\
\hline 1 & $\begin{array}{l}\text { Equalization } \\
\text { Tank/pH } \\
\text { Adjustment }\end{array}$ & $\begin{array}{l}\text { Waste } \\
\text { Water }\end{array}$ & 0 & $\$ 6,937$ & $\$ 19,500$ & 2.8 \\
\hline 2 & $\begin{array}{l}\text { Dissolved Air } \\
\text { Flotation }\end{array}$ & $\begin{array}{l}\text { Waste } \\
\text { Water }\end{array}$ & $\overline{0}$ & $\$ 17,002$ & $\$ 164,745$ & 9.7 \\
\hline 3 & $\begin{array}{l}\text { Wastewater } \\
\text { Recycling System }\end{array}$ & $\begin{array}{l}\text { Waste } \\
\text { Water }\end{array}$ & 275,264 gals. & $\$ 5,349$ & $\$ 71,314$ & 13.3 \\
\hline
\end{tabular}




\section{Other Brainstorming Opportunities}

Hang mats up and do not dry

Change hours of production to operate during cooler hours

Train customers on what is acceptable and not acceptable

Use a lower $\mathrm{pH}$ product

Wash mats in cold water

Conduct a study of individual waste streams

Change the schedule to adjust for different types of loads and wash cycles

Chemical precipitate

Acid cracking

Treat mop heads with soluble water solution instead of oil

Stop oiling mop heads

Treat heavy waste water stream

Utilize potato sludge to break the FOG bond

Use centrifuge extractor

Stop overdrying

Use microwave boiler to dry clothes

Reduce the quantities of detergents used

Implement ozonation technology

VOC stripper on shop towels
Put restrictions in contract to customers--and enforce 


\section{Pollution Prevention Opportunity Assessment Worksheet 5 Final Summary}
Date 08/06/96
P20A ID Code Laundry-1
Facility Commercial Laundry
Activity Washing Industrial Laundry

\section{Proposed Opportunities and Discussion}

The EPA will be introducing new guidelines specific to Industrial Laundries in 1998 and targeting the Oil and Grease limits. At that time, laundries will have 3 years to come into compliance. This proposal will determine much of the direction for The commercial laundry since the new City of Richland permit does not have an Oil and Grease limit as the Publicly Owned Treatment Works (POTW) can use their wastewater at the wastewater treatment plant as a viable food source for the microorganisms.

Three opportunities were investigated. Each contingent upon the previous opportunity having already been implemented.

Opportunity \#1 Equalization Tank/pH Adjustment: The equalization tank will balance out the highs and lows and adjust the $\mathrm{pH}$ with Sulfuric Acid. The $\mathrm{pH}$ currently ranges between 8 and 11.5 with the standard begin $<10$ for appropriate discharge limits. Since the reduction in $\mathrm{pH}$ is minor, the adjustment in acid will be minor as well.

Opportunity \#2 Dissolved Air Flotation: The Dissolved Air Flotation will assist in lowering the suspended solids (SS), biochemical oxygen demand (BOD), and Oil and Grease by mixing air bubbles with the waste water. The waste adheres to the bubbles and creates a float blanket which is skimmed off and pressed into dry cakes.

Although the Commercial laundry currently accepts laundry from any business, this process will allow for a larger customer base if they were to begin receiving a large quantity of laundry which generated significant pollutants.

Opportunity \#3 Wastewater Recycling System: The wastewater recycling system will route $40 \%$ of the exiting wastewater through a filter and back to beginning of the process for reuse.

\section{Recommendations and Schedule for Implementation}

Each of the opportunities described should be implemented in sequence beginning with Opportunity \#1. The first opportunity should be implemented immediately as it has a reasonable payback and will control the $\mathrm{pH}$ to the appropriate discharge limits. 
Once the Environmental Protection Agency guidelines for Industrial Laundries are published and final, it is further recommended to consider the Dissolved Air Flotation (DAF) technology. If the guidelines state a stringent limit $(<100 \mathrm{mg} / \mathrm{l})$ for Oil and Grease, the DAF unit should be installed as it will remove the Oil and Grease from the waste stream. Implementing this technology will also show to their customers that they are a "green" business and doing the right thing for the environment.

The third and final opportunity is recommended for implementation only if the capital equipment cost is significantly lowered in the future years. The vendor, Hydro Modular Systems is building a prototype water recycler which would be worth investigating in the future years for a closedloop recycling system. 
Pollution Prevention Opportunity Assessment

Pilot Study

Automotive Repair Shop 


\section{Pollution Prevention Opportunity Assessment Worksheet 1 Team and Activity Description}

Date 06/11/96 P2OA ID Code Automotive-1 Facility Autor.1otive Repair Shop

Activity Automotive Repairs

\begin{tabular}{|c|c|}
\hline Team Members (*Leader) & Telephone \\
\hline Mary Ann St. Martin & $943-7485$ \\
\hline Mary Betsch * & $372-1627$ \\
\hline
\end{tabular}

\section{Description of Activity to be Examined in this P2OA}

The automotive shop floor is divided up into six bays. A vehicle may move between several bays for one service depending on the need.

Bay \#1 is primarily used for brake and front end alignment. For a brake repair, the tires are first taken off and then the hoses are crimped to avoid brake fluid from escaping. Then, the brakes are cleaned with the aqua washer which is serviced by Safety Kleen ${ }^{\mathrm{TM}}$. For master cylinder calipers, the brake fluid is squeezed into a bucket and stored as hazardous waste. Safety Kleen ${ }^{\mathrm{TM}}$ also manages the brake fluid. The wheel bearings are first wiped down witlı a rag and then the bearing is packed with grease. A freon recycling unit extracts freon from the vehicle and returns filtered freon to the vehicle in a closed-loop system. The bay contains one tiucket of old grease which could be disposed of safely. Typical wastes generated in this bay are grease, oily rags, spills, brake fluid, solvent, asbestos, used brakes, and grease.

Bay \#2 contains a parts washer which is serviced by Safety Kleen ${ }^{\mathrm{TM}}$. The solvent is recycled until it is too dirty, then Safety Kleen ${ }^{\top M}$ replaces the solvent. Rotors and brake drums are refaced by grinding. The metal filings are disposed of as municipal solid waste. Asbestos waste from the brakes is combined in the aqua washer. Wastes generated in this bay include oily rags, metal filings, and solvent.

Bay \#3 contains a sunken floor which has access to the sewer. No liquids are sent down this drain and the current plan is to seal the drain. Alignment and brake inspections occur in this bay. Wastes generated here include waste oil, oily rags, and scrap metal.

Bay \#4 is dedicated to exhaust and brake repair. The aqua washer is moved to this bay as needed for cleaning brakes. Oil changes occur in this bay. The filters are punctured, drained, and disposed of as municipal solid waste. The oil is collected and stored in a postable unit. Once full it is stored in a 250 gallon tank outside the shop floor area. Differential fluicl, transmission fluid 
and engine oil is combined in the same tank. The oil is collected by Safety Kleen ${ }^{\mathrm{TM}}$ for recycling. Bay \#4 is also the location of hazardous waste storage. Antifreeze and brake fluid are collected in 55-gallon drums which Safety $\mathrm{Kleen}^{\mathrm{TM}}$ manages. The wastes generated in Bay \#4 are differential fluid, transmission fluid, antifreeze, oily rags, engine oil, scrap metal, and slag.

Bay \#5 is primarily designed for diagnostics testing and air condition repairs. Typical wastes found in this bay are freon, oil, antifreeze, transmission fluid, and grease.

Bay \#6 is a storage area. Used catalytic converters are stored here for sale to an offsite vendor. In addition, there is one 55-gallon drum of orphan material. Just off Bay \#6 a storage area exists which contains an air compressor, oil, and antifreeze. The air compressor is drained daily to minimize condensation build up. The oil is stored in large bins and pressurized. Typical wastes generated here include cardboard and used parts.

Outside the shop there is a 250 gallon tank for used oils collection. The differential fluid, transmission fluid, and engine oil are pumped from the mobile collection drum inside the shop to this tank. The oil is picked up every 6-8 months. A metal scrap pile containing tail pipes, mufflers, and other metals is staged outside too. The metal is picked up once a week for recycling by an offsite vendor. A 55-gallon drum of orphan material is also staged outside.

Used tires are stacked outside and picked up by an offside vendor for $\$ 1.00 /$ tire. No more than 200 tires collect before the vendor is called for pick up service.

Cardboard is difficult to recycle in the City of Richland as there is no routine recycling pick-up service available. Consequently, the cardboard is broken down and put in the dumpster for municipal solid waste. Occasionally, a vendor will come and take the cardboard away for recycling. However, there is not a formal program in place for pick up service. The pallets are collected near the cardboard and are picked up for repair and recycling by an offsite vendor. The vendor varies from time to time.

A locked storage unit contains new tires and used batteries. The batteries are collected at no cost by Interstate who delivers new batteries. Interstate only takes the same number of used batteries as are delivered new.

A small metal scrap pile exists outside the back door. It is combined with the larger scrap pile on the other side of the building and collected by an offside vendor for recycling.

The parts storage room contains new parts and products for servicing vehicles. In addition, used brake cores containing asbestos are collected here for the vendor to pick up. A problem exists in that the vendor refuses to pick up the used brake cores and therefore remain stockpiled in the parts storage room.

Spills are adsorbed with FloorDry and disposed of as municipal solid waste. Typical spills include oils, brake fluid, and transmission fluid. 
The cost for environmental services such as tire disposal and hazardous waste disposal is passed onto the customer. 


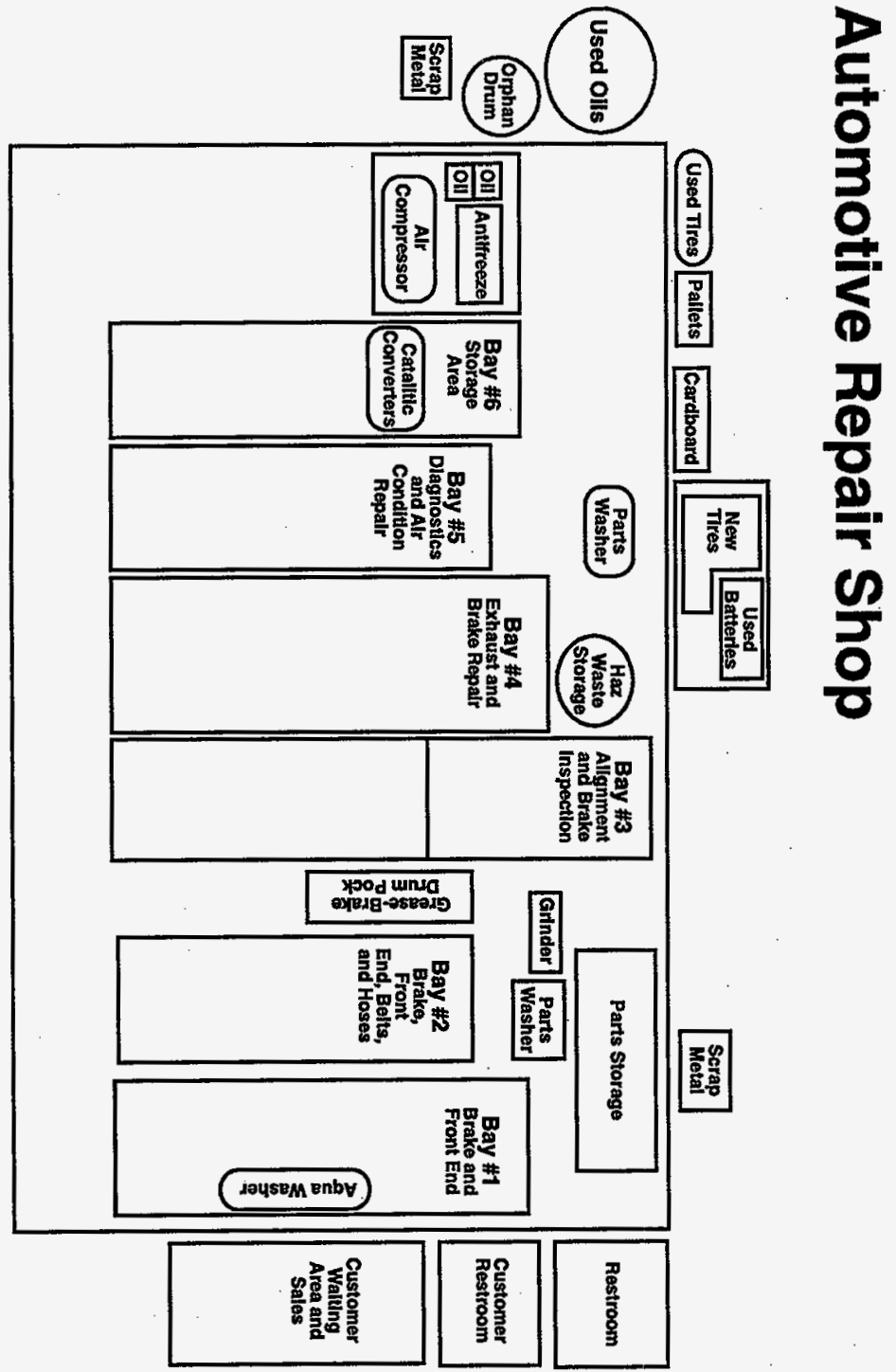




\section{Pollution Prevention Opportunity Assessment \\ Worksheet 2 \\ Activity Flow Diagram}

Date 06/15/96 P2OA ID Code Automotive-1 Facility Automotive Repair Shop

Activity Automotive Repairs

\begin{tabular}{|lr|}
\hline \multicolumn{2}{|c|}{$\begin{array}{c}\text { Chenical and Radioactive } \\
\text { Inputs }\end{array}$} \\
\hline \multicolumn{1}{|c|}{ Name } & \multicolumn{1}{c|}{ Qty. } \\
\hline Brake fluid & gals. \\
Antifreeze & $243 \mathrm{lbs}$. \\
Engine Oil & 300 gals. \\
Solvent & 430 gals. \\
Transmission Fluid & 50 qts. \\
Concrete Cleaner & 100 lbs. \\
Freon (R12/R134A) & 360 lbs. \\
& \\
\hline
\end{tabular}

\begin{tabular}{|lr|}
\hline \multicolumn{2}{|c|}{ Material Inputs } \\
\hline \multicolumn{1}{|c|}{ Name } & \multicolumn{1}{|c|}{ Qty. } \\
\hline Vehicles for Service & 3,000 ea. \\
Clean Rags & 4,000 ea. \\
Misc. Parts & 2,000 ea. \\
Tires & 560 ea. \\
Batteries & 100 ea. \\
Grease & 100 lbs. \\
Oil Filters & 750 ea. \\
Kitty Litter & 100 lbs. \\
Mop Water & 260 gals. \\
\hline
\end{tabular}

\begin{tabular}{|c|c|}
\hline \multicolumn{2}{|c|}{ Energy Inputs } \\
\hline Name & Qty. \\
\hline Air Compressor & $3,000 \mathrm{kWh}$ \\
\hline & \\
\hline & \\
\hline & \\
\hline & \\
\hline & \\
\hline
\end{tabular}

Activity

Automotive Repairs

Activity Time Period

1 Year

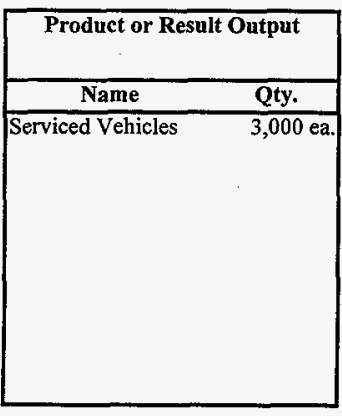

Radioactive Waste Output

Name

Qty.

\begin{tabular}{|lr|}
\hline \multicolumn{2}{|c|}{ Hazardous Waste Output } \\
\hline \multicolumn{1}{|c|}{ Name } & \multicolumn{1}{c|}{ Qty. } \\
\hline Antifreeze & 1,243 lbs. \\
Brake Fluid & 8 gals. \\
Used Oil & 300 gals. \\
Spent Solvent & 430 gals. \\
Batteries & 100 ea. \\
Kitty Litter & 100 lbs. \\
& \\
\end{tabular}

\begin{tabular}{|c|}
\hline Mixed Waste Output \\
\hline Name \\
\hline
\end{tabular}

\begin{tabular}{|lr|}
\hline \multicolumn{1}{|c|}{ Non-Harardous Waste Output } \\
\hline Name & \multicolumn{1}{c|}{ Qty. } \\
\hline Oily Rags & $4,000 \mathrm{ea}$. \\
Scrap Metal & $900 \mathrm{lbs}$. \\
Callets & $12 \mathrm{ea}$. \\
Used Parts & $400 \mathrm{lbs}$. \\
Tires & $2,000 \mathrm{ea}$. \\
Dirty Mop Water & $560 \mathrm{ea}$. \\
Concrete Clizaner & $260 \mathrm{gals}$. \\
Grease & $100 \mathrm{lbs}$. \\
Oil Filters & $100 \mathrm{lbs}$. \\
\hline
\end{tabular}

\begin{tabular}{|c|c|}
\hline \multicolumn{2}{|c|}{ Other } \\
\hline Name & Qty. \\
\hline
\end{tabular}




\section{Pollution Prevention Opportunity Assessment \\ Worksheet 3 \\ Pollution Prevention Opportunity Description}

Date 08/26/96 P2OA ID Code Automotive-1 Facility Automotive Repair Shop

Activity Automotive Repairs

P2O No. 1 P2O Title Post-Consumer Absorbent

\section{Current Practice}

When spills occur, FloorDry is used to absorb the spilled materials such as oils, fluids, and fuel. The material is disposed of in the municipal solid waste landfill. Additionally, each day each bay is mopped down with water. Once a week, the mop buckets are dumped in the sink and fresh water is added for the week's activities.

\section{Recommended Action}

Purchase Spill-Dri from Absorption Corp, for cleaning the shop floor to eliminate mop water. Purchase Absorbent W particulate for absorbing spills such as oil and fuel. Both Absorbent products are made from $100 \%$ reclaimed cellulose wood fibers from the pulp and paper industry which saves natural resources. In contrast, polypropylene sorbents are made from oil and clay sorbents are strip mined. FloorDry, which is the absorbent currently used at the automotive repair shop is a clay-like diatomaceous earth product.

Spill-Dri is a concentrated industrial absorbent that picks up spills from floors--including the sheen, and is the environmental alternative to clay. To clean up and retain a 5-gallon oil spill, a 10 -pound bag of Spill-Dri will absorb the spill whereas a 50-pound bag of clay is necessary to do the same job. Spill-Dri absorbs and retains more liquids which reduces waste and minimizes disposal costs. Some of the features of Spill Dri in comparison to clay are following:

- Clay absorbents are hazardous and contain respirable silica dust. Spill-Dri is safe and does not contain silica dust.

- Clay absorbents are International Agency for Research on Cancer IARC-listed as a probable carcinogen. Spill-Dri is not IARC listed.

- Clay absorbents have slow liquid absorption. Spill-Dri is fast at absorbing liquids.

- Clay absorbents are abrasive. Spill-Dri is non-abrasive. 
- Clay absorbents are heavy. Spill-Dri is lightweight.

- Clay absorbents are not incinerable. Spill-Dri is incinerable.

Absorbent $\mathrm{W}$ particulate is designed to contain and control hydrocarbons (wil-based liquids) while repelling water. It absorbs oil immediately on contact while repelling water--it even floats when saturated. The hydrocarbons are absorbed into the cellulose fibers, preventing leaching and draining commonly associated with polypropylene sorbents. Absorbent W also comes in socks, pillows, and pads for easy clean-up. Some of the advantages of Absorbent: W over traditional polypropylene and clay sorbents:

Absorbs liquids within fibers vs. adsorbing liquids on fibers' exterior only.

Absorbs immediately on contact, faster than polypropylene and clay.

Absorbs up to 2-3 times more volume than polypropylene sorbents, minimizing waste.

Absorbs up to 14 times more volume than clay sorbents.

Retains the liquid absorbed; prevents leaching and draining of sorbed liquicls.

Absorbs all hydrocarbons while repelling water.

Floats, even when fully saturated, for easy retrieval.

Anti-static.

One 10-quart bag of Absorbent $W$ is equivalent to one 50-pound bag of clay in volume of liquid absorbed. No free silica--prevents health problems (silicosis) associated with clay and

diatomaceous earth. The product works in all temperatures, sub-freezing to hot.

According the Absorption Corp, the absorbent can be safely placed in the r.unicipal solid waste landfill. However, Absorption Corp. recommends placing the content in a plastic garbage bag before disposing of it in the dumpster.

\section{Calculation of Waste Reduction and/or Energy Savings}

Reduced Raw Water: 1,565 lbs.

Approximately 5 gallons of dirty mop water is disposed of once a week. Using Spill-Dri will eliminate raw water consumption.

5 gallons/week $\mathrm{x} 52$ weeks/year $=260$ gallons/year

260 gals $\times 3.78$ liters $/$ gal $\times 1 \mathrm{~kg} /$ liter $\times 1 \mathrm{lb} / 0.4539 \mathrm{kgs}=2,165 \mathrm{lbs}$.

Absorption Corp. estimates that the automotive repair shop will consume 5 bags of Spill-Dri per month in cleaning the shop floor. Each bag weighs approximately $10 \mathrm{lbs}$.

$5 \mathrm{bags} / \mathrm{month} \times 12 \mathrm{months} /$ year $\times 10 \mathrm{lbs} / \mathrm{bag}=600 \mathrm{lbs} / \mathrm{year}$

$2,165 \mathrm{lbs} /$ year $-600 \mathrm{lbs} /$ year $=1,565 \mathrm{lbs} /$ year 


\section{Reduced Spill Collection: 83 Ibs.}

Approximately $100 \mathrm{lbs}$. of FloorDry is used annually to collect spills. Absorbent $\mathrm{W}$ is up to six times more absorbent than FloorDry. Each bag of Absorbent W weighs approximately 2 lbs.

6 divided by $100 \mathrm{lbs} /$ year $=16.6 \mathrm{lbs} /$ year

$100 \mathrm{lbs} /$ year $-16.6 \mathrm{lbs} /$ year $=83.4 \mathrm{lbs} /$ year

$1,565 \mathrm{lbs} / \mathrm{yr}+83 \mathrm{lbs} / \mathrm{yr}=1,648 \mathrm{lbs} /$ year

Total Annual Waste Reduction: $1,648 \mathrm{lbs} / \mathrm{year}$

\section{Calculation of Annual Cost Savings}

\section{Costs}

\section{Absorbent W: $\$ 40$}

Approximately $100 \mathrm{lbs}$. of FloorDry is used annually to collect spills. Absorbent W is up to six times more absorbent than FloorDry. Each bag of Absorbent W weighs approximately 2 lbs.

6 divided by $100 \mathrm{lbs} /$ year $=16.6 \mathrm{lbs} /$ year

The cost of Absorbent $W$ is $\$ 4.95$ per bag.

$16.6 \mathrm{lbs} / \mathrm{yr}$ divided by $2 \mathrm{lbs} / \mathrm{bag}=8 \mathrm{bags}$

8 bags $\times \$ 4.95 /$ bag $=\$ 39.60 /$ year

\section{Spill Dri: $\$ 345$}

The cost of Spill-Dri is $\$ 5.75 / \mathrm{bag}$ (if purchasing by the pallet ( 60 bags), the cost is reduced to $\$ 5.25 / \mathrm{bag}$ ). Adsorption Corp. estimates that The automotive repair shop will use approximately 5 bags/month based upon use at other small automotive shops.

5 bags/month $\times \$ 5.75 /$ bag $\times 12$ months $/$ year $=\$ 345 /$ year

\section{Benefits}

\section{Reduced Raw Water Consumption: \$0}

Approximately 260 gallons of dirty mop water is disposed of weekly. The City of Richland charges $\$ .005 /$ gallon which is a negligible cost. 


\section{Reduced Sewer Disposal: \$0}

The automotive repair shop's sewer disposil costs are below the minimum charge of $\$ 47.00$. Therefore, the reduced sewer disposal is negligible.

\section{Eliminate Use of FloorDry: $\$ 28$}

For a $25 \mathrm{lb}$ bag, FloorDry costs $\$ 6.95 / \mathrm{bag}$. Approximately $100 \mathrm{lbs}$ of FloorDry is used annually. 4 bags $/$ year $\times \$ 6.95 /$ bag $=\$ 27.80 /$ year

\section{Eliminate Use of Concrete Cleaner: $\$ 100$}

The cost of DJ's Concrete Cleaner is $\$ 100$ for a 100 pound drum. The product is biodegradable and contains no phosphates. Approximately 100 pounds are consumed anr.ually.

\section{Reduced Labor: \$546}

The shop's personnel estimate that a $35 \%$ reduction in labor would be achieved by using absorbent in place of mopping. It takes approximately 5 hours to mop the shop floor at a cost of $\$ 6.00$ /hour.

5 hours/week $\times \$ 6.00 /$ hour $\times 52$ weeks/yr $\times .35=\$ 546$

Total Annual Costs Savings: $\$ 289$

Total Annual Costs: $\$ 385$

Total Annual Benefits: $\$ 674$

Benefits - Costs $=$ Total Annual Cost Savings

$\$ 674-\$ 385=\$ 289$

\section{Calculation of Implementation Cost and Payback}

There is no up-front implementation cost for switching products and practices. The payback is immediate. 


\section{Vendor/Contact Information}

Absorption Corp.

Steve Valentine

P.O. Box 5667

Bellingham, WA 98227-5667

Phone: (360) 734-7415 X3009

Fax: (360) 671-1588 


\begin{tabular}{|c|c|c|}
\hline \multicolumn{3}{|c|}{$\begin{array}{l}\text { Pollution Prevention Opportunity Assessment } \\
\text { Worksheet } 3 \\
\text { Pollution Prevention Opportunity Description }\end{array}$} \\
\hline \multicolumn{3}{|c|}{ Activity Automotive Repairs } \\
\hline P2O No. 2 & P2O Title Improved Solvent $\mathrm{O}_{1}$ & Ing Practices \\
\hline
\end{tabular}

\section{Current Practice}

Leo's Line Up and Tires uses two parts cleaners serviced by Safety Kleen ${ }^{\top \mathrm{M}}$--one green and one red. The parts washers are used for cleaning and degreasing metal parts. The green parts cleaner uses a cyclonic force that separates contaminants from the solvent. As solvent becomes contaminated during the normal parts cleaning process, used solvent is drawn into the system's cyclonic separator where centrifugal action filters out the solid particles trapping them in a separate chamber for later removal by Safety Kleen ${ }^{\text {TM }}$. The clean solvent is then drawn upward for reuse. This technique virtually eliminates evaporation loss. The "Premium Gold Solvent" that flows through the parts cleaner features a higher flashpoint $\left(150^{\circ} \mathrm{F}\right)$ and a lower vapor pressure than traditional parts cleaning solvents. This formula contains little or no (less than .4 ppm) benzene, chlorinated solvents, or ozone-depleting substances.

The red unit is an adjustable parts cleaner which rolls right up to the job, then adjusts to the most convenient height. A five gallon reservoir holds conventional solvent, which is pumped through a brush-tipped hose for easy parts cleaning. Solvent running into the sink drains back into the reservoir tank. Safety Kleen's ${ }^{\text {TM }}$ A105 Solvent Recycle is used in the red parts washer which contains petroleum distillates.

The parts washers are located on either end of the shop floor--one in Bay 2 and the other in Bay 5. They were placed in these locations to reduce foot traffic.

For hard to clean parts, mechanics often lay the part in the solvent sink and let the solvent run on the part for several hours. This practice can evaporate solvent quickly as it ras up to a $40 \%$ evaporation rate according to Metro-Seattle and the Washington State Department of Ecology.

The solvent-laden parts are cumbersome to put back on the vehicle wet. Therefore, the mechanics either wipe the part off with a rag, or rinse the part in a bucket of water. 


\section{Recommended Action}

Improving solvent practices involves several steps to ensure the most efficient use of solvent. All of the opportunities are fairly simple and are grouped together to realize the greatest savings.

Replace the red parts washer with a green cyclonic washer which uses a less hazardous solvent and also reduces evaporation loss.

Relocate the parts washers side by side in a central location and implement a two-stage cleaning system. Use the first tank for pre-soaking parts in "dirty" solution and the second tank containing fresh cleaning solution for the final cleaning. Replenish the solution in the first tank with "used" solution from the second tank to double the life of the solvent. To reduce evaporation, locate the solvent sinks away from heat sources.

To further reduce evaporation, turn off the solvent stream when not in use.

Allow parts to drain completely by installing wire racks inside the solvent sinks. Excess solvent will drip off and be captured in the sink for reuse. The draining process will also eliminate the need to wipe or rinse off parts to remove solvent.

Lastly, replace solvent only when it is too dirty. This will earn The automotive repair shop waste minimization credit with Safety Kleen ${ }^{\mathrm{TM}}$.

Calculation of Waste Reduction and/or Energy Savings

Evaporative Savings: 95 gallons

By replacing the red unit with a green cyclonic unit, evaporation loss will be eliminated during the washing process. Each time the red unit is serviced, a new 55-gallon drum of solvent is replaced. The red unit is serviced every 12-weeks. According to Metro-Seattle and the Washington State Department of Ecology, solvent has up to a $40 \%$ evaporation rate.

52 weeks/yr divided by 12 weeks/service $=4.3$ services/year

4.3 services/year $\times 55$ gallons/service $\times .40=94.6$ gallons

\section{Replace Solvent Less Often: 287 gallons}

The green parts washer is currently on a 15-week service cycle. A discount can be achieved through Safety-Kleen' ${ }^{\top M}$ waste minimization credit feature. This can be realized if the service representative adds up to 2 gallons of solvent, and a filter and enhancer to clean the solvent.

The red unit is on a 12-week cycle and waste minimization credit is not available. 
If two green units are placed side by side for two-stage cleaning, Safety Kleen ${ }^{\mathrm{rM}}$ anticipates that the 15-week cycle can be extended to 20 -weeks and only the truly dirty solvent from the first tank will be disposed of as hazardous waste. The According to Safety Kleen ${ }^{\top M}$, the green units are replaced half as often as the red tanks. Only one green unit will need to be replaced as the "clean" solvent in the second drum will move to the "dirty" stage.

Red Unit:

52 weeks $/ y r$ divided by 12 weeks $/$ service $=4.3$ services $/$ year

4.3 services $/$ year x 55 gals $/$ service $=237$ gallons $/ y r$

Green Unit 15-Week Service:

52 weeks/yr divided by 15 weeks $/$ service $=3.5$ services $/$ year

3.5 services $/$ year $\times 55$ gals $/$ service $=193$ gallons $/ y r$

Green Unit 20-Week Service:

52 weeks $/$ yr divided by 20 weeks/service $=2.6$ services $/$ year

2.6 services $/$ year $\times 55$ gals $/$ service $=143$ gallons $/ \mathrm{yr}$

$193 \mathrm{gals} / \mathrm{yr}-143 \mathrm{gals} / \mathrm{yr}=50$ gallons $/$ year

Total Solvent Reduction: 237 gals +50 gals $=287$ gallons

\section{Draining Parts: 86 gallons}

Safety Kleen ${ }^{\mathrm{TM}}$ estimates that $20 \%$ of the solvent can be reclaimed through a drip-dry process. The automotive repair shop is currently using 430 gallons of solvent annually.

Red Unit:

52 weeks/yr divided by 12 weeks/service $=4.3$ services $/$ year

4.3 services $/$ year $x 55$ gallons $/$ service $=237$ gallons $/$ yr

Green Unit:

52 weeks/yr divided by 15 weeks/service $=3.5$ services/year 
3.5 services/year $\times 55$ gallons/service $=193$ gallons $/ \mathrm{yr}$

430 gals $\times .20=86$ gallons

Total Waste Reduction: 95 gals/yr +287 gals/yr +86 gals/yr $=468$ gallons/year

\section{Calculation of Annual Cost Savings}

\section{Costs}

\section{Green Solvent Tank and Solvent: $\$ 415$}

Although 2 green solvent units will be used under this initiative, the cost will be for 1 solvent unit. Only one drum will be replaced per service call as the "clean" solvent will be moved to the "dirty" stage. According to Safety Kleen ${ }^{7 M}$, the green units are replaced half as often as the red tanks. Safety Kleen ${ }^{\mathrm{TM}}$ charges $\$ 159.75$ every 20 -weeks for the green unit. Each service call includes the cost of the solvent, the use of the solvent washer, and disposal.

\section{Green Unit--20 Week Service}

52 weeks/yr divided by 20 weeks/service $=2.6$ services/year

2.6 services $/$ year $\mathrm{x} \$ 159.75 /$ service $=\$ 415.35 /$ year

\section{Benefits}

\section{Reduced Solvent: $\$ 874$}

The automotive repair shop currently spends $\$ 73.25$ every 12-weeks for the red unit and $\$ 159.75$ every 15-weeks for the green unit. Each service call includes the cost of the solvent, the use of the solvent washer, and disposal cost. Safety Kleen ${ }^{\mathrm{TM}}$ estimates that the service call for the green units can be extended to 20 -weeks and only one drum will be replaced per service call as the "clean" solvent will be moved to the "dirty" stage. According to Safety Kleen" ${ }^{\mathrm{TM}}$, the green units are replaced half as often as the red tanks.

\section{Red Unit:}

52 weeks/yr divided by 12 weeks/service $=4.3$ services/year

4.3 services $/$ year $\times \$ 73.25 /$ service $=\$ 314.98 /$ year

Green Unit--15 Week Service 
52 weeks/yr divided by 15 weeks/service $=3.5$ services/year

3.5 services/year x $\$ 159.75 /$ service $=\$ 559.13 /$ year

Green Unit--20 Week Service

52 weeks/yr divided by 20 weeks/service $=2.6$ services $/$ year

2.6 services/year x $\$ 159.75 /$ service $=\$ 415.35 /$ year

$\$ 559.13-\$ 415.35=\$ 143.78$

Only 1 green unit will be replaced per service call saving an additional $\$ 415.35$ annually.

$\$ 314.98+\$ 143.78+\$ 415.35=\$ 874.11$

\section{Evaporative Savings: $\$ 117$}

According to Metro-Seattle and Washington State Department of Ecology, $40 \%$ evaporation loss can be reclaimed by changing from the red unit to the green unit. By replacing the red unit with a green cyclonic unit, evaporation loss will be eliminated during the washing process. Each time the red unit is serviced, a new 55-gallon drum of solvent is replaced. The red unit is serviced and a new 55 -gallon drum replaced every 12 -weeks at $\$ 73.25$ per service.

52 weeks/yr divided by 12 weeks/service $=4.3$ services/year

4 services/year $x 55$ gallons/service $\times .40=88$ gallons

88 gals $/$ year $\times \$ 73.25 /$ service $\times 1$ service $/ 55$ gals $=\$ 117.20 /$ year

\section{Draining Parts: $\$ 172$}

Safety Kleen ${ }^{\top M}$ estimates that $20 \%$ of the solvent can be reclaimed through a drip-dry process. Installing wire racks inside the solvent units will capture the solvent for reuse. The automotive repair shop is currently using 430 gallons of solvent annually at a cost of $\$ 874$.

$\$ 874$ divided by 430 gallons $=\$ 2 /$ gallon

430 gallons $\times .20 \times \$ 2 /$ gal $=\$ 172$

Waste Minimization Credit: $\$ 24$ 
Waste Minimization Credit can be earned only by utilizing the green solvent units. Credit will be received if the service representative adds up to 2 gallons of solvent, a filter and enhancer. The filter and enhancer helps settle the sludge and clean the solvent. Based upon results from small automotive shops, Safety Kleen ${ }^{\mathrm{TM}}$ estimates that The automotive repair shop will receive 1 discount per year. The Waste Minimization Credit is a $15 \%$ discount on the service call.

$\$ 159.75 \times .15=\$ 23.96$

Total Annual Costs: $\$ 415$

Total Annual Benefits: \$1,187

Total Annual Cost Savings: $\$ 772$

Benefits - Costs $=$ Total Annual Cost Savings

$\$ 1,187-\$ 415=\$ 772$

\section{Calculation of Implementation Cost and Payback}

Wire racks are $\$ 17.00$ each from Safety $\mathrm{Kleen}^{\mathrm{TM}}$. The racks are sold separately and mount directly on the parts washer for draining purposes. One rack will be purchased for each solvent unit.

Implementation Cost divided by Annual Cost Savings = Payback

$\$ 34$ divided by $\$ 772=.04$ years

\section{Vendor/Contact Information \\ Safety-Kleen ${ }^{\mathrm{TM}}$ Corporation}

Terry Hoberecht

814 East Ainsworth

Pasco, WA 99301

Phone: (509) 547-8771

Fax: (509) 547-1644 


\section{Pollution Prevention Opportunity Assessment Worksheet 3 \\ Pollution Prevention Opportunity Description}

Date $08 / 26 / 96$ P2OA ID Code Automotive-1 Facility Auton Iotive Repair Shop

Activity Automotive Repairs

P2O No. $3 \quad$ P2O Crush Oil Filters and Recycle

\section{Current Practice}

Used oil filters are punctured and drained for 24-hours before disposal in the municipal solid waste landfill.

\section{Recommended Action}

Crush oil filters and recycle the filter as scrap metal. The oil can be recycle 1 as used waste oil too. The MBI-1 oil filter crusher manufactured by the Main Squeeze ${ }^{T M}$ of Monroe Washington provides over $98 \%$ recovery of waste oil which is the industry maximum. This recovery rate includes used oil within the filter, oil which remains bound up in the filtration media, and oil trapped in the filters anti-drain casing. The MBI-1 crusher operates at $50,0010 \mathrm{lbs}$ of force. Steel recyclers throughout the U.S. are beginning to apply a crush level standard that all crushed filters will have to meet or beat. A minimum force of $40,000 \mathrm{lbs}$. exerted upon each filter individually, is becoming the standard requirement to make a filter suitable for scrap feed steel production.

The MBI-1 is a lightweight machine which comes completely assembled, with filter, regulator, and lubricator installed. All that is required for installation is to bolt the unit to the wall and attach the existing shop air.

Some of the features, characteristics, and benefits of the MBI-1 oil filter cru; sher are as follows:

Air powered hydraulic, input $8.6 \mathrm{cfm}$ at $85 \mathrm{psi}$, output $10,000 \mathrm{psi}$.

Machined from solid steel billet, magnetic particle tested, roller burnished bore; shaft is 2-1/4" diameter 450 hard chrome, rated capacity at 10,000 psi 25.8 tons. Meets or exceeds American National Standards Institute ANSI B30.1.

The frame is totally welded high-strength steel with minimum tensil strength of 180,000 psi. Stress relieved.

The thrust plate is machined from hardened chromolly. 
The MBI-1 filter press made is America with a lifetime warranty.

Total Force $\quad 51,600 \mathrm{lbs}$

Weight $85 \mathrm{lbs}$.

Height - 28.5"

Cycle Time $\quad 45$ secs. @ 85 psi max

Width 8.25"

Depth 7.25"

Capacity $\quad 6$ " $\mathrm{x} 4.25$ " dia. filter

Mounting 4 bolts spread pattern

Finish Black powder coat

\section{Calculation of Annual Waste Reduction and/or Energy Savings}

Filter Recycling: 1,500 lbs.

The MBI-1 reduces filters 20 percent their original size. Approximately 750 used oil filters are generated annually at an average size of 6" high x 4.5" diameter. According to The shop's personnel, the average weight of one filter, drained for one hour is $2.0 \mathrm{lbs}$.

750 filters $/$ year $\times 2.0 \mathrm{lbs} /$ filter $=1,500 \mathrm{lbs} /$ year

Oil Recycling: 514 lbs.

In addition, with the MBI-1, The automotive repair shop can recycle $98 \%$ of the oil contained in the used filter. Simply dumping and draining filters retains up to $44 \%$ of the filter's oil according to Safety Kleen ${ }^{T M}$. Each drained (hot drained for 24 hours) filter still contains approximately 12 ounces of oil. Motor oil has a specific gravity of 0.877 .

750 filters/year $\times 12 \mathrm{oz} /$ filter $=9,000 \mathrm{oz} /$ year

$9,000 \mathrm{oz} /$ year $=70.31$ gallons

70.31 gals $\times 3.783$ liters $/$ gal $\times 0.877 \mathrm{SpG} \times 1 \mathrm{~kg} / 1$ liter $\times 1 \mathrm{lb} / .4539 \mathrm{kgs}=513.91 \mathrm{lbs}$.

Total Waste Reduction

$1,500 \mathrm{lbs} / \mathrm{yr}+514 \mathrm{lbs} / \mathrm{yr}=2,014 \mathrm{lbs} / \mathrm{year}$

Calculation of Annual Cost Savings

Costs

Used Oil Recycling: \$0 
Leo's Line-Up and Tire has an established used oil recycling contract with Safety Kleen ${ }^{\mathrm{TM}}$. The additional oil generated ( 70 gallons) by crushing the filters can be added to the existing used oil collection program at no extra cost per Terry Hoberecht at Safety Kleen ${ }^{\mathrm{TM}}$.

\section{Benefits}

\section{Reduced Filter Disposal Cost: $\$ 654$}

Currently, The automotive repair shop does not pay a hazardous waste disposal fee for used oil filters. The filters are punctured and drained for 24-hours and then disposed of in the municipal solid waste landfill. However, the EPA is proposing stricter regulations for used oil.

As of January 1, 1995, Minnesota, Texas and Rhode Island outlawed oily waste in their landfills to alleviate ground water pollution. For every quart of oil that is introduced into the ground water, enough water is ruined to supply 30 people with drinking water for a lifetime. It is estimated that in time, even the smaller counties will treat used oil filters as hazardous waste and not accept filters in their landfills.

Safety Kleen ${ }^{\top M}$ charges $\$ 109 /$ drum (30-gallon drum) for pick up and recycling of used oil filters. According to Main Squeeze ${ }^{\mathrm{TM}}$, approximately 125 filters fit in a drum. The automotive repair shop generates approximately 750 filters annually

750 filters/yr divided by 125 filters $/$ drum $=6$ drums $/$ year

$6 \mathrm{drums} /$ year $\mathrm{x} \$ 109 / \mathrm{drum}=\$ 654$

\section{Recycling Revenue: $\$ 15$}

The MBI-1 reduces filters 20 percent their original size. Approximately 750 used oil filters are generated annually at an average size of 6" high x 4.5" diameter. According to The automotive repair shop personnel, the average weight of one filter, drained for one hour is $2.0 \mathrm{lbs}$.

750 filters/year $\times 2.0 \mathrm{lbs} /$ filter $=1,500 \mathrm{lbs} /$ year

Tommy's Steel and Salvage is the only recycler in the Tri-Cities who will accept crushed used oil filters for scrap metal recycling. The current cost per pound is $\$ .01$.

$1,500 \mathrm{lbs} /$ year $\times .01 / 1 \mathrm{bs}=\$ 15.00$

Total Annual Costs: $\$ 0$

Total Annual Benefits: $\$ 669$

Total Anmual Cost Savings: $\$ 669$ 
Benefits - Costs = Total Annual Cost Savings

$\$ 669-\$ 0=\$ 669$

\section{Calculation of Implementation Cost and Payback}

Implementation Cost divided by Cost Savings = Payback

The cost of the MBI-1 oil filter crusher is $\$ 1,295$ each.

$\$ 1,295$ divided by $\$ 669=1.94$ years

\section{Vendor/Contact Information}

Main Squeeze ${ }^{\mathrm{TM}}$

17476-H 147th Street SE

Monroe, WA 98272

Phone (800) 845-7404

Fax (360) 794-9126

Safety Storage, Inc.

2301 Bert Drive

Hollister, CA 95023

Phone: (408) 637-5955

Fax: (408) 637-7405

Safety Kleen ${ }^{\mathrm{TM}}$ Corp.

Terry Hoberecht

814 East Ainsworth

Pasco, WA 99301

Phone: (509) 547-8771

Fax: (509) 547-1644 


\section{Pollution Prevention Opportunity Assessment \\ Worksheet 4 \\ Pollution Prevention Opportunities Summary}

Date 09/09/96

P20A ID Code Automotive-1

Facility Automotive Repair Shop

Activity Automotive Repairs

\begin{tabular}{|c|c|c|c|c|c|c|}
\hline P2ONo. & P20 Title & $\begin{array}{c}\text { Waste } \\
\text { Class } \\
\text { Reduced }\end{array}$ & $\begin{array}{l}\text { Annual Waste } \\
\text { Rerluction or } \\
\text { Energy Savings }\end{array}$ & $\begin{array}{c}\text { Estimated } \\
\text { Annual } \\
\text { Savings }\end{array}$ & $\begin{array}{c}\text { Estimated } \\
\text { Implumentation } \\
\text { Cost }\end{array}$ & Payback \\
\hline 1 & $\begin{array}{l}\text { Post-Consumer } \\
\text { Absorbent }\end{array}$ & Sanitary & $1,648 \mathrm{lbs}$ & $\$ 289$ & $\$ 0$ & Immediate \\
\hline 2 & $\begin{array}{l}\text { Improved Solvent } \\
\text { Operating Practices }\end{array}$ & Hazardous & 468 gals. & $\$ 772$ & $\$ 34$ & 0.04 \\
\hline 3 & $\begin{array}{l}\text { Crush Oil Filters } \\
\text { and Recycle }\end{array}$ & Sanitary & $2,014 \mathrm{lbs}$ & $\$ 669$ & $\$ 1,295$ & 1.94 \\
\hline
\end{tabular}




\section{Other Brainstorming Opportunities}

Portable oil/antifreeze filtration system

Solvent recycling/reuse system

Solvent alternatives

Institute just in time purchasing

Use first in first out policy

Use drip trays under leaking cars and removed parts

Determine how clean parts need to be-cleaning may not be necessary in some instances

Remove bulk of dirt and grime from parts with wire brush prior to solvent cleaning

Educate the customer

Set up contracts for recyclables

Segregate transmission oil from used motor oil

Pre-rinse parts before using solvent

Institute good housekeeping policy

Purchase re-refined or recycled products (oil, transmission fluid, gear oil, solvents, antifreeze, reconditioned parts, re-treaded tires, refurbished batteries, and air conditioner refrigerant) 


\section{Pollution Prevention Opportunity Assessment Worksheet 5 Final Summary}

Date 09/10/96 P2OA ID Code Automotive-1 Facility Automotive Repair Shop Activity Automotive Repairs

\section{Proposed Opportunities and Discussion}

Three pollution prevention opportunities were investigated in detail from a list of brainstorming ideas.

Opportunity \#1 Post-Consumer Absorbent: Absorbent made from 100\% reclaimed cellulose wood fibers from the pulp and paper industry will save natural resources. The absorbent will replace the FloorDry currently being used at The automotive repair shop fo: spills and eliminate the routine mopping of the shop floor.

Opportunity \#2 Improved Solvent Operating Practices: Several initiatives will increase the life of the solvent. (1) Replace the red parts washer with a green cyclonic washer which uses a less hazardous solvent and eliminates evaporation; (2) Relocate the parts washers side by side for two-stage cleaning; (3) Turn off the solvent stream when not in use; (4) Drain parts; and (5) Replace solvent only when it is dirty.

Opportunity \#3 Crush Oil Filters and Recycle: By crushing used oil filters for recycling, $98 \%$ of the oil will be removed from the filter prior to recycling and the filter media can be recycled locally as scrap metal.

\section{Recommendations and Schedule for Implementation}

Each of the opportunities investigated have excellent payback periods and all should be implemented within the year. There are additional safety benefits for the eniployees handling spill clean-up. For example, the post-consumer absorbent does not contain sespirable silica dust, and it is not a probable carcinogen. These features reduce OSHA requirements and can improve employee morale.

Special attention should be made to the improved solvent operating practices. Each of the initiatives should be implemented for the optimum cost savings. However, each can be implemented independently of the others and still minimize waste in each cése.

The automotive repair shop has an environmental slogan (Concerned about your safety and our environment) which supports implementation of these additional pollution prevention measures. 
Additionally, The automotive repair shop has recently opened another automotive service center located just a few blocks from the original location. Each of the pollution prevention opportunities can be easily implemented a new the shop and realize twice the savings. 
Appendix D: Formal Assessments 


\section{Pollution Prevention Assessment}

Winery 


\section{Pollution Prevention Assessment Worksheet 1 \\ Team and Activity Description}

Date 10/04/96 ID Code Winery-1 Activity Winemaking

Business Name and Address Winery, Riclland

Business Contact and Phone

\begin{tabular}{|lc}
\hline Team Members $\left({ }^{*}\right.$ Leader) & Telephone \\
& \\
Jill Engel-Cox & $372-0307$ \\
Dr. James Wise & $375-4478$ \\
Matt Zybas & $943-7467$ \\
Mary Betsch $*$ & $372-1627$ \\
\hline
\end{tabular}

\section{Description of Activity to be Examined in this Assessment}

At The winery, harvest begins in early October and lasts for approximately 1 month. The winemaker determines the exact time for picking grapes by first testing small clusters in a laboratory which have been stemmed and crushed.

\section{Crushing:}

Opposite the cellar is a large concrete pad where much of the initial stages of the wine-making begins. Here, the red grapes are brought in from the fields in large bins. The grapes are sent to a crusher-stemmer to remove the leaves and stems from the grapes. The drun of the crusherstemmer rotates so that the juice, seeds, and skins easily fall through the holes to a basin beneath, while the stems and leaves, which are too large to slip through, stay inside. In the process of crushing, juice inevitably spends some time in contact with the grape skins. This can contribute both color and possibly some degree of bitter flavor, depending upon the length of exposure and the temperature of the grapes. A ton of grapes yields somewhere between 60 to 70 cases of wine.

\section{Pressing:}

Next, the juice and the grape skins are put in a basket press and the grapes are pressed. Pressing occurs in October and runs through November. The basic mechanics of pressing involve forcing the just-harvested grapes against an immovable object to extract juice through pressure. With the basket press, pressure is exerted downward and the juice escapes through the slots. As the amount of pressure used in the winepress increases, so does the likelihood that the juice will contain unwanted flavor compounds. Under extreme pressure, grape skins can be so severely pressed that they shred and release harsh, bitter flavors. The remaining "cake" from the basket press (seeds and skins) is spread onto the vineyard as compost. 


\section{Fermentation:}

Wine is the result of fermentation, a natural process in which the sweet juice of grapes is converted into alcohol, carbon dioxide, and another liquid through the action of yeast and other microflora. Fermentation occurs when the yeast metabolizes the sugar and in the process converts it into carbon dioxide and ethanol, an alcohol. As soon as all available sugar has been consumed, the yeast stops working. About 55 to $60 \%$ of the sugar in grapes, a combination of fructose and dextrose, is converted into alcohol by the yeast with the remaining 40 to $45 \%$ becoming carbon dioxide that escapes into the air. At its most active stage, fermentation generates considerable heat. In general, the cooler the temperature, the longer the fermentation time.

The juice from the basket press is pumped into stainless steel tanks where it is fermented for several weeks. Sulfur and yeast are added and the tanks are kept at a cold temperature of $45^{\circ} \mathrm{F}$. Glycol is used to chill the tanks which are stored outside on the concrete pad. Sediment, referred to as lees, from fermentation is approximately $1-3 \%$ of the total volume.

White grape juice is trucked into the winery and stored directly in the stainless steel tanks. Occasionally, yeast and other additives are added.

\section{Clarifying:}

After fermentation, a range of particles, both visible and invisible, remain in wine--among the most common being spent yeast cells, protein particles, tannins, and grape skins. Clarification is the process of removing such particles from newly fermented wines so as to leave the wines bright, clear, and visually acceptable. It also serves to remove many potential health dangers and prepare the wine for bottling. At the winery, clarification takes place during the winter months of January and February.

Two types of clarification are practiced at The winery--racking and filtration. Basically, racking is the transfer of wine from one container to another so carefully that only clear wine moves, and sediment along with a small amount of wine is left behind. It is natural primarily because it relies on gravity to pull unwanted particles to the bottom of the container. After allowing some time for settling to occur, the winemaker removes the clearer wine from the fermentation lees (mainly yeast cells, skins, and seeds). Racking stops the fermentation process. The fermentation tanks have racking valves located at about the anticipated sediment level. The clearer wine is pumped into the next tank through a hose attached to the valve.

Racking removes only those particles that precipitate out from the wine naturally and therefore filtering is used to remove the rest of the unwanted particles. Rough, fine, and sterile filtration are practiced before the wine is bottled. The wine is pumped through a series of screens holding pads or membranes which vary in porosity. The pads are coated with diatomaceous earth. Sterile filtration, using the finest pads, is able to capture the smallest suspended particle and is completed just prior to bottling. Used filters are washed in a washing machine with bleach and reused. 
The stainless steel tanks are cleaned with a pressure washer using hot water. Soda ash is used to dissolve the tartaric acid buildup on the tank walls.

\section{Aging:}

All the wines age in 55-gallon oak barrels inside the cellar. The new barrels are used for white wines and thereafter for red wines due to color. As wine ages in wood, the alcohol and tannins leach out flavors from the container, and these wood flavors are usually desirable additions. Generally, the smaller the container, the faster the aging process. The wine is stirred once a week which makes the wine sweet.

\section{Stabilizing and Bottling:}

Putting the wine into bottles is the final step in the winemaking process and occurs in the spring. Cold stabilization forces the wine to form natural tartrate crystals in a storajge vessel to prevent the harmless but unsightly crystals from showing up in the bottled wine. Wines are coldstabilized by being chilled at $25^{\circ} \mathrm{F}$ for several days. The cellar remains at $60^{\circ} \mathrm{F}$ when not under cold-stabilization. A master blend is created in a large tank just before bottling. This process allows the barrel-aged wines time to be combined and "marry" achieving uniformity of the entire bottling. The wine is bottled, corked, labeled and put in cases to sell locally' and across the United States.

\section{Miscellaneous:}

For sanitation purposes, a large quantity of water is used to wash down equipment and the concrete pad. In addition, water is used inside the cellar area. The water is received from a deep well and the majority of gray water is sent to a down-well on the winery property. The remaining water used is absorbed into the ground or evaporated.

The winery has two on-demand gas hot water heaters which remain at a constant temperature. Additionally, two oversized 25-ton chillers are used to keep the stainless ste el tanks cold and also refrigerate the cellar.

Used pallets are stored outside and collected by the glass company. Other solid wastes such as cardboard, wood, and glass are recycled at Clayton Ward in Richland.

The vineyard, approximately 4 acres, is itrigated with drip irrigation and a nister. All the pruning remains are chipped and laid down as bark in the garden areas of the business. No sprays have been applied to the vineyard. However, mildew spray, weed spray, and fertilizer are scheduled for application next year.

The cellar is approximately $2,000 \mathrm{ft}^{2}$. It is insulated and built into the hillsicle providing additional insulation. The doors however are not weather-stripped. 

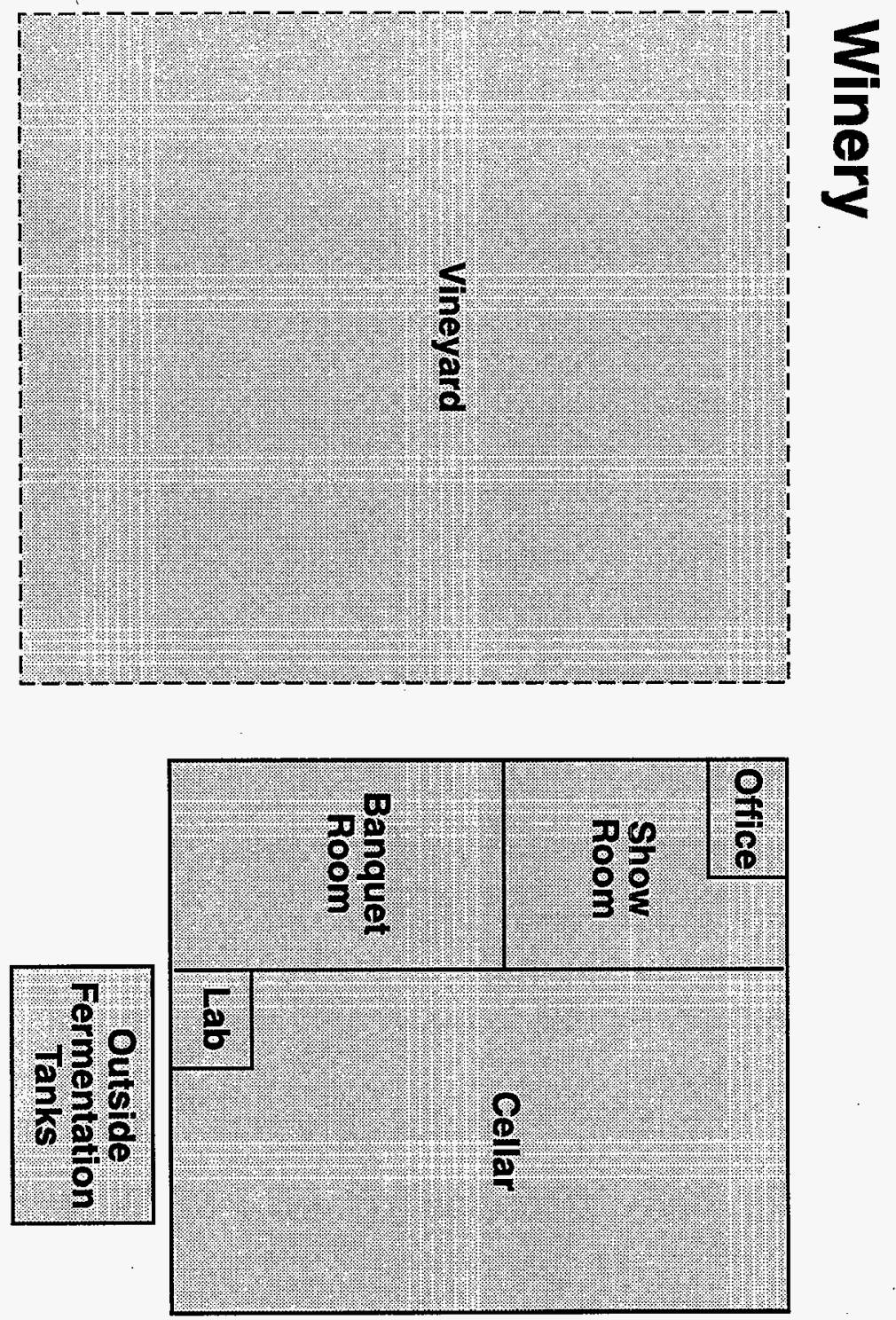


\section{Pollution Prevention Assessment \\ Worksheet 2 \\ Flow Diagram}

Date 10/07/96 ID Code Winery-1 Business Winery

Activity Winemaking

\begin{tabular}{|lr|}
\hline \multicolumn{2}{|c|}{ Chemical Inputs } \\
\hline \multicolumn{1}{|c|}{ Name } & \multicolumn{1}{c|}{ Qty. } \\
\hline Sodium Hydroxide & $1 \mathrm{qt}$. \\
Buffer Solutions & $<1 \mathrm{qt}$. \\
Tartaric Acid & $0-200 \mathrm{lbs}$. \\
DE & $1 \mathrm{ton}$ \\
Bentonite Clay & $1 \mathrm{ton}$ \\
Soda Ash & $50 \mathrm{lbs}$. \\
Cleaning Product & $25 \mathrm{lbs}$. \\
Weed Spray & 2.5 gals. \\
Fertilizer & $1,500 \mathrm{lbs}$. \\
Mildew Spray & $25 \mathrm{lbs}$. \\
& \\
& \\
\end{tabular}

\begin{tabular}{|lr|}
\hline \multicolumn{2}{|c|}{ Material Inputs } \\
\hline \multicolumn{1}{|c|}{ Name } & \multicolumn{1}{c|}{ Qty. } \\
\hline Red Grapes & 16 tons \\
White Grape Juice & 18,000 gals. \\
Filter Sheets & 250 ea. \\
Filter Membranes & 3 ea. \\
Water/Pre-Filters & $3 \mathrm{ea}$. \\
Cardboard--Iroduct & $10,000 \mathrm{ea}$. \\
Cardboard--Ship & $300 \mathrm{lbs}$. \\
Corks & $120,000 \mathrm{ea}$. \\
Pack Peanuts & 70 bags \\
Glass Bottles & $120,000 \mathrm{ea}$. \\
Oak Barrels & $10 \mathrm{ea}$. \\
Rinsewater & 5,000 gals. \\
Yeast & $50 \mathrm{lbs}$. \\
Pruning Stocks & $9,000 \mathrm{lbs}$. \\
\hline
\end{tabular}

\begin{tabular}{|lr|}
\hline \multicolumn{3}{|c|}{ Energy Inputs } \\
\hline Name & \multicolumn{1}{c|}{ Qty. } \\
\hline Electrical Equip. & $121,320 \mathrm{kWh}$ \\
Gas Heating & $20,700 \mathrm{kWh}$ \\
& \\
\end{tabular}

\begin{tabular}{|c|}
\hline Activity \\
Winemaking \\
Activity Time Period \\
1 Year \\
\hline
\end{tabular}

\begin{tabular}{|cc|}
\hline \multicolumn{2}{|c|}{ Product or Result Output } \\
\hline Name & Qty. \\
\hline Bottied Wine & 10,000 Cases \\
& \\
& \\
\hline
\end{tabular}

\begin{tabular}{|lc|}
\hline \multicolumn{2}{|c|}{ Hazardous Waste Output } \\
\hline Name & Qty. \\
\hline Lees/DE & 400 gals. \\
Lees/Bentonite & 100 gals. \\
& \\
& \\
\hline
\end{tabular}

\begin{tabular}{|lr|}
\hline Non-Hazardous Waste Output \\
\hline \multicolumn{1}{|c|}{ Name } & \multicolumn{1}{c|}{ Qty. } \\
\hline Red Pomace & 1 ton \\
Red Stems & 1 ton \\
Red Pressed Lees & 36 gals. \\
White Stenis & 1,000 gals. \\
White Porrace & 1,000 gals. \\
\hline
\end{tabular}




\section{Pollution Prevention Assessment Worksheet 3 \\ Pollution Prevention Opportunity Description}
Date $11 / 07 / 96$
ID Code Winery-1
Business Winery

Activity Winemaking

P2O No. 1 P2O Title Reflective Roof Coating

\section{Current Practice}

The $2,000 \mathrm{ft}^{2}$ cellar is maintained at a constant $60^{\circ} \mathrm{F}$ and cooled in the summer months with glycol chillers.

The aesthetics of the exterior building is extremely important as visitors frequent the facilities for receptions and tours.

The 5-year old pitched roof is comprised of asphalt shingles and is dark-colored which can absorb $70 \%$ to $90 \%$ of the radiant energy from the sun that strikes the surface. Some of this absorbed energy is then transferred into the cellar by way of conduction, resulting in heat gain. In contrast, light-colored surfaces effectively reflect most of the heat away from the building.

The roof is insulated with insulation greater than $\mathrm{R}-11$.

The mean summer temperature in Richland according to the Hanford Meteorology Center is 70 ${ }^{\circ} \mathrm{F}$ from 1945 to 1990 , and the average high temperature is $84^{\circ} \mathrm{F}$.

\section{Recommended Aetion}

Paint the area over the cellar with a reflective roof coating to improve energy efficiency and extend or maximize roof service life by reflecting harmful ultraviolet radiation away from the roof membrane. White paint is $90^{\circ} \mathrm{F}$ cooler than black paint. Reflective coatings also can slow the aging process by reducing day-to-day membrane temperatures. Simulation analysis suggests that a reflective roof color can cut a buildings cooling load by $10-60 \%$. The higher numbers are associated with uninsulated roofs.

One of the earliest whole-building studies that measured cooling-energy savings from reflective roof coatings was performed by the Mississippi Power Company. The utility monitored two identical side-by-side single-story commercial office buildings after the roof of one had been covered with a reflective white elastomeric coating. Both existing buildings had R-11 roof 
insulation. The results of the experiment indicated that summertime air conditioning was reduced by $22 \%$ in the building with the reflective roof coating.

Spot measurements under full sun at midsummer in Florida showed shingls: surface temperatures of $160-170^{\circ} \mathrm{F}$ prior to the reflective roof treatment, compared to $110^{\circ} \mathrm{F}$ after the coating was applied. The analysis assumed that with an $81^{\circ} \mathrm{F}$ average summer temperature, a reflective roof coating would reduce energy consumption by $10 \%$ (i.e. $35 \mathrm{kWh}$ versus $39 \mathrm{liWh}$ per day).

Consideration of the color of the roof coating is important to The winery. The Florida Solar Energy Center has evaluated the solar reflectance of some 37 different roofing materials, with the measured data showing that white roof materials generally exhibit the best performance.

However, it appears possible to tailor paints and pigments and optimize their performance.

Reflective roof coatings are elastomeric and encompass a variety of specialy products. They are formulated from latex/acrylic, hypalon, neoprene, silicone and urethane. Many hybrid products exist, and new formulations are introduced frequently. Many elastomeric coatings are compatible with most common roof membranes. Previous tests of reflective roof coatings have demonstrated the ability to reduce air conditioning power consumption by an average of $19 \%$.

The reflective coatings can be applied to composition roofs with conventional painting methods such as brush, roll or spray.

\section{Calculation of Waste Reduction and/or Energy Savings}

The cellar glycol cooling system is electrically powered by two 25 -ton compressors and three $3 / 4$ (.75) hp fans. The glycol system also is used for cooling the fermentation tanks which are located in the cellar and also serve as a cooling source. According to The vinery, approximately $90 \%$ of the chiller demand is used for cooling tanks and $10 \%$ is used for cociling the cellar itself.

According to the City of Richland Energy department, the average fan operstes at 746 Watts.

Three $3 / 4$ hp Fans:

746 watts/fan x 3 fans x 0.75 x 24 hrs/day x 365 days/year $\times 1 \mathrm{Wh} / 1,000 \mathrm{kWh}$

$=14,502 \mathrm{kWh} /$ year

Two 25-ton Chillers:

50 tons $\times 1 \mathrm{~kW} /$ ton $\times 24$ hours/day $\times 365$ days $/$ year $=432,000 \mathrm{kWh} / \mathrm{year}$

The chillers are used for chilling the fermentation tanks and cooling the celliar. According to The winery, $90 \%$ of the chiller-use is for the fermentation tanks and $10 \%$ for cooling the cellar.

$432,000 \mathrm{kWh} /$ year $\times 0.10=43,200 \mathrm{kWh} /$ year 
$14,502 \mathrm{kWh}+43,200 \mathrm{kWh}=57,702 \mathrm{kWh} /$ year

Assumption: Each piece of equipment runs 1/2 the amount of time.

$57,702 \mathrm{kWh} /$ year divided by $2=28,851 \mathrm{kWh} /$ year

According to Hydro-Therm, a business can achieve a $15 \%$ - $35 \%$ (average $25 \%$ ) reduction in energy consumption.

Total Energy Savings: $28,851 \mathrm{kWh} / \mathrm{year} \times .25=7,212 \mathrm{kWh} / \mathrm{year}$

\section{Calculation of Annual Cost Savings}

Total Annual Benefit:

Reduced Energy Consumption

In 1994-95, the Winery's monthly electric bill was an average $\$ 599$. According to the Benton Rural Electric Association, the current rate for a commercial building is $\$ 0.0498 / \mathrm{kWh}$.

$7,212 \mathrm{kWh} \times \$ 0.0498 / \mathrm{kWh}=\$ 359 /$ year

Reduced Roof Deterioration

According to Hydro-Therm, a reflective roof coating can extend the life of a roof 10 to 15 years. The average life of a roof is 30 years and the roof in the cellar is 5 years old.

The average cost of a roof covering $2,000 \mathrm{ft}^{2}$ is $\$ 5,000$ according to several vendors in the TriCities. The reflective roof coating will extend the life of the winery roof an estimated additional 12.5 years.

Assumption: Existing roof and new roof costs are equal.

Existing Roof:

5 years $/ 30$ years $=1 / 6$ or 0.16

$0.16 \times \$ 5,000=\$ 800$

$\$ 5,000-\$ 800$ divided by 25 years $=\$ 168 / \mathrm{yr}$

$\$ 168 / \mathrm{yr} \times 12.5 \mathrm{yrs}=\$ 2,100$

$\$ 2,100 / 37.5 \mathrm{yrs}=\$ 56 / \mathrm{yr}$ 
Total Annual Benefits $=\$ 359+\$ 56=\$ 415$

Total Annual Costs $=$ None

Total Annual Benefits - Total Annual Costs $=\$ 415-\$ 0=\$ 415$

\section{Calculation of Implementation Cost and Payback}

Typical coverage of a white elastomeric coating is $25 \mathrm{ft}^{2}$ per gallon, based cn an application of two coats to a target thickness of 40 mils. Cost for the material from vendor's is approximately $\$ 25$ for a 5 -gallon container when purchased in quantity.

$2,000 \mathrm{ft}^{2} / 25 \mathrm{ft}^{2} /$ gallon $=80$ gallons

80 gallons $\times \$ 25 /$ gallon $=\$ 2,000$

A typical labor cost might be approximately $\$ 1$ per $\mathrm{ft}^{2}$ for the required application.

$2,000 \mathrm{ft}^{2} \times \$ 1 / \mathrm{ft}^{2}=\$ 2,000$

$\$ 2,000+\$ 2,000=\$ 4,000$

Payback: $\$ 4,000 / \$ 415.19=9.6$ years

\section{Vendor/Contact Information}

Polycoat ${ }^{\mathrm{TM}}$ Systems, Inc.

Richard Sellers

5 Depot Street

Hudson Falls, NY 12839

Hydro-Therm Protective Coatings, Inc.

Joel Carver

3410 South Filmore

Amarillo, TX 79110

Healy Industries, Inc.

Justin Healy

45 Shipwatch Road

Savannah, GA 31410 


\section{Pollution Prevention Assessment Worksheet 3 \\ Pollution Prevention Opportunity Description}

Date $11 / 07 / 96$

ID Code Winery-1

Business Winery

Activity Winemaking

P2O No. 2 P2O Title Insulate Fermentation Tanks, Chillers and Associated Piping

\section{Current Practice}

Fiberglass insulation is used on a small number of fermentation tanks and around only a portion of the tank area. The chillers as well as the piping from the chillers to the tanks is exposed to the outside ambient weather conditions. Approximately 4 tanks reside inside and 8 tanks outside. However, not all the tanks are in use at a given time. The sizes of the tanks vary in size from 5' diameter $x 8^{\prime}$ high to $10^{\prime}$ diameter $\times 11^{\prime}$ ' high. A 4" and a 3" pipe runs from the chiller to the tanks and both freeze from condensation in the winter.

\section{Recommended Action}

Install bubble foil insulated jacketing (3/16" thick) on each of the fermentation tanks. The jacketing would be held in place with 1 " polybelting fitted with " $D$ " rings for attachment. In addition, wrap the chiller and associated piping with polyisocyanurate urethane insulation with a factory applied vapor barrier 2 " in thickness. The urethane is jacketed with 0.020 " high impact PVC.

Wrapping the fermentation tanks was performed four years ago at Coventry Vail Winery in Prosser. According to the maintenance manager, an energy savings between $22-25 \%$ can be realized with this practice. Additional savings are realized with less mold and cleanup. The maintenance manager noticed that it took the red grapes a little longer to get to fermentation temperature. However, once at the optimum temperature, it remained constant. Coventry Vail wrapped the tanks themselves.

\section{Calculation of Waste Reduction and/or Energy Savings}

Reduced Energy Usage on 4" Piping:

The chiller piping is 4 " in diameter and a length of approximately 42 feet.

The current heat gain with no insulation is $28 \mathrm{BTU} / \mathrm{hr} / \mathrm{ft}$. 
$28 \mathrm{BTU} / \mathrm{hr} / \mathrm{ft} \times 42 \mathrm{feet}=1176 \mathrm{BTU} / \mathrm{hr}=0.34 \mathrm{~kW}$

$0.34 \mathrm{~kW} \times 8760$ hours $/$ year $=2,978 \mathrm{kWh} / \mathrm{ye}$ ar

With 2 " thick insulation the heat gain is 3 and the energy efficiency is $88.3 \%$.

$3 \mathrm{BTU} / \mathrm{hr} / \mathrm{ft} \times 42$ feet $=123 \mathrm{BTU} / \mathrm{hr}$

$123 \mathrm{BTU} / \mathrm{hr} / \mathrm{ft}=0.04 \mathrm{~kW}$

$0.04 \mathrm{~kW} \mathrm{x} \mathrm{8,760} \mathrm{hours/year}=4.92 \mathrm{kWh} /$ year

$2,978 \mathrm{kWh} /$ year $-4.92 \mathrm{kWh} /$ year $=2,973 \mathrm{kWh} /$ year

Reduced Energy Usage on 3" Piping:

The chiller piping is 3 " in diameter and a length of approximately 41 feet.

The current heat gain with no insulation is $21 \mathrm{BTU} / \mathrm{hr} / \mathrm{ft}$.

$21 \mathrm{BTU} / \mathrm{hr} / \mathrm{ft} \times 41 \mathrm{ft}=861 \mathrm{BTU} / \mathrm{hr}=0.25 \mathrm{~kW}$

$0.25 \mathrm{~kW} \times 8760$ hours/year $=2,190 \mathrm{kWh} /$ year

With 2" thick insulation the heat gain is 3 and the energy efficiency is $86.7 \%$.

$3 \mathrm{BTU} / \mathrm{hr} / \mathrm{ft} \times 42 \mathrm{ft}=123 \mathrm{BTU} / \mathrm{hr}=0.04 \mathrm{~kW}$

$0.04 \mathrm{kWh} \times 8,760$ hours/year $=4.92 \mathrm{kWh} /$ year

$2,190 \mathrm{kWh} /$ year $-4.92 \mathrm{kWh} /$ year $=2,185 \mathrm{kWh} /$ year

Reduced Energy Usage on Chiller:

The chiller heat gain is currently $30 \mathrm{BTU} / \mathrm{hr} / \mathrm{ft}^{2}$. The chiller itself is approximately $250 \mathrm{ft}^{2}$.

The current heat gain with no insulation is $30 \mathrm{BTU} / \mathrm{hr} / \mathrm{ft}^{2}$

$30 \mathrm{BTU} / \mathrm{hr} / \mathrm{ft}^{2} \times 250 \mathrm{ft}^{2}=7,500 \mathrm{BTU} / \mathrm{hr}$

$7,500 \mathrm{BTU} / \mathrm{hr}=2.20 \mathrm{~kW}$

$2.20 \mathrm{~kW} \mathrm{x} \mathrm{8,760} \mathrm{hours/year}=19,272 \mathrm{kWh} /$ year 
With insulation the heat gain is $2 \mathrm{BTU} / \mathrm{hr} / \mathrm{ft}^{2}$

$2 \mathrm{BTU} / \mathrm{hr} / \mathrm{ft}^{2} \times 250 \mathrm{ft}^{2}=500 \mathrm{BTU} / \mathrm{hr}$

$500 \mathrm{BTU} / \mathrm{hr}=0.15 \mathrm{~kW}$

$0.15 \mathrm{~kW} \mathrm{x} 8,760$ hours $/$ year $=1,314 \mathrm{kWh} /$ year

$19,272 \mathrm{kWh} /$ year $-1,314 \mathrm{kWh} /$ year $=17,958 \mathrm{kWh} /$ year

Total Energy Reduction:

$2,973+2,185+17,958=23,116 \mathrm{kWh} /$ year

\section{Calculation of Annual Cost Savings \\ Total Annual Benefit: \\ Reduced Energy Usage on 4" Piping:}

The current heat gain with no insulation is $21 \mathrm{BTU} / \mathrm{hr} / \mathrm{ft}$.

$2,978 \mathrm{kWh} /$ year $\times \$ 0.0498 / \mathrm{kWh}=\$ 148 /$ year

With 2 " thick insulation the heat gain is 3 and the energy efficiency is $88.3 \%$.

$4.92 \mathrm{kWh} /$ year $\times \$ 0.0498 / \mathrm{kWh}=0.25$

$\$ 148 /$ year $-\$ 0.25=\$ 148$

Reduced Energy Usage on 3 " Piping:

The current heat gain with no insulation is $21 \mathrm{BTU} / \mathrm{hr} / \mathrm{ft}$.

$2,190 \mathrm{kWh} /$ year $\times \$ 0.0498 / \mathrm{kWh}=\$ 109$

With 2" thick insulation the heat gain is 3 and the energy efficiency is $86.7 \%$.

$4.92 \mathrm{kWh} /$ year $\times \$ 0.0498 / \mathrm{kWh}=0.25$

$\$ 109 /$ year $-\$ 0.25=\$ 108$ 


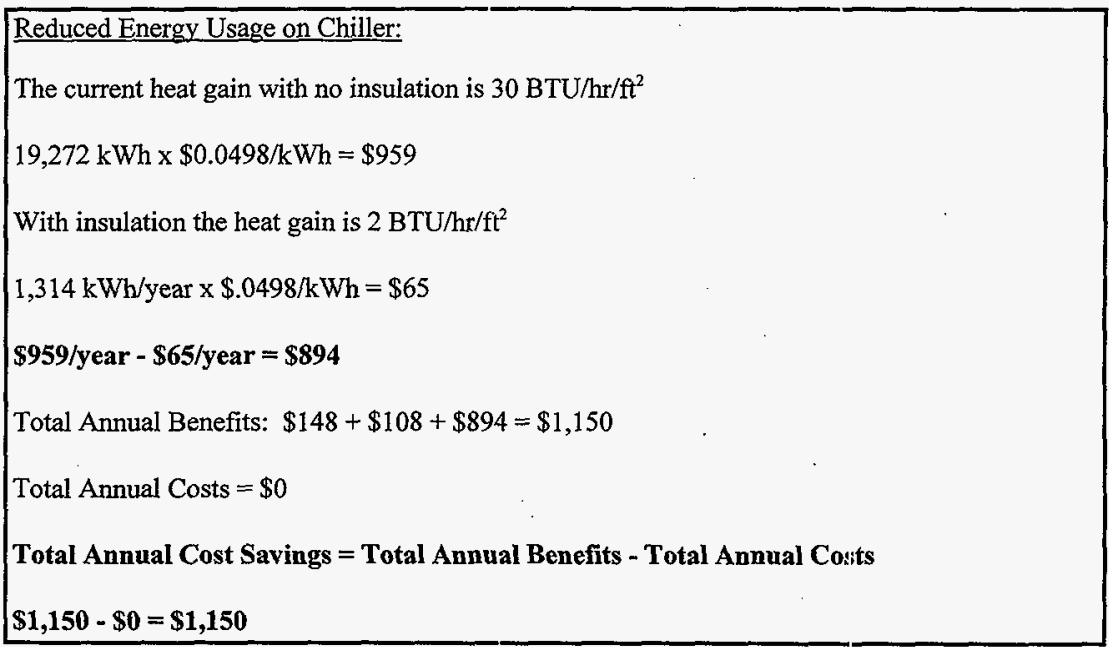

\section{Calculation of Implementation Cost and Payback}

The implementation cost is $\$ 26,441$ according to Design Industrial Services. Inc. This cost includes installation. If the winery chooses to install insulation themselves the implementation cost would be reduced by $\sim \$ 3,600$.

Payback $\$ 26,441 / \$ 1,150=23$ years

Vendor/Contact Information
Design Industrial Services Inc.
Ron Landby
109 B. North Washington Street
Kennewick, WA 99336

(509) 582-5599 


\title{
Pollution Prevention Assessment \\ Worksheet 3 \\ Pollution Prevention Opportunity Description
}

\author{
Date $12 / 06 / 96$ \\ ID Code Winery-1 \\ Business Winery
}

Activity Winemaking

P2O No. 3 P2O Title Filtering with Harborlite Perlite

\section{Current Practice}

Currently, The winery is using diatomaceous earth for rough filtration. Diatomaceous earth or Diatomite, is a processed natural material, chiefly composed of the skeletons of diatoms, used as a filter material. Filtration is a physical process in winemaking whereby solid particles are strained from wine using filters. Rough filtration involves using a relatively thick layer of diatomaceous earth. It is added to the wine, which is then passed through a pad filter machine. During the process a thick layer forms on the filter pads. As the cloudy wine passes through, small particles are trapped, allowing clear wine to pass through the process.

Diatomaceous earth contains crystalline silica, which is considered by Occupational Safety Health Association to be a hazardous material, however it is not disposed of as a hazardous waste. According to the Washington State Department of Ecology, it is not disposed of as a hazardous waste because the waste generated at the winery passes all tests for direct disposal.

\section{Recommended Action}

Filter with Harborlite Perlite filter medium as an alternative to diatomaceous earth. Perlite is an igneous mineral which occurs in areas of volcanic geologic origin. When pure alumina silicate glass segregates from other materials within a subterranean body of molten volcanic magna, and if the molten glass then comes into contact with ground water, the glass hydrates and perlite is formed. When applied to filter septa as slurry-borne deposits, these particle shapes form porous filter media coatings which are ideal for filtration applications.

Harborlite filteraids contain no detectable crystalline silica and it is not a hazardous product. The perlite has a neutral $\mathrm{pH}$, a very low trace mineral content, and is free of biological material.

The product has a low density which results in a low settling rate in slurries. The low settling rate enables Perlite to more easily remain in suspension as it enters the pressure filtration. The diatomaceous earth currently used tends to migrate more rapidly to the lower portions of the filter chamber. 
Perlite's suspension characteristics result in improved cake uniformity which enhances filter cycle length, increases filtration rate, and provides a dependably-stable filtrate clarity throughout the length of the run. These characteristics make Perlite an appropriate alternative for winemaking. Badger Mountain Winery is currently using Perlite as a filter aid and are pleased with the product.

\section{Calculation of Waste Reduction and/or linergy Savings}

Harborlite Perlite weighs less than diatomaceous earth-up to $70 \%$ less. A bag of Perlite provides the same volume of filter cake as does a bag of diatomaceous earth, but with a greatly reduced expenditure of filteraid weight.

For example: a typical 1,000-square foot pressure leaf filter might require iwo bags of diatomaceous earth to form a layer of precoat material. Each diatomite bag contains sufficient filteraid to provide approximately 2.3 cubic feet of disposable filter medium, so this charge will produce a precoat approximately $1 / 16$ inch thick. Each diatomaceous earth bag weighs 50 pounds. In this example, 100 pounds of diatomaceous earth are required to precoat.

Each bag of Perlite filteraid of equivalent permeability also contains sufficient filteraid to provide 2.3 cubic feet of disposable filter medium. However, each bag of Ferlite will only weigh 16 to 35 pounds, depending on permeability grade. The two-bag Harborlite precoat will therefore only weigh $32 \%$ to $70 \%$ as much as the diatomaceous earth precoit, and will remain in slurry suspension much mote easily during filter fill-up.

As a result, the Perlite precoat material will disperse more uniformly across the filter's vertical cross section, and will therefore produce a more uniform precoat. At the same time, Perlite will provide savings in filteraid weight and cost.

Perlite's true filteraid cost is usually only $30 \%$ to $70 \%$ of the diatomaceous earth filteraid cost.

According to Scott Laboratories, diatomaceous earth is purchased in $50 \mathrm{lb}$ bags and Perlite in 35 $\mathrm{lb}$ bags. For filtering wine, one $50 \mathrm{Ib}$ bag of diatomaceous earth is equivalent to a $35 \mathrm{lb}$ bag of Perlite.

$50 \mathrm{lbs}-35 \mathrm{lbs}=15 \mathrm{lbs}$ per bag. 
The winery uses 1 ton of diatomaceous earth annually.

1 ton $=2,000 \mathrm{lbs}$

$2,000 \mathrm{lbs} / 50 \mathrm{lbs}$ per bag $=40 \mathrm{bags} / \mathrm{yr}$

$40 \mathrm{bags} / \mathrm{yr} \times 15 \mathrm{lbs} / \mathrm{bag}=600 \mathrm{lbs} / \mathrm{yr}$

Total Annual Waste Reduction: $600 \mathrm{lbs}$

\section{Calculation of Annual Cost Savings}

According to Scott Laboratories, the average cost of diatomaceous earth is $\$ 27.40 / \mathrm{bag}$ and the cost of Perlite (Harborlite $800 \mathrm{~S}$ ) is $\$ 25.70 / \mathrm{bag}$.

$\$ 27.40-\$ 25.70=\$ 1.70 / \mathrm{bag}$

The winery currently uses 40 bags of diatomaceous earth/year

40 bags $/ y r \times \$ 1.70 / \mathrm{bag}=\$ 68 /$ year

Total Annual Benefits $=\$ 68$

Total Annual Costs $=\mathbf{\$ 0}$

Total Annual Cost Savings = Total Annual Benefits - Total Annual Costs

$\$ 68-\$ 0=\$ 68$

\section{Calculation of Implementation Cost and Payback}

The cost for implementing this new product is $\$ 0$ and therefore the payback for this initiative is immediate.

\section{Vendor/Contact Information}

Scott Laboratories

(707)765-6666 


\section{Pollution Prevention Assessment Worksheet 4 \\ Pollution Prevention Opportunities Summary}
Date $12 / 17 / 96$
ID Code Winery-1
Business Winery

Activity Winemaking

\begin{tabular}{|c|l|c|r|r|r|r|}
\hline P2O No. & \multicolumn{1}{|c|}{ P20 Title } & $\begin{array}{c}\text { Waste } \\
\text { Class } \\
\text { Reduced }\end{array}$ & $\begin{array}{c}\text { Anmual Waste } \\
\text { Reduction or } \\
\text { Energy Savings }\end{array}$ & $\begin{array}{c}\text { Estimated } \\
\text { Annual } \\
\text { Savings }\end{array}$ & $\begin{array}{c}\text { Eitimated } \\
\text { Implementation } \\
\text { Cost }\end{array}$ & Payback \\
\hline 1 & $\begin{array}{l}\text { Reflective Roof } \\
\text { Coating }\end{array}$ & Energy & $7,212 \mathrm{kWh}$ & $\$ 415$ & $\$ 4,000$ & 9.6 \\
\hline 2 & $\begin{array}{l}\text { Insulating Tanks, } \\
\text { Chillers and } \\
\text { Associated Piping }\end{array}$ & Energy & $23,116 \mathrm{kWh}$ & $\$ 1,150$ & $\$ 26,441$ & 23 \\
\hline 3 & $\begin{array}{l}\text { Filtering with } \\
\text { Perlite }\end{array}$ & Hazardous & 600 lbs. & $\$ 68$ & & Immediate \\
\hline
\end{tabular}

\section{Other Brainstorming Ideas Not Researched}

\begin{tabular}{|c|c|}
\hline Opportunity & Reason \\
\hline Weather-strip double doors on front of cellar & Adding on in the future \\
\hline $\begin{array}{l}\text { Replace windows in loft area with thermopane, weather-strip and cover } \\
\text { with stormwindows }\end{array}$ & Customer not interested now \\
\hline Seal large gap at the top of the rollup door & Customer not interested now \\
\hline Hang clear plastic strips inside rollup door & Customer not interested now \\
\hline Keep rollup door closed when not in use & Already practicing \\
\hline Build a canopy/retractable shelter & Not pollution p:evention \\
\hline $\begin{array}{l}\text { Replace light fixtures in the banquet room with higher energy efficient } \\
\text { lightbulbs. }\end{array}$ & Not a large potential savings \\
\hline Use quick release heads on all hoses. & Already in place \\
\hline Reuse graywater for irrigation & Too big of a project \\
\hline Sell lees to distilleries & Not feasible in this area \\
\hline $\begin{array}{l}\text { Request suppliers produce boxes that can be shipped back to the supplier } \\
\text { for reuse }\end{array}$ & Customer not interested now \\
\hline Purchase corks in reusable cardboard cartons & Customer not interested now \\
\hline Recover waste wine & Do this as much as possible now \\
\hline Sell/give-away old barrels to local nurseries & Give away barrs:ls to customers \\
\hline Recover chemicals through ultra/micro filtration & PNNL conducting study \\
\hline Stop filtering wine & Customer not interested now \\
\hline Filter wine with egg whites and gelatin & Already practiced \\
\hline Minimize water usage during tank clean-out & Customer not interested now \\
\hline
\end{tabular}




\section{Pollution Prevention Assessment Worksheet 5 Final Summary}
Date $12 / 18 / 96$
ID Code Winery-1
Business Winery

Activity Winemaking

\section{Proposed Opportunities and Discussion}

Three opportunities were investigated for the winery.

Reflective Roof Coating: By painting a reflective roof coating on the cellar, The winery will save an estimated $7,212 \mathrm{kWh} /$ year for a cost savings of $\$ 415$. This reflects a $15-35 \%$ reduction in energy consumption and reduced roof deterioration. A reduced implementation cost of $\$ 2,000$ will be realized if the owners paint the roof themselves.

Insulating Fermentation Tanks, Chillers and Associated Piping: This opportunity had the greatest cost savings of $\$ 1,150$ per year. The savings is from reduced energy consumption by wrapping the tanks, chillers and associated piping. A reduced implementation cost savings of $\sim 3,600$ would be realized if the winery installs the insulation on the fermentation tanks themselves. It has been noted in this industry that wrapping the tanks looks nice and may be an added benefit for this opportunity.

Filtering with Harborlite Perlite: The implementation cost for this opportunity is $\$ 0$ and therefore the annual cost savings of $\$ 68$ would be achieved immediately upon implementation. The Perlite is a safer product than diatomaceous earth and does not contain silica dust. In addition to the cost savings on the Perlite, the winery can achieve additional cost savings through the added suspension. The Perlite will stay in suspension longer and therefore increasing length of filtration. No statistical analysis was available as to the length of time it remains in suspension and therefore was not calculated.

\footnotetext{
Recommendations and Schedule for Implementation

It is recommended to implement Opportunity \#3 "Filtering with Perlite" immediately as the cost to implement is $\$ 0$ and it has proven success in this industry. Opportunity \#2 would be best implemented in stages since it has a high implementation cost. Wrapping 3 tanks per year would achieve a portion of the cost savings with full implementation in 3 years. It is further recommended to wrap the piping immediately as the pipes freeze in the winter from condensation. The aesthetics of the winery is important and therefore it is recommended to implement the reflective roof coating (Opportunity \#1) if a pastel color is chosen rather than pure white.
} 
Pollution Prevention Assessment

Medical Clinic 


\section{Pollution Prevention Assessment \\ Worksheet 1 \\ Team and Activity Description}

Date 11/25/96 ID Code Medical-1 Activity Routine Clinic Activities

Business Name and Address Medical Clinic, Richland

Business Contact and Phone

\begin{tabular}{|lc|}
\hline Team Members $\left({ }^{*}\right.$ Leader $)$ & Telephone \\
Dr. James Wise & $627-5869$ \\
Jeff McCullough & $943-7438$ \\
Mary Betsch & $372-1627$ \\
\hline
\end{tabular}

\section{Description of Activity to be Examined in this Assessment}

The medical clinic treats occupational and sick patients. The Medical clinic facility is an immediate care facility owned by one Doctor. Typical waste streams identified at The medical clinic were solvents, photographic chemicals, infectious waste, and solid sanitary wastes.

\section{Infectious Waste}

Infectious wastes include syringes and other sharps, tissue culture bottles and flasks, membrane filters in plastic dishes, collection specimen bottles, slides and plates, rubber gloves, and swabs. Physicians and medical staff mix solid sanitary waste and infectious waste together in red bags. Infectious waste is more expensive to manage than solid sanitary waste and The medical clinic spends approximately $\$ 2,500 /$ month managing infectious waste and $\$ 108 /$ month for solid sanitary waste. Much of the waste contained in the red bags is actually solid sanitary waste such as packaging, gloves, masks, and glassware. The infectious waste is picked up by BrowningFerris ${ }^{\mathrm{TM}}$ Industries $\left(\mathrm{BFI}^{\mathrm{TM}}\right)$ once a month. BFI ${ }^{\mathrm{TM}}$ has trained the medical clinic staff on segregation techniques, however, improper segregation practices continues to be a problem. The infectious waste bags are sent to the storage area via. a dumbwaiter. The bags stack up because the staff assumes someone else will take responsibility.

\section{Solid/Sanitary Waste}

A large quantity of paper is generated at the facility as documentation of patient files must be secured in three separate locations. The copies of patient records are not double-sided.

Cardboard is broken down and then disposed of in the solid sanitary waste dumpster. Newspaper is similar in that it is collected separately and then placed in the dumpster as waste.

Approximately $50 \%$ of the employees actively recycle aluminum cans. The collection areas are staged near two vending machines. 
In the storage area downstairs, patient files are stored for 7 years or until the patient turns 21 if he/she is a minor. All record-keeping is done by hand and in hard-copy format as it is easier to train employees this method because there is a high turn-over rate. The storage area also contains all the medical supplies.

The solid sanitary waste disposal cost is $\$ 108.71$ per month which includes a weekly pickup.

\section{Water}

Twelve restrooms, including two showers are included in the facility layout and do not have water restriction devices.

\section{Energy}

The utilities are metered in three separate locations: 310 Torbett, 1514 Jadivin, and 1516 Jadwin.

Insulation Levels

310 Torbett

Walls R-11

Roof R-19

Metal frame windows with insulated glass

\section{4/1516 Jadwin}

Wall R-19

Roof R-30

Metal frame windows with insulated glass

Both buildings are well insulated and further envelope improvements would not be cost effective. In fact, if both buildings where built today, under the prevailing Non-Residential Energy Code, only slight changes would be needed to comply.

\section{Mechanical}

310 Torbett

The building was originally served by electric resistance heat with air conditioning. At some point the units where converted to heat pumps. There currently is (1) 2.5 and (1) 5 ton heat pump each with Honeywell ${ }^{\circledast}$ T8611 5/1/1 thermostats (Mon.-Fri. are the same program and Sat. and Sun. are independent). There does not appear to be outside air provided to each air handler.

$1514 / 1516$ Jadwin

The new building is served by (2) 5 ton, (1) 4 ton, (1) 3 ton, (1) 2.5 ton and (1) 2 ton, heat pumps. All have Honeywell ${ }^{\circledR}$ T8611 T7300 7-day programmable thermostats. Each air handler is provided outside air. Any time the air handlers are running, fresh air is introduced to the respective spaces. 


\section{Lighting}

\section{Torbett}

The lighting system is older technology magnetic "energy saving" ballasts with T-12 40W lamps. Overall the building is lit to $2.2 \mathrm{~W} / \mathrm{ft}^{2}$ ( $1.8 \mathrm{~W} / \mathrm{ft}^{2}$ fluorescent and $0.4 \mathrm{~W} / \mathrm{ft}^{2}$ incandescent). Outdoor lighting control relies upon human switching.

\section{$1514 / 1516 \mathrm{Jadwin}$}

The lighting system is predominantly older technology magnetic "energy saving" ballasts with $\mathrm{T}-1234 \mathrm{~W}$ (Econ-o-watt ${ }^{T M}$ ) lamps. Overall the building is lit to approximately $1.7 \mathrm{~W} / \mathrm{ft}^{2}$. Outdoor lighting is controlled via photocell.

The lighting system is older technology and is not energy efficient. The overhead lighting ballasts are not electronic. However, in the new section of the building, the lamps used are of the "Econ-o-watt ${ }^{\top M "}$ and are economical although not energy efficient. Incandescent lights are primarily used in recessed cans, light bars, and lamps.

Several of the thermostat controls which control large areas of the building are located inside exam rooms. Since the thermostat heats or cools according to the temperature it senses on the thermostat control itself, it does not provide an accurate temperature reading. It is dependent on what occurs in the room, rather than what is happening in the larger area the thermostat controls.

It is common practice at the medical clinic for staff to move the thermostat according to one's own comfort level. Several of the units upon investigation were set to the wrong day. Further, the unoccupied temperature was set for $69^{\circ} \mathrm{F}$ and the occupied temperature was set for $72^{\circ} \mathrm{F}-\mathrm{a}$ $3{ }^{\circ} \mathrm{F}$ difference. The business hours for The medical clinic are from 8:00 a.m. to 5:00 p.m. and the unoccupied mode was set for 8:00 p.m.

The outside lights on the north end of the building are operated by a photocell. However, the south end light in the parking lot is illuminated 24-hours a day.

The lighting in the lobby of the old section is excessive due to the combination of windows, skylights, and overhead lighting.

The copy machines and some other office equipment are left on 24-hours a day.

A ceiling panel was removed some time ago and never replaced. Although insulation is in the roof, energy is lost through this open space.

\section{Hazardous Waste}

Fixer and developer waste is generated from X-rays and the X-ray equipment. An offsite vendor handles the fixer waste as well as replenishes the product. The developer is discharged to the sewer and is within acceptable permit limits. The vendor managing the fixer treats the waste before it is discharged to the sewer in Pasco. 
Dirty instruments are cleaned and sterilized with hazardous and non-hazarclous detergents in the clean-up room. Instruments are soaked, cleaned, and finally sterilized. Clcan instruments are bagged and last from 3-6 months. The instrument is re-cleaned after 6 months whether or not it is used.

Hydrochloric Acid remains from past practices and requires proper disposal.

\section{Miscellaneous Information}

The clinic is privately owned, with the owner working on the premises. The clinic manager is ultimately responsible for waste management. Managing waste properly is not a priority and therefore the medical staff does not concern itself with segregating wastes biecause it does not directly feel a impact from the costs or the savings. 


\section{Medical Clinic Upper Level}

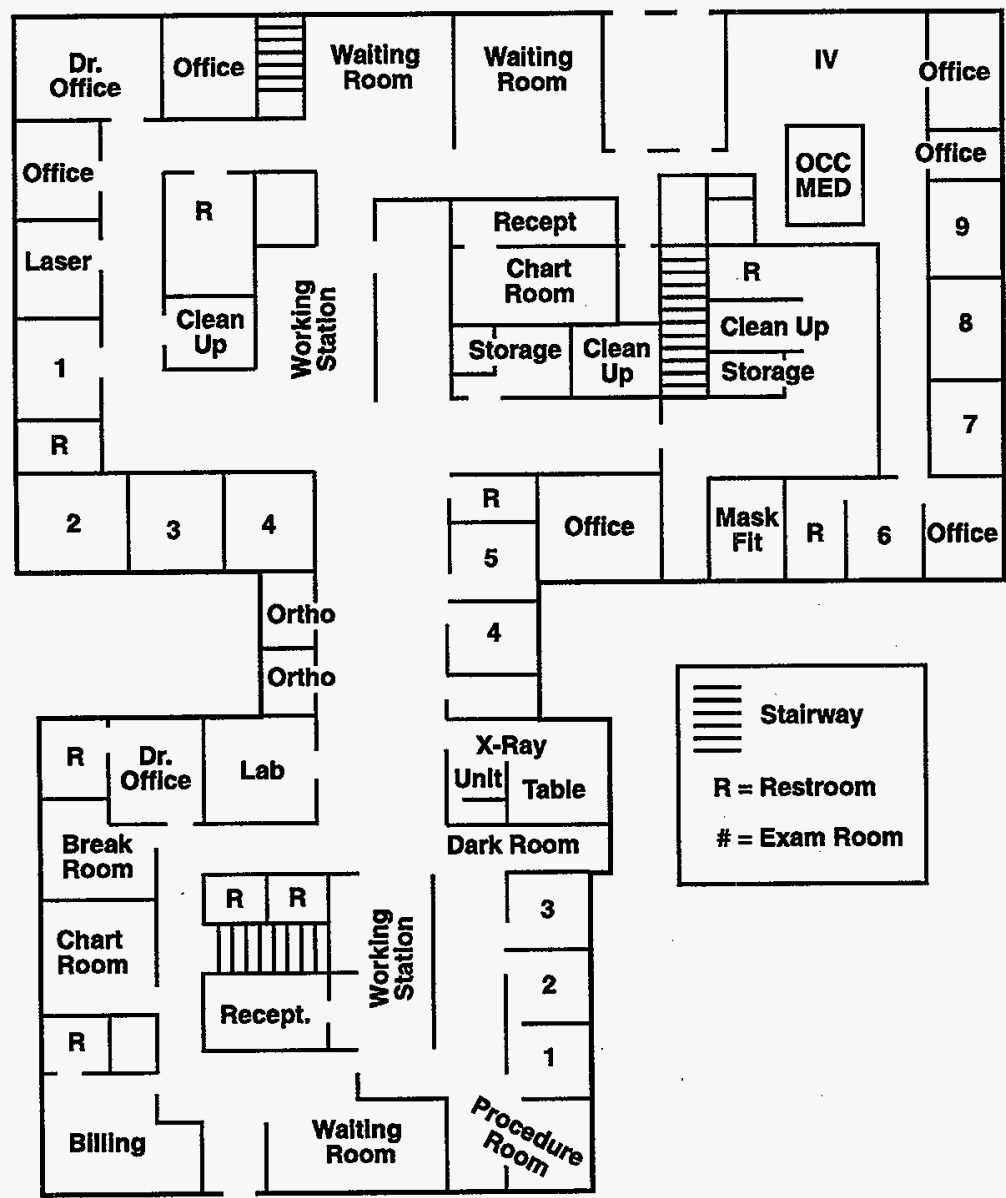



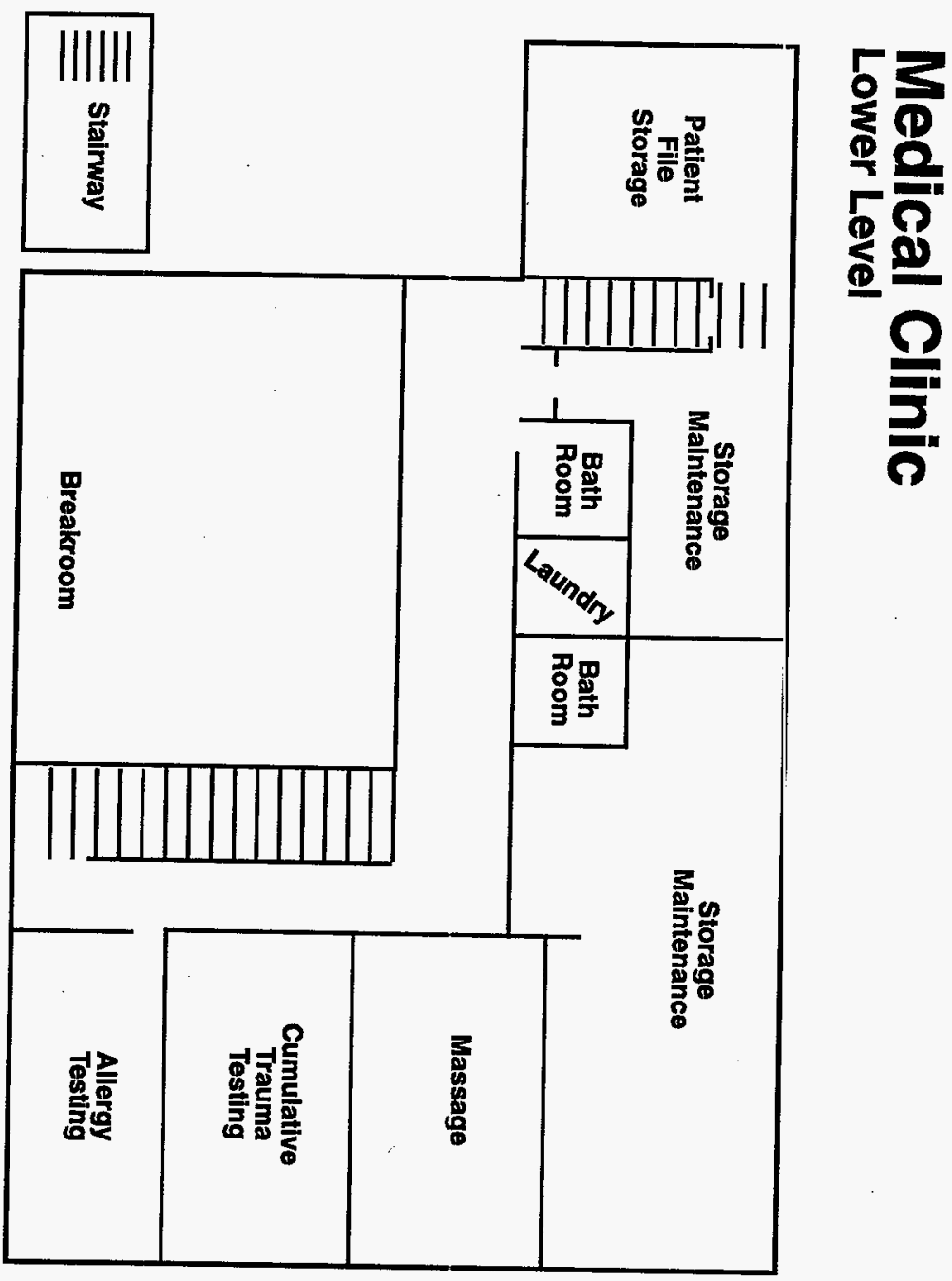


\section{Pollution Prevention Assessment \\ Worksheet 2 \\ Flow Diagram}

Date 11/26/96 - ID Code Medical-1 Business Medical Clinic

Activity Routine Clinic Activities

\begin{tabular}{|lc|}
\hline \multicolumn{2}{|c|}{ Chemical Inputs } \\
\hline \multicolumn{1}{|c|}{ Name } & Qty. \\
\hline Fixer & 260 gals. \\
Cleaning Supplies & Unknown \\
& \\
& \\
& \\
& \\
& \\
\hline
\end{tabular}

\begin{tabular}{|c|c|}
\hline \multicolumn{2}{|c|}{ Material Inputs } \\
\hline Name & Qty. \\
\hline $\begin{array}{l}\text { Medical Supplies } \\
\text { (Glass, Paper, } \\
\text { Plastic) }\end{array}$ & $253 \mathrm{~m}^{3}$ \\
\hline
\end{tabular}

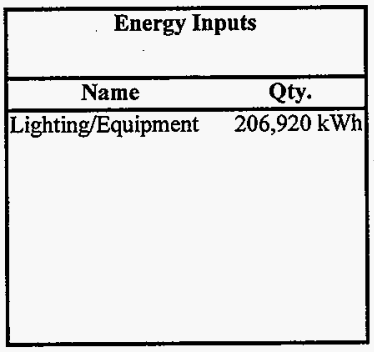

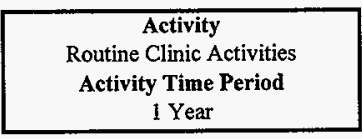

\begin{tabular}{|c|}
\hline Product or Result Output \\
\hline Name \\
\hline \\
\\
\\
\end{tabular}

\begin{tabular}{|lr|}
\hline \multicolumn{1}{|c|}{ Hazardous Waste Output } \\
\hline \multicolumn{1}{|c|}{ Name } & Qty. \\
\hline Infectious Waste & $15 \mathrm{~m}^{3}$ \\
Spent Fixer & 260 gals. \\
& \\
& \\
& \\
\hline
\end{tabular}

\begin{tabular}{|cc|}
\hline \multicolumn{2}{|c|}{ Non-Hazardous Waste Output } \\
\hline Name & Qty. \\
\hline Used Supplies & $238 \mathrm{~m}^{3}$ \\
& \\
\\
\end{tabular}

Note: The medical clinic has weekly solid sanitary waste pickup of a $6 \mathrm{md}^{3}$ dumpster which accounts for the 238 $\mathrm{m}^{3}$ disposed of annually. It was assumed the dumpster was full upon pickup. 


\title{
Pollution Prevention Assessment Worksheet 3 \\ Pollution Prevention Opportunity Description
}

Date 12/19/96 ID Code Medical-1 Business Medical Clinic

Activity Routine Clinic Activities

P20 No. 1 P2O Title Improved Segregation of Infectious Waste

\begin{abstract}
Current Practice
According to the U.S. Environmental Protection Agency (EPA), infectious is defined as "capable of producing infection; pertaining to or characterized by the presence of pathogens." A pathogen is "any disease-producing microorganism or material." Etiologic agent is defined as "a viable microorganism or its toxin which causes, or may cause, human disease." The related term "biohazard" is defined as an "infectious agent presenting a risk or potential risk to the well-being of man, either directly through his infection or indirectly through disruptior. of his environment."

Infectiousness as a characteristic of some wastes is difficult to define and inzpossible to quantify due to the characteristics of pathogens, the nature of disease, and the factors that determine the induction of disease.
\end{abstract}

The EPA recommends that the following types of waste be considered infectious waste and that they be managed as hazardous waste.

- Isolation wastes

- Cultures and stocks of etiologic agents

- Blood and blood products

- Pathological wastes

- Other wastes from surgery and autopsy

- Contaminated laboratory wastes

- Sharps

- Dialysis unit wastes 
- Body parts

- Discarded biologicals

- Contaminated equipment

A large volume of waste generated at health care facilities is the by-product of a system that has developed the ability to provide the best health care available. However, little attention has been given to the environmental side effects and waste costs associated with this care including significant amounts of medical waste.

Some of the common infectious wastes found at Physicians Immediate Laboratory are: (1) Syringes and other sharps; (2) Tissue culture bottles and flasks; (3) Membrane filters in plastic dishes; (4) Collection specimen bottles; (5) Slides and plates; (6) Rubber gloves; and (7) Swabs.

The infectious waste containers collect both solid sanitary waste and infectious waste and because infectious waste costs more to manage than solid sanitary waste, The medical clinic is paying more than necessary. The medical clinic staff do not properly segregate the waste types. There are 30 infectious waste containers (sharps and bags) and 90 sanitary waste containers. Five areas (laboratory and surgery rooms) are considered the areas with the most problem with proper segregation. One bag of infectious waste is generated 7 days/week in one room, one bag of infectious waste is generated 5 days/week in another room, and 5 sharps containers are generated/week in the other areas. The sharps containers are collected and placed in an infectious bag which is in turn put into a box downstairs. Between 6-8 infectious waste bags fill one $15 " \times 15 " \times 28$ " box.

Browning-Ferris Industries ${ }^{\mathrm{TM}}\left(\mathrm{BFI}^{\mathrm{TM}}\right)$, the waste management company managing Physician Immediate Care's infectious waste, recently conducted an all-staff training to decipher what materials were acceptable and unacceptable in the infectious waste containers. Since the training, an improvement was identified. However, recently, old habits have continued and the majority of the waste in the red bags is sanitary waste.

\section{Recommended Action}

Establish a written plan for infectious waste management that will ensure proper treatment of the waste and provide for effective and efficient management practices prior to disposal.

Segregation of the infectious waste stream should include directions for discarding of infectious waste directly into separate containers marked for infectious waste. The plan should also include proper disposal of sanitary waste in the designated receptacles. The plan might include additional items such as: (1) Management commitment, (2) Waste reduction goals; (3) Packaging and storage procedures; and (4) Sterilizing procedures.

Implementation of the plan includes the development of easily identifiable signs over the infectious and sanitary disposal areas for employees to properly dispose of waste. The signs 
should read: "Infectious Waste Only" and "Trash Only." Additionally, emiployees will be reminded of exactly what should be disposed of in the infectious bags through several large posters strategically placed throughout the clinic. All physicians and staff should be made aware of the plan and its purpose.

The Albany Medical Center in Albany, New York recently established a comprehensive program for not only managing infectious waste, but instituted a thorough pollution prevention program. This information could be utilized in establishing a similar approach for The medical clinic. Contact Mary Betsch (509) 372-1627 for more information.

\section{Calculation of Waste Reduction and/or Energy Savings}

Approximately 10-15 (average 12.5) boxes of infectious waste is disposed of per month at the medical clinic.

The medical clinic boxes are considered "medium" and each box contains 27.25 gallons according to Browning-Ferris Industries.

According to The medical clinic staff, between $5 \%$ and $10 \%$ of the waste disposed of as infectious is actually considered infectious waste.

12.5 boxes $x 27.25$ gals $/$ box $=340$ gals $/$ month

340 gals/month $\times 7.5 \%=25$ gals $/$ month

340 gals $/$ month -25 gals $/$ month $=315$ gallons $/$ month

315 gals/month $\times 12$ months/year $-3,780$ gallons/year

\section{Calculation of Annual Cost Savings}

Approximately $\$ 200$ per box of infectious waste is charged to The medical clinic. Approximately $10-15$ boxes per month are disposed of as infectious waste. According to The medical clinic staff, between $5 \%$ and $10 \%$ (average $7.5 \%$ ) of infectious waste is actually considered infectious waste.

The cost for solid sanitary waste management is $\$ 108.71$ per month for weekly pick-up. It is estimated that no cost adjustment will be necessary as a result from increase sanitary waste disposal. 
12.5 boxes/month $\times 12$ months/year $\times \$ 200 /$ box $=\$ 30,000 /$ year

$\$ 30,000 /$ year $\times 7.5 \%=\$ 2,250 /$ year

$\$ 30,000 /$ year $-\$ 2,250=\$ 27,750 /$ year

\section{Calculation of Implementation Cost and Payback}

The cost of 10 each 4 " $\times 5$ " signs is estimated at $\$ 7.50$ each including layout and design. Five signs will read "Infectious Waste Only" and five signs will read "Trash Only." The signs will be prepared with a sticky backing for easy placement on wall or waste receptacle.

10 each $\times \$ 7.50=\$ 75$

The cost of 10 each $22 "$ x 34 " full color laminated posters is estimated at $\$ 126$ each including typesetting, formatting, setup, printing, and mounting.

$\$ 126 \times 10=\$ 1,260$

The estimated time of developing a written plan is 16 hours at $\$ 10.50 /$ hour labor.

$\$ 10.50 /$ hour $\times 16$ hours $=\$ 168.00$

The total implementation cost is then: $\$ 75.00+\$ 1,260+\$ 168.00=\$ 1,503$

Payback $=\$ 1,503$ divided by $27,750 /$ year $=.05$ years

Vendor/Contact Information

Posters: $\quad$ Eagle Printing and Graphics (943-2611)

Signs:

Fast Signs

(735-0708) 


\section{Pollution Prevention Assessment \\ Worksheet 3 \\ Pollution Prevention Opportunity Description}

Date 12/19/96 ID Code Medical-1 Business Medical Clinic

Activity Routine Clinic Activities

P2O No.2 P2O Title Double-Side Copies and Recycle

\section{Current Practice}

The medical clinic's physicians and staff see approximately 105 patients daily. For each patient, a large quantity of paperwork must be archived for legal reasons. Typical paperwork for patients includes: Encounter (sign-in) sheet, new patient form, laboratory work, $x$-ray, flow sheet, insurance forms, school physical form, Medicare card copy, pharmacy card copy, hearing, EKG, history, drug screening, mask fit, and breath alcohol. Two copiers (Xerox 5312/5314 and Minolta $^{T M}$ EP 2121) with the capacity of 20 copies/minute are used to copy jatient records and other confidential information as well as reports.

These copiers do not have duplexing capabilities. Neither of the existing copy machines will accommodate a duplexing attachment. The cost of operating small machines is double that what it costs to operate large machines as supplies are extremely costly for the smaller units. Two more copy machines are beyond repair and the medical clinic is planning to purchase one new machine. All copy machines are in the "on" position 24-hours a day.

There is not a recycling contract established for recycling paper and therefore all white ledger paper is disposed of in the landfill.

\section{Recommended Action}

Copy paperwork for patients on both sides of paper and recycle any paper generated which is no longer useful. In addition, duplex reports and all other materials copied.

Set up recycling areas which would include 3 recycling boxes, one at each copier. In addition, employees should be encouraged to take an empty box and recycle paper in their offices. Once the individual containers are full, they can be transferred to the larger recycling boxes. Because of the location and quantity of paper generation, it will be necessary to handle paper recycling by the medical clinic staff. The closest recycling station for commercial businesises is available at Clayton Ward at 1950 Saint Road in Richland (509-375-4086). Clayton Ward is not adding new customers for regular pick up service due to the low cost of paper. 
Purchase a new copy machine that has the capacity to copy 60 copies/minute. Based upon the quantity of paper copied, the Minolta ${ }^{\text {TM }} 6000 \mathrm{CS} / \mathrm{PRO}$ Copier is recommended. The EP 6000 is made from recycled plastic and constructed with recyclable parts. In addition, this copier uses a non-toxic, organic photoconductive drum and capable of photocopying on recycled paper and in duplex mode. Furthermore, the Minolta ${ }^{\top M} 6000$ is an energy star copier. Energy star office equipment can reduce energy consumption by approximately $50 \%$ by automatically turning off when not in use.

Fully reconditioned copiers including the Minolta ${ }^{\text {TM }} 6000 \mathrm{ES} / \mathrm{PRO}$ are available for purchase at half price. These copiers are 1 year old and were originally used by the Hanford Transition Team.

Since staff are not accustomed to duplexing copies, a simple awareness must be institutionalized. A briefing at the all employee staff meeting will also be necessary.

\section{Calculation of Waste Reduction and/or Energy Savings}

\section{Photo Copying on Both Sides of the Paper}

The medical clinic operates 7 days per week and sees 105 patients daily on the average. For each occupational care patient, approximately 20 sheets of paper are generated. For each sick patient, approximately 6 sheets of paper are generated. Occupational care accounts for $20 \%$ of the patients and $80 \%$ for sick patients.

1 ream of paper ( 500 sheets at $20 \mathrm{lb}$ weight) weighs approximately $5 \mathrm{lbs}$. according to Boise Cascade.

Paper use will be cut in half for duplexing.

Occupational care patients:

105 patients/day $\times 20 \%=21$ patients/day

20 sheets/patient $\times 21$ patients/day x 365 days/year $\times 1$ ream $/ 500$ sheets $\times 5 \mathrm{lbs} / \mathrm{ream}=\mathbf{1 , 5 3 3}$ lbs/year.

Sick patients:

105 patients/day $\times 80 \%=84$ patients/day

6 sheets/patient x 84 patients/day x 365 days/year x 1 ream $/ 500$ sheets $\times 5$ lbs/ream $=1,839$ lbs/year.

In addition to the patient records, The medical clinic staff copy reports, studies, and other medical-related information. This quantity is not quantifiable by The medical clinic. 
$1,533 \mathrm{lbs} /$ year $+1,839 \mathrm{lbs} /$ year $=3,372 \mathrm{lbs} /$ year

One half of the paper generation is saved by copying on both sides.

3,372 lbs/year divided by $2=1,686 \mathrm{lbs} /$ year

\section{Recycling}

The medical clinic staff estimate that 50 sheets of white ledger paper are disposed of daily in 10 trash receptacles which could be recycled.

50 sheets $/$ day $\times 10$ receptacles $=500$ sheets $/$ day

500 sheets/day $\times 365$ days/year $\times 1$ ream/500 sheets $\times 5 \mathrm{lbs} / \mathrm{ream}=\mathbf{1 , 8 2 5} \mathrm{lbs} / \mathrm{year}$

$1,686 \mathrm{lbs} /$ year $+1,825 \mathrm{lbs} /$ year $=3,511 \mathrm{lbs} /$ year

\section{Calculation of Annual Cost Savings}

\section{Supplies}

The cost in supplies is exceedingly high for small copy machines. The machines the medical clinic is currently using are no exception. The cost for operating the two small copiers is approximately 2.8 cents/copy in supplies only.

The cost per copy using the Minolta ${ }^{\mathrm{TM}} 6000$ is 1.8 cents/copy which includes the purchase of the machine, service, and supplies.

The medical clinic operates 7 days per week and sees 105 patients daily on tie average. For each occupational care patient, approximately 20 sheets of paper are generated. For each sick patient, approximately 6 sheets of paper are generated. Occupational care accounts for $20 \%$ of the patients and $80 \%$ for sick patients.

\section{Current Cost Per Year:}

Occupational care patients:

105 patients/day $\times 20 \%=21$ patients/day

20 sheets/patient $\times 21$ patients/day $\times 365$ days/year $\times \$ 0.028 /$ sheet $=\$ 4,292$

Sick patients:

105 patients/day $\times 80 \%=84$ patients/day 
6 sheets/patient $\times 84$ patients/day $\times 365$ days/year $\times \$ 0.028 /$ sheet $=\$ 5,150$

$\$ 4,292+\$ 5,150=\$ 9,442$

Cost Per Year Using Minolta ${ }^{\text {TM }}$ 6000:

Occupational care patients:

105 patients/day $\times 20 \%=21$ patients/day

20 sheets/patient $\times 21$ patients/day $\times 365$ days/year $\times 0.018 /$ sheet $=\$ 2,759$

Sick patients:

105 patients/day $\times 80 \%=84$ patients/day

6 sheets/patient $\times 84$ patients/day $\times 365$ days/year $\times 0.018 /$ sheet $=\$ 3,311$

$\$ 2,759+\$ 3,311=\$ 6,070$

$\$ 9,442-\$ 6,070=\$ 3,372$

Photo Copying on Both Sides of the Paper

Paper use will be cut in half for copying on both sides of the paper. The estimated cost by Abadan is $\$ 5.00 /$ ream.

Occupational care patients:

105 patients/day $\times 20 \%=21$ patients/day

20 sheets/patient $\times 21$ patients/day $\times 365$ days/year $\times 1$ ream $/ 500$ sheets $\times \$ 5.00 /$ ream $=\$ 1,533$

Sick patients:

105 patients/day $\times 80 \%=84$ patients/day

6 sheets/patient $\times 84$ patients/day x 365 days/year $\times 1$ ream $/ 500$ sheets $\times \$ 5.00 /$ ream $=\$ 1,839$

$\$ 1,533+\$ 1,839=\$ 3,372$

Copying on both sides of the paper will reduce paper usage by half.

$\$ 3,372 / 2=\$ 1,686$ 
The revenue for recycling paper is negligible. The cost per pound is $\$ .01$ for delivered paper

Total Annual Cost Savings is $\$ 3,372+\$ 1,686=\$ 5,058$

\section{Calculation of Implementation Cost and Payback}

The cost of a new reconditioned Minolta ${ }^{\mathrm{TM}} 6000$ is $\$ 5,500$ (original price $\$ 14,000$ )

Basin Recycling will provide the recycling stands and bags to the medical clinic at no cost.

Payback: $\$ 5,500 / \$ 5,058=1.1$ years

Vendor/Contact Information

Reconditioned Copy Machine: Abadan (946-7693) 


\section{Pollution Prevention Assessment Worksheet 3 Pollution Prevention Opportunity Description}
Date 12/19/96
ID Code Medical-1
Business Medical Clinic

Activity Routine Clinic Activities

P2O No. 3 P2O Title Lighting Retrofit

\section{Current Practice}

In the old section of the building, the vast majority of the fluorescent light ballasts at the medical clinic are electromagnetic and require input power of 82 watts. The attached spreadsheet specifically spells out the quantities and types of lamps at the clinic. Typically, F40T12 fluorescent lights in quantities of two, three, and four are placed in the overhead lighting. Two rooms, the lab and an exam room operate bi-level. The majority of the exam rooms contain "cool" $\left(5,000^{\circ} \mathrm{K}\right)$ fluorescent lights.

All other lighting in the old building is incandescent for lamps, recessed cans and other miscellaneous lighting.

Due to the operating hours and the type of ballasts and lamps in the new section of the building, it was excluded from the analysis as the ballasts and lamps are relatively energy efficient already.

The old section of the building is occupied 13 hours per day, 7 days a week. All lights are turned off after operating hours.

\section{Recommended Action.}

Install energy efficient electronic ballasts and lamps in the old section of the building. Because electronic ballasts function at high frequency, the fluorescent lighting systems they operate can convert power to light more efficiently and operate at a higher frequency than systems run by standard electromagnetic ballasts. For example, electronic ballasts can produce about 10 percent more light from standard fluorescent lamps using the same power as electromagnetic ballasts. Electronic ballasts are designed to produce the same amount of light from standard fluorescent lamps as conventional electromagnetic ballasts using significantly $(\sim 30 \%)$ less power. The electronic ballasts can be easily retrofitted into the existing fluorescent lighting systems.

Additionally, replace all incandescent lighting with high efficient fluorescent lighting. Replacement bulbs are available for all incandescents. Many studies have explored the influence of lighting on the way people respond to a space. The results show that lighting can reinforce 
subjective impressions. To alter the characteristics of light and create warrner tones in the Clinic, the "warm white fluorescent lamp" is recommended, especially in the exam rooms.

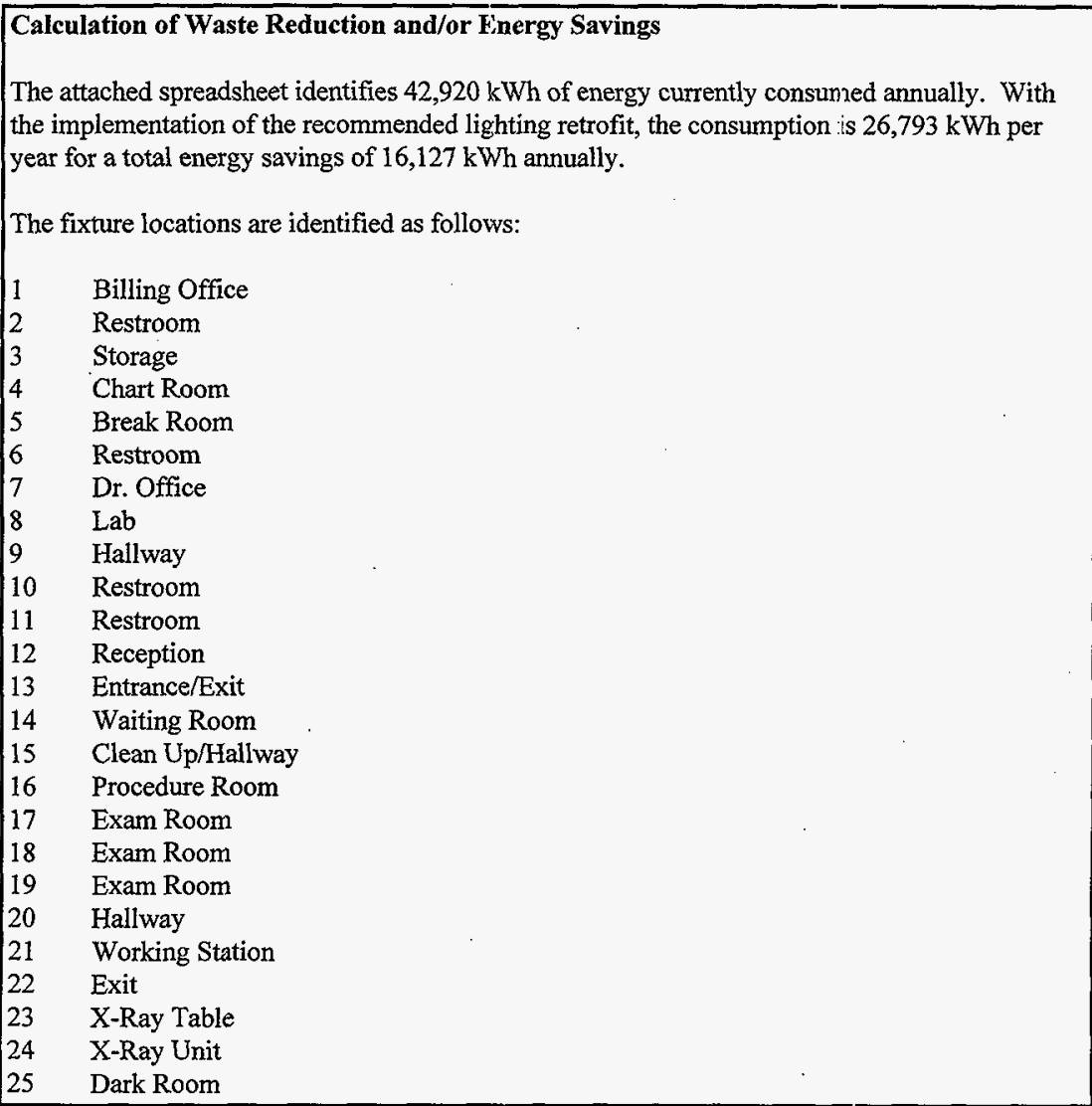

\section{Calculation of Anuual Cost Savings}

The attached spreadsheet shows the cost savings by fixture location. Before the lighting retrofit the annual cost for lighting is $\$ 1,628$ and after the retrofit, the cost is $\$ 1,016$. The annual cost savings achieved by this initiative is therefore, $\$ 612$. 


\section{Calculation of Implementation Cost and Payback}

The implementation cost for the complete retrofit is estimated conservatively at $\$ 4,023$ which includes labor.

$\$ 4,023 / \$ 612=6.6$ years.

\section{Other Energy-Related Opportunities}

Energy Conservation Measures (ECM's) for no cost

1. Discontinue use of 300 Watt torchiers used in the waiting areas. These fixtures, while decorative, consume a relatively high amount of energy with little useful light provided.

2. Reconnect or "cap" supply air duct in upstairs mechanical area (above ceiling). A supply air duct is disconnected and distributes conditioned air to an unoccupied space. A dominant supply air duct leak causes the building to be negatively pressured. A negatively pressured building causes air infiltration from the outside.

3. Verify/reduce water heater temperatures to $120-130^{\circ} \mathrm{F}$. Water heaters maintain temperature settings 24 hours per day 365 days per year. They lose heat through normal use but also by standby losses to it's surroundings.

4. Install "low flow" showerheads and faucet aerators. The City offers these devices at no cost to customers with electric water heating.

5. Maintain programmable thermostat settings. Set thermostats for $65^{\circ} \mathrm{F}$ during unoccupied and 70-72 ${ }^{\circ} \mathrm{F}$ occupied heating mode. Set thermostats for $80^{\circ} \mathrm{F}$ during unoccupied and 74-76 'F occupied cooling mode. Set occupied/unoccupied times according to "hours-ofoperation" (thermostats automatically "turn-on" to achieve settings before start times)

ECM's for under $\$ 25.00$

1. Retrofit incandescent lights with compact fluorescent. Compact fluorescent lights consume $75 \%$ less energy, last five (5) times longer, and "give-off" less heat which, in turn, must be removed from the air conditioning system. Install compact fluorescent lights in areas with operating hours greater than four (4) hours per day.

2. Weather-strip and install threshold on metal exit door in rear of new building. Outside air brought-in for mechanical ventilation and allowed-in from infiltration is the major component of the buildings heat loss/gain. 
3. Install water heater tank insulation wraps. Increasing the insulation values will reduce standby losses.

4. Install locking thermostat covers. An integral cover, which allows temporary adjustment of the temperature but reverts to automatic program settings, is available for the T 8600 series thermostat ( 2 thermostats located in this facility). A full locking cover is available for the T7300 series thermostats located in the "new" building. Training one to four people in the proper use of the thermostats will help avoid unauthorized use.

5. Delamp/deballast 4 lamp fixtures to 2 lamp where overlit. Several arees provide more light than necessary to perform given tasks. Simply removing lamps (you m ist also disconnect the ballasts) will reduce the installed wattage.

ECM's for under $\$ 100.00$

1. Relocate thermostats located in rooms which do not "represent" zone tenperatures. Thermostats are easily "fooled" by local temperatures which causes comfort problems for the rest of the zone.

2. Install water heater time-clocks. Time clocks will minimize stand-by losses by preventing water operation during unoccupied periods. The T7300 thermostats can be used (with associated relays) to control water heaters in the new building.

3. Install occupancy sensors in bathrooms, offices, exam rooms, etc. Energy savings would vary depending upon hours of operation and number of fixtures controlled.

4. Install timeclock or photocell to control outdoor lighting. The outdoor lighting on the old side appears to be "on" 24 hours per day or relies upon human switching.

ECM's for more than $\$ 100.00$

1. Air balance the HVAC system. Have a qualified HVAC technician/engineer perform a room-by-room load calculation and adjust airflow accordingly. Determine the correct amount of fresh outside air required for each zone and adjust airflow accordingly. Currently all outside air dampers are wide open.

2. Install automatic closing devices on outside air ducts. Mechanical, spring loaded or barometric dampers should be installed on fresh air intakes, exhausts and relief vents.

\section{Vendor/Contact Information}

Cree Electric

(547-6588)

Sagetree Electric

(783-3532)

Total Energy Management $\quad(946-4500$ 
Appendix D: Formal Assessments

\section{EXISTING LIGHTING SCHEDULE \\ Medical Clinic}

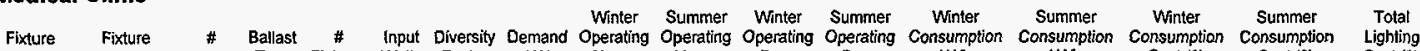

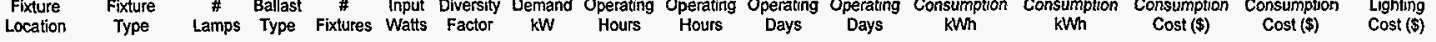

\begin{tabular}{ll}
1 & F40T12 \\
2 & Incandescent \\
3 & incardescent \\
4 & F40T12 \\
5 & F40T12 \\
6 & F40T12 \\
7 & F40T12 \\
8 & F34T12 \\
9 & F40T12 \\
& FB40T12 \\
10 & incandescent \\
11 & incandescent \\
12 & F40T12 \\
13 & incandescent \\
14 & F40T12 \\
& incandescent \\
15 & F40T12 \\
16 & F40T12 \\
17 & F40T12 \\
18 & F40T12 \\
19 & F40T12 \\
20 & F40T12 \\
21 & F40T12 \\
22 & incandescent \\
23 & incandescent \\
& incandescent \\
24 & incandescent \\
25 & incandescent \\
26 & F34T12 \\
& Exit Signs \\
& \\
\hline
\end{tabular}

$\begin{array}{lrrrr}\text { EE } & 2 & 172 & 100 \% & 0.344 \\ & 2 & 75 & 5 \% & 0.0075 \\ & 1 & 60 & 1 \% & 0.0006 \\ \text { EE } & 2 & 172 & 100 \% & 0.344 \\ \text { EE } & 3 & 172 & 100 \% & 0.516 \\ \text { EE } & 1 & 86 & 100 \% & 0.086 \\ \text { EE } & 2 & 172 & 100 \% & 0.344 \\ \text { EE } & 2 & 108 & 100 \% & 0.216 \\ \text { EE } & 1 & 86 & 100 \% & 0.086 \\ \text { EE } & 3 & 86 & 100 \% & 0.258 \\ & 2 & 60 & 100 \% & 0.12 \\ & 2 & 75 & 100 \% & 0.15 \\ \text { EE } & 3 & 172 & 100 \% & 0.516 \\ & 1 & 100 & 100 \% & 0.1 \\ \text { EE } & 2 & 172 & 100 \% & 0.344 \\ & 1 & 60 & 100 \% & 0.06 \\ \text { EE } & 1 & 172 & 100 \% & 0.172 \\ \text { EE } & 4 & 172 & 100 \% & 0.688 \\ \text { EE } & 1 & 172 & 100 \% & 0.172 \\ \text { EE } & 4 & 172 & 100 \% & 0.688 \\ \text { EE } & 4 & 172 & 100 \% & 0.688 \\ \text { EE } & 20 & 86 & 100 \% & 1.72 \\ \text { EE } & 3 & 172 & 100 \% & 0.516 \\ & 1 & 100 & 100 \% & 0.1 \\ & 2 & 60 & 100 \% & 0.12 \\ & 2 & 75 & 100 \% & 0.15 \\ & 1 & 75 & 100 \% & 0.075 \\ & 1 & 60 & 100 \% & 0.06 \\ \text { EE } & 1 & 72 & 100 \% & 0.072 \\ & 3 & 60 & 100 \% & 0.18\end{array}$

$\begin{array}{llll}13 & \mathbf{1 3} & \mathbf{2 1 0} & \mathbf{1 5 5} \\ 13 & 13 & 210 & 155 \\ 13 & \mathbf{1 3} & 210 & 155 \\ 13 & 13 & 210 & 155 \\ 13 & 13 & 210 & 155 \\ 13 & \mathbf{1 3} & 210 & 155 \\ 13 & 13 & 210 & 155 \\ 13 & 13 & 210 & 155 \\ 13 & 13 & 210 & 155 \\ 13 & \mathbf{1 3} & \mathbf{2 1 0} & 155 \\ 13 & 13 & 210 & 155 \\ 13 & \mathbf{1 3} & 210 & 155 \\ 13 & 13 & 210 & 155 \\ 13 & 13 & 210 & 155 \\ 13 & 13 & 210 & 155 \\ 13 & 13 & 210 & 155 \\ 13 & 13 & 210 & 155 \\ 13 & 13 & 210 & 155 \\ 13 & \mathbf{1 3} & 210 & 155 \\ 13 & \mathbf{1 3} & 210 & 155 \\ 13 & 13 & 210 & 155 \\ 13 & 13 & 210 & 155 \\ 13 & \mathbf{1 3} & 210 & 155 \\ 13 & \mathbf{1 3} & 210 & 155 \\ 13 & 13 & 210 & 155 \\ 13 & 13 & \mathbf{2 1 0} & 155 \\ 13 & \mathbf{1 3} & \mathbf{2 1 0} & 155 \\ 13 & \mathbf{1 3} & 210 & 155 \\ 13 & 13 & 210 & 155 \\ 24 & 24 & 210 & 155 \\ 13 & & & \end{array}$

$\begin{array}{rr}939 & 693 \\ 20 & 15 \\ 2 & 1 \\ 939 & 693 \\ 1409 & 1040 \\ 235 & 173 \\ 939 & 693 \\ 590 & 435 \\ 235 & 173 \\ 704 & 520 \\ 328 & 242 \\ 410 & 302 \\ 1409 & 1040 \\ 273 & 202 \\ 939 & 693 \\ 164 & 121 \\ 470 & 347 \\ 1878 & 1386 \\ 470 & 347 \\ 1878 & 1386 \\ 1878 & 1386 \\ 4696 & 3466 \\ 1409 & 1040 \\ 273 & 202 \\ 328 & 242 \\ 410 & 302 \\ 205 & 151 \\ 184 & 121 \\ 197 & 145 \\ 907 & 670 \\ 24694 & 18226\end{array}$

$\begin{array}{rrr}\$ 37.10 & \$ 24.82 & \$ 61.91 \\ \$ 0.81 & \$ 0.54 & \$ 1.35 \\ \$ 0.06 & \$ 0.04 & \$ 0.11 \\ \$ 37.10 & \$ 24.82 & \$ 61.91 \\ \$ 55.64 & \$ 37.22 & \$ 92.87 \\ \$ 9.27 & \$ 6.20 & \$ 15.48 \\ \$ 37.10 & \$ 24.82 & \$ 61.91 \\ \$ 23.29 & \$ 15.58 & \$ 38.87 \\ \$ 9.27 & \$ 6.20 & \$ 15.48 \\ \$ 27.82 & \$ 18.61 & \$ 46.43 \\ \$ 12.94 & \$ 8.66 & \$ 21.60 \\ \$ 16.18 & \$ 10.82 & \$ 27.00 \\ \$ 55.64 & \$ 37.22 & \$ 92.87 \\ \$ 10.78 & \$ 7.21 & \$ 18.00 \\ \$ 37.10 & \$ 24.82 & \$ 1.91 \\ \$ 6.47 & \$ 4.33 & \$ 10.80 \\ \$ 18.55 & \$ 12.41 & \$ 30.96 \\ \$ 74.19 & \$ 49.63 & \$ 123.82 \\ \$ 18.55 & \$ 12.41 & \$ 30.96 \\ \$ 74.19 & \$ 49.83 & \$ 123.82 \\ \$ 74.19 & \$ 49.63 & \$ 123.82 \\ \$ 185.48 & \$ 124.08 & \$ 309.55 \\ \$ 55.64 & \$ 37.22 & \$ 92.87 \\ \$ 10.78 & \$ 7.21 & \$ 18.00 \\ \$ 12.94 & \$ 8.66 & \$ 21.60 \\ \$ 16.18 & \$ 10.82 & \$ 27.00 \\ \$ 8.09 & \$ 5.41 & \$ 13.50 \\ \$ 6.47 & \$ 4.33 & \$ 10.80 \\ \$ 7.76 & \$ 5.19 & \$ 12.96 \\ \$ 35.83 & \$ 23.97 & \$ 59.81 \\ \$ 975.41 & \$ 652.51 & \$ 1,627.92\end{array}$


Appendix D: Formal Assessments

PROPOSED LIGHTING SCHEDULE

Medical Clinic

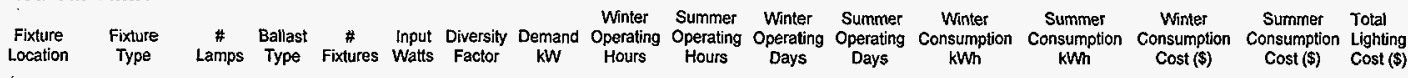

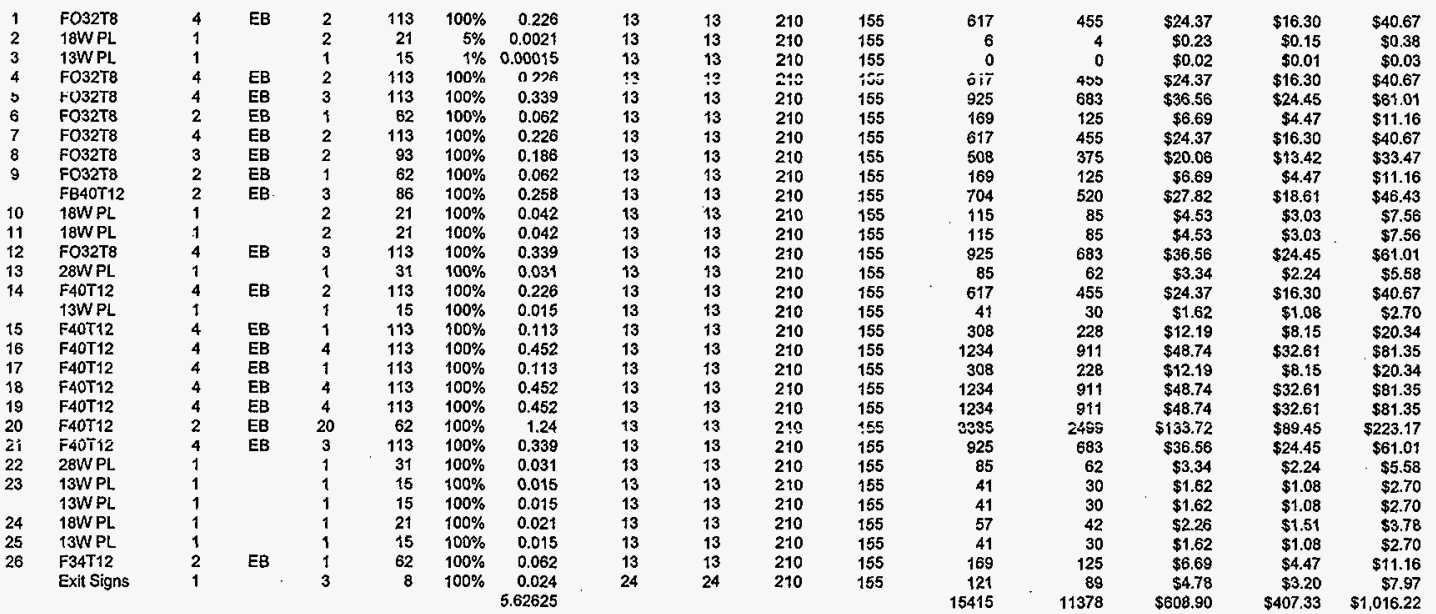




\section{Pollution Prevention Assessment \\ Worksheet 4 \\ Pollution Prevention Opportunities Summary}

Date $12 / 18 / 96$

ID Code Medical-1

Business Medical Clinic

Activity Routine Clinic Activities

\begin{tabular}{|c|l|c|r|r|r|r|}
\hline P20 No. & \multicolumn{1}{|c|}{ P20 Title } & $\begin{array}{c}\text { Waste } \\
\text { Class } \\
\text { Reduced }\end{array}$ & $\begin{array}{c}\text { Annual Waste } \\
\text { Reduction or } \\
\text { Energy Savings }\end{array}$ & $\begin{array}{c}\text { Estimated } \\
\text { Annual } \\
\text { Savings }\end{array}$ & $\begin{array}{c}\text { Estimated } \\
\text { Implementation } \\
\text { Cost }\end{array}$ & Payback \\
\hline 1 & $\begin{array}{l}\text { Improved } \\
\text { Segregation of } \\
\text { Infectious Waste }\end{array}$ & Hazardous & 3,780 gals. & $\$ 27,750$ & $\$ 1,503$ & 0.05 \\
\hline 2 & $\begin{array}{l}\text { Double-Side Copies } \\
\text { and Recycle }\end{array}$ & $\begin{array}{c}\text { Solid } \\
\text { Sanitary }\end{array}$ & 3,511 lbs. & $\$ 5,058$ & $\$ 5,500$ & 1.1 \\
\hline 3 & Lighting Retrofit & Energy & $16,127 \mathrm{kWh}$ & $\$ 612$ & $\$ 4,023$ & 6.6 \\
\hline
\end{tabular}

\section{Other Brainstorming Ideas Not Researched}

\section{Opportunity}

\section{Reason}

Reduce packaging

Minimize disposables

Institute low flow toilets and showers

Use larger cleaning chemical containers

Use less toxic cleaners

Replace ceiling panel in lunchroom

Recycle cardboard, cans, and glass

Institute an environmental management and incentives program
Already implemented

Regulations prohibit and already launcer through Crystal Linen

Customer not interested now

Janitorial company handles this area

Required for rush sterilization jobs

Customer not interested now

Customer not interested now

Customer not interested now 


\section{Pollution Prevention Assessment Worksheet 5 \\ Final Summary}

Date 01/21/97

ID Code Medical-1

Busineiss Medical Clinic

Activity Routine Clinic Activities

\section{Proposed Opportunities and Discussion}

Segregation of Infectious Waste: Improved segregation of infectious and sanitary waste will save an estimated 3,780 gallons of infectious waste for a cost savings of $\$ 27,750$ annually. Implementation requires writing a waste management plan and awareness and educational efforts at an estimated cost of $\$ 1,500$.

Double-Side Copies: Purchasing a copy machine will payback in a little over a year from copying patient records on both sides of the paper and recycling paper. The short payback is primarily a result of the excessive cost of supplies for the existing small copy machines. The waste reduction is 3,511 pounds per year for a cost savings of $\$ 5,058$.

Lighting Retrofit: Install energy-efficient electronic ballasts fluorescent lighting in the old part of the building. The payback is 6.6 years related to an annual cost savings cf $\$ 612$ and an implementation cost of $\$ 4,023$. The energy saved by this initiative is $16,12 \% \mathrm{kWh}$ annually.

\section{Recommendations and Schedule for Implementation}

It is recommended to implement all three opportunities evaluated as all have a reasonable payback. Immediately put in place a pollution prevention plan for improved segregation of waste. The majority of the dollars spent at the medical clinic are related to waste disposal. The savings would be realized virtually immediately. Some training may need to accompany the implementation of this initiative.

Duplexing copies has an added benefit of increased space for patient files. The medical clinic staff estimated a $25 \%$ and $30 \%$ reduction.

Although the payback for retrofitting the lights is over 6 years, it is still an energy and cost savings benefit to the medical clinic and should be implemented. A 3 to 5 ytar term loan from the City of Richland is available at 3\% - 3.5\% interest and can be utilized for this purpose. 
Pollution Prevention Assessment

\section{Hotel}




\section{Pollution Prevention Assessment \\ Worksheet 1 \\ Team and Activity Description}

Date 12/31/96 ID Code Hotel-1 Activity Routine Hotel Activities

Business Name and Address Hotel

Business Contact and Phone

\begin{tabular}{|ll|}
\hline Team Members $\left({ }^{\star}\right.$ Leader) & Telephone \\
Jill Engel-Cox & $372-0307$ \\
Dr. James Wise & $627-5869$ \\
Gail Baasch & $943-7730$ \\
Mary Betsch ${ }^{*}$ & $372-1627$ \\
\hline
\end{tabular}

\section{Description of Activity to be Examined in this Assessment}

The hotel is a 107,300 square foot hotel and restaurant located in Richland, WA.

The hotel chain has recently been purchased by new management. The majority of the hotel operates on gas and most of the lighting has been upgraded to energy efficient lamps and ballasts which was implemented in 1993 under the EPA's Energy Smart program.

\section{Kitchen}

The Hotel caters events such as weddings, business luncheons, and receptions in the hotel. In addition, room service requests are sent to the kitchen for preparation as well as the meals for the adjacent restaurant.

The kitchen is a large commercial kitchen equipped with 2 walk in refrigera:ors and 1 freezer maintained at $40^{\circ} \mathrm{F}$ and $0.5^{\circ} \mathrm{F}$ respectively. The refrigeration is $\mathrm{R}-12$ and $\mathrm{R}-502$. The refrigerators and freezers both have 3 " plastic sheeting hanging inside the dcor to help maintain the temperature. All cooking is gas-powered, and the grease generated from cooking is collected in a grease trap (downstairs adjacent to the laundry) which is picked up by a rendering service who recycles the grease. The leftover food is typically disposed of as solid sanitary waste. However, non-profit groups have been given food from the hotel from time to time.

All cleaning products used in the kitchen are purchased from EcoLab ${ }^{\top M}$. The products are primarily used for washing dishes. Two areas are designated for washing dishes-one area for pots and pans and a large area with a dishwasher for dishes, silverware, and ylasses. The final rinse dishwasher water is recycled and used as the first rinse in the next load. The water is maintained at $180^{\circ} \mathrm{F}$. No drying is required. 
Cardboard generated from products is temporarily staged in the kitchen and recycled on the lower level. Glass is collected in small bins but it is not recycled due to the market price. Tin is flattened and then disposed of as sanitary waste.

The linens used on banquet tables are double layered-the stained and burned cloths are placed on the bottom and the fresh linens on the top.

A small quantity of paper products are used for catering picnics and for emergency use.

\section{Restaurant and Bar Area}

All food prepared for the restaurant is generated in the adjoining kitchen. The lighting in the restaurant and bar area is mood lighting and dimmable but not energy efficient lighting primarily incandescent. Colored table cloths are placed on the tables as well as cloth napkins.

\section{Pool and Spa Area}

The gas-powered spa is maintained at $102^{\circ} \mathrm{F}$ year-round. A pool blanket is placed over the spa when not in use in order to keep the heat in. The pool is kept at a minimum of $45^{\circ} \mathrm{F}$ in the winter months and $80^{\circ} \mathrm{F}$ in the spring and summer months. All chemicals including chlorine and acid are purchased from EcoLabs ${ }^{\top M}$ and kept inside the hotel. The pool and spa systems have an automatic chemical feed system.

\section{Guest Wing}

The Hotel has a total of 150 rooms. New guests receive clean sheets, soaps, and other small items. The bedspreads and blankets are cleaned on an as needed basis. The sheets are changed daily for stay-over guests and the soaps and sundries remain and are not changed. When a guest checks out of the hotel, the soaps and sundries are collected and disposed of as solid sanitary waste. The carpets are cleaned twice a year and as needed. The hotel housekeeping has a practice of turning the lights off and keeping the thermostats turned low while the guests are away and when the rooms are unoccupied. All rooms are equipped with low flow shower heads and faucet aerators. Some of the toilets have water restricting devices attached but it is not widespread.

Two public restrooms are located on the first floor, and two on the lower level. The halls contain vending machines where guests can purchase drinks in aluminum and plastic. Recycling (aluminum and plastic) is not available to hotel guests or employees. If aluminum cans are left in rooms, the housekeeping staff will sometimes collect the cans for themselves.

\section{Housekeeping Storage Room}

This room contains supplies and equipment for the housekeeping staff. Phone books were collected here and recycled. The lights in this room are on a timer so that they go off when the room is not in use.

\section{Outside Landscaping}


The pesticide and herbicide application is contracted to a local vendor as is the lawn mowing. The limbs, clippings, and branches are disposed of as solid sanitary waste. EcoLab ${ }^{T M}$ provides pest control inside the building. However, Senske handles the outside pest and herbicide control.

\section{"Dirt" Room}

This room is used for storing wine, beer, and hard liquor. The beer is kept in cold refrigeration units. It is also storage for paper products and various other equipment and supplies.

\section{Pool Storage Room}

Air filters and cartridge filters are stored here as well as chlorine tablets, acid, and snow melt.

\section{Chiller/Mechanical Room}

The primary and secondary chiller located here use R-22. An air compressor and several heat exchangers run in this room. Two 5,000 gallon water heaters-one storage tank and one electric backup, are stored in this room. The electric tank is used for storage only and electric heat is used to heat this water if the heat exchanger is not keeping up. The sand filter for the swimming pool is changed every 2 years and it is backwashed 2 to 3 times a week depending on the use. Cartridge filters are used on the spa and changed once a month. Two small water leaks were noticed.

\section{Laundry}

The hotel uses three commercial washing machines with automatic chemical feed. All the products used in the laundry such as stain removers, soap, and bleach are pirchased by EcoLabs ${ }^{\mathrm{TM}}$. The floor drain goes directly to the sewer and the piped water is sent through a grease trap before final disposal to the sewer. Lint is collected from the wastewater. The laundry staff washes the engineering rags as well as the hotel sheets, tablecloths and other miscellaneous items. Three commercial dryers dry the items before being sent to the flatwork ironer where the items are ironed before folding.

\section{Outside Boiler Room}

Two main large boilers service the entire facility. In addition, an undersized boiler was purchased several years ago and provides the heat for the dishwasher and some of the water for the laundry. Both units operate in the winter months. Also located outside the hotel is the trash compactor, cardboard and paper recycling.

\section{Engineering Shop}

Paints, solvents, epoxies, degreasers, fluids, cleaning solutions, oils, and adkesives as well as nuts, bolts, pipe, belts, and other equipment occupy the shelves in the Enginzering Shop. Greasy rags are stored in a metal canister and sent to the onsite laundry for washing. Recently the hotel corporate office required that the hotel safely dispose of all chemicals not in the original containers. Alkaline ${ }^{T M}$ batteries are used for TV remote controls, pagers, and flashlights. Enamel paint is used for trim work. 


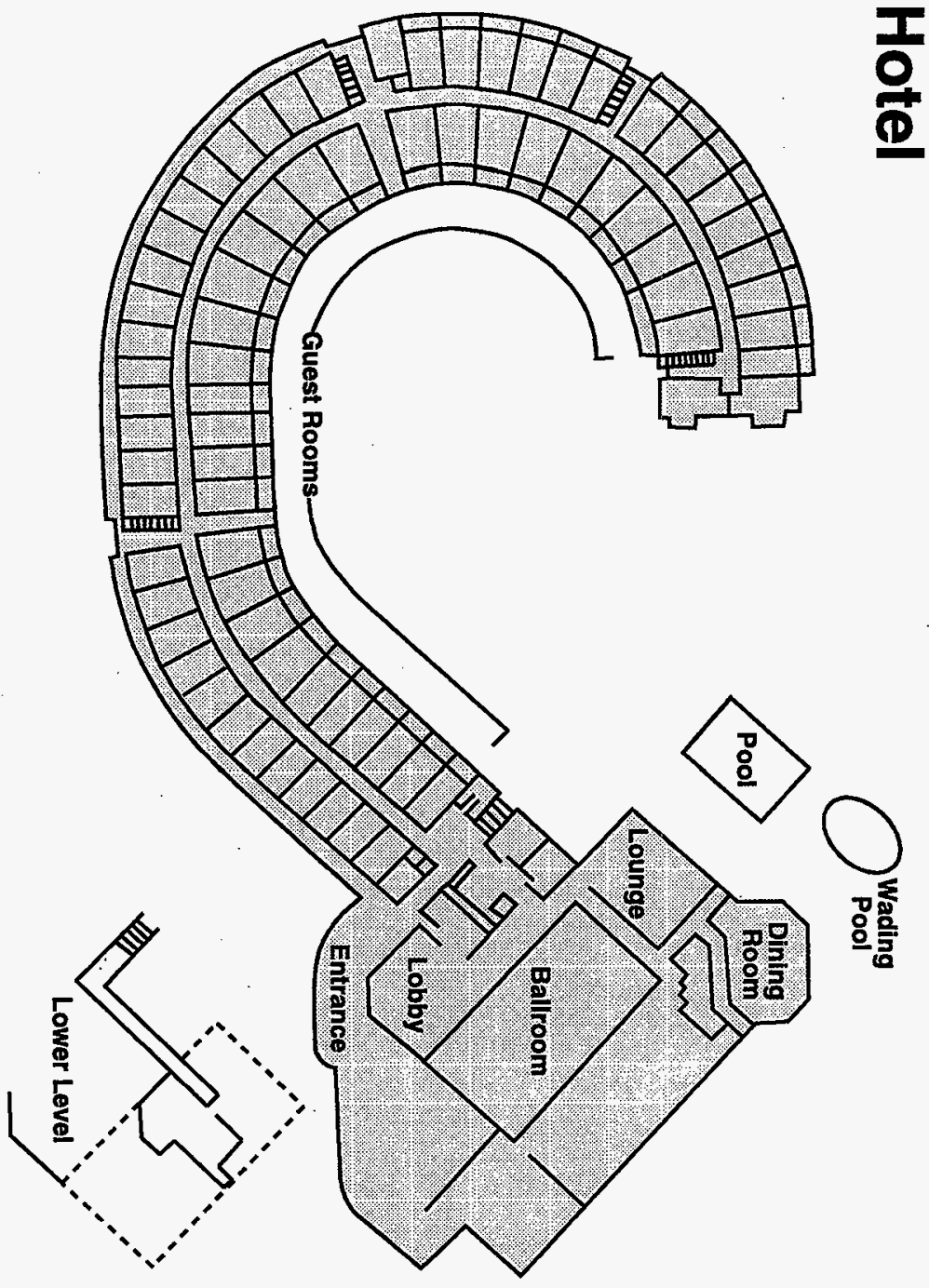




\section{Pollution Prevention Assessment \\ Worksheet 2 \\ Flow Diagram}

Date 12/31/96 ID Code Hotel-1 Business Hotel

Activity Routine Hotel Activities

\begin{tabular}{|lr|}
\hline \multicolumn{1}{|c|}{ Chemical Inputs } \\
\hline \multicolumn{1}{|c|}{ Name } & \multicolumn{1}{c|}{ Qty. } \\
\hline Laundry Chemicals & $100 \mathrm{lbs}$. \\
Pesticides & 2 gals. \\
Kitchen Chemicals & $100 \mathrm{lbs}$. \\
Maint. Chemicals & $100 \mathrm{lbs}$. \\
Pool Chemicals & $200 \mathrm{lbs}$. \\
& \\
& \\
& \\
\hline
\end{tabular}

\begin{tabular}{|lr|}
\hline \multicolumn{2}{|c|}{ Material Inputs } \\
\hline \multicolumn{1}{|c|}{ Name } & \multicolumn{1}{|c|}{ Qty. } \\
\hline Food & N/A \\
Textiles & N/A \\
Paper Products & N/A \\
Raw Water & $15,300,000$ gals. \\
& \\
& \\
& \\
& \\
\hline
\end{tabular}

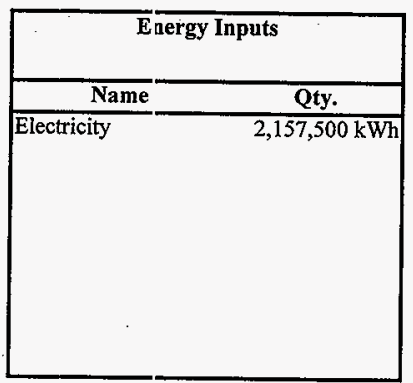

\section{Activity}

Routine Flotel Activities

Activity Time Period

1 Year

\begin{tabular}{|c|c|}
\hline \multicolumn{2}{|c|}{ Product or Result Output } \\
\hline Name & Qty. \\
\hline \multirow[t]{5}{*}{ Clean Hotel } & $107,300 \mathrm{ft}^{2}$ \\
\hline & \\
\hline & \\
\hline & \\
\hline & \\
\hline & \\
\hline
\end{tabular}

\begin{tabular}{|c|}
\hline Hazardous Waste Output \\
\hline Name \\
\hline \\
\hline \\
\end{tabular}

\begin{tabular}{|cc|}
\hline Non-Hazar-dous Waste Output \\
\hline Name & Qty. \\
\hline Solid Sanitary Waste & 624 yds $^{3}$ \\
& \\
\\
\end{tabular}




\section{Pollution Prevention Assessment \\ Worksheet 3 \\ Pollution Prevention Opportunity Description}

Date 02/05/97 ID Code Hotel-1 Business Hotel

Activity Routine Hotel Activities

P2O No. 1 P2O Title Environmentally Safe Ice Melt

\section{Current Practice}

The product used for melting snow and ice on sidewalks contains magnesium chloride or calcium chloride which can leave a slick oily residue. Additionally simple blends are sometimes purchased which typically have rock salt as its primary ingredient and can be harsh on vegetation.

\section{Recommended Action}

Apply SSS Ice Melter to snow and ice. SSS Ice Melter contains no ingredients that could damage concrete or stain carpet or leather. It is also safer to handle because it is non-exothermic (characterized or formed by heat). It will not burn or irritate skin and does not require the protection of special gloves or goggles.

SSS Ice Melter melts effectively down to $0{ }^{\circ} \mathrm{F}$. It is safer for grass than other rock salt-based blends or calcium chloride because it releases usable plant nutrients (nitrogen and potash) in the melting process. The product can be purchased from General Supply in Yakima. Deliveries are free to the Tri Cities businesses on Tuesdays.

\section{Calculation of Waste Reduction and/or Energy Savings}

SSS Ice Melter keeps the melted snow and ice from refreezing twice as long as calcium chloride based de-icers.

The hotel currently uses 500 lbs. of ice melt per year.

$500 \mathrm{lbs} . / 2=250 \mathrm{lbs}$. 


\section{Calculation of Annual Cost Savings}

The cost of the existing products and the SSS Ice Melter are comparable. The cost ranges from $\$ 32-\$ 34$ (average $\$ 33$ ) per $100 \mathrm{lbs}$. The hotel purchases $500 \mathrm{lbs}$. annually:

$\$ 33 \times 5=\$ 165$

Half the quantity of de-icer is required with the SSS Ice Melter.

$\$ 165 / 2=\$ 83$

\section{Calculation of Implementation Cost and Payback}

There is no implementation cost for this opportunity and therefore the payback is immediate.

\section{Vendor/Contact Information}

\section{General Supply}

P.O. Box 2217

Yakima, WA 98907

Phone: (509) 248-1241

Fax: (509) 248-3664 


\section{Pollution Prevention Assessment \\ Worksheet 3 \\ Pollution Prevention Opportunity Description}

Date 02/11/97 ID Code Hotel-1 Business Hotel

Activity Routine Hotel Activities

P2O No. 2 P2O Title Toilet Adaptation

\section{Current Practice}

The hotel has approximately 100 older-style Kohler ${ }^{\mathrm{TM}}$ toilets, 15 Colton toilets, and 35 American Standard ${ }^{\top \mathrm{MM}}$ toilets. This includes the 12 additional visitor restrooms. toilets use between 5-7 gallons per flush. The hotel is interested in a reduction in water use. However, the solution must be adaptive, flush clear, and be reliable.

\section{Recommended Action}

Install the Niagara Adjustable Flush Flapper on all 162 toilets to reduce the gallons per flush from 5-7 gallons to 3-4.5 gallons. When the toilet is flushed, the flapper opens and water enters through the adjustable opening in the bushing insert of the flapper. As the water enters, air is forced through the bleed hole in the side of the flapper cone. When filled with water, the flapper closes over the tank outlet before all the water in the tank is released into the bowl. The adjustable flapper bushing insert adjusts from the fully opened position (for fastest closing, least water used) to fully closed position (slowest closing, most water used) with many positions available in between.

In other words, the larger the opening in the bushing insert, the sooner the flapper will close and the more water will be saved. The bushing should be adjusted to the largest opening and still clear the bowl and achieve a "gurgling" sound at the end of the flush, and refill the bowl to its original level after each flush. Not refilling the bowl may result in double flushing.

The toilet flapper (Model \#N3145) has a five year warranty

This specific adaptation is recommended as the hotel can select the opening size to optimize water savings and deliver a complete flush. 


\section{Calculation of Waste Reduction and/or Energy Savings}

The hotel has 162 toilets each using between 5-7 gallons (average 6 gals.) of water per flush. It is estimated that each toilet is flushed 4 times/day.

The hotel is 61 percent full on the average throughout the year.

According to Niagara Conservation, the hotel can expect to use 3-4.5 gals/f ush (average 3.75) with the toilet flapper.

162 toilets $\times 0.61=99$ toilets used per average

Current Water Use: 99 toilets x 6 gals/flush $\times 4$ flushes/day x 365 days/yr $=: 867,240$ gals/yr

Water Use with Flapper: 99 toilets x 3.75 gals/flush x 4 flushes/day x 365 clays/yr $=542,025$ gals/yr

867,240 gals $/ \mathrm{yr}-542,025 \mathrm{gals} / \mathrm{yr}=325,215 \mathrm{gals} / \mathrm{yr}$

The total waste reduction is $325,215 \mathrm{gals} / \mathrm{yr}$

\section{Calculation of Annual Cost Savings}

According to the City of Richland, raw water costs $\$ 0.57 / 748$ gallons for thst hotel.

325,215 gals $/$ yr $\times \$ 0.57 / 748$ gals $=\$ 248 / \mathrm{yr}$

Sewer costs $\$ 0.61 /$ unit. One unit $=750$ gallons.

$325,215 \mathrm{gals} / \mathrm{yr} \times 1 \mathrm{unit} / 750 \mathrm{gals} \times \$ 0.61 /$ unit $=\$ 265 / \mathrm{yr}$

$\$ 248 / \mathrm{yr}+\$ 265 / \mathrm{yr}=\$ 513 / \mathrm{yr}$

The total cost savings is $\$ 513 / y r$

\section{Calculation of Implementation Cost and Payback}

The toilet flappers are $\$ 3.00$ each for a quantity of 150 or more.

165 toilets $\times \$ 3.00 /$ toilet flapper $=\$ 495$

Installation would take approximately 5 minutes according to Niagara Conservation. The average wage for the Maintenance/Engineer is $\$ 7.00 /$ hour. 
5 minutes/installation $\times 1$ hour $/ 60$ minutes $\times \$ 7.00 /$ hour $\times 150$ installations $=\$ 88$

$\$ 495+\$ 88=\$ 583$

The implementation cost is $\$ 583$

$\$ 583 / \$ 513=1.1$ years

The payback is 1.1 years

\section{Vendor/Contact Information}

Niagara Conservation

Mitch DeEsso

45 Horse Hill Road

Cedar Knolls, NJ 07927

1-800-831-8383 X129 


\section{Pollution Prevention Assessment Worksheet 3 \\ Pollution Prevention Opportunity Description}

Date 02/21/97 ID Code Hotel-1 Business Hotel

Activity Routine Hotel Activities

P2O No. 3 P2O Title Install Energy Efficient Hybrid Ballasts in Bathrooms

\section{Current Practice}

Recently a full lighting retrofit was completed at the hotel. However, the ballasts in the bathroom were not part of the retrofit as there was television and radio intelference when the electronic ballasts were installed.

The existing ballasts are Magnatec 412-L-SLH-TC-P and 446-L-SLH-TC-P' with T-12 lamps.

\section{Recommended Action}

Install the ADVANCE ${ }^{\ominus}$ PowrKut ${ }^{\mathrm{TM}}$ low frequency electronic ballasts. The PowrKut ${ }^{\mathrm{TM}}$ ballasts have light output and energy savings comparable to electronic rapid start bellasts. When used with energy saving lamps (T8), the PowrKut ${ }^{\mathrm{TM}}$ provides energy savings of up to 35 percent compared to conventional ballasts used with standard lamps.

PowrKut ${ }^{\mathrm{TM}}$ operation of fluorescent lamps at a frequency of $60 \mathrm{~Hz}$ will not interfere with high frequency sensitives of some electronic equipment. Low frequency operation will not interfere with powerline carrier systems, infrared control systems, radio or television reception or portable phone transmission.

PowrKut ${ }^{\mathrm{TM}}$ ballasts do not contain PCBs and are physically interchangeable; with magnetic counterparts used in the same application.

The recommended ballasts are PowrKut ${ }^{\mathrm{TM}} \mathrm{RK}-132-\mathrm{TP}$ and RK-2532-TP.

Additionally, it is recommended to replace lamps with energy efficient T-8 fluorescent lamps.

\section{Calculation of Waste Reduction and/or Energy Savings}

The hotel is 61 percent full on the average throughout the year.

Assumption: The guests occupy the rooms on the average between 5 p.m. and 8 a.m. (15 hours). 
Assumption: The lamp in the bathroom is in the "on" position 25 percent of the time.

The retrofit from the existing system to the PowrKut ${ }^{\mathrm{TM}}$ includes the following:

Existing Lamps and Ballasts:

412-L-SLH-TC-P $\quad \mathrm{w} / \mathrm{F} 40 \mathrm{~T} 12 \mathrm{lamp}=50 \mathrm{Watts}$

446-L-SLH-TC-P $\quad \mathrm{w} / \mathrm{F} 40 \mathrm{~T} 12$ lamp $\quad=\quad \underline{86 \mathrm{Watts}}$

136 Watts

$\begin{array}{llll}\text { Recommended Lamps and Ballasts: } & = & 34 \text { Watts } \\ \text { RK-132-TP } & \text { w/F32T8 lamp } & = & \text { 62 Watts } \\ \text { RK-2532-TP } & \text { w/F32T8 lamp }\end{array}$

136 Watts -96 Watts $=40$ Watts

40 Watts $\times 150$ rooms $\times 0.61$ occupancy $=3,660$ Watts

3,660 Watts $\times 15$ hours/day $\times 365$ days/year $\times 0.25$ light used $=5,009,625$ Watt hours/year

$5,009,625 / 1,000=5,010 \mathrm{kWh} /$ year

\section{Calculation of Annual Cost Savings}

The average commercial rate for electricity is $\$ 0.0351 / \mathrm{kWh}$ according to the City of Richland.

$5,010 \mathrm{kWh} /$ year $\times \$ 0.0351 / \mathrm{kWh}=\$ 176 /$ year

According to ADVANCE ${ }^{\ominus}$, the maintenance cost would be half that of the existing maintenance cost due to the longer operation of lamps.

The Maintenance/Engineer staff wage is an average of $\$ 7.00 /$ hour

The hotel staff estimate the bulb replacement takes approximately 10 minutes to accomplish. Approximately 30 light changes occur annually.

10 minutes/light change $\times 30$ light changes/year $\times 1$ hour $/ 60$ minutes $\times \$ 7.00 /$ hour $=\$ 35 /$ year

$\$ 35 / 2=\$ 18 /$ year

$\$ 176 /$ year $+\$ 18 /$ year $=\$ 194 /$ year

The average annual cost savings is therefore $\$ 194$. 


\section{Calculation of Implementation Cost and Payback}

The cost of the ADVANCE ${ }^{\otimes}$ PowrKut ${ }^{\mathrm{TM}}$ is $\$ 20.10$ each, assuming the hotel purchases the quantity of 150 each.

$\$ 20.10 \times 150$ rooms $=\$ 3,015$

The cost of the energy efficient T-8 lamps is $\$ 2.50$ each for a package of 2.5 at the hotel rate.

$\$ 2.50 / 25=\$ .10 /$ lamp

$\$ .10 /$ lamp x 150 rooms $\times 2$ lamps/bathroom $=\$ 30$

$\$ 3,015+\$ 30=\$ 3,045$

The payback is therefore $\$ 3,045 / \$ 194=16$ years

\section{Vendor/Contact Information}

Stoneway Electric

630 Railroad Road

Richland, WA 99352

(509) 943-4664 


\section{Pollution Prevention Assessment Worksheet 4 \\ Pollution Prevention Opportunities Summary}

Date 02/22/97

ID Code Hotel-1

Business Hotel

Activity Routine Hotel Activities

\begin{tabular}{|c|l|c|r|r|r|r|}
\hline P20 No. & \multicolumn{1}{|c|}{ P20 Title } & $\begin{array}{c}\text { Waste } \\
\text { Class } \\
\text { Reduced }\end{array}$ & $\begin{array}{c}\text { Annual Waste } \\
\text { Reduction or } \\
\text { Energy Savings }\end{array}$ & $\begin{array}{c}\text { Estimated } \\
\text { Annual } \\
\text { Savings }\end{array}$ & $\begin{array}{c}\text { Estimated } \\
\text { Implementation } \\
\text { Cost }\end{array}$ & Payback \\
\hline 1 & $\begin{array}{l}\text { Environmentally } \\
\text { Safe Ice Melt }\end{array}$ & Hazardous & $250 \mathrm{lbs}$. & $\$ 83$ & $\$ 0$ & Immediate \\
\hline 2 & Toilet Adaptation & Water & 325,215 gals. & $\$ 513$ & $\$ 583$ & 1.1 \\
\hline 3 & $\begin{array}{l}\text { Install Energy } \\
\text { Efficient Electronic } \\
\text { Ballasts in } \\
\text { Bathrooms }\end{array}$ & Energy & $5,010 \mathrm{kWh}$ & $\$ 194$ & $\$ 3,045$ & 16.0 \\
\hline
\end{tabular}

\section{Other Brainstorming Ideas Not Researched}

\section{Opportunity \\ Reason}

Compost food waste

Compost landscaping materials

Replace CFC chillers

Insulate chillers

Use non-hazardous products

Use reusable gloves in kitchen

Install a gray water collection system from kitchen to landscaping area

Recycle tin from kitchen

Purchase paper products made from recycled materials

Use reusable coffee filters

Heat spa and pool with solar

Purchase high efficiency ice machines

Use latex paint for trimwork

Install dispensers for soap and shampoo

Train employees in new poliution prevention methods

Recycle water in laundry area

Install motion detectors in infrequently occupied areas

Upgrade heat/cool controls to a computer system

Use reusable air filters

Insulate or replace commercial dryers

Install low-flow sink aerators

Install low-flow showerheads
Customer not interested now

Not a large quantity

Customer not interested now

Customer not interested now

Customer will initiate themselves

Customer not interested now

The Battelle labs will investigate

Customer not interested now

Customer not interested now

Customer not interested now

Customer not interested now

Customer not interested now

Customer will initiate himself

A corporate decision

Customer not interested now

Combined with gray water option

Timers already installed

Too costly

Customer not interested now

Too costly

Already installed

Already installed 


\section{Opportunity}

Reason

Allow guests to choose how often the sheets/towels are changed Provide aluminum can recycling

Provide a receptacle for recycling paper in the guest rooms

Fix air leaks

A corporate discision Customer not interested now Customer not interested now Outside temperature too warm for meaningful infrared test 


\section{Pollution Prevention Assessment \\ Worksheet 5 \\ Final Summary}

Date 02/06/97 ID Code Hotel-1 Business Hotel

Activity Routine Hotel Activities

\section{Proposed Opportunities and Discussion}

Environmentally Sound Ice Melt

An alternative product, SSS Ice Melter was investigated for de-icing sidewalks. The SSS Ice Melter does not contain any hazardous ingredients and it does not require the protection of special gloves or goggles for application. It can melt effectively down to $0^{\circ} \mathrm{F}$ and releases usable plant nutrients in the melting process: An annual reduction of $250 \mathrm{lbs}$. can be achieved for a cost savings of $\$ 83$ if this opportunity is implemented.

\section{Toilet Adaptation}

Installation of the Niagara Adjustable Flush Flapper on all 162 toilets will reduce the gallons per flush from 5-7 gallons to 3-4.5 gallons per flush. The annual cost savings is $\$ 513$ for eliminating 325,215 gals. of water.

\section{Install Energy Efficient Hybrid Ballasts in Bathrooms}

The PowrKut ${ }^{\mathrm{TM}}$ ballast will not interfere with high frequency sensitivity of some electronic equipment. Low frequency operation will not interfere with powerline carrier systems, infrared control systems, radio or television reception or portable phone transmission. Replacing the magnetic ballasts with electronic ballasts will save $\$ 194$ per year and 5,010 kWh per year. The implementation cost is over $\$ 3,000$ providing a payback period of 16 years.

\section{Several other opportunities were investigated which were easy to implement:}

\section{Recycle Guest Soaps}

Baker Commodities does not accept soap at their rendering plant. However, the Pasco Mission will pick up the soap for reuse at the Mission at no cost to the hotel. The Pasco hotel has an ongoing program where housekeeping collects the soaps in a container for the Pasco Mission who picks up the soaps once a month. A similar program could be easily instituted at the Richland hotel. Contact the Pasco Mission on 547-2112 or 545-6313 for collection.

\section{Recycle Batteries}

The City of Richland will accept alkaline batteries for recycle at no cost to the hotel. The batteries can be collected in a large container and delivered to the City of Richland landfill with prior notice to the Moderate Risk Waste Facility staff at 943-7387. 
Additionally, Rayovac ${ }^{\otimes}$ Renewal $^{\oplus}$ rechargeable alkaline ${ }^{T M}$ batteries and the associated power station is available from Stoneway Electric and other retail stores. Renewa ${ }^{\otimes}$ alkaline batteries can be reused 25 times or more and they are the most environmentally respisnsible batteries you can buy. The Renewal batteries are available in D, C, AA, and AAA battery sizes. The batteries contain no hazardous cadmium and are mercury free. The power station can charge any combination of up to eight $\mathrm{D}, \mathrm{C}, \mathrm{AA}$, or AAA batteries. The AA and AAA batteries are $\$ 5.80$ each and the $C$ and $D$ batteries are $\$ 5.23$ each. The charger is $\$ 35.33$.

\section{Recycle Glass}

The large dumpster of glass contains several different types of glass and the refore must be segregated into either brown or clear glass before recycling. Green glass from commercial businesses and china is not accepted at any local recycler. An ongoing glass recycling program could easily be established for brown and clear glass. The bins for collecticn should be clearly marked to avoid commingling glass colors. A contract with a local recyclet would need to be established for recycling brown and clear glass.

\section{Recycle Fluorescent Tubes}

Upon investigation, the Hanford Centralized Consolidation and Recycling Center cannot accept fluorescent tubes from commercial businesses. However, fluorescent tubes can be recycled through Salesco Systems. Salesco Systems will provide the shipping containers at a cost of $\$ 2.25$ for a 4' lamp box and $\$ 4.50$ for a $8^{\prime}$ ' lamp box. The contract will cost a minimum of $\$ 50$ to process the material delivered to Salesco and a minimum of $\$ 500$ for pickup and processing. Contact Margo Brower on 1-800-368-9095 to set up a contract.

\section{Recommendations and Schedule for Implementation}

It is recommended to immediately replace the ice melt with the environmentally safe brand as it is an immediate payback. Additionally, the toilet adaptations should be purichased for water conservation within the year. It is recommended to first try the sample provided to ensure it will adequately do the job. Due to the poor payback on the hybrid ballasts, it is not recommended to implement now. However, as ballasts need replacement, the PowrKut ${ }^{\top \mathrm{M}}$ shculd be used in place of the magnetic ballast.

Furthermore, it is recommended for the hotel to participate in the "Green Hotels Association." The corporate hotel is already a charter member of this association which is committed to encouraging, promoting and supporting ecological consciousness in the hospitality industry. Green Hotels Association members may receive the complete "Conservation Guidelines and Ideas" booklet which contains ideas for the following areas: lawn and gardea, pest control, restaurants, public areas, laundry, swimming, pool, solid waste, composting, offices, purchasing, maintenance, conventions, new construction, refurbishment, and the community.

The Hotel can receive public relations benefits through the Green Hotels Association. The Green Hotels Association logo notifies hotel guests of the hotel's environmental practices. Hotels are finding that guests like to know hotels are doing their part to conserve and protect the 
environment. Call 713-789-8889 to contact the Green Hotels Association to begin receiving the benefits of being a "green" hotel.

Finally, a detailed energy audit was performed for the Hotel in 1992 sponsored by the City of Richland. This report is on file at the Resource Energy Management Office. A copy can easily be obtained by calling Jeff McCullough on 943-7438. 
Pollution Prevention Assessment

Apartment Complex 


\section{Pollution Prevention Assessment \\ Worksheet 1 \\ Team and Activity Description}

Date 02/07/97 ID Code Apartment-1 Activity Multi-Family Living

Business Name and Address Apartment Complex

Business Contact and Phone

Team Members (*Leader)

Mary Ann St. Martin

Dr. James Wise

Gail Baasch

Matt Zybas

Mary Betsch *

Jeff McCullough
Telephone

943-7485

$627-5869$

943-7730

943-7467

$372-1627$

943-7438

\section{Description of Activity to be Examined in this Assessment}

The apartment manager has developed a goal for instituting "green" practices and is very willing to implement pollution prevention initiatives at this apartment complex.

The Apartment complex is comprised of the following unit schematics:

48 apartments with 1 bedroom 1 bath combinations

36 apartments with 2 bedroom 1 bath combinations

96 apartments with 2 bedroom 2 bath combinations

48 apartments with 3 bedroom 2 bath combinations

The complex also contains individual garages, a maintenance shed, a sports court, an office, a pool and a recreational facility. The office, pool and recreational facility are commonly referred to as the "cabana." Currently, the market-rate apartments are at 75 percent capacity and range from $\$ 605 /$ month to $\$ 835 /$ month.

The City of Richland Wastewater Treatment Plant operators have identified problems with the grease trap in the past. However, recently no build-up has been seen due primarily to awareness through a mailer to all residents reminding them to not put grease down the drain.

The apartments and the surrounding buildings operate on electricity. The individual apartment fireplaces are wood burning except for the large fireplace in the cabana which is gas. The pool 
and the spa are also gas powered. The residents pay for their own utilities (electricity, phone, and sewer). Dumpsters are located in 6 locations. Primarily, the dumping locations include one large and one small dumpster. Recycling is not available in these areas anil therefore, recyclables are mixed in with the solid sanitary waste. The maintenance personnel dumps solid sanitary waste at least once a day and sometimes twice daily. A trash compactor, owned by the apartment complex compacts the trash before it is eventually disposed of at the City of Richland landfill. Cardboard recycling is available for residents at a separate location.

The apartments are unfurnished. However, a private company can provide furnishings at an additional cost to the resident. The apartments are just over 1 year old. Vinyl siding was used in the construction rather than wood for maintenance purposes. All toilets, showers, and sinks are energy and/or water efficient. A washer/dryer combination is available in every unit, as well as a standard 55-gallon water heater. Incandescent 40 and 60 Watt bulbs are used primarily throughout the complex. The outside lighting (180 Watt floodlight at each stairwell) is on a photocell and is metered by the complex. Small pets are allowed in the apartments.

When a resident moves into an apartment, he/she is given a move-in packet which includes a variety of coupons, renters insurance information, newsletters, and general information about Richland living. When the resident moves out, a series of cleaning, paintin; maintenance activities are conducted to ensure the apartment is back to its criginal condition.

A variety of materials and chemicals were left-over after construction. A srnall amount of materials and chemicals were kept for ongoing use and the remainder were disposed of properly. Products used on a routine basis include paint, power washer solution, ice melt, ant and roach killer, and fertilizers. Alkaline ${ }^{\top M}$ batteries are kept on hand for smoke detectors and flashlights.

Lawn mowing is contracted to an outside company and the contract stated that is was the responsibility of the contractor to haul the grass clippings away. Mulching was tried in the past and it became a problem with grass in the pool and other common areas.

The cabana contains a common area for residents to use for parties and othes: personal occasions. The lighting is primarily cans and sconces. The pool is adjacent to the cabana and is heated to 70 $-80^{\circ} \mathrm{F}$ in the summer. The spa is heated year-round. Because the pool and spa are propane powered by an onsite tank, the cost for heat is exceptionally high $(\sim \$ 700 / \mathrm{month})$. A pool blanket is kept on the pool and spa when not in use. The pool chemicals are stored adjacent to the pool in a locked shed.

Four properties are managed in the Tri Cities by the same manager and comjany.

The apartment manager's goals from this assessment include:

- Suggest initiatives which will save money

- Implement recycling for residents 


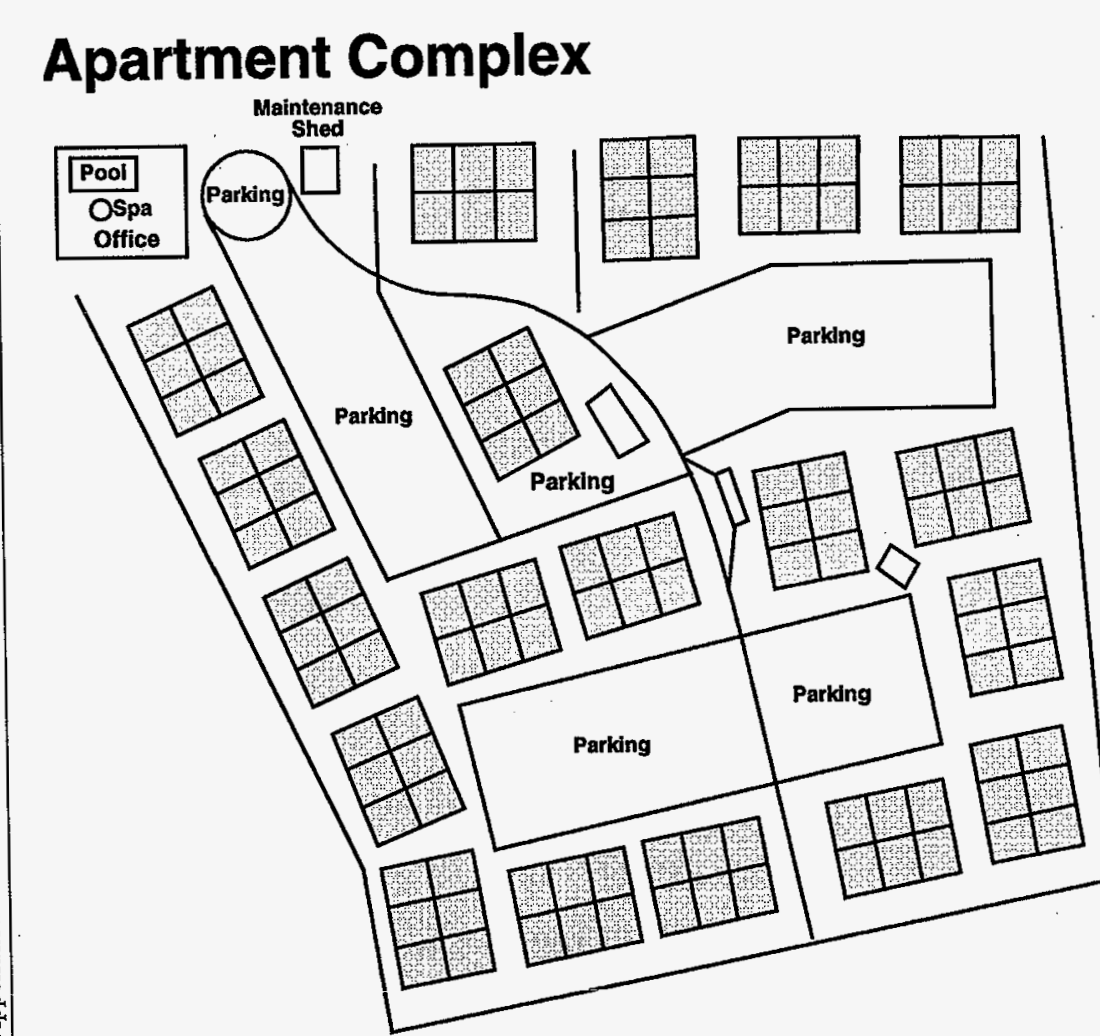




\section{Pollution Prevention Assessment \\ Worksheet 2 \\ Flow Diagram}

Date 02/07/97

ID Code Apartment-1

Business Apartment Complex

Activity Multi-Family Living

\begin{tabular}{|lr|}
\hline \multicolumn{2}{|c|}{ Chemical Inputs } \\
\hline \multicolumn{1}{|c|}{ Name } & Qty. \\
\hline Chlorine & $125 \mathrm{lbs}$. \\
Acid & $125 \mathrm{lbs}$. \\
Fertilizer & 7 tons \\
& \\
Paint & 40 gals. \\
Chemicals & $50 \mathrm{lbs}$. \\
& \\
& \\
\hline
\end{tabular}

\begin{tabular}{|lr|}
\hline \multicolumn{2}{|c|}{ Material Inputs } \\
\hline \multicolumn{1}{|c|}{ Name } & Qty. \\
\hline Raw Water & 31 tons \\
$\begin{array}{l}\text { Grass } \\
\text { Household } \\
\text { Disposable Materials }\end{array}$ \\
\hline
\end{tabular}

\begin{tabular}{|lr|}
\hline \multicolumn{2}{|c|}{ Energy Inputs } \\
\hline \multicolumn{1}{|c|}{ Na me } & Qty. \\
\hline $\begin{array}{l}\text { Electricity } \\
\text { Propane }\end{array}$ & 6,270 gals. \\
& \\
& \\
\end{tabular}

\section{Activity}

Multi-Family Living

Activity Time Period 1 Year

\begin{tabular}{|cc|}
\hline \multicolumn{2}{|c|}{ Product or Result Output } \\
\hline Name & Qty. \\
\hline Maintained Apts. & 288 ea. \\
\\
\end{tabular}

\begin{tabular}{|lr|}
\hline \multicolumn{2}{|c|}{ Hazardous Waste Output } \\
\hline \multicolumn{1}{|c|}{ Name } & Qty. \\
\hline $\begin{array}{l}\text { Chemicals } \\
\text { Paint }\end{array}$ & 40 gals. \\
& \\
& \\
& \\
& \\
\hline
\end{tabular}

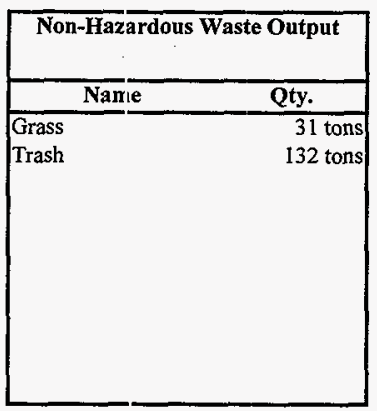




\section{Pollution Prevention Assessment Worksheet 3 Pollution Prevention Opportunity Description}
Date $02 / 18 / 97$
ID Code Apartment-1
Business Apartment Complex

Activity Multi-Family Living

P2O No. $1 \quad$ P2O Title Lighting Retrofit for Apartment Controlled Lighting

\section{Current Practice}

The apartment complex controlled lighting is the cabana area and all outdoor lighting. At the door of each apartment, one 60 Watt lamps in on photocell. The outdoor storage room is also a 60 Watt lamp but is operated by a switch inside the apartment. Additionally, on every unit there are between four-six (average 5) 180 Watt floodlights.

In the office/cabana area, there are ten 60 Watt lamps, twenty-seven 75 Watt cans, six 75 Watt sconces, eight F40T12 fluorescent fixtures, and four 40 Watt lamps.

\section{Recommended Action \\ Replace all incandescents with compact fluorescents or energy efficient fluorescents for the apartment complex controlled lighting. According to Real Goods ${ }^{T M}$, compact fluorescents use only $1 / 4$ of the energy of a standard incandescent bulb. In addition, since compact fluorescents last 10 to 13 times longer than standard incandescents, the need to replace lamps will be less frequent. \\ Furthermore, according to Electric Ideas Clearinghouse, the T-8 fluorescent lamps cost approximately $\$ 6.00$ less than F40T12 lamps. \\ A spreadsheet is attached indicating the specific lamps and ballasts for the retrofit. \\ It is not recommended to alter the 90 Watt floodlights as these are presently energy efficient.}

\section{Calculation of Waste Reduction and/or Energy Savings \\ Occupancy in the apartments was based upon 50 weeks/year. \\ A spreadsheet is attached which indicates the energy savings associated with this recommendation.}


It identifies that the annual energy savings for replacing the lighting for the complex controlled lighting is $61,650 \mathrm{kWh}$.

\section{Calculation of Annual Cost Savings}

The cost of electricity for the apartment complex is $\$ 0.043 / \mathrm{kWh}$.

A spreadsheet is attached which indicates the cost savings associated with this recommendation.

It identifies that the annual cost savings for replacing the lighting for the complex controlled lighting is $\$ 2,676$.

\section{Calculation of Implementation Cost and Payback}

A spreadsheet attached identifies the implementation cost which includes materials and labor. Outdoor compact fluorescent lamps should be equipped with cold weather ballasts.

The implementation cost which includes labor is approximately $\$ 4,530$.

$\$ 4,530 / \$ 2,676=1.7$ years.

The payback is therefore 1.7 years.

\section{Vendor/Contact Information}

\section{Stoneway Electric Supply}

630 Railroad Road

Richland, WA 99352

(509) 943-4664

\section{Electric Ideas Clearinghouse}

Cindy Wills

P.O. Box 43171

Olympia, WA 98504

1-800-872-3568

\section{Real Goods $^{\text {TM }}$}

555 Leslie Street

Ukiah, CA 95482-5507

1-800-762-7325 
City of Richland, Energy Resources Division-Technical Assistance

Jeff McCullough

650 George Washington Way

Richland, WA 99352

(509) 943-7496 


\section{Pollution Prevention Assessment \\ Worksheet 3 \\ Pollution Prevention Opportunity Description}

Date 02/18/97 In Code Apartment-1 Business Apartment Complex

Activity Multi-Family Living

P2O No. 2 P2O Title Lighting Retrofit for Apartment Renters

\section{Current Practice}

The Apartment complex is comprised of the following unit schematics:

48 apartments with 1 bedroom 1 bath combinations

36 apartments with 2 bedroom 1 bath combinations

96 apartments with 2 bedroom 2 bath combinations

48 apartments with 3 bedroom 2 bath combinations

Inside each 1 bedroom / 1 bath apartment, there is one 60 Watt bulb in the entry area, one 60 Watt lamp in the dining room, four T-12 fluorescent lamps in the kitchen, four 40 Watt lamps in the bathroom, two 250 Watt heat lamps in the bathroom, and two 60 Watt sconces in the hallway.

Inside each 2 bedroom / 1 bath apartment, there is one 60 Watt bulb in the entry area, one 60 Watt lamp in the dining room, four T-12 fluorescent lamps in the kitchen, four 40 Watt lamps in the bathroom, two 250 Watt heat lamps in the bathroom, and four 60 Watt sionces in the hallway.

Inside each 2 bedroom / 2 bath apartment, there is one 60 Watt bulb in the entry area, one 60 Watt lamp in the dining room, four T-12 fluorescent lamps in the kitchen, eight 40 Watt lamps in the bathroom, four 250 Watt heat lamps in the bathroom, and four 60 Watt sconces in the hallway.

Inside each 3 bedroom / 2 bath apartment, there is one 60 Watt bulb in the entry area, one 60 Watt lamp in the dining room, four T-12 fluorescent lamps in the kitchen, eight 40 Watt lamps in the bathroom, four 250 Watt heat lamps in the bathroom, and six 60 Watt sconces in the hallway.

\section{Recommended Action}

Replace the incandescent lamps with compact fluorescent lamps in each apartment. Furthermore, retrofit the kitchen fluorescents with electronic ballasts and T-8 lamps in each 
apartment. This retrofit will be an added "selling" feature as residents often inquire about the utility cost before establishing a contract.

Calculation of Waste Reduction and/or Energy Savings

A spreadsheet is attached which indicates the energy savings associated with this

recommendation. It is based upon 100 percent occupancy at 50 weeks/year.

It identifies that the annual energy savings for replacing the lighting for the apartment lighting is as follows (based upon 100 percent occupancy):

\begin{tabular}{lll} 
Apt Style & Apt. Savings & Complex Savings \\
\hline 1 Bedroom/1 Bath & $4,454 \mathrm{kWh} /$ year & $213,771 \mathrm{kWh} /$ year \\
2 Bedroom/1 Bath & $4,595 \mathrm{kWh} /$ year & $165,403 \mathrm{kWh} /$ year \\
2 Bedroom/2 Bath & $4,916 \mathrm{kWh} /$ year & $471,974 \mathrm{kWh} /$ year \\
3 Bedroom/2 Bath & $4,926 \mathrm{kWh} /$ year & $236,466 \mathrm{kWh} /$ year
\end{tabular}

The combined total energy savings for the complex (all apartment renters) is therefore $1,087,614 \mathrm{kWh} / \mathrm{year}$.

\section{Calculation of Annual Cost Savings}

The attached spreadsheet indicates that the annual cost savings for the apartments is as follows:

$\begin{array}{lll}\text { Apt Style } & \text { Apt. Savings } & \text { Complex Savings } \\ \text { 1 Bedroom/1 Bath } & \text { \$193/year } & \$ 9,278 / \text { year } \\ \text { 2 Bedroom/1 Bath } & \$ 199 / \text { year } & \$ 7,178 / \text { year } \\ \text { 2 Bedroom/2 Bath } & \$ 213 / \text { year } & \$ 20,484 / \text { year } \\ \text { 3 Bedroom/2 Bath } & \$ 214 / \text { year } & \$ 10,263 / \text { year }\end{array}$

The combined total cost savings for the complex (all apartment renters) is therefore $\$ 47,203$ /year.

\section{Calculation of Implementation Cost and Payback}

The implementation cost including materials and labor is as follows:

\begin{tabular}{ll} 
Apt Style & Apt. Cost \\
\hline 1 Bedroom/1 Bath & $\$ 212$ \\
2 Bedroom/1 Bath & $\$ 240$ \\
2 Bedroom/2 Bath & $\$ 522$ \\
3 Bedroom/2 Bath & $\$ 550$
\end{tabular}

The total combined implementation cost is $\$ 1,524$. 
The implementation cost for this opportuniry would be assumed by the apartment complex, however the apartment renters would realize the annual cost savings.

$\$ 1,524 / \$ 47,203=0.03$ years.

The payback is therefore 0.03 years.

Vendor/Contact Information

Electric Ideas Clearinghouse

Cindy Wills

P.O. Box 43171

Olympia, WA 98504

1-800-872-3568

Stoneway Electric Supply

630 Railroad Road

Richland, WA 99352

(509) 943-4664

City of Richland, Energy Resources Division--Technical Assistance Jeff McCullough

650 George Washington Way

Richland, WA 99352

(509) 943-7496 


\section{Pollution Prevention Assessment \\ Worksheet 3 \\ Pollution Prevention Opportunity Description}

Date 02/22/97 ID Code Apartment-1 Business Apartment Complex

Activity Multi-Family Living

P2O No. 3 P2O Title Wrap Hot Water Heaters with Insulated Blankets

\section{Current Practice}

The individual apartment hot water heaters are not wrapped. The hot water heaters are ASHRAE standard 90A-1980 with ratings 48-55. The hot water heaters are 55-gallons and operate at 240 Volts. The hot water heaters are set at an average of $120^{\circ} \mathrm{F}$.

\section{Recommended Action}

Wrap hot water heaters with insulated blankets to prevent heat loss and save energy and money. This opportunity will help maintain the water temperature at the thermostat setting.

\section{Calculation of Waste Reduction and/or Energy Savings}

According to the Consumer Guide to Home Energy Savings, an insulating jacket will reduce standby heat loss (heat lost through the walls of the tank) by 25 - 45 percent, saving 4 - 9 percent (6.5 average) on water heating bills.

The Washington State University Cooperative Extension Energy Program recommended that based upon the type of hot water heaters in the apartments, wrapping the tanks is viable solution for energy savings.

According to a study "End-Use Load Submetering Project" conducted by the Pacific Northwest National Laboratories, the following approximations were identified:

$2,300 \mathrm{kWh} /$ year for the first person

$2,400 \mathrm{kWh} /$ year for the next person

An additional $300 \mathrm{kWh} /$ year per person for all additional persons per year

The apartment complex estimates that on the average 2 people occupy each of the 228 apartments.

$2,300 \mathrm{kWh} /$ year $+2,400 \mathrm{kWh} /$ year $=4,700 \mathrm{kWh} /$ year 
$4,700 \mathrm{kWh} /$ year $\times 228$ apartments $=1,071,600 \mathrm{kWh} /$ year

The apartment complex is currently at 75 percent capacity.

$1,071,600 \mathrm{kWh} /$ year $\times 0.75$ percent capacity $=803,700 \mathrm{kWh} /$ year

$803,700 \mathrm{kWh} /$ year $\times 0.065$ percent savings $=52,241 \mathrm{kWh} /$ year

The total annual energy savings is therefore $52,241 \mathrm{kWh}$.

\section{Calculation of Annual Cost Savings}

The residential electricity rate in the City of Richland is $\$ 0.043 / \mathrm{kWh}$.

$52,241 \mathrm{kWh} /$ year $\times \$ 0.043 / \mathrm{kWh}=\$ 2,246 /$ year

The total annual cost savings is therefore $\$ 2,246$.

\section{Calculation of Implementation Cost and Payback}

Pre-cut insulation jackets are $\$ 12.99$ at Eagle Hardware and Garden ${ }^{\mathrm{TM}}$. This cost could easily be lower if a contract was established for purchasing in bulk.

$\$ 12.99 \times 228$ apartments $=\$ 2,961$

According to the Washington State University Cooperative Extension Energy Program the installation is expected to take approximately 10 minutes per tank at an average cost of $\$ 15 /$ hour.

10 minutes $/$ tank $\times 1$ hour $/ 60$ minutes $\times \$ 15 /$ hour $\times 228$ tanks $=\$ 570$

$\$ 2,961+\$ 570=\$ 3,531$

The apartment complex would pay for the iniplementation cost while the reriters would realize the annual cost savings.

$\$ 3,531 / \$ 2,246=1.6$ years

The payback is therefore 1.6 years. 
Vendor/Contact Information

Eagle Hardware and Garden ${ }^{\mathrm{TM}}$

1020 North Colorado

Kennewick, WA 99336

(509) 736-1451 


\section{Pollution Prevention Assessment Worksheet 3 \\ Pollution Prevention Opportunity Description}

Date 02/22/97 ID Code Apartment-1 Business Apariment Complex

Activity Multi-Family Living

P2O No. 4 P2O Title Heat Pool and Spa with Solar

\section{Current Practice}

The 25,000 gallon pool and 750 gallon spa are heated by propane. The pool is heated to $70-80$ ${ }^{\circ} \mathrm{F}$ in the summer. The spa is heated year-round to approximately $102^{\circ} \mathrm{F}$. A pool blanket is kept on the pool and spa when not in use.

The mean monthly temperatures (in ${ }^{\circ} \mathrm{F}$ ) at the Hanford Meteorology Station in Richland, WA are as follows:

January $\quad 29.5$

February $\quad 36.6$

March $\quad 49.8$

April $\quad 52.8$

May $\quad 61.8$

June $\quad 69.2$

July $\quad 76.5$

August $\quad 74.4$

September $\quad 65.5$

October $\quad 53.0$

November $\quad 39.9$

December $\quad 32.8$

\section{Recommended Action}

Heat pool and spa with solar. The solar heating system recommended is a simple operation. Using the pump that circulates pool water through the filter, the water is automatically diverted by an electronic temperature control and a motorized valve so that it flows through the many small passages of the solar collectors. While passing through the collector, it is warmed by the sun. The warm water then flows directly back to the pool. When the pool tas reached the desired temperature, the water then by-passes the solar collector and returns directly to the pool. 
The recommended system has been successfully used at other apartment complexes in the Northwest. Approximately ten 4' x 12' collectors would be required for the apartment system.

It was assumed that the pool would be heated May - September between $70-80^{\circ} \mathrm{F}$ and the spa heated to a temperature of $102^{\circ} \mathrm{F}$. The propane tank should remain in place to heat the spa in the winter months and in the summer evenings. The backup heater will only have to pick up the last few degrees in the summer months to heat the spa so it will operate less than it would without solar.

A lifetime warranty is available for the solar collectors described from Sun, Wind and Fire.

\section{Calculation of Waste Reduction and/or Energy Savings}

Last year, The apartment complex used 6,270 gals of propane to heat the pool and spa.

The pool and spa each consume 50 percent of the total propane according to Sun, Wind, and Fire. 6,270 gals $/ 2=3,135$ gals each for the pool and spa.

Sun, Wind, and Fire estimated that a 90 percent savings could be achieved for the pool with a 75

${ }^{\circ} \mathrm{F}$ average pool temperature.

$3,135 \mathrm{gals} / \mathrm{yr} \times 0.90$ percent savings $=2,822 \mathrm{gals} / \mathrm{yr}$.

Sun, Wind, and Fire estimated that a 20 percent savings could be achieved for the spa with a 102 ${ }^{\circ} \mathrm{F}$ average spa temperature.

3,135 gals $/ y r \times 0.20$ percent savings $=627$ gals $/ y r$.

2,822 gals $/$ yr +627 gals $/$ yr $=3,449$ gals $/ y r$

The total average savings is therefore 3,449 gals/yr

\section{Calculation of Annual Cost Savings}

Amerigas $^{\top M}$ in Kennewick, WA services the apartment complex with propane at an average cost of $\$ 1.49 /$ gallon.

$3,449 \mathrm{gals} / \mathrm{yr} \times \$ 1.49 / \mathrm{gal}=\$ 5,139$ savings

The average annual cost savings is $\mathbf{\$ 5 , 1 3 9}$ 


\section{Calculation of Implementation Cost and Payback}

Approximately ten 4' $\times 12^{\prime}$ collectors would be required including the panel kit, the system kit, hold down strap, auto control with sensors, drains, ball valves, and two thermometers. Sun, Wind and Fire estimated that the materials would cost approximately $\$ 3,360$ and the installation would cost approximately $\$ 960$.

$\$ 3,360+\$ 960=\$ 4,320$.

The implementation cost is approximately $\mathbf{\$ 4 , 3 2 0}$.

$\$ 4,320 / \$ 5,139=0.8$ years

The payback is 0.8 years

\section{Vendor/Contact Information}

Sun, Wind \& Fire

Alternative Energy Supply Co., Inc.

Brent Gunderson

7637 S.W. $33^{\text {rd }}$ Ave.

Portland, OR 97219

Phone: (503) 245-2661

Fax: (503) 245-2661 


\title{
Pollution Prevention Opportunity Assessment Worksheet 3 \\ Pollution Prevention Opportunity Description
}

\author{
Date $02 / 24 / 97$ \\ P2OA ID Code Apartment-1 \\ Facility Apartment Complex
}

Activity Multi-Family Living

P2O No. 5 P2O Title Implement a Recycling Program

\section{Current Practice}

Cardboard recycling is available to residents in one location. Trash, which includes recyclables is disposed of in one of the six dumpster areas located throughout the complex. The size of the area for the dumpsters is $11.8^{\prime}$ long $x 8^{\prime}$ ' wide. Currently, two dumpsters are in each dumpster area. The dumpsters are 5.3' long $x 3^{\prime}$ ' wide with room for a third dumpster. Residents have requested recycling opportunities and the management is supportive of this endeavor as residents look at recycling as an added amenity. Apartment residents will appreciate the opportunity to recycle on their premises.

The dumpsters are emptied at least once a day by the maintenance crew. The solid sanitary waste is compacted and picked up by the City of Richland twice a month. The apartment complex cannot provide transportation of the recyclables to a recycling center.

\section{Recommended Action}

Implement a recycling program for all residents. In order to achieve the best recycling rates, it is recommended to implement recycling areas at the source-at the individual apartments.

Furthermore, it is recommended to offer recycling for 3 commodities: clear glass, newspaper/magazines, and aluminum/tin. It has been approved by Clayton Ward to comingle newspaper/magazines and aluminum/tin. In addition, it is recommended to continue recycling cardboard through Basin Recycling. As the program is accepted and utilized, additional commodities can easily be added.

A U.S. Environmental Protection Agency study shows that it takes the average household two minutes a day to recycle.

Utilize 14 gallon recycling totes for the apartment renters to place recyclables in for recycling. All recyclables will be commingled in the totes. On a designated day of the week, apartment renters can place the recyclable totes at one of the six dumpster locations for pickup by the maintenance crew. 
The totes can be picked up and placed in a special fabricated towable flatbed cart similar to the carts used for collecting and transporting solid sanitary waste. The recyclables must be moved to a larger staging area where the City of Richland will remove and haul recyclables to the recycling center at no extra cost. The towable flatbed cart, compatible with the apartment complexes existing tractor, can be used to transfer the recyclables to the large 20 cubic yard recycling roll-off. The area near the lift station is recommended as the best location. The location is suited for also enhancing awareness for recycling as it is located near the apartment entrance. The maintenance crew can then separate the recyclables into the designated compartments. When one or more of the compartments is full, the maintenance crew should alert the City of Richland and the City will pick up and transfer the roll-off to the recycling station. The totes can be stacked at the dumpsters for renters to pick up after collection.

It is recommended to designate a recycling coordinator for the apartment complex. It could be someone from the management company, a resident, or a maintenance person. The coordinator should deal with all facets of the recycling program.

Finally, include recycling articles and information in the apartment newsletters to keep residents aware of the recycling program and other pollution prevention opportunities. A simple graph of the monthly recycling results will continue to generate enthusiasm for the program. Residents can be educated about the recycling program upon move-in as detailed instructions can be provided in the "Resident Move-In" packet. Probably the single most important factor in any relationship is the quality and quantity of communication. Good renter-landlord relations from beginning to end will elicit cooperation in any endeavor, including recycling. People care about the environment and want to do what's right, especially if it is easy and convenient for them.

The program may need to be revised after it gets underway. The recycling coordinator will need to keep any eye on the collection containers and adjust the frequency of collections as necessary. With any recycling program, the challenge of contamination must be addressed immediately. When garbage or non-compatible material is mixed in with recyclables, it can ruin the rest of the materials in the container. If the contamination level is too high, the entire load could be rejected by the hauler and have to be landfilled. At first, it is recommended to monitor the recycling containers weekly. By immediately removing contamination, the potential of "copy cat" contaminators is avoided. If other residents see contamination in the containers, they may assume it's okay or it just doesn't matter. If continued contamination occurs, re-educating residents may be necessary and is recommended at least twice a year.

The majority of the problems that plague a recycling program result from a liack of information. It is important to communicate residents' responsibilities and the details of the recycling program in a clear, concise and consistent manner. Below is a sample introductory leiter to residents when initially starting the recycling program. 


\section{Sample Introductory Letter}

Dear Resident:

We are pleased to announce that this apartment complex is establishing a recycling collection program to reduce the amount of garbage going to the Richland landfill. This is a response to your recent inquiries for recycling opportunities.

When you recycle, you save natural resources. Recycling helps to conserve energy because products made from recycled materials often require less energy to make than those made from raw materials. Recycling also creates jobs and helps our economy.

We are offering recycling for:

\section{Clear Glass, Newspaper, Magazines, Aluminum, Tin, and Cardboard.}

By separating these items from your regular garbage in the recycling totes provided, you can help improve our environment! The recycling totes are available for residents at no charge in the office. Please place full recycling totes outside your apartment door on Mondays for recycling pickup. Cardboard should be flattened and recycled at the large cardboard recycling container on the south end of the complex.

\section{IMPORTANT: Please do not mix garbage with the recyclables.}

If you have any questions, please contact the apartment manager.

Thank you for your participation!

\section{Calculation of Waste Reduction and/or Energy Savings}

As the apartment complex residents divert recyclables out of the waste stream and into recycling containers, the dumpsters will not fill up as often.

This apartment complex currently generates approximately 11 tons of solid sanitary waste per month. Of that, according to the 1992 Washington State Waste Characterization Study, the mean percentage of recyclables from multi-family residential generators in Eastern Washington is as follows:

Newspaper and Magazines $\quad 8.0 \%$

Aluminum and Tin $\quad 3.1 \%$

Clear Glass $\quad \underline{5.0 \%}$

$16.1 \%$

11 tons $/$ month $\times 12$ months $/$ year $=132$ tons $/$ year

132 tons/year $\times 0.161$ percent recyclables $=21.3$ tons/year 
It is anticipated that This apartment complex will have an 80 percent participation rate

21.3 tons/year $\times 0.80$ percent participation rate $=17$ tons/year

The total waste reduction is therefore 17 tons/year

\section{Calculation of Annual Cost Savings}

The City of Richland will keep the revenue from the recyclables for servicing the recycling drop box.

The apartment complex currently is charged $\$ 24.65 /$ ton for solid sanitary waste disposal.

17 tons/year $\times \$ 24.65 /$ ton $=\$ 419 /$ year

In addition, it costs $\$ 80.54$ per collection pickup. The apartment complex averages 2 pickups/month. The City of Richland picks up solid sanitary waste when The apartment complex generates approximately 5.5 tons. The apartment complex calls the City of Richland when the solid sanitary waste is ready for pickup.

Current Practice:

2 pickups/month $\times 12$ months $/$ year $=24$ pickups $/$ year

24 pickups/year $\times \$ 80.54 /$ pickup $=\$ 1,933 /$ year

New Practice:

132 tons generated annually -17 tons diverted for recycling $=115$ tons/year

115 tons/year x 1 pickup/5.5 tons $=21$ pickups/year

$21 \mathrm{pickups} /$ year $\mathrm{x} \$ 80.54 / \mathrm{pickup}=\$ 1,691 /$ year

$\$ 1,933 /$ year $-\$ 1,691 /$ year $=\$ 242 /$ year

According to Western Fabrication, it is expected to take an additional 4 hours per week to manage recyclables. The existing process takes 4 hours per day to collect solid sanitary waste. It is anticipated that the reduction in waste (17 tons) will result in a 15 percent reduction in labor collection overall. The average cost per hour for a maintenance worker is $\$ 15$.

Reduction in Labor for Collection of Solid Sanitary Waste:

1 pickup/day $\times 365$ days/year $\times 4$ hours/pickup $\times \$ 15 /$ hour $=\$ 21,900$ in labor.

$\$ 21,900 \times 15$ percent reduction $=\$ 3,285$ 
Addition in Labor for Recycling:

4 hours/pickup x 52 pickups/year x $\$ 15 /$ hour $=\$ 3,120$

$\$ 3,285-\$ 3,120=\$ 165$

$\$ 419 /$ year $+\$ 242 /$ year $+165 \$=\$ 826 /$ year

The total annual cost savings is therefore $\$ 826 /$ year

\section{Calculation of Implementation Cost and Payback}

Laminate posters explaining the new recycling opportunities. A sample poster is provided for duplication. Place the weatherproof posters on the outside of each dumpster areas and throughout the complex. The cost for this is minimal as The apartment staff can prepare the posters in-house. In addition, a sample "doorhanger" is provided for reminding residents to recycle cardboard when moving.

The cost of a 30 cubic yard recycling box is approximately $\$ 3,095$. Dividers cost $\$ 945$ for a total of $\$ 1,890$ as 2 dividers would be required for collecting three recycling commodities. When purchasing, it is imperative to select a model that is compatible with the City of Richland trucks for loading and unloading purposes.

The special towable flatbed cart is $\$ 500$. The 14 -gallon totes are $\$ 6.00$ each for a total of $\$ 1,368$ for 228 totes.

Freight for all the above items would cost approximately $\$ 315$ delivered to the apartment complex.

$\$ 3,095+\$ 1,890+\$ 500+\$ 1,368+\$ 315=\$ 7,168$

$\$ 7,168 / \$ 826=8.7$ years

The payback is therefore 8.7 years 


\section{Vendor/Contact Information}

City of Richland-Recycling Pick Up Service

Matt Zybas

P.O. Box 190

Richland, WA 99352

(509) 943-7467

Western Fabrication-Recycling Units

Mark Choate

2403 N. University

Spokane, WA 99208

(509) 922-1300

1-800-456-7886 


\section{Worksheet 4 \\ Pollution Prevention Opportunities Summary}

Date 03/01/97 ID Code Apartment-1 Business Apartment Complex

Activity Multi-Family Living

\begin{tabular}{|c|c|c|c|c|c|c|}
\hline P2O No. & P2O Title & $\begin{array}{c}\text { Waste } \\
\text { Class } \\
\text { Reduced }\end{array}$ & $\begin{array}{l}\text { Annual Waste } \\
\text { Reduction or } \\
\text { Energy Savings }\end{array}$ & $\begin{array}{c}\text { Estimated } \\
\text { Annual } \\
\text { Savings }\end{array}$ & $\begin{array}{c}\text { Estimated } \\
\text { Implementation } \\
\text { Cost }\end{array}$ & Payback \\
\hline 1 & $\begin{array}{l}\text { Lighting Retrofit } \\
\text { for Apartment } \\
\text { Controlled Lighting }\end{array}$ & Energy & $61,650 \mathrm{kWh}$ & $\$ 2,676$ & $\$ 4,530$ & 1.7 \\
\hline 2 & $\begin{array}{l}\text { Lighting Retrofit } \\
\text { for Apartment } \\
\text { Renters }\end{array}$ & Energy & $1,087,614 \mathrm{kWh}$ & $\$ 47,203$ & $\$ 1,524$ & $\overline{0.03}$ \\
\hline 3 & $\begin{array}{l}\text { Wrap Water heaters } \\
\text { with Insulated } \\
\text { Blankets }\end{array}$ & Energy & $52,241 \mathrm{kWh}$ & $\$ 2,246$ & $\$ 3,531$ & 1.6 \\
\hline 4 & $\begin{array}{l}\text { Heat Pool and Spa } \\
\text { with Solar }\end{array}$ & Energy & 3,449 gals. & $\$ 5,139$ & $\$ 4,320$ & 0.8 \\
\hline 5 & $\begin{array}{l}\text { Implement a } \\
\text { Recycling Program }\end{array}$ & $\begin{array}{c}\text { Solid } \\
\text { Sanitary } \\
\text { Waste }\end{array}$ & 17 tons & $\$ 826$ & $\$ 7,168$ & 8.7 \\
\hline
\end{tabular}

\section{Other Brainstorming Ideas Not Researched}

\section{Opportunity}

Purchase supplies in bulk containers and/or concentrate

Substitute non-hazardous products for maintenance supplies

Sponsor a yard sale for residents

Minimize use of pesticides and herbicides

Mulch lawn

Reduce applications of water blast

Install pre-programmable thermostats

Weatherstrip around doors and windows

Institute a car-pooling program

Provide an organic gardening plot for residents
Reason

Already implemented

Customer will do this themselves

Already implemented

None used currently

Grass found in pool and in apartments

Customer not interested now

Customer not interested now

Customer already doing this

Customer not interested now

Customer not interested now 


\section{Pollution Prevention Assessment Worksheet 5 \\ Final Summary}

Date 03/01/97 ID Code Apartment-1 Business Apar'ment Complex

Activity Multi-Family Living

\section{Proposed Opportunities and Discussion}

\section{Lighting Retrofit for Apartment Controlled Lighting}

This opportunity had a remarkable savings considering the low-priced electricity rates in Richland. Although the existing fixtures and lamps are relatively new, this opportunity is worthwhile due to the annual cost savings. of $\$ 2,676$ and short payback period of 1.7 years.

\section{Lighting Retrofit for Apartment Renters}

Careful consideration of this opportunity revealed a considerable cost savings to the apartment renters. Although implementation of this ojportunity would be realized by the apartment complex, this opportunity is worth the investment for reduced utility rates as a "selling" feature. It is important to note that when selecting an electronic ballast for the kitchen, a low-frequency ballast is recommended to ensure there is no TV/radio interference. The PowrKut ${ }^{\mathrm{TM}}$ Advance ${ }^{\infty}$ ballast available from Stoneway Electric is a good choice. The annual cost savings to the renters for this opportunity was $\$ 47,203 /$ year with a payback of 0.03 years.

\section{Wrap Water Heaters with Insulated Blankets}

The water heaters are insulated with R-7 insulation. The apartment renters 'will realize the cost savings for this initiative and it could be a "selling" feature as with the above lighting retrofit. The payback is 1.6 years with an annual cost savings to all the renters of $\$ 2,246$.

\section{Heat Pool and Spa with Solar}

The critical component is space availability for the solar panels. The office roof is identified as the best location for placement. This opportunity takes advantage of the "free" sun and considerably reduces natural gas consumption. The average annual cost savings for this opportunity is $\$ 5,139$ for a payback of 0.8 years. One consideration is the cost of propane is rapidly decreasing and is anticipated to decrease. Therefore, the apartment complex may wish to recalculate the cost savings as the cost per gallon is reduced.

\section{Implement a Recycling Program}

The waste reduction was considerable at 17 tons/year. However, due to the high implementation cost, the payback was 8.7 years with an annual cost savings of $\$ 826$. A camera-ready poster and door-hanger are attached for promoting the recycling program at the apartment complex. 


\section{Additional Pollution Prevention Opportunities Include the Following:}

\section{Environmentally Friendly Ice Melt}

SSS Ice Melter contains no ingredients that could damage concrete or stain carpet or leather. It is also safer to handle because it is non-exothermic (characterized or formed by heat). It will not burn or irritate skin and does not require the protection of special gloves or goggles.

SSS Ice Melter melts effectively down to $0^{\circ} \mathrm{F}$. It is safer for grass than other rock salt-based blends or calcium chloride because it releases usable plant nutrients (nitrogen and potash) in the melting process. SSS Ice Melter keeps the melted snow and ice from refreezing twice as long as calcium chloride based de-icers. Therefore, half the quantity of de-icer is required with the SSS Ice Melter. The product can be purchased from General Supply (509-248-1241) in Yakima. Deliveries are free to the Tri Cities businesses on Tuesdays. The cost of the existing products and the SSS Ice Melter are comparable. The cost ranges from $\$ 32-\$ 34$ (average $\$ 33$ ) per $100 \mathrm{lbs}$.

\section{Rechargeable Batteries}

Rayovac $^{\oplus}$ Renewal $^{\boxplus}$ rechargeable alkaline ${ }^{\mathrm{TM}}$ batteries and the associated power station is available from Stoneway Electric (509-943-4664). Renewal ${ }^{\circledR}$ alkaline ${ }^{T M}$ batteries can be reused 25 times or more and they are the most environmentally responsible batteries you can buy. The Renewal batteries are available in D, C, AA, and AAA battery sizes. The batteries contain no hazardous cadmium and are mercury free. The power station can charge any combination of up to eight $\mathrm{D}, \mathrm{C}, \mathrm{AA}$, or AAA batteries. The AA and AAA batteries are $\$ 5.80$ each and the $\mathrm{C}$ and $\mathrm{D}$ batteries are $\$ 5.23$ each. The charger is $\$ 35.33$.

\section{Recommendations and Schedule for Implementation}

It is recommended to implement the apartment-controlled lighting retrofit and the solar heating immediately because of the short payback. According to Sun, Wind and Fire, The apartment complex is eligible for a 10 percent Federal tax credit. Furthermore, Sun, Wind and Fire has leasing opportunities available for apartment renters. For the system recommended, the monthly payment would be approximately $\$ 100 /$ month plus tax.

Considering the apartment renters will reap the rewards of reduced utility costs by wrapping the water heaters and the apartment lighting retrofit, these opportunities must be considered on the basis of whether or not the apartment complex feels these improvements add significant value as a "selling" feature to potential apartment renters.

Start-up costs for a recycling program are considerable. However, the U.S. Navy recently purchased three large recycling containers and realized that they only need two. Potential exists to purchase the excess container at a low cost rate. The contact for negotiating the "used" purchase price is Dan Wells at 206-304-3071. Since establishing a recycling program was a goal of the apartment manager at the onset of this assessment, identifying a used roll-off may reduce the implementation costs by approximately $\$ 1,500-\$ 2,000$. This opportunity is recommended 
for implementation despite the payback period as recycling was determined a priority for the apartment complex and residents have inquired about recycling opportunities. 
Appendix D: Formal Assessments

\begin{tabular}{|c|c|}
\hline \multicolumn{2}{|c|}{ AREA DESCRIPTION } \\
\hline $\begin{array}{l}\text { APARTMENT CC } \\
\text { CONTROLLLD } \\
\text { 60 Watt Ine } \\
75 \text { WattPAR-38 } \\
\text { 75 Watt Ine } \\
\text { 4-F40T12 ES } \\
\text { 40 Watt Inc } \\
\text { 60 Watt Inc } \\
\text { TOTALS }\end{array}$ & $\begin{array}{l}\text { OMPLEX } \\
\text { LIGHTING } \\
\text { cabanaloffice } \\
-18 \text { ceiling } \\
\text { wall sconce } \\
\text { cabanalotice } \\
\text { cabanaloffice } \\
\text { spt. porch lights, po }\end{array}$ \\
\hline $\begin{array}{l}\text { TENENT CONTh } \\
1 \text { Bedroom/1 Ba } \\
40 \text { Watt inc } \\
60 \text { Watt inc } \\
60 \text { Watt inc } \\
250 \text { Watt Ht } \\
\text { 4.FoT12 ES } \\
\text { 60 Watt inc } \\
\text { TOTALS }\end{array}$ & $\begin{array}{l}\text { ROLLED LIGHTING } \\
\text { ath unit, } 48 \text { units } \\
\text { bath } \\
\text { hall } \\
\text { entry, dining } \\
\text { bath } \\
\text { kitchen } \\
\text { storage area }\end{array}$ \\
\hline $\begin{array}{l}2 \text { Bedroom unit } \\
40 \text { Watt lnc } \\
60 \text { Watt inc } \\
60 \text { Watt Inc } \\
250 \text { Watt Ht } \\
\text { 4-F40T12 ES } \\
60 \text { Watt inc } \\
\text { TOTALS }\end{array}$ & $\begin{array}{l}\text { t1 Bath, } 36 \text { unlts } \\
\text { bath } \\
\text { hall } \\
\text { entry, dining } \\
\text { bath } \\
\text { kitchen } \\
\text { storage area }\end{array}$ \\
\hline $\begin{array}{l}2 \text { Badroom unit } \\
\text { 40 Watt inc } \\
60 \text { Watt inc } \\
60 \text { Watt inc } \\
250 \text { Watt Ht } \\
\text { 4.F40T12 ES } \\
\text { 60 Watt Inc } \\
\text { TOTALS }\end{array}$ & $\begin{array}{l}\text { /2 Bath, } 96 \text { units } \\
\text { bath } \\
\text { hall } \\
\text { entry, dining } \\
\text { bath } \\
\text { kitchen } \\
\text { storage area }\end{array}$ \\
\hline $\begin{array}{l}\text { 3 Bedroom unit } \\
40 \text { Watt inc } \\
60 \text { Watt inc } \\
60 \text { Watt inc } \\
\text { 250 Watt Ht } \\
\text { 4-F40T12 ES } \\
\text { 60 Watt ine } \\
\text { TOTALS }\end{array}$ & $\begin{array}{l}\text { 12 Eath, } 48 \text { units } \\
\text { bath } \\
\text { hall } \\
\text { entry, dining } \\
\text { bath } \\
\text { kitchen } \\
\text { slorage area }\end{array}$ \\
\hline
\end{tabular}

\begin{tabular}{|c|c|c|c|c|c|c|}
\hline & & EXISTING & 3 SYSTE & & & \\
\hline $\begin{array}{l}\text { Lof } \\
\text { Lamps }\end{array}$ & $\begin{array}{c}\text { Wattage of } \\
\text { system } \\
\text { (kW) }\end{array}$ & $\begin{array}{l}\text { Hours of } \\
\text { Userrr }\end{array}$ & $\begin{array}{l}\text { Lampss } \\
\text { Yr }\end{array}$ & $\begin{array}{l}\text { Lamp Life } \\
\text { Existion }\end{array}$ & $\begin{array}{c}\text { EWhyr Per } \\
\text { Apt. }\end{array}$ & Proposed Lamp \\
\hline 10 & 0.60 & 4,615 & 4.6 & 1,000 & 2,769 & $15 W \mathrm{WFL}$ \\
\hline 27 & 2.03 & 4,615 & 2.3 & 2,000 & 9.345 & 23W CFL \\
\hline 6 & 0.45 & 4,615 & 6.2 & 750 & 2,077 & ZOW CFL. \\
\hline 8 & 1.38 & 4.615 & 0.2 & 20,000 & 6,369 & T-8 32Watt \\
\hline 4 & 0.16 & 4.615 & 4.6 & 1,000 & 738 & $11 W$ CFL \\
\hline 228 & 13.68 & 4,380 & 4.4 & 1,000 & $\begin{array}{r}263 \\
21,561\end{array}$ & $15 \mathrm{~W}$ CFL \\
\hline 4 & 0.16 & 878 & 0.9 & 1,000 & 140 & I1W CFL \\
\hline 2 & 0.12 & 1.404 & 1.4 & 1,000 & 168 & (15W CFL \\
\hline 2 & 0.12 & 1,404 & 1.4 & 1,000 & 168 & 15WCFL \\
\hline 2 & 0.50 & 105 & 0.021 & 5,000 & s3 & 175W PAR38/H \\
\hline 1 & 1.72 & 2,457 & 0.1 & 20,000 & 4,226 & T-8 32Watt \\
\hline 1 & 0.06 & 37 & 0.037 & 1,000 & 2 & $15 W$ CFL \\
\hline 4 & 0.16 & 913 & 0.9 & 1,000 & 146 & 11W CFL \\
\hline 4 & 0.24 & 1,404 & 1.4 & 1,000 & 337 & $15 W \mathrm{CF}$ \\
\hline 2 & 0.12 & 1,404 & 1.4 & 1,000 & 168 & $15 W$ CFL \\
\hline 2 & 0.50 & 176 & 0.035 & 5,000 & 88 & 175W PAR39/H \\
\hline 1 & 9.72 & 2,457 & 0.1 & 20,000 & 4,226 & T-8 32Watt \\
\hline 1 & 0.06 & 37 & 0.037 & 1,000 & $\begin{array}{r}2 \\
4,967\end{array}$ & 15W CFL \\
\hline 8 & 0.32 & 9,053 & 1.1 & 1,000 & 337 & 11W CFL \\
\hline 4 & 0.24 & 1,404 & 1.4 & 1,000 & 337 & $15 W \mathrm{CFL}$ \\
\hline 2 & 0.12 & 1,404 & 1.4 & $\$, 000$ & 168 & $15 \mathrm{WCL}$ \\
\hline 4 & 1.00 & 211 & 0.042 & 5,000 & 211 & 175W PAR38H \\
\hline 4 & 1.72 & 2.457 & 0.1 & 20.000 & 4.226 & T-8 32Watt \\
\hline 1 & 0.06 & 37 & 0.037 & 1,000 & $\begin{array}{r}2 \\
5,281\end{array}$ & $15 W \mathrm{CFL}$ \\
\hline 8 & 0.32 & 1,229 & 1.2 & 1,000 & 393 & $11 W \mathrm{CFL}$ \\
\hline 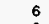 & 0.30 & 1,404 & 1.4 & 1,000 & 421 & $15 W$ CFL \\
\hline 2 & 0.12 & 1,404 & 1.4 & 1,000 & 168: & $15 \mathrm{~W}$ CFL \\
\hline 4 & 1.00 & 211 & 0.0 & 5,000 & 211 & 175W PAR3B/H \\
\hline 4 & 1.72 & 2,457 & 0.1 & 20,000 & 4,226 & $T-832$ Watt \\
\hline 1 & 0.06 & 37 & 0.037 & 1,000 & $\begin{array}{r}2 \\
5.422\end{array}$ & $15 W \mathrm{CFL}$ \\
\hline
\end{tabular}

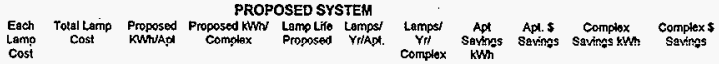

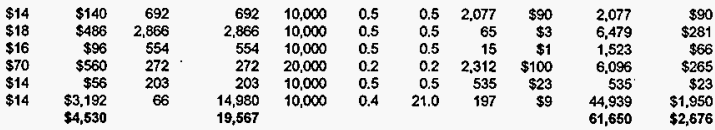

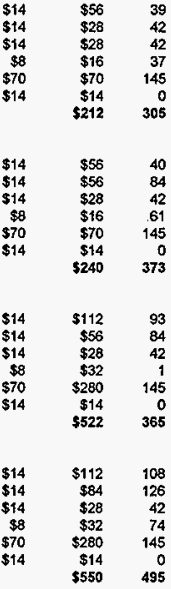

$\begin{array}{rrr}1,853 & 10,000 & 0.1 \\ 2,022 & 10,000 & 0.1 \\ 2,022 & 10,000 & 0.1 \\ 1,769 & 5,000 & 0.0 \\ 6,958 & 20,000 & 0.1 \\ 0 & 10,000 & 0.0 \\ 14,624 & & \\ & & \\ 1,446 & 10,000 & 0.1 \\ 3,033 & 10,000 & 0.1 \\ 1,516 & 10,000 & 0.1 \\ 2,211 & 5,000 & 0.0 \\ 5,219 & 20,000 & 0.1 \\ 0 & 10,000 & 0.0 \\ 13,424 & & \\ & & \\ & & \\ 8,896 & 10,000 & 0.1 \\ 8,087 & 10,000 & 0.1 \\ 4,044 & 10,000 & 0.1 \\ 81 & 5,000 & 0.0 \\ 13,916 & 20,000 & 0.1 \\ 0 & 10,000 & 0.0 \\ 35,024 & & \\ & & \\ 5,189 & 10,000 & 0.1 \\ 6,065 & 10,000 & 0.1 \\ 2,022 & 10,000 & 0.1 \\ 3,538 & 5,000 & 0.0 \\ 6,958 & 20,000 & 0.1 \\ 0 & 10,000 & 0.0 \\ 23,773 & & \\ & & \end{array}$

$\begin{array}{llll}4.2 & 102 & \$ 4 & 4,886 \\ 6.7 & 126 & \$ 5 & 6,065\end{array}$

$\begin{array}{lllll}6.7 & 126 & \$ 5 & 6,065 & \$ 263\end{array}$

$\begin{array}{rrrrr}1.0 & 16 & \$ 1 & 758 & \$ 33 \\ 5 & 4,081 & . \$ 177 & 195.892 & \$ 8.502\end{array}$

$\begin{array}{rrrrr}0.2 & 2 & \$ 1 & 195,892 & \$ 8,502 \\ & 4,454 & \$ 503 & \mathbf{2 1 3 , 7 7 1} & \$ 9,278\end{array}$

$\begin{array}{lllll}4.4 & 106 & \$ 5 & 3,811 & \$ 165\end{array}$

$\begin{array}{llrlr}6.7 & 253 & \$ 11 & 9,098 & \$ 395 \\ 6.7 & 128 & \$ 5 & 4,549 & \$ 197\end{array}$

$\begin{array}{rrrrr}1.7 & 26 & \$ 1 & \$ 948 & \$ 41 \\ 5.9 & 4,081 & \$ 177 & 146,919 & \$ 6,376\end{array}$

$\begin{array}{rrrrr}0.1 & 2 & \$ 0 & 79 & \$ 3 \\ & 4,595 & \$ 199 & 165,403 & \$ 7,178\end{array}$

$\begin{array}{lllll}5.1 & 244 & \$ 11 & 23,452 & \$ 1,018 \\ 6.7 & 253 & \$ 11 & 24,261 & \$ 1,053\end{array}$

$\begin{array}{rrrrr}6.7 & 126 & \$ 5 & 12,131 & \$ 526 \\ 2.0 & 210 & \$ 9 & 20,137 & \$ 874\end{array}$

$\begin{array}{rrrrr}5.9 & 4,081 & \$ 177 & 391,783 & \$ 17,003 \\ 0.4 & 2 & \$ 0 & 210 & \$ 9 \\ & & \$ 213 & 477,974 & \$ 20,484\end{array}$

$\begin{array}{rrrrr}5.9 & 285 & \$ 12 & \mathbf{1 3 , 6 8 1} & \mathbf{\$ 5 9 4} \\ 6.7 & 295 & \$ 13 & \mathbf{1 4 , 1 5 2} & \$ 614 \\ 6.7 & \mathbf{1 2 6} & \$ 5 & 6,065 & \$ 263 \\ 2.0 & 137 & \$ 6 & 6,571 & \$ 285 \\ 5.9 & 4,081 & \mathbf{\$ 1 7 7} & 195,892 & \$ 8,502 \\ 0.2 & 2 & \$ 0 & 105 & \$ 5 \\ & \mathbf{4 , 9 2 6} & \mathbf{\$ 2 1 4} & \mathbf{2 3 6 , 4 6 6} & \mathbf{\$ 1 0 , 2 6 3}\end{array}$ 
Appendix E: Survey 
Thank you for completing this survey. This will only take a few minutes of your time and it will help promote and possibly expand the program for other small businesses like yours. Please return the survey to Mary Betsch RUST Federal Services, P.O. Box 700, H6-06 Richland, WA 99352. You can also FAX it to 373-0743. Thank you for your participation in the program.

1. Which of the waste reduction opportunities recommended in the Pollution Prevention Assessment have you:

Implemented

Plan to implement

Do not plan to implement

2. Have you thought of any other pollution prevention opportunities not covered in the assessment that you are planning to implement? If so, please list.

3. Rank the top 5 factors for and against implementation, from (1) most important, to (5) least important

FOR IMPLEMENTING

The initial investment cost

Time to implement

The payback period

The annual cost savings

Reduce regulatory burden

Improve worker health and safety

Reduce impacts to environment

Improve public image

Other (please explain)

\section{FOR NOT IMPLEMENTING}

The initial investment cost

Time to implement

The payback period

The annual cost savings

Reduce regulatory burden

Improve worker health and safety

Reduce impacts to environment

Improve public image

Other (please explain) 
4. On a scale of 1 to 5 , how satisfied were you with the pollution prevention solutions identified? (1 indicates very dissatisfied, 3 is neutral, and 5 indicates very satisfied.)

$$
\begin{array}{lllll}
1 & 2 & 3 & 4 & 5
\end{array}
$$

5. On a scale of 1 to 5 , how useful was the information provided in the Assessment? ( 1 indicates very dissatisfied, 3 is neutral, and 5 indicates very satisfied.)
1
2
3
4
5

6. Would you recommend this assistance program to other small business owners?

If so, what type of business?

7. What aspects of the Pollution Prevention Assessment did you find most educational?

8. Recognizing the time you spent coordinating the Assessment, did you feel the Assessment was cost-effective for you?

9. Would you recommend the City of Richland continue this service in the future?

10. Other comments? 
Appendix F: Public and Private Technical Assistance Programs 


\section{Small Business Technical Assistance Programs and Private Partnerships for Washington State Businesses}

\section{U.S. Environmental Protection Agency, Region 10}

Washington State is part of the U.S. Environmental Protection Agency's Region 10 which also includes the states Alaska, Idaho and Oregon. The Office of Waste and Chemicals Management contains the Prevention and Recycling programs. This office supports the philosophy under the Pollution Prevention Act of 1990 that the best way to prevent pollution is to move up the waste management hierarchy towards source reduction with the next best solution recycling. Finally, the waste management options of treatment and disposal are considered the least desirable by the U.S. Environmental Protection Agency after source reduction and recycling.

\section{Enviro\$en\$e}

Enviro $\$$ en\$e is a pollution prevention network that integrates technical information from Federal agencies and industries in all 50 states. Enviro\$en\$e was developel to relay technical pollution prevention information such as vendor information, solvent substitution lists, publications, compliance and enforcement information, and international resources. The U.S. Environmental Protection Agency has demonstrated that voluntary goals and commitments achieve environmental results in a timely and cost-effective way through its' "Partners for the Environment" programs. Because of this effort, thousands of organizations are working cooperatively with the U.S. Environmental Protection Agency to set and reach environmental goals. These collaborative efforts include WasteWi\$e, Climate Wise, Green Lights, Energy, Star, Water Alliances for Voluntary Efficiency, and others.

\section{Energy Star Program}

Energy Star is a U.S. Environmental Protection Agency developed program aimed at reducing pollution through voluntary implementation of energy-saving strategies. The Energy Star Buildings program is a voluntary energy-efficiency partnership between U.S. commercial and industrial building-owners and the U.S. Environmental Protection Agency. The U.S. Environmental Protection Agency has identified that energy-efficient technologies can cut energy use by more than $40 \%$. Partners (approximately 75 in 1997) are required to complete upgrades in at least $50 \%$ of their building space within seven years of signing a Memorandum of Understanding with the U.S. Environmental Protection Agency.

This program provides building owners an opportunity to act responsibly by reducing atmospheric pollution and greenhouse gas emissions while at the same time lowering their operating costs. The U.S. Environmental Protection Agency recognizes companies participating in the program and provides technical assistance, including a hotline, manuils, case studies, and software, to help plan and implement building upgrades. 
The U.S. Department of Energy's Energy Star Office Equipment program is a voluntary program for computer and office equipment manufacturers. They are asked to develop desktop computers, monitors, printers, fax machines and copiers that can power-down while not in use. Energy Star Office Equipment can reduce energy consumption by approximately $50 \%$. The U.S. Environmental Protection agency encourages private businesses to commit to purchasing only Energy Star office equipment.

\section{Green Lights Program}

The U.S. Department of Energy Green Lights program began in 1991 with over 1,900 partnerships including small and medium-sized business, governments, non-profit groups, and universities. Green Lights is the first step in the Energy Star Building Program. The goal of the program is to prevent pollution by encouraging U.S. institutions to use energy-efficient lighting technologies. For each partnership, a Green Lights team is identified which identifies financial needs, conducts trial installations, and develops a five-year action plan.

Green Lights members sign an agreement with the U.S. Environmental Protection Agency which states that the participant agrees to survey 100 percent of their facilities and within 5 years upgrade 90 percent of the square footage that can be upgraded profitably without compromising lighting quality. A profitable project is one that "on a facility aggregate basis maximizes energy savings while providing an annualized internal rate of return that is greater than 20 percent. Participants are required to update the U:S. Environmental Protection Agency of their progress annually. On the average, Green Lights participants experience a $50 \%$ rate of return.

\section{Water Alliances for Voluntary Efficiency Program}

The Water Alliances for Voluntary Efficiency (WAVE) program was designed to be similar to Green Lights, but in this case to promote more efficient water use. The WAVE program began in 1992 with hotels and lodging associations as the target audience for this program. In 1996, there were 26 hotel chains participating in the WAVE program dedicated to reducing water and energy consumption through the installment of water-efficient equipment, linking water-use efficiency to reduced costs, and informing hotel guests and employees about the benefits of water efficiency.

Hotels and lodging associations choosing to take part in the WAVE program must sign an agreement with the U.S. Environmental Protection Agency. Participants agree to survey water devices and consider options for achieving greater water use efficiency. Information on the implementation success is reported to the U.S. Environmental Protection Agency annually.

\section{WasteWi\$e}

Over 400 organizations participate in the U.S. Department of Energy's WasteWi\$e Program whose main tenant is a voluntary solid waste reduction initiative through waste prevention, collecting recyclables, and increasing the manufacture or purchase of recycled products. The program is flexible in allowing companies to set their own waste reduction goals 
based on their own circumstances. WasteWi\$e partners provide the U.S. Department of Energy with their annual waste reduction goals and report their progress annually. Technical assistance is provided to partner companies through a helpline, a variety of publications, and workshops.

\section{American Institute for Pollution Prevention}

The American Institute for Pollution Prevention is a non-profit orgacization founded in 1989 by the U.S. Environmental Protection Agency's Office of Research and Development and comprised of industry trade associations and professional societies. The Arrerican Institute for Pollution Prevention is primarily focused on the exchange of ideas betweer industry, academia and government. A practical guide, "A Primer for Financial Analysis of Pollution Prevention Projects" was prepared to assist industry in justifying investment decisions for pollution prevention projects.

\section{The Small Business Initiative}

The Small Business Initiative is a Department of Energy sponsored jrogram comprised of the Kansas City Plant, Sandia National Laboratories, Los Alamos National Laboratory, Lawrence Livermore National Laboratory, Savannah River Site, and the Oak Ridge Y-12 Plant. The program is focused on increasing the competitiveness of U.S. owned snuall and medium sized manufacturers through technology transfer.

Companies of less than 500 employees can receive up to 80 hours of no cost technical assistance or consultation to resolve manufacturing problems. Companies are limited to 3 requests in a 12 month period. In addition to the technical assistance program, the Kansas City Plant periodically advertised a Call for Proposals to stimulate industry ideas for new products and processes. The U.S. Department of Energy provides the Kansas City Plant $\$ 500,000$ each fiscal year to support this program. The program limits the U.S. Department of Energy contribution to $\$ 50,000$ per project and requires a matching in-kind contribution by industry through a mini-Cooperative Research and Development Agreement.

The Kansas City Plant receives referrals from several different organizations, called intermediaries, for technical assistance, partnership agreements, and the National Machine Tool Partnership. Small businesses are encouraged to use technologies located in federal facilities and subsidizes their fee for use. Finally, federal personnel are temporarily placed in academia or private industry to transfer technologies and expertise.

\section{$\mathrm{NICE}^{3}$}

A grant program, known as $\mathrm{NICE}^{3}$, provides funding to state/industry partnerships for projects demonstrating energy efficiency, clean production, and economic competitiveness in industry. Industry applicants must submit project proposals through a state inergy, pollution prevention, or business development office. Funds are awarded to state/industry partnerships that can match federal funds at least dollar for dollar. Awardees receive a one-time grant of up to $\$ 400,000$ for the proposed project.

The application consists of two parts. Part one contains technical information such as the concept description, innovation, cost-efficiency, energy savings, waste savir.gs, economic 
competitiveness, and commercialization. Part two primarily contains the cost application information. Three evaluations are conducted by U.S. Department of Energy staff before the final selection is made. Since $1991, \mathrm{NICE}^{3}$ has sponsored 40 projects totaling $\$ 12.3$ million of U. S. Department of Energy funding. Recognizing the Pollution Prevention Act of 1990, source reduction proposals are given preference. However, proposals that integrate source reduction and recycling approaches are also considered.

\section{Climate Wise}

Climate Wise is a partnership between the U.S. Environmental Protection Agency, the U.S. Department of Energy, and U.S. industries. The purpose of the program is to encourage and assist industry in using methods and technologies that are energy efficient and environmentally sound. Industries can become members and participate in Climate Wise by completing a 1-page application. As part of the partnership agreement, industry agrees to do the following:

- Establish a process for identifying and subsequently implementing cost-effective energy efficiency and pollution prevention actions.

- Submitting a Climate Wise Action Plan describing Climate Wise commitments and implementation timelines.

- Annually report the results of their actions.

In return, the Climate Wise staff provide technical assistance, business-to-business exchanges, positive public recognition, and access to financial resources.

\section{Washington State Department of Ecology}

As regulators, the Washington State Department of Ecology enforces law and regulations established at the federal, state and local levels. The small business assistance provided by Ecology includes education, awareness and training, development and printing publications, and on site technical assistance.

In 1992, Ecology conducted "shop sweeps" targeted at the automotive industry. This particular industry was selected because: (1) The large number of automotive businesses; (2) The number of potential hazardous wastes, and (3) The volume of hazardous wastes generated annually. Auto body, auto dealerships, auto repair, machine shops, radiator shops, service stations, tire dealers, and transmission shops were targeted. Over 1,700 automotive shops in Washington state were audited. The visits were conducted with the local city or county agency and allowed field staff to talk with owners and mangers providing specific answers to specific problems. Each year a new industry as the primary focus for the ongoing campaign.

Two key education tools were used during the on-site visits: (1) A two-page checklist; and (2) A packet of written materials. The checklists and booklets were developed with help from Ecology, local government staff, and automotive associations and business. The checklist was designed to collect data on the types, quantities, and management of waste streams. 
The packets included specially-designed booklets for various autor.otive shops. Ecology has developed a document titled, "Waste Reduction in Your Busiress" which provides a simple approach to managing waste, evaluation of pollution prevention options, and other waste reduction resources. Other resources useful for industries and provided by Ecology include fact sheets for particular industries and waste streams, copies of laws and regulations at no-cost, countless brochures, and onsite technical assistance.

\section{Rebuild America}

Rebuild America is a U.S. Department of Energy energy-saving program that helps communities reduce energy use in their buildings. The U.S. Department of Energy forms partnerships with businesses in a community and provide the local expertise and resources necessary to carry out a pre-approved action plan. The action plan identifies priorities, sets goals, and explains how the partnership will be organized and managed. Partnerships can include government, the private sector, local and regional institutions, non-rrofit groups, and community organizations for designing a community-based program to improve the energy efficiency of its buildings. Communities with completed action plans may apply for technical and financial assistance through a series of solicitations.

\section{National Institute for Standards Technology}

The National Institute of Standards and Technology (NIST) was established by Congress in 1901 to support industry, commerce, scientific institutions, and all branches of Government to advance measurement science and develop standards. NIST's primary mission is to promote U.S. economic growth by working with industry to develop and apply techrology, measurements, and standards. The NIST Manufacturing Extension Partnership is a nationwide network of extension centers, co-funded by state and local governments, that provides small and medium-sized manufacturers access to technical assistance as they upgrade their operations to boost performance and competitiveness.

\section{Responsible Care ${ }^{\circledast}$}

Responsible Care is an environment, safety and health performance-improvement initiative designed to respond to public concerns about the chemical industry's responsible management of the chemicals it manufacturers and uses. Responsible Care ${ }^{(3)}$ was developed by the Chemical Manufacturers Association in 1988 to respond to public concerns about he manufacture and use of chemicals. Chemical Manufacturers Association member companies must participate in Responsible $\mathrm{Care}^{\otimes}$ as an obligation of membership in the association.

Responsible Care requires member companies to: (1) Improve performance in health, safety and environmental quality; (2) Listen and respond to public concerns; (3) Assist each other to achieve optimum performance; and (4) Report their progress to the publis. Six performancebased Codes comprise the program. The Codes require companies to adopt environmental management systems and to audit their progress toward the environmental goals they set for themselves. 
The Pollution Prevention Code was adopted in 1990. It set three goals that go beyond government regulations and existing industry programs: continuous reductions in emissions to air, land and water; long-term reductions in the amount of waste generated; and the responsible management of remaining wastes. If a company implements this Code, the goal is to establish a downward trend in the amount of wastes generated and contaminants and pollutants released into the environment.

\section{The Washington Technology Center}

The Washington Technology Center (WTC) sponsors research by establishing partnerships between state government, academia, and private industry. More than half of the company partners are small organizations with 30 or fewer employees. Participating companies have access to valuable university and government expertise and resources in advanced materials and manufacturing, biotechnology and biomedical instrumentation, computer systems and software, human interface technology, and microelectronics. The WTC matches company needs with the resources and expertise in Washington's research universities and also provides funding support. 
Appendix G: Bibliography 
Allenby, B.R. 1992. "Achieving Sustainable Development Through Industrial Ecology." International Environmental Affairs., 4(1) 56-68.

Allenby, B.R., Gonzales, M.A., and Raber, E. 1996. "Implementing Industrial Ecology and Design for Environment Practices: Lawrence Livermore National Laboratory." Total Quality Environmental Management., 5(3) 37-59.

Anderson, T.L. and Leal, D.R. 1991. Free Market Environmentalism. Westview Press, Inc., Colorado.

Bormann, H.F. and Kellert, S.R. (Eds.) 1991. Ecology, Economics, Ethics: The Broken Circle. Yale University Press, New Haven and London.

Chechile, R.A. and Carlisle S. (Eds.) 1991. Environmental Decision Making: A Multidisciplianry Perspective. Van Nostrand Reinhold, New York.

Costanza, R. (Ed.) 1991. Ecological Economics: The Science and Management of Sustainability. Columbia University Press, New York, New York.

Curran, M.A. 1993. "Broad-Based Environmental Life Cycle Assessment." Environmental Science and Technology. 27(3) 430-436.

Dennison, M.S. 1996. Pollution Prevention Strategies and Technologies. Government Institutes, Inc., Maryland.

Ditz, D., Ranganathan J., and Banks R. 1995. Green Ledgers: Case Studies in Corporate Environmental Accounting. World Resources Institute, Maryland.

Dorfman, R. and Dorfman N.S. (Eds.) 1993. Economics of the Environment. $3^{\text {rd }}$ ed. W.W. Norton and Company, Inc., New York.

Dorland, D., Baria, D.N., and Bergeron, J.T. 1995. "Improving Quality with Waste Minimization for Small Businesses." Total Quality Environmental Management., 5(1) 59-69.

Hawken, P. 1993. The Ecology of Commerce: A Declaration of Sustainability. HarperCollins Publishers, Inc., New York.

Higgins, T.E. 1995. Pollution Prevention Handbook. CRC Press, Florida.

Hirschhorn, J.S. 1997. "Pollution Prevention Revolution: Failed and why it Ultimately will Succeed." Pollution Prevention Review., 7(1) 11-30.

Keoleian, G.A., and Menerey, D. 1994. "Sustainable Development by Design: Review of Life Cycle Design and Related Approaches." Air and Waste., 44(1) 645-668. 
Kleiner, A. 1991. "What Does it Mean to be Green?" Harvard Business Review. 69(8) 38-47.

Odum, E.P. 1993. Ecology and our Endangered Life-Support Systems, $2^{\text {nd }}$ ed. Sinauer Associates, Inc., Massachusetts.

Piasecki, B. and Asmus, P. 1990. In Search of Environmental Excellence: Moving Beyond Blame. Simon and Schuster Inc., New York.

Power, T.M. 1996. “The Wealth of Nations.” Issues in Science and Technology., 11(1) 48-54.

Rappaport, A. and Flaherty, M.F. 1992. Corporate Responses to Environmental Challenges: Initiatives by Multinational Management. Quoram Books, New York.

Resource Conservation and Recovery Act (RCRA). 1976. Public Law 94-580, as amended, 42 USC 6901 et seq. [Latest amendment: Public Law 102-389, 6 October 1992..]

Revised Code of Washington (RCW) Chapter 70.105. 1983. "Hazardous Waste Management."

Revised Code of Washington (RCW) Chapter 70.105A. 1989. "Hazardous Waste Fees."

Romm, J.J. 1994. Lean and Clean Management: How to Boost Profits and Productivity by Reducing Pollution. Kodansha America, Inc., New York.

Rossiter, A.P. (Ed.). 1995. Waste Minimization Through Process Design. McGraw-Hill, Inc., New York.

Schmidheiny S. and Zorraquin F. with the World Business Council for Sustainable Development. Financing Change. 1996. The Financial Community, Eco-efficiency, and Sustainable Development. The MIT Press, Massachusetts and London.

Schmidheiny, S. 1992. Changing Course: A Global Business Perspective on Development and the Environment. MIT Press, Massachusetts.

Silver, C.S. and DeFries, R.S. 1990. One Earth One Future: Our Changing Global Environment. National Academy Press, Washington D.C.

Smart, B. (Ed.). 1992. Beyond Compliance: A New Industry View of the Environment. World Resources Institute.

Stead, E.W. and Stead J.G. 1992. Management for a Small Planet: Strategic Decision Making and the Environment. Sage Publications, London.

Superfund Amendments and Reauthorization Act (SARA) of 1986. 1986. Public Law. 
Tisdell, C.A. 1993. Environmental Economics: Policies for Environmental Management and Sustainable Development. Edward Elgar Publishing Limited, England.

U.S. Congress. 1993. Industry. Technology, and the Environment. Office of Technology Assessment, Washington D.C.

United Nations Environment Programme. 1994. Partnerships for Sustainable Development: The Role of Business and Industry. The Price of Wales Business Leaders Forum, United Kingdom.

van den Bergh J. and van der Straaten J. (Eds.) 1994. Toward Sustainable Development: Concepts, Methods, and Policy. Island Press, Washington D.C. and California.

Wann, D. 1990. Biologic: Environmental Protection by Design. Johnson Publishing Company, Colorado.

Washington Administrative Code (WAC) 173-303. 1994. "Dangerous Waste Regulations." Washington State Department of Ecology, Olympia, WA. 
THIS PAGE TNTENTIONALIX LEST BLANK 